IVANDICK CRUZELLES RODRIGUES

DA RESPONSABILIDADE CIVIL POR DANOS DECORRENTES DE EXPOSIÇÃO OCUPACIONAL AOS NANOMATERIAIS: UM ESTUDO SOBRE MÉTODOS INTEGRATIVOS NO DIREITO DO TRABALHO BRASILEIRO

Tese de Doutorado

Orientador: Prof. Dr. Homero Batista Mateus da Silva

USP - Universidade de São Paulo

FD - Faculdade de Direito

São Paulo/SP 
DA RESPONSABILIDADE CIVIL POR DANOS DECORRENTES DE EXPOSIÇÃO OCUPACIONAL AOS NANOMATERIAIS: UM ESTUDO SOBRE MÉTODOS INTEGRATIVOS NO DIREITO DO TRABALHO BRASILEIRO

Tese apresentada à Banca Examinadora do Programa de Pós-Graduação em Direito, da Faculdade de Direito da Universidade de São Paulo, como exigência parcial para obtenção do título de Doutor em Direito, na área de concentração de Direito do Trabalho e da Seguridade Social, sob a orientação do Prof. Dr. Homero Batista Mateus da Silva.

USP - Universidade de São Paulo

FD - Faculdade de Direito

São Paulo/SP 


\begin{tabular}{|c|}
\hline R696r \\
Rodrigues, Ivandick Cruzelles. \\
Da responsabilidade civil por danos decorrentes de exposição \\
ocupacional aos nanomateriais: um estudo sobre métodos \\
integrativos no direito do trabalho brasileiro / Ivandick Cruzelles \\
Rodrigues. \\
414 f.: il. ; $30 \mathrm{~cm}$ \\
Tese (Doutorado em Direito do Trabalho) - Universidade \\
de São Paulo, São Paulo, 2019. Orientador: Homero Batista \\
Mateus da Silva. \\
Bibliografia: f. 386-414. \\
1. Inovação. 2. Nanotecnologia. 3. Meio ambiente do trabalho. \\
4. Exposição ocupacional. 5. Saúde e segurança do trabalho. 6. \\
Responsabilidade civil do empregador. I. Silva, Homero Batista da, \\
orientador. II. Título. \\
CDU 34:331(81)
\end{tabular}

Bibliotecária Responsável: Ana Lucia Gomes de Moraes-CRB 8/6941 


\title{
DA RESPONSABILIDADE CIVIL POR DANOS DECORRENTES DE EXPOSIÇÃO OCUPACIONAL AOS NANOMATERIAIS: UM ESTUDO SOBRE MÉTODOS INTEGRATIVOS NO DIREITO DO TRABALHO BRASILEIRO
}

\author{
Tese apresentada a Banca Examinadora do \\ Programa de Pós-Graduação em Direito, da \\ Faculdade de Direito da Universidade de São \\ Paulo, como exigência parcial para obtenção do \\ título de Doutor em Direito, na área de \\ concentração de Direito do Trabalho e da \\ Seguridade Social, sob a orientação do Prof. Dr. \\ Homero Batista Mateus da Silva.
}

BANCA EXAMINADORA:

Orientador: Prof. Dr. Homero Batista Mateus da Silva - FDUSP

Profa. Dra. Arline Sydneia Abel Arcuri - FUNDACENTRO

Prof. Dr. Guilherme Guimarães Feliciano - FDUSP

Prof. Dr. José Francisco Siqueira Neto - MACKENZIE

Profa. Dra. Maria Hemilia Fonseca - FDRPUSP

Prof. Dr. Wilson Engelmann - UNISINOS 
Aos meus avós, Moacyr Rodrigues dos Santos e Irany Pena Carmelo dos Santos (in memoriam), pelos exemplos ensinados. Às minhas filhas, Valentina e Madalena, pelos exemplos a serem aprendidos. 


\section{AGRADECIMENTOS}

Agradeço muito às diversas pessoas envolvidas no processo de ingresso, evolução e conclusão do curso de doutorado, suportando-me nos momentos difíceis e celebrando comigo as conquistas, em especial:

- Ao meu estimado orientador, Prof. Dr. Homero Batista Mateus da Silva, pela generosidade, pelas valorosas lições empregadas e hábil condução deste aprendiz no território da pesquisa científica e na realização de um sonho - Obrigado, professor!

- À minha esposa amada e paciente, Paula, e às minhas meninas, Valentina e Madalena, por tanto carinho e amor - Obrigado, meus amores!

- Aos meus amigos de trabalho, por terem a sabedoria e a serenidade de manter atenção redobrada aos interesses de nossos clientes durante os meus momentos de ausência - Obrigado, João, Vivian, Leandro, Beatriz, Fabiane, Camila e Nayna!

- À Faculdade de Direito da Universidade Presbiteriana Mackenzie, todo o seu corpo docente, discente e administrativo, o que faço nas figuras especiais do Prof. Dr. Felipe Chiarello de Souza Pinto e Prof. Dr. José Francisco Siqueira Neto, por ser o começo de toda esta história e por ser a minha casa - Isso é Mackenzie!

- Aos vários amigos e colegas que, de alguma forma, colaboraram para o desenvolvimento desse trabalho - Muito obrigado! 
"A humanidade está adquirindo toda a tecnologia certa por todas as razões erradas". Richard Buckminster Fuller - Arquiteto e Escritor Americano (Homenageado com o batismo da molécula de fulereno $-\mathrm{C}_{60}$ ) 


\section{RESUMO}

RODRIGUES, Ivandick Cruzelles. Da responsabilidade civil por danos decorrentes de exposição ocupacional aos nanomateriais: um estudo métodos integrativos no direito do trabalho brasileiro. 2019. 414 fls. (Tese de Doutorado) - Faculdade de Direito, Universidade de São Paulo, São Paulo, 2019.

A presente tese tem por escopo a promoção do estudo de duas categorias de grande importância para os sistemas jurídicos modernos, obrigados a regular relações cada vez mais complexas, porém incapazes de acompanhar a velocidade das transformações e inovações tecnológicas: as lacunas jurídicas e os métodos de integração normativa. Objetivamente, pretendeu-se investigar a hipótese de como o direito do trabalho brasileiro interagiria com o fenômeno denominado nanotecnologia, conjunto de técnicas que deu à humanidade o poder de manipular a matéria na sua forma mais íntima: átomos e moléculas. Para tanto, partiu-se da investigação desse fenômeno, identificando seus conceitos e terminologias, bem como entendendo suas aplicações. Ato contínuo, considerando o caráter revolucionário da nanotecnologia, passou-se a investigar como e onde ela está se desenvolvendo, além de identificar os interessados (stakeholders) nessa evolução, estudando especialmente as ações governamentais para implementação da IBN Iniciativa Brasileira de Nanotecnologia. Porém, partindo da casuística de desastres ambientais ocorridos num passado muito próximo, percebeu-se que os riscos tecnológicos atrelados ao desenvolvimento e à aplicação indiscriminada da nanotecnologia podem causar danos em escala global, colocando em xeque a saúde e segurança humanas e do meio ambiente, sendo este último considerado pela doutrina como uma Gestalt. Como equilibrar o anseio pelo progresso produtivo e econômico - e pelas maravilhas a serem criadas para consumo - e a necessária cautela para fincar bandeira numa zona cinzenta do conhecimento e evitar catástrofes em escala mundial? Como minimizar os impactos negativos da nanotecnologia no meio ambiente e na saúde da fauna, da flora e das pessoas, em especial dos trabalhadores? O direito brasileiro admite alguma abertura para incidência do soft law do direito internacional? Quais são os cuidados, do ponto de vista jurídico, a serem adotados com o meio ambiente do trabalho? Como deve ser a responsabilização dos agentes pelos possíveis danos decorrentes da aplicação da nanotecnologia no meio ambiente de trabalho? Essas são as questões centrais - desdobradas em outras apontadas como problemas a serem investigados e potencialmente resolvidos por esta tese. Não há no ordenamento jurídico brasileiro qualquer legislação de regência que regule as relações jurídicas impactadas pela nanotecnologia, o que configura uma lacuna no ordenamento. Atores sociais, em âmbito nacional e internacional, estão se dedicando a identificar uma base regulatória comum que seja amplamente aceita e capaz de pautar os cuidados que devem envolver a nanotecnologia no meio ambiente de trabalho, gerando um equilíbrio entre a visão tecnofílica e a visão tecnofóbica. Neste sentido, a contribuição da presente tese ao debate se dá em três eixos: (i) identificar os princípios gerais de direito comumente aceitos pelos Organismos Internacionais como influenciadores no desenvolvimento dos seus instrumentos de soft law aplicáveis ao problema da exposição aos nanomateriais; (ii) verificar se, no caso específico da exposição ocupacional e sua repercussão no Direito do trabalho, por força da previsão contida no caput do art. $8^{\circ}$, CLT, seria juridicamente possível a aplicação desses instrumentos de soft law no direito interno, para suprir a lacuna legislativa; e (iii) investigar, como solução alternativa à aplicação desses instrumentos de soft law, qual seria o melhor método integrativo existente no direito interno para os casos concretos envolvendo a exposição do trabalhador à nanopoluição laboroambiental.

Palavras-chaves: Inovação; Nanotecnologia; Meio Ambiente do Trabalho; Exposição Ocupacional; Saúde e Segurança do Trabalho; Responsabilidade Civil do Empregador. 


\section{ABSTRACT}

RODRIGUES, Ivandick Cruzelles. Civil liability for damages arising out of occupational exposure to nanomaterials: a study on integration methods in the Brazilian labor law. 2019. 414 fls. (Thesis of Doctorate) - Faculty of Law, University of São Paulo, São Paulo, 2019.

The purpose of this thesis is to promote the study of two mechanisms of great importance to modern legal systems, which are obliged to regulate ever more complex relations, unable to keep pace with technological changes and innovations: legal gaps and integration. Objectively, it was intended to investigate the hypothesis of how Brazilian labor law would interact with the phenomenon called nanotechnology, a set of techniques that gave mankind the power to manipulate matter in its most intimate form: atoms and molecules. To do so, we started with the investigation of this phenomenon, identifying its concepts and terminologies, as well as understanding its applications. Considering the revolutionary nature of nanotechnology, we investigated how and where it has been developed, as well as identified the stakeholders in this evolution, especially studying the governmental actions for the implementation of IBN Brazilian Nanotechnology Initiative. However, starting from the series of environmental disasters that occurred in the very near past, it was realized that the technological risks linked to the development and the indiscriminate application of nanotechnology can cause damage globally, jeopardizing human's health and safety and also the environment, considered as a Gestalt. How to balance the yearning for productive and economic progress - and for the wonders to be created for consumption - and the necessary caution to lay a flag in a gray zone of knowledge and avoid catastrophes on a world scale? How to minimize the negative impacts of nanotechnology on the environment and on the health of fauna, flora, and people, especially workers? Does Brazilian law admit any openness to the incidence of soft law in international law? What is the legal care to be taken with the work environment? How should the agents be held accountable for possible damages resulting from the application of nanotechnology in the workplace? These are the central issues, to be unfolded in some others, pointed as problems to be investigated and potentially solved by this thesis. There is no Brazilian legislation that governs the juridical relationships impacted by nanotechnology, which constitutes a lack of law in the legal system. Social actors, nationally and internationally, are working to identify a common regulatory base that could be widely accepted and capable of guiding the care that should be involved in nanotechnology at the workplace, generating a balance between the technophilic vision and the technophobic vision. In this sense, the contribution of this thesis to the debate takes place in three axes: (i) to identify the general principles of law commonly accepted by International Organizations as influencers in the development of their soft law instruments, applicable to the problem of exposure to nanomaterials; (ii) to verify whether, in the specific case of occupational exposure and its repercussion in Labor Law, by virtue of the forecast contained in the caput of art. 8th, CLT, it would be legally possible to apply these soft law instruments in domestic law, to fill the legislative gap; and (iii) to investigate, as an alternative solution to the application of these soft law instruments, what would be the best integrative method in domestic law for concrete cases involving workers' occupational exposure to nanopollution.

KEYWORDS: Nanotechnology; Work Environment; Occupational Exposure; Health and safety; Employer's Liability. 


\section{RÉSUMÉ}

RODRIGUES, Ivandick Cruzelles. La responsabilité civile pour les dommages résultant de l'exposition professionnelle aux nanomatériaux: étude des méthodes d'intégration dans le droit du travail brésilien. 2019. 414 fls. (Thèse de doctorat) - Faculté de droit, Université de São Paulo, São Paulo, 2019.

L'objet de notre recherche c'est est de promouvoir l'étude de deux mécanismes essentiels pour les systèmes juridiques modernes lesquelles régulent des rapports de plus en plus complexes, incapables de suivre le rythme des changements et des innovations technologiques : les lacunes juridiques et l'intégration normative. Objectivement, il a été envisagé d'étudier l'hypothèse selon laquelle le droit du travail brésilien pourrait interagir avec le phénomène appelé nanotechnologie, c'est-à-dire un ensemble de techniques qui donnait à l'homme le pouvoir de manipuler la matière dans sa forme la plus intime: atomes et molécules. Pour ce faire, nous avons commencé par étudier ce phénomène, en identifiant leurs concepts et sa terminologie, ainsi que la compréhension de son application. Compte tenu de la nature révolutionnaire de la nanotechnologie, nous avons étudié ensuite comment et où elle a été développée, identifiant les acteurs de cette évolution(stakeholders), en particulier en étudiant les actions gouvernementales à faveur de la mise en œuvre de l'IBN - Initiative Brésilien du Nanotechnologie. Néanmoins, à partir de la série de catastrophes environnementales survenues très récemment, il a été reconnu que les risques technologiques liés au développement et à l'application aveugle de la nanotechnologie peuvent causer des dommages à l'échelle mondiale, mettant en péril la santé et la sécurité des personnes (Gestalt). Comment équilibrer l'aspiration au progrès productif et économique - et la création des merveilles pour la consommation - et la prudence nécessaire pour exploiter une zone grise du savoir et éviter des catastrophes à l'échelle mondiale? Comment minimiser les impacts négatifs des nanotechnologies sur l'environnement et sur la santé de la faune, de la flore et des hommes, en particulier des travailleurs? Le droit brésilien admet-il une ouverture à l'incidence du soft law en droit international? Quel est le soin juridique à prendre avec l'environnement de travail? Comment les agents devraient-ils être tenus responsables des éventuels dommages résultant de l'application de la nanotechnologie sur le lieu de travail? Tels sont les problèmes centraux à parcourir et potentiellement résolus par cette thèse. Aucune loi brésilienne ne régit les relations juridiques affectées par les nanotechnologies, ce qui constitue un vide juridique dans le système. Les responsables, tantôt au niveau national qu'à l'international, s'efforcent d'identifier une base réglementaire commune qui pourrait être largement acceptée et capable de guider les soins dans la nanotechnologie sur le lieu de travail, entraînant ainsi un équilibre entre une vision technophile et une vision technophobe. Par conséquent, cette thèse se déroule sur trois axes: (i) identifier les principes généraux de droit communément acceptés par les organisations internationales en tant qu'influenceurs dans le développement de leurs instruments de loi non contraignants, applicables au problème de l'exposition aux nanomatériaux; (ii) vérifier si dans le cas particulier de l'exposition professionnelle et de ses répercussions sur le droit du travail, en vertu de la prévision contenue dans l'article 8ème de la CLT, il serait juridiquement possible d'appliquer ces instruments de soft law en droit interne pour combler ce vide législatif; et iii) étudier, en tant que solution de remplacement à l'application de ces instruments de soft law, quelle serait la meilleure méthode d'intégration en droit interne impliquant l'exposition professionnelle de travailleurs à des nanopolutions.

Mots-clés: Nanotechnologie; Environnement du travail; Exposition professionnelle; Santé et sécurité; Responsabilité des employeurs. 


\section{SUMÁRIO}

ÍNDICE DE ABREVIAÇÕES .....................................................................................12

ÍNDICE DE FIGURAS, GRÁFICOS E TABELAS ........................................................17

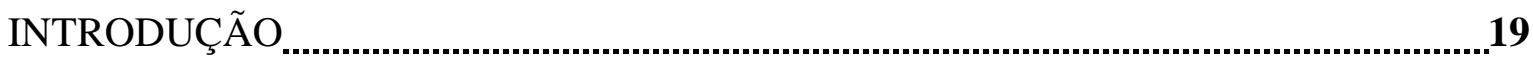

CAPÍTULO 1 - O QUE É NANOTECNOLOGIA?

1.1. Panorama científico e tecnológico atual.................................................24

1.2. Definições e terminologias correlatas da nanotecnologia

1.3. Aplicações práticas da nanotecnologia .................................................57

CAPÍTULO 2 - A CONSTRUÇÃO DA REGULAÇÃO DA NANOTECNOLOGIA NO CONTEXTO DA SOCIEDADE DE RISCO

2.1. A sociedade de risco: Elementos de nexo entre a lógica de produção de riqueza e a lógica sobre produção de risco.

2.2. O ambiente promotor de inovação, a cadeia produtiva do mercado de nanotecnologia e a problemática do risco tecnológico

2.3. Dos princípios como elementos-chave para desenvolvimento da regulação da nanotecnologia e proteção contra o risco tecnológico............107

2.3.1. Prevenção

2.3.2. Precaução 117

2.3.3. Informação 123

2.3.4. Design seguro (safe-by-design) 129

2.3.5. Poluidor-pagador

CAPÍTULO 3 - DA EXPOSIÇÃO OCUPACIONAL AOS NANOMATERIAIS COMO UM PROBLEMA DE RISCO TECNOLÓGICO MUNDIAL: UM OLHAR SOBRE O DIREITO COMPARADO INTEGRATIVAMENTE AO DIREITO DO TRABALHO BRASILEIRO

3.1. Do papel do direito comparado como método normativo heterointegrativo 
3.2. É possível o reconhecimento das normas de soft law como manifestação do direito comparado e a sua utilização na regulação da nanotecnologia?

3.3. Regulação do controle do risco de exposição ocupacional aos nanomateriais no direito comparado e nos diplomas especializados de soft law. 166

3.3.1. Diretrizes da Organização Mundial de Saúde (OMS) para proteção dos trabalhadores de potenciais riscos dos nanomateriais manufaturados 175 3.4. Do soft law sobre controle de risco de exposição ocupacional como fonte do direito do trabalho brasileiro para supressão de lacuna legislativa. 188

CAPÍTULO 4 - DA NANOPOLUIÇÃO LABOR-AMBIENTAL E DA RESPONSABILIDADE CIVIL OBJETIVA E COMPARTILHADA: UM OLHAR SOBRE O DIREITO AMBIENTAL, INTEGRATIVAMENTE AO DIREITO DO TRABALHO BRASILEIRO

4.1. Do direito à preservação do equilíbrio no meio ambiente do trabalho e da higidez física do trabalhador. 194

4.2. O papel da analogia no direito do trabalho brasileiro e o problema (ainda persistente) da lacuna legislativa no controle do risco de exposição ocupacional aos nanomateriais 211

4.3. Conceito de nanopoluição labor-ambiental e conflitos de hipóteses envolvendo a responsabilidade civil 231

4.4. Da subsunção da Lei n. 12.305/2010 às relações labor-ambientais: proposições de analogia para incidência da teoria da responsabilidade civil objetiva e compartilhada. 247

Anexo I: Diretrizes da OMS para proteção dos trabalhadores de potenciais riscos dos nanomateriais manufaturados. 


\section{ÍNDICE DE ABREVIAÇÕES}

ABDI - Agência Brasileira de Desenvolvimento Industrial

ABNT - Associação Brasileira de Normas Técnicas

ANMT - Associação Nacional de Medicina do Trabalho

API.nano - Arranjo Promotor de Inovação em Nanotecnologia

Art. - Artigo

BIRD - Banco Interamericano para Reconstrução e Desenvolvimento

BSI - British Standards Institution

CBAN - Centro Brasileiro-Argentino de Nanotecnologia

CBCIN - Centro Brasil-China de Pesquisa e Inovação em Nanotecnologia

CBPF - Centro Brasileiro de Pesquisas Físicas (RJ)

CC - Código Civil

CCDPN - Centro de Caracterização e Desenvolvimento de Protocolos para Nanotecnologia

CCNANOMAT - Comitê Consultivo de Nanotecnologia e Materiais Avançados

CCS - Centro de Componentes Semicondutores

CDC - Código de Defesa do Consumidor

CDTN - Centro de Desenvolvimento da Tecnologia Nuclear (MG)

CENANO - Centro de Caracterização em Nanotecnologia para Materiais e Catálise

CETENE - Centro de Tecnologias Estratégicas do Nordeste (PE)

CIJ - Corte Internacional de Justiça

CIN - Comitê Interministerial de Nanotecnologias

CLN - Complexo Laboratorial Nanotecnológico

$\mathrm{cm}$ - centímetro

CNANO - Centro de Nanociência e Nanotecnologia

CNEN - Comissão Nacional de Energia Nuclear

CONPEDI - Conselho Nacional de Pesquisa e Pós-graduação em Direito

DUDH - Declaração Universal dos Direitos Humanos

EMBRAPA - Empresa Brasileira de Pesquisa Agropecuária

EPA - Environmental Protection Agency

FAO - Organização das Nações Unidas para Alimentação e Agricultura

FMI - Fundo Monetário Internacional 
FUNDACENTRO - Fundação Jorge Duprat Figueiredo de Segurança e Medicina do Trabalho

IBMP - Instituto de Biologia Molecular do Paraná (PR)

IBN - Iniciativa Brasileira de Nanotecnologia

ICC - International Chamber of Commerce (Câmara de Comércio Internacional)

INCA - Instituto Nacional de Câncer

INMETRO - Instituto Nacional de Metrologia, Qualidade e Tecnologia

INPI - Instituto Nacional de Propriedade Industrial

IPEN - Instituto de Pesquisas Energéticas e Nucleares (SP)

IPT - Instituto de Pesquisas Tecnológicas (SP)

ISO - International Organization for Standardization

JT - Justiça do Trabalho

LABDIS - Laboratório de Fabricação e Caracterização de Nanodispositivos Semicondutores

LABNANO - Laboratório Multiusuário de Nanociências e Nanotecnologia

LABNANO-AMAZON - Laboratório de Nanociências e Nanotecnologia da Amazônia

LANano - Laboratório Associado de Desenvolvimento e Caracterização de

Nanodispositivos e Nanomateriais

LARnano - Laboratórios Associados em Rede de Nanotecnologia

LC - Lei Complementar

LCE - Laboratório de Caracterização Estrutura

LCNano - Laboratório Central de Nanotecnologia

LENI - Laboratório Estratégico de Nanometrologia do Inmetro (RJ)

LIN - Laboratório Integrado de Nanotecnologia de IPEN (SP)

LINDEN - Laboratório Interdisciplinar para o Desenvolvimento de Nanoestruturas

LMNano - Laboratório Multiusuário de Nanotecnologia

LNNA - Laboratório de Nanotecnologia para o Agronegócio

LNNANO - Laboratório Nacional de Nanotecnologia

LPP - Laboratório de Processos Químicos e Tecnologia de Partículas

LQN - Laboratório de Química de Nanoestruturas de Carbono

$\mathrm{m}$ - metro

MCTIC - Ministério da Ciência, Tecnologia, Inovações e Comunicações

MPT - Ministério Público do Trabalho

NANOBIOSS - Laboratório de Síntese de Nanoestruturas e Interação com Biossistemas

NAP-NN - Núcleo de Apoio à Pesquisa em Nanotecnologia e Nanociências 
NIOSH - National Institute for Occupational Safety and Health

nm - nanômetro

NNI - National Nanotechnology Initiative

NRC - National Research Council

OCDE - Organização para a Cooperação e Desenvolvimento Econômico

OEA - Organização dos Estados Americanos

OIT - Organização Internacional do Trabalho

OMC - Organização Mundial do Comércio

OMS - Organização Mundial de Saúde

ONG - Organização Não Governamental

ONU - Organização das Nações Unidas

OSHA - Occupational Safety and Health Administration

PUC-Rio - Pontifícia Universidade Católica do Rio de Janeiro

PUC-SP - Pontifícia Universidade Católica de São Paulo

Sibratec - Sistema Brasileiro de Tecnologia

SisNANO - Sistema Nacional de Laboratórios em Nanotecnologias

STF - Supremo Tribunal Federal

STJ - Superior Tribunal de Justiça

TRF - Tribunal Regional Federal

TRT - Tribunal Regional do Trabalho

TST - Tribunal Superior do Trabalho

UFABC - Universidade Federal do ABC (SP)

UFC - Universidade Federal do Ceará

UFMG - Universidade Federal de Minas Gerais

UFPA - Universidade Federal do Pará

UFPE - Universidade Federal de Pernambuco

UFPR - Universidade Federal do Paraná

UFRGS - Universidade Federal do Rio Grande do Sul

UFRJ - Universidade Federal do Rio de Janeiro

UFSC - Universidade Federal de Santa Catarina

UFSCar - Universidade Federal de São Carlos (SP)

UFV - Universidade Federal de Viçosa (MG)

UNCTAD - United Nations Conference on Trade and Development (Conferência das Nações Unidas sobre Comércio e Desenvolvimento) 
UNESCO - Organização das Nações Unidas para a Educação, Ciência e Cultura UNESP - Universidade Estadual de São Paulo

UNICAMP - Universidade de Campinas

USP - Universidade de São Paulo

WEF - World Economic Forum 


\section{ÍNDICE DE FIGURAS, GRÁFICOS E TABELAS}

Figura 01. Modelo Atômico de Sommerfeld 29

Figura 02. Escala Nanométrica.

Figura 03. Distribuição regional dos laboratórios estratégicos e associados que formam o SisNANO. 42

Figura 04. Diagrama esquemático demonstrando algumas formas de nano-objetos 54

Figura 05. Números da distribuição de produtos, empresas e países 64

Figura 06. Ecossistema de inovação brasileiro. 78

Figura 07. Planejamento estratégico da Setec/MCTIC considerando o impulso tecnológico, frentes de ação, elementos de atração e a pressão da demanda. 81

Figura 08. Ciclos de desenvolvimento industrial de Kondratieff... 83

Figura 09. Eixo de Desenvolvimento Sustentável e ações estratégicas para as Tecnologias Convergentes e Habilitadoras 85

Figura 10. Especificação dos ciclos de desenvolvimento das nanoestruturas 86

Figura 11. Estratégia de captação e alocação de recursos para o desenvolvimento sustentável das Tecnologias Convergentes e Habilitadoras, tendo como exemplo a nanotecnologia ...89 Figura 12. Relação esquemática da nanotoxicologia com as propriedades físico-químicas de nanomateriais. . .96

Figura 13. Paradigma para caracterização de risco, definido pela National Academy of Sciences (EUA) 98

Figura 14. Etapas do ciclo de vida dos produtos 99

Figura 15. Representação gráfica da relação entre área de superfície e volume do material 100

Figura 16. Critérios CLEAR de avaliação da comunicação. 128

Figura 17. Relação entre agentes na avaliação de nanossegurança na cadeia de valor...... 133

Figura 18. Protocolo para tomada de decisões de gestão de risco, 135

Figura 19. Pirâmide hierárquica para conhecimento, comunicação e gestão de risco. 136

Figura 20. Formas de penetração das nanopartículas no organismo humano 168

Figura 21. Distribuição dos efeitos das nanopartículas nos organismos vivos. 169

Figura 22. O que é uma nanopartícula?. 178

Figura 23. Diretrizes da OMS para proteção de trabalhadores contra potencial riscos dos nanomateriais manufaturados: Recomendações. 
Figura 24. Diferenciação entre nanopoluição e nanorresíduos

Gráfico 01. Uso de nanomateriais por segmento de indústria (em números de aplicação) 62

Gráfico 02. Número de produtos por segmento por país 63

Gráficos 03 e 04. Mercado e Produção em toneladas de NpAg e Percentuais de substâncias químicas associadas a produtos comerciais no ano de 2013. 92

Gráfico 05. Nanomateriais utilizados em produtos por divisões industriais. 93

Tabela 01. Cronologia dos fatos mais importantes na história da nanotecnologia até 2014. (adaptada) 41

Tabela 02. Classificação de patentes por campo de aplicação. 58

Tabela 03. Classificação de patentes por subáreas da nanotecnologia 58

Tabela 04. Principais riscos emergentes identificados 72

Tabela 05. Documentos de segurança e regulação em nanotecnologia. 173

Tabela 06. Quantidade mensal de acidentes do trabalho, por situação do registro e motivo $2015 / 2017$ 174

Tabela 07. Principais temas recorrentes na Justiça do Trabalho. 223 


\section{INTRODUÇÃO}

Inovação.

Social, científica, tecnológica, civilizacional, produtiva, política, econômica, fashion, humana. Pouco importa em que campo seja, estamos sempre inovando.

A espécie humana, diferenciada das demais pela inteligência e pela consciência existencial, progrediu muito mais e em muito menos tempo do que qualquer outra espécie que se tenha notícia. Ela compreendeu e dominou as forças da natureza, utilizando-as em seu benefício. Ao invés de se adaptar ao ambiente, ela subjugou a natureza para que atendesse aos seus desígnios.

No estado da arte das técnicas produtivas, chegamos num patamar até então só imaginado pela ficção científica (ou pela mitologia, se preferir): a manipulação direta de moléculas e átomos, podendo literalmente ser utilizados como blocos de construção de brinquedo. É, sem sombra de dúvidas, um dos maiores domínios que nossa espécie conseguiu impor à natureza.

Trata-se da nanotecnologia, definida como o conjunto de técnicas que permitem a manipulação da matéria em partículas cujos tamanhos variam entre $1^{-9} \mathrm{~m}$ e $100^{-9} \mathrm{~m}$. Só para ter ideia das grandezas envolvidas, bastaria comparar o volume de uma bola de futebol ao volume da lua, por exemplo.

Da mesma forma que as dimensões de tamanho assustam, as dimensões econômicas que envolvem a nanotecnologia também parecem irreais. Em previsões feitas pela National Nanotechnology Initiative ${ }^{1}$, programa do Governo Americano para fomento da nanotecnologia, a expectativa era de que o mercado global focado neste setor atingisse a soma de US\$ 3,7 trilhões no ano de 2018.

${ }^{1}$ Cf. item 2.2, nota de rodapé 101. 
Governos, universidades, pesquisadores, empresas, trabalhadores e consumidores formarão a cadeia de stakeholders, isto é, de interessados neste mercado trilionário e altamente inovador. Em termos de importância, é praticamente consenso entre os grandes países do mundo e as diversas organizações internacionais, de que se trata de uma grande revolução tecnológica, impactando o mundo de uma forma ainda não vista e pouco imaginada.

Os campos de aplicação são infindáveis ${ }^{2}$. São mais de 8.000 produtos já disponibilizados no mercado em mais de 60 países, em setores como agricultura, automotivo, construção civil, cosméticos, eletrônicos, proteção ambiental, alimentício, medicina, usos domésticos, têxtil, equipamentos esportivos, defesa militar e além.

O Brasil também tem o seu programa de nanotecnologia. Trata-se da Iniciativa Brasileira de Nanotecnologia $(\mathrm{IBN})^{3}$, uma rede de institutos de pesquisa, laboratórios, universidades, centros de inovação, fundos de fomento e empresas envolvidos num ecossistema de inovação e geração empreendedora para o desenvolvimento de tecnologias que tragam vantagens econômicas, ambientais e sociais de competitividade ao Brasil, tanto no âmbito do mercado interno quanto global.

Há também ampla comercialização de produtos fabricados com matéria em nanoescala, ou utilizando algum tipo de processo nanotecnológico, especialmente para o uso doméstico. Produtos como o Ecotextil ${ }^{\circledR}$, impermeabilizante para tecidos desenvolvido e comercializado pela EasyTech Shield ${ }^{\odot}$ (https://www.easytechshield.com.br/loja/ecotextil-

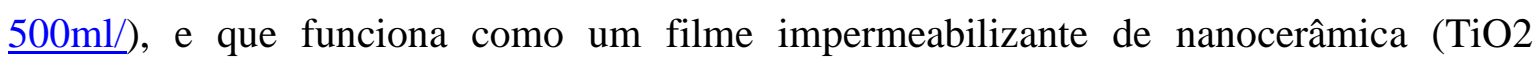
nanoparticularizado) aplicado apenas com um borrifador, sem necessidade de qualquer equipamento de proteção individual, já estão no mercado brasileiro, sendo que trabalhadores e consumidores estão em contato com estas substâncias, sobre as quais eles pouco sabem 4 .

\footnotetext{
${ }^{2}$ Cf. Tabelas 02 e 03, Figura 05 e Gráficos 01, 02, 03 e 05.

${ }^{3} \mathrm{Cf}$. Item 2.2, nota de rodapé 95.

${ }^{4}$ DISCLAIMER: Trata-se realmente de uma exemplificação aleatória, sem qualquer conotação ou imputação de responsabilidade a quem quer seja. Os nomes dos produtos e empresas são reais, todos eles localizados através de pesquisa no Google.com. Não foi pesquisado e nem se cogita a ideia de que os produtos elou empresas ora mencionadas estiveram ou estão envolvidos em algum caso de contaminação do meio ambiente do trabalho. Qualquer semelhança com eventual caso concreto que tenha acontecido, ou venha a acontecer, não passará de mera coincidência.
} 
Nestas horas, o conhecimento popular nos lembra que "quanto maior risco, maior o ganho", servindo de estopim para que o conhecimento científico seja instigado a se questionar sobre os riscos desse mercado valioso. E, apesar do caráter revolucionário, não há como se olvidar de que todas as revoluções tecnológicas vieram acompanhadas de efeitos colaterais altamente complexos e danosos, sendo certo que é dever universal de preservação da espécie e do planeta aprender com as experiências negativas do passado. Diversos desastres ambientais e humanos ocorreram por conta da aplicação de tecnologias ainda em desenvolvimento, cujos riscos se apresentavam em maior quantidade do que os benefícios.

Num cenário social como este, considerando as premissas de que (i) já temos da presença da nanotecnologia em uso no mercado brasileiro; (ii) o incremento do risco pela tecnologia pode potencializar sobremaneira os efeitos colaterais da inovação; e (iii) a percepção cientifica sobre a nanotecnologia já possui resultados mais concretos sobre os potenciais problemas, causa perplexidade o fato de que o ordenamento jurídico pátrio não possua qualquer legislação para a regência das relações jurídicas envolvendo a nanotecnologia.

Essa lacuna é o ponto de partida da presente pesquisa, já que o Brasil entende que a nanotecnologia é uma ferramenta fundamental para o desenvolvimento do país, integrando-a ao plano nacional de ação em CT\& I ${ }^{5}$. Todavia, sua capacidade de investimento é pífia quando comparada com outros países ao redor do mundo, o que gera sérias preocupações sobre a saúde e segurança do meio ambiente e de todos os brasileiros que, direta ou indiretamente, acabarão por suportar os problemas decorrentes de seu mau uso.

Quando pensamos no caso dos trabalhadores e na posição que o Brasil ocupa no ranking mundial de acidentes de trabalho ${ }^{6}$, não fica difícil imaginar que, num curto espaço de tempo, surgirão casos de doenças e acidentes profissionais possivelmente ligados por um nexo de causalidade ou concausalidade à exposição ocupacional aos nanomateriais.

\footnotetext{
${ }^{5} \mathrm{Cf}$. Item 2.2, nota de rodapé 95.

${ }^{6}$ ASSOCIAÇÃO NACIONAL DE MEDICINA DO TRABALHO. Brasil é quarto lugar no ranking mundial de acidentes de trabalho. Disponível em <https://www.anamt.org.br/portal/2018/04/19/brasil-e-quarto-lugarno-ranking-mundial-de-acidentes-de-trabalho/>. Visitado em 08.mai.2019.
} 
Não obstante o dano que estes trabalhadores possam enfrentar contra sua saúde e higidez física, sem uma legislação de suporte, fica complicado definir quais seriam os critérios para o estabelecimento desse nexo de causalidade e quais seriam as normas de saúde e segurança do trabalho ${ }^{7}$ incidentes nas hipóteses de exposição ocupacional, aguda ou crônica, o que pode causar injustiças graves para ambas as partes envolvidas numa eventual lide.

Verificada a presença da vedação ao non liquet em nosso ordenamento jurídico, como consta do art. $4^{\circ}$ da LINDB, o Juiz não poderá se escusar de julgar uma ação alegando a existência de lacuna na lei. Ele será obrigado a aplicar os métodos integrativos que constarem da legislação de regência do caso concreto, a ser definida conforme a natureza jurídica da discussão.

No caso do direito do trabalho, os métodos integrativos estão estabelecidos no art. $8^{\circ}$, CLT, podendo o Juiz, na ausência de legislação específica aplicável ao caso concreto, decidir "pela jurisprudência, por analogia, por equidade e outros princípios e normas gerais de direito, principalmente do direito do trabalho, e, ainda, de acordo com os usos e costumes, o direito comparado".

Diante desta lacuna, a presente tese, após justificar a importância e explicitar quais os princípios jurídicos que melhor se coadunariam com as previsões constitucionais e que deveriam ser aplicados às relações jurídicas que envolvem nanotecnologia, tentará apresentar duas soluções juridicamente possíveis, valendo-se, em ambos os casos, dos métodos integrativos autorizados pelo diploma celetista.

A primeira solução possível foi construída com base no método heterointegrativo do direito comparado. A aplicação deste método permitiu buscar no direito estrangeiro e/ou internacional, em especial nas normas de soft law, as previsões necessárias para resolução de situações mais concretas, tais como: métodos para identificação dos

\footnotetext{
${ }^{7}$ Gustavo Filipe Barbosa GARCIA conceitua este conjunto de normas como "ramo interdisciplinar da ciência, vinculado ao Direito do Trabalho, tendo por objeto a proteção, a prevenção e a recuperação da saúde e a segurança do trabalhador." (GARCIA, Gustavo Filipe Barbosa. Curso de direito do trabalho. 11.ed., Rio de Janeiro: Forense, 2017, p. 1176).
} 
nanomateriais, medidas preventivas obrigatórias, limites de exposição, EPIs e EPCs aplicáveis, critérios para definição de responsabilidades etc.

A relevância dessa solução se justifica pela ideia de que as normas de soft law, produzidas pelos diversos organismos internacionais, são a melhor e mais bem-acabada expressão da metodologia do direito comparado, vez que se trata de norma construída de maneira democrática, com amplo debate internacional, com cuidado às proporcionalidades e aos objetivos de preservação da vida, além de normalmente serem calcadas em evidências científicas bastante sólidas.

Logo, é possível intuir que elas representam aquilo que é considerado o estado da arte na nanotecnologia, sendo as mais aptas a orientar a um equilíbrio social razoável entre os riscos e os benefícios desse desenvolvimento tecnológico. Considerando os objetivos deste estudo e a especificidade da matéria (exposição ocupacional dos trabalhadores aos nanomateriais), serão estudadas as normas produzidas pela OMS e OCDE, vez que, apesar de debater o tema, a OIT ainda não as produziu.

Não obstante tais diplomas de soft law representarem o melhor padrão normativo que se poderia obter (considerado o fato de que se está estruturando a norma a partir de métodos integrativos), há, aparentemente, uma certa resistência por parte do Poder Judiciário em aplicar a metodologia do direito comparado em casos de lacunas no direito interno.

Para que, por conta desta aparente resistência, os estudos ora promovidos tenham sidos em vão e sejam relegados apenas ao plano teórico, uma segunda solução jurídica será proposta, também construída com base em métodos integrativos. Desta vez, será a analogia a sustentar as razões de decidir do Juiz, que poderá buscar, segundo se apresenta, no direito ambiental a legislação de regência que melhor se adequa aos princípios a seguir propostos para as relações jurídicas que envolvem nanotecnologia.

Ao cabo, as conclusões apresentadas reafirmarão a importância dos métodos integrativos para o bom funcionamento de um ordenamento jurídico que se proponha contemporâneo e que dê conta de acompanhar a velocidade da evolução tecnológica, não deixando que as relações acabem por atingir seus pontos extremos, totalmente tecnofílicas ou totalmente tecnofóbicas, sustentando um equilíbrio social dinâmico e trazendo bem-estar social. 


\section{CONCLUSÕES}

As conclusões ora apresentadas são compostas pela síntese dos principais pontos abordados pela tese, os quais partem dos pressupostos apresentados, em especial três deles: (i) o potencial danoso da aplicação indiscriminada da nanotecnologia; (ii) a ausência de legislação de regência apara a matéria; e (iii) a importância dos métodos normativos integrativos, os quais promovem, dentro de uma visão sistemática aberta do direito, seu império e completude, mesmo quando incapaz de acompanhar a velocidade das transformações sociais. Caso esses pressupostos sejam alterados, as conclusões ora apresentadas também poderão ser alteradas.

Diante do todo exposto, conclui-se que:

1. A complexidade da existência humana faz surgir uma série infindável de necessidades a serem supridas, dada a necessidade de adaptar-se ao ambiente. Somente a espécie humana evoluiu ao ponto de acumular conhecimento sobre seu meio ambiente e utilizá-lo para subjugar a natureza aos seus desígnios.

2.

A nanotecnologia dá à humanidade o domínio da técnica de manipulação da matéria em escala atômica, sendo que, segundo as definições da Química, matéria "é tudo que possui massa e ocupa espaço" e corpo "é uma porção limitada de matéria que serve para determinado fim".

3.

Em 29 de dezembro de 1959, o físico Richard FEYNMAN profere celebrada palestra na American Physical Society, apresentando ao mundo a concepção teórica da nanotecnologia, bem como prevendo o impacto revolucionário que tal tecnologia teria sobre a produção de produtos. Em 1974, o termo nanotecnologia foi cunhado pelo pesquisador Norio TANIGUCHI para diferenciar a engenharia em escala micrométrica $\left(10^{-6} \mathrm{~m}\right)$ das escalas ainda menores, isto é, nanométrica $\left(10^{-9} \mathrm{~m}\right)$.

4. No Brasil, segundo o sítio eletrônico do Ministério da Ciência, Tecnologia, Inovações e Telecomunicações (MCTIC), as esparsas ações governamentais de desenvolvimento da nanotecnologia foram recentemente concentradas na Iniciativa Brasileira de Nanotecnologia (IBN), com o objetivo de promover a competitividade da indústria brasileira. A iniciativa é assim descrita no relatório "Estratégia nacional de ciência, tecnologia e inovação 2016-2022”. Nas previsões do MCTIC, a nanotecnologia ocupa 
posição de destaque, vez que é entendida como elemento-chave para o bom desenvolvimento tecnológico e socioeconômico do país.

5. Um nanômetro é igual a um bilionésimo do metro $\left(10^{-9} \mathrm{~m}\right)$. Os "nanoprodutos" podem ser de vários tipos: elaborados em tamanho nanométrico; elaborados por agregação de nanomateriais; na forma de filmes; na forma de tubos; em fibras; em estruturas etc. Todavia, nem consumidores, nem reguladores ou os concorrentes sabem exatamente os tipos, as quantidades e as concentrações desses nanomateriais. Não se sabe onde ou como estão presentes, quais as suas características, seus potenciais efeitos etc.

6.

Para que seja possível desenvolver uma legislação que cumpra o papel de incentivar o desenvolvimento da nanotecnologia, sem se descuidar da proteção da sociedade e meio ambiente, é necessário chegar-se a um consenso sobre a definição do que são os nanomateriais e seus termos correlatos. A mais bem-sucedida das tentativas até o momento foi realizada pela ISSO - ISO/TS 80004 (Nanotechnology - Vocabulary), norma de padronização focada na linguagem a ser aplicada para a nanotecnologia.

7. Sobre a nossa realidade, pela Fundação Jorge Duprat Figueiredo de Segurança e Medicina do Trabalho também foi desenvolvida uma visão própria de nanotecnologia, presente em sua Nota Técnica n. 01/2018/FUNDACENTRO: A nanotecnologia permite a criação de materiais em escala nanométrica de aproximadamente 1 a 100 nanômetros, sendo que 1 nanômetro equivale a 1 bilionésimo do metro. Partículas nesta escala apresentam propriedades químicas, físicas e atividade biológica diferentes de materiais em escalas superiores; por exemplo, os pontos de ebulição, cor, dureza, reatividade química, toxicidade dos materiais mudam quando estão em nanoescala (NIOSH, 2008; FUNDACENTRO, 2008). Conceitos bastante semelhantes são adotados pelo MCTIC e pela ABDI, servindo, então, para seu uso jurídico.

8. A revolução trazida pela nanotecnologia é baseada nas mudanças das propriedades físicas e químicas sofridas pela matéria. Em escala nanométrica, determinados materiais podem se tornar mais resistentes, mais flexíveis, mais duráveis, refletir melhor a luz, conduzir melhor a eletricidade, serem mais reativos ou qualquer outra característica afim.

9. Em termos de aplicações, são encontrados, exemplificativamente, produtos relacionados aos setores de construção civil (novos materiais, vidros, tintas, filmes de cobertura, aditivos para concreto etc.), pigmentação, energia (geração, distribuição, armazenamento etc.), recuperação ambiental (tratamento de água, filtros, tratamento de vazamento de petróleo, tratamento de resíduos etc.), alimentos (embalagem, 
armazenamento, processamento etc.), transformação industrial (plásticos, materiais magnéticos, maquinários etc.), tecnologia da informação (filmes isolantes, placas de circuitos, chips, displays etc.), medicina (restauração dental, auxiliares para diagnósticos, aplicações terapêuticas medicamentosas etc.), têxtil (protetores e filmes para tecido etc.), automotivo (colas adesivas, tintas, partes esparsas, beneficiamento de aço, filmes protetores, ceras etc.), dentre outros, já existindo registros de informações sobre mais de 8.000 produtos, desenvolvidos por mais de 1950 empresas, distribuídas em mais de 55 países ao redor do mundo.

10. Na sociedade pós-moderna, a definição de risco está atracada, atualmente, nos domínios da antropologia social e da sociologia, as quais entendem que os riscos são definidos e selecionados culturalmente.

11. No campo da sociologia, a análise sobre as teorias de Ulrich BECK, para os fins desta tese, se justifica ante o fato de que se trata de autor que trabalha, como elemento central de seus estudos, o conceito de risco e o papel que o chamado conhecimento científico representa na sociedade pós-industrial, sendo que o recorte epistemológico a ser aqui aplicado analisa apenas três pontos específicos: (i) a lógica existente entre produção de riquezas e produção de riscos; (ii) a manipulação do discurso científico por força do poder econômico; e (iii) a conceituação do risco social como fruto de um processo cultural.

12. Como dito acima, o conceito de risco na sociedade pós-industrial retrata uma construção cultural e está atrelado ao tipo de efeito colateral tecnológico gerado a partir do processo de produção de riquezas, sendo este o marco referencial que delimita a passagem da sociedade industrial para a sociedade pós-industrial.

13. Na sociedade industrial, os riscos tecnológicos, oriundos do progresso das técnicas e dos meios de produção, eram visíveis (ou, pelo menos, detectáveis) e quantificáveis, além de possuírem efeitos previsíveis. Contudo, a sociedade pós-industrial rompe com essa característica, vez que o avanço científico tem criado riscos invisíveis, imperceptíveis à sensibilidade humana, além de serem quase imprevisíveis e apresentarem consequências devastadoras.

14. Para BECK, essa mudança de paradigma é a gênese da sociedade de risco, pois a absorção da natureza primitiva pela indústria humana, devolvida sob a forma de natureza industrializada, é a principal fonte desses riscos invisíveis.

15. A citada modernização verifica-se pela implicação da lógica de produção de riquezas e da lógica de produção de riscos: enquanto na sociedade industrial a produção de riquezas controla a produção de riscos, na sociedade de risco é a produção de riscos que 
domina a produção de riquezas. Como corolário dessa lógica: se a produção de riscos não é mais dominada, mas sim dominante, seus efeitos já não são mais limitáveis, seja social, geográfica ou economicamente.

16. Considerando este cenário social, torna-se um problema relevante o potencial impacto da integração da nanotecnologia aos meios de produção industrial, em especial, para esta tese, ao que diz respeito à saúde e segurança dos trabalhadores, que passarão a ficar expostos aos nanomateriais.

17. No mundo empresarial, as estratégias baseadas em inovação passaram a ocupar uma posição de destaque nessa corrida pela liderança de mercados, sendo que a busca ferrenha pela inovação serve de motor para impulsionar a evolução tecnológica e garantir a sobrevivência do capitalismo.

18. Dada o potencial de risco das novas tecnologias, a importância da existência de uma regulação que trate da inovação, bem como a atuação do Estado ao longo de todo o percurso de desenvolvimento, ora fiscalizando ora participando, mostra-se de extrema relevância, vez que traz mais segurança (especialmente jurídica e financeira) aos investidores e desenvolvedores. Principalmente nos casos onde há muito risco envolvido, sem a atuação do Estado, nada seria possível.

19. No Brasil, o papel do Estado como agente de inovação é definido pela própria Constituição Federal que, em seu art. 218, capitula a promoção e incentivo do desenvolvimento científico, da pesquisa, da capacitação científica e tecnológica e da inovação, visando sempre o bem público e voltada à solução dos problemas brasileiros e para o desenvolvimento do sistema produtivo nacional e regional.

20. O Decreto n. 9.283, de 7 de fevereiro de 2018, que busca estabelecer medidas de incentivo à inovação e à pesquisa científica e tecnológica no ambiente produtivo, com vistas à capacitação, ao alcance da autonomia tecnológica e ao desenvolvimento do sistema produtivo nacional e regional (regulamentador da Lei n. 10.973/2004), estabeleceu o conceito jurídico de ambientes promotores de inovação.

21. Conforme estratégia de desenvolvimento definida pelo MCTIC, a nanotecnologia se encontra inserida dentre as Tecnologias Convergentes e Habilitadoras, entendidas como aquelas tecnologias que têm capacidade de “(...) causarem mudanças tecnológicas radicais que transformam a humanidade e sua cultura, bem como tem o potencial e a tendência de gerar um ciclo acelerado de desenvolvimento e criar tecnologias derivadas aplicadas virtualmente a todos os campos de conhecimento, beneficiando o 
aumento do desempenho humano, seus processos e produtos, qualidade de vida e justiça social".

22.

Ainda segundo a estratégia montada pelo Governo brasileiro: “A forma para se alcançar estes objetivos é aliar o conhecimento gerado na academia - que, desde a sua concepção, tenha buscado como meta a solução de problemas em processos, produtos e serviços científicos, tecnológicos e inovadores - com a capacidade gerencial e transformadora da economia do setor industrial, tendo como base a demanda mercadológica e social. Portanto, a estratégia básica deste Plano é a promoção da integração entre a academia e a indústria".

23. Em que pese o flerte que a ótica de mercado faz com o conhecimento científico, aplicado ou aplicável, bem como a existência de comandos constitucionais e legais os quais impõem um papel empreendedor ao Estado, fato é que as grandes falhas tecnológicas, ocorridas em episódios bem mais frequentes do que se gostaria, conduziram nossa sociedade ao quadro evolutivo compatível com o denominado de sociedade de risco, como descrito anteriormente.

24. Na pós-modernidade, esse risco já não é tangível ao conhecimento científico vigente, se destacando por três características essenciais: invisibilidade, globalidade e transtemporalidade. Para demonstrar como essas três características se aplicam à tese em debate, é possível realizar o exercício de subsunção destas à nanotecnologia, compreendendo-se que: (i) a nanotecnologia lida com partículas imperceptíveis aos sentidos humanos; (ii) seus potenciais danosos são relativamente desconhecidos, já que a física, a química e a biologia em escala nano não se comportam do mesmo jeito que nas escalas maiores, o que torna ineficaz os métodos atuais de monitoramento e elevam os riscos à escala global; e (iii) não conhecemos os limites de exposição e as taxas de concentração e/ou toxicidade das nanopartículas, pouco sabemos sobre bioacumulação ou sobre qualquer outra informação relacionada ao tempo de exposição a essas partículas. O fato de os nanomateriais possuírem também grande área de superfície também é relevante, em razão de aumentar a reatividade dos materiais.

25. Sobre a questão ambiental, a história já nos apresentou casos suficientemente trágicos aptos a comprovar o chamado efeito bumerangue e os riscos invisíveis pósmodernos, em que o meio ambiente natural e do trabalho representaram o primeiro front de exposição aos riscos tecnológicos.

26. Sobre a saúde humana, a nanotoxicologia vem se encarregando de buscar entender os efeitos da toxicidade dessa nova particularização das substâncias, além de 
garantir novas linhas de pesquisas para patologistas e epidemiologistas, no que diz respeito às novas doenças e suas formas de propagação, tudo relacionado à nanotecnologia.

27.

Temos aqui presente um paradoxo: De um lado, a inovação tecnológica nos traz progresso, diversas melhorias para a qualidade de vida e conforto; mas, por outro lado, os riscos agregados estão potencialmente nos levando à extinção.

28. Para se atingir uma efetividade do Direito em face às novas tecnologias, é necessário que a linguagem jurídica e a linguagem tecnológica consigam dialogar, permitindo ao operador do direito certo grau de conhecimento sobre os riscos tecnológicos, bem como ao cientista certo grau de conhecimento sobre as categorias jurídicas, sendo que somente esta condição permitirá a existência de um processo consciente para tomadas de decisões.

29.

A adoção da nanotecnologia como instrumento de produção, em função do pouco conhecimento que ainda se tem, demanda a criação de uma regulamentação rígida o suficiente para garantir a utilização responsável dessa tecnologia ainda experimental (visão tecnofílica), porém sem que isso represente um entrave real para o seu desenvolvimento (visão tecnofóbica).

30. No contexto brasileiro, recentemente, alguns poucos estudiosos vêm publicando artigos, dissertações, teses e livros que denunciam a escassez de debates sobre a pauta alusiva ao desenvolvimento de pesquisas na área de nanotoxicologia o que, consequentemente, demonstra o abismo existente entre o corpo técnico conhecedor dos riscos tecnológicos envolvendo os nanomateriais e os legisladores. Merece destaque a crítica formulada por Homero Batista Mateus da SILVA, ao apontar que a legislação brasileira, há muito tempo, não promove uma revisão de suas normas de saúde e segurança do trabalho, bem como não se encontra preparada para os impactos da nanotecnologia sobre a saúde ocupacional.

31. Em razão dessa lacuna, e considerando que diversas empresas, ICTs, universidades, pesquisadores e demais atores sociais têm interesses legítimos, cuja tutela jurídica se faz indispensável, a contribuição da presente tese ao debate se dá em três eixos: (i) identificar, no Direito Internacional Público e no Direito brasileiro, os princípios gerais de direito comumente aceitos como influenciadores no desenvolvimento dos seus instrumentos regulatórios; (ii) verificar se, no caso específico da exposição ocupacional e sua repercussão no Direito do Trabalho, por força da previsão contida no caput do art. $8^{\circ}$, CLT, seria juridicamente possível a aplicação dos instrumentos de soft law desenvolvidos por Organismos Internacionais no direito interno, para suprir a lacuna legislativa; e (iii) 
investigar, na eventual conclusão de impossibilidade de aplicação desses instrumentos de soft law, qual seria a solução existente no direito interno para os casos concretos envolvendo a exposição do trabalhador à nanopoluição laboro-ambiental.

32. Apesar da recente introdução do conceito de risco tecnológico no ordenamento jurídico, fato é que tanto a Lei n. 10.973/2004 quanto o Decreto n. 9.283/2018 não trazem qualquer definição específica sobre o desenvolvimento e aplicação da nanotecnologia, e muito menos sobre a responsabilidade civil imputada aos casos de danos decorrentes da concretização desses riscos tecnológicos surgidos de suas aplicações, o que, por si só, já demandaria algum tipo de regulamentação própria sobre o tema.

33. Considerando que o Juiz não pode se eximir de julgar o caso concreto alegando lacuna na lei, e que existe uma probabilidade real de que lides surgidas a partir de exposição aos nanomateriais podem vir a ser apresentadas perante o Poder Judiciário, por determinação do art. $4^{\circ}$ da LINDB, "o caso de acordo com a analogia, os costumes e os princípios gerais de direito". As lides trabalhistas, com base na regra prevista no art. $8^{\circ}$, caput, CLT, nas situações de lacuna legal, serão resolvidas "pela jurisprudência, por analogia, por equidade e outros princípios e normas gerais de direito, principalmente do direito do trabalho, e, ainda, de acordo com os usos e costumes, o direito comparado, mas sempre de maneira que nenhum interesse de classe ou particular prevaleça sobre o interesse público".

34. Ante a potencial ocorrência de exposição laboro-ambiental aos nanomateriais, adota-se como ponto de partida hermenêutico os direitos fundamentais previstos no art. $7^{\circ}$, caput e XXII; art. 200, VIII; e art. 225, todos da Constituição Federal de 1988. Segundo estes dispositivos constitucionais, os trabalhadores têm direito, além de outros que venham melhorar suas condições de trabalho, à redução dos riscos inerentes ao trabalho, por meio de normas de SST, bem como fazem jus a um meio ambiente do trabalho protegido e equilibrado, preservando-se sua qualidade de vida. A regulamentação desses direitos fundamentais se realizará através de normas jurídicas, as quais a mais balizada doutrina costuma distinguir entre regras e princípios.

35. Os princípios são categoria relevantes, do ponto de vista sistêmico, exercendo funções fundamentais dentro dos sistemas jurídicos, vez que representam a gênese para a atividade legislativa e o status quo a que se pretende chegar, fornecendo soluções de caráter generalistas e atuando na lacuna, integração e interpretação do ordenamento. Para a regência das relações jurídicas relacionadas à nanotecnologia, foram indicados cinco princípios: Prevenção, Precaução, Informação, Design Seguro e Poluidor-Pagador. 
36. Oriundo da Declaração da Rio 92, lavrada na Conferência das Nações Unidas sobre meio ambiente e desenvolvimento, o princípio da prevenção se associa muito bem os riscos perante os quais o conhecimento científico já funciona como uma das barreiras protetoras contra o dano, podendo prever as relações de causa e consequência. O princípio da prevenção está diretamente conectado com o direito à vida, no sentido de que, considerando a irreversibilidade e irreparabilidade dos danos ambientais, a prevenção é medida impositiva, sob pena de tornar o direito absolutamente ineficaz. O art. 225 da Constituição estabelece que é dever do Poder Público e da coletividade a preservação do meio ambiente para as gerações futuras, estabelecendo uma série de estratégias para tal. Do ponto de vista da lógica deôntica, o princípio estabelece um conteúdo axiológico proibitivo para geração de poluição, e um conteúdo axiológico obrigatório para adoção da responsabilidade civil objetiva como consequência da ocorrência da poluição. O princípio da prevenção diz à humanidade para monitorar e controlar as fontes emissoras de poluição, refreando qualquer processo antes de que se perca o controle. Sem a adoção das medidas no tempo correto, impossível será a realização de uma prevenção eficaz

O princípio da precaução, por sua vez, é mais afeto aos riscos caracterizados pela invisibilidade, globalidade e transtemporalidade. Também oriundo da Declaração do Rio, ele é aplicável aos casos em que a incerteza científica sobre determinado empreendimento traga ameaça de danos sérios ou irreversíveis ao meio ambiente, o que inclui o meio ambiente do trabalho. O princípio apresenta um conteúdo axiológico proibitivo no que diz respeito ao comportamento inconsequente, face à existência de riscos dotados de grande incerteza potencialmente danosos, e um conteúdo axiológico obrigatório para a adoção de medidas preventivas e impeditivas de concretização dos riscos.

38 .

A nanotecnologia é dotada de várias possibilidades de insucesso diretamente conectadas ao conhecimento insuficiente de suas propriedades, situação que se encaixa perfeitamente no conceito de risco tecnológico. Portanto, é exatamente para hipóteses como esta que o princípio da precaução se mostra pertinente, pois deverá ser aplicado para proteger a sociedade e o meio ambiente, inclusive o do trabalho, contra as incertezas da nanotecnologia, mediante avaliação e ponderação dos riscos.

39.

O princípio da informação surge também na Declaração do Rio de Janeiro de 1992, trazendo em si um conteúdo axiológico obrigatório ao Estados de prestar informações à população. Esta é a melhor maneira de tratar questões ambientais e assegurar a participação, no nível apropriado, de todos os cidadãos interessados. No nível nacional, cada indivíduo deve ter acesso adequado a informações relativas ao meio ambiente de que 
disponham as autoridades públicas, inclusive informações sobre materiais e atividades perigosas em suas comunidades, bem como a oportunidade de participar de processos de tomada de decisões, especialmente quando há envolvimento da nanotecnologia, como afirma a Organização Internacional do Trabalho: “A fim de garantir uma segurança química, é importante estabelecer um sistema nacional de avaliação e de classificação dos produtos químicos e fazer com que as informações dos fabricantes e dos importadores sejam adequadamente comunicadas aos utilizadores no seu local de trabalho, através de uma rotulagem adequada e de fichas de informações de segurança. Para melhorar a prevenção no local de trabalho, tais informações deverão incidir sobre os perigos e as precauções de segurança (nomeadamente as medidas de controlo de emergência) e também sobre as prescrições legais estabelecidas a nível nacional. Os trabalhadores deverão ser correctamente informados e formados sobre os perigos potenciais, deverão ainda ser implementados meios de prevenção técnica para imitar a exposição. Sempre que se revelar necessário, deve ser fornecido e utilizado um equipamento de protecção individual, embora essa seja geralmente considerada uma solução de último recurso, após terem sido tomadas as restantes precauções. É conveniente instaurar uma gestão eficaz dos produtos químicos para evitar os seus efeitos nocivos. Cada produto químico terá de ser correctamente identificado antes de ser comercializado. Deve ser efectuada uma avaliação profunda das eventuais propriedades perigosas e devem ser aperfeiçoados métodos de manipulação não perigosos que evitem a exposição, ou que, pelo menos, reduzam os riscos ao mínimo".

40. A inclusão desse princípio no âmbito do direito do trabalho se dá por força do art. $7^{\circ}$, XXII, CF, pelo qual é direito dos trabalhadores, além de outros que melhorem sua condição social, a redução dos riscos inerentes ao trabalho, por meio de normas de saúde, higiene e segurança; e sua importância reside no fato de que, sem possuir informações sobre as substâncias às quais se estão expostas e sobre como proceder para cuidar de sua saúde, as pessoas entrarão em estado de alienação sobre os riscos ocupacionais e de consumo, condição agravante para que se tornem vítimas potenciais de danos à sua higidez física e/ou ambientais.

41. A preservação do meio ambiente e o desenvolvimento socioeconômico são desafios intimamente conectados, cujas estratégias devem ser desenvolvidas em conjunto, garantindo-se a sustentabilidade de ambos, não sendo fácil ponderar os riscos e benefícios da inovação tecnológica sem uma estrutura robusta de tomada de decisões, voltada para o entendimento proativo e o gerenciamento de perigos, exposições e riscos potenciais resultantes para a segurança, saúde, bem-estar e produtividade, por meio da aplicação de 
uma abordagem baseada em ciência e prática, com a finalidade de construir e sustentar lideranças, culturas, e sistemas normativos que sejam relevantes e confiáveis. Portanto, vital será a abordagem via gerenciamento de risco, mas que apenas poderá existir e ser desenvolvida de forma frutífera se as características dos nanomateriais que influenciam na liberação, exposição, destino, cinética, perigo e/ou bioacumulação de substâncias forem identificadas, com disponibilização de muita informação sobre tais mecanismos.

42.

Por conta disto, é contido no princípio do design seguro um conteúdo axiológico obrigatório de zelo pelo desenvolvimento sustentável a priori, tal como proposto pela OCDE: “Em vez de realizar testes de segurança após o desenvolvimento e a produção de um produto ou serviço habilitado para nanotecnologia, é preferível desenvolver aplicações de MN [nanomateriais] que sejam 'mais seguros pelo design'. Para permitir isso, recomendações e estratégias de testes alternativos podem começar a ser compiladas, que podem ser usadas pela indústria para desenvolver produtos nano-habilitados seguros (ou pelo menos mais seguros). Alguns materiais podem ser descartados ou priorizados, com base nos resultados de testes alternativos. Os produtores podem começar a incorporar o feedback da tomada de decisões no design do material e devem adotar uma perspectiva de ciclo de vida, incorporando o conhecimento atual de como os MNs se comportam em várias matrizes".

43. É digno de nota que o Governo brasileiro (MCTIC) também incluiu o princípio do design seguro no Plano de Ação para o mercado de nanotecnologia. No Direito interno, a aplicação do princípio do design seguro teria por objetivo o cumprimento de duas determinações constitucionais, quais sejam, as previsões do art. 225, IV (exigir, na forma da lei, para instalação de obra ou atividade potencialmente causadora de significativa degradação do meio ambiente, estudo prévio de impacto ambiental, a que se dará publicidade) e V (controlar a produção, a comercialização e o emprego de técnicas, métodos e substâncias que comportem risco para a vida, a qualidade de vida e o meio ambiente).

44. O último princípio, o do poluidor-pagador, dialoga com a necessidade de preservação do meio ambiente, face à geração de resíduos potencialmente poluentes, oriundos da aplicação ou do descarte de produtos envolvendo a nanotecnologia. Ele tem por característica essencial o estabelecimento de um nexo causal direito entre a conduta do agente e a geração de poluição, criando uma responsabilidade objetiva a ser aplicada ao caso. Em outras palavras, o princípio estabelece um conteúdo axiológico proibitivo para geração de poluição e um conteúdo axiológico obrigatório para adoção da responsabilidade civil objetiva, como consequência da ocorrência da poluição. A visão do Supremo Tribunal 
Federal converge com a dos doutrinadores, ao julgar a ADI 3.378, no sentido de que o princípio do poluidor-pagador representa uma forma de imputar ao responsável pela degradação ambiental a responsabilidade de manter e, caso necessário, recuperar o equilíbrio do meio ambiente a ser entregue as próximas gerações, sempre primando-se pela aplicação do princípio da proporcionalidade.

45.

Não obstante a existência de lacuna legislativa, por força dos comandos estabelecidos no art. $4^{\circ}$ da LINDB e do art. $8^{\circ}$, caput, da CLT, como já citado alhures, a tese se debruçará sobre duas hipóteses envolvendo os métodos integrativos: (i) estudar a possibilidade dos aplicação dos diplomas de soft law nos casos envolvendo o Meio Ambiente do Trabalho, utilizando-se como método integrativo o direito comparado, para fins de aplicação de medidas de Saúde e Segurança do Trabalho e fixação da responsabilidade civil aplicável; e (ii), ainda que seja afastada a primeira hipótese, estuda-se a existência de normas já vigentes do Direito brasileiro, em especial normas de Direito Ambiental, aptas a produzir, ainda que primariamente, medidas de proteção da saúde humana e ambiental, bem como para estabelecer as formas de responsabilidade civil, utilizando-se a analogia como método integrativo.

46.

Com o desenvolvimento acelerado da nanotecnologia, esse crescimento do grau de complexidade social sobe mais um ponto na escala, sem qualquer sistema de freios e contrapesos, o que torna bastante difícil a vida de todos os stakeholders, cujos interesses em sua grande parte, legítimos - serão diretamente impactados. Para conseguir esse equilíbrio dinâmico, eis que a sociedade está em perpétua transformação, caberá ao ordenamento jurídico balancear e compatibilizar a maior quantidade de interesses possíveis, guardando uma necessária calibragem entre eles. Só assim será atingido o objetivo maior esperado dos formuladores de políticas públicas e legislação, bem como dos julgadores, no cumprimento de suas atividades.

47. Para supressão das lacunas do ordenamento jurídico, admitem-se métodos integrativos, os quais podem ser autointegrativos (a solução desenhada nascerá dentre as normas de direito interno positivo) ou heterointegrativos (a solução desenhada partirá de outras fontes do direito), classificados conforme a origem da solução adotada para o caso concreto. Essa distinção, feita por MASCARO, é tida como compatível com o direito do trabalho, inclusive, sendo adotada por GARCIA, ao definir o método do direito comparado e classificá-lo como método heterointegrativo, opondo-se à analogia, que seria um método autointegrativo. 
48

A proximidade cultural, gerada pela globalização, entre países geograficamente distantes também afetou o campo das relações jurídicas, impulsionando a criação e desenvolvimento de uma das principais metodologias heterointegrativas para harmonização de normas jurídicas: o direito comparado.

49.

Em revisão bibliográfica, um dos pontos mais citados foi o embate teórico sobre a natureza jurídica do direito comparado, isto é, se se trataria de uma metodologia para integração do ordenamento jurídico, mediante preenchimento das lacunas normativas e dotado de força normativa, ou se se trataria de um ramo científico do direito, cuja função seria apenas a de servir como exercício intelectivo, sem força qualquer força normativa. A maioria dos autores consultados manifestou apoio à linha metodológica de integração, sendo que, no domínio do direito do trabalho, face à redação do art. $8^{\circ}$ da CLT, seria até incoerente não o fazer, razão pela qual também foi adotada aqui a citada linha metodológica.

50 .

Pela definição de Wagner MENEZES, são diplomas de soft law “documentos solenes derivados de foros internacionais, que têm fundamento no princípio da boa-fé, com conteúdo variável e não obrigatório, que não vinculam seus signatários a sua observância mas que, por seu caráter e importância para o ordenamento da sociedade global, por refletirem princípios e concepções éticas e ideais, acabam por produzir repercussões no campo do Direito Internacional e também para o Direito Interno dos Estados". Com isso, percebe-se a influência irradiante que o soft law vem imprimindo no desenvolvimento do direito como um todo, servindo de referência especialmente para a criação de normas de direito interno ou, até mesmo, incorporando-se a este diretamente.

51. André de Albuquerque Cavalcanti ABBUD fará um alerta metodológico absolutamente pertinente, no sentido de que há de se ter cuidado na hora de efetuar a transposição de normas jurídicas, inclusive as de soft law, visando a preservação da proporcionalidade e compatibilidade na sua aplicação, mediante comparação e respeito às realidades socioeconômicas e culturais dos países e/ou organismos estudados para ver como o direito se comporta.

52.

A concepção de que a feitura dos diplomas de soft law decorre da aplicação da metodologia do direito comparado pode ser aprendida a partir do ensinamento de Carlos MAXIMILIANO, já que a formação desse tipo de diploma legal, ainda que não totalmente vinculante, representa grandes esforços de negociações e composições, realizado no âmbito das relações internacionais, não apenas se encerrando em mera sobreposições de legislações estrangeiras, mas sim como fruto de um processo democrático e internacional, sendo este 
modelo satisfatório para produzir estas normas flexíveis de conteúdo jurídico, não necessariamente vinculativas.

53. Diante dos ideais de soberania e de garantismo do Estado em relação ao indivíduo, o que a doutrina percebeu pela mudança de postura do Direito Internacional (de ius gentium para ius inter gens) foi o crescimento do voluntarismo estatal, em detrimento da proteção do ser humano, através da adoção do juspositivismo como filosofia orientadora das relações jurídicas e da ausência de consequências pelas violações das regras de direito internacional.

54. Os diversos atentados contra a humanidade, praticados no século XIX e XX, demonstraram a falácia do juspositivismo enquanto filosofia jurídica, vez que os ordenamentos jurídicos postos pelos Estados não foram capazes de impedir todos os acontecimentos negativos em escala global.

55. É notório que dois dos efeitos nocivos da globalização financeira e de produção, quais sejam, (i) concentração e o (ii) abuso do poder econômico, mormente ocorrentes quando as estratégias empresariais geram violações de direitos humanos (ex.: uso de trabalhos forçados para produção) ou se dão apenas para fugir da soberania de seus países através da escolha de países com legislações menos garantistas (ex.: dumping social mediante transnacionalização da empresa), são condições que geram distúrbios severos no que deveria ser a livre concorrência internacional das economias nacionais.

56. No caso da nanotecnologia, uma das possíveis aplicações nefastas de seu domínio seria a criação de armas químicas ou bioquímicas, para utilização contra populações pré-determinadas, viabilizando-se verdadeiros genocídios ao redor do globo e outros atos de natureza terrorista, sendo que a ausência de regulação específica para o setor serviria de critério para atração das empresas interessadas nestas atividades. Na banda das consequências indesejadas (culposas), temos a questão da geração dos nanorresíduos e da nanopoluição, a ser causada pelo uso indiscriminado dos nanomateriais, em especial daqueles com capacidade provocar mutações genéticas e de interferir nos processos ecossistêmicos (equilíbrio ecológico, seleção natural e conservação das massas da matéria), e até para a própria economia. A prejudicialidade causada pelos nanorresíduos e nanopoluição representará, neste momento, a concretização do chamado efeito bumerangue, presente na teoria de BECK.

57. A razão de ser do Estado positivista restou superada, sendo necessário buscar na recta ratio universal uma nova ordem que inclua o indivíduo e o meio ambiente na posição de titulares de direitos e deveres fundamentais recíprocos, como forma de realização 
de uma comunidade internacional realmente integrada, voltada à perenidade do planeta e das espécies. A regulamentação da nanotecnologia, por ainda ser algo incipiente, poderia ser construída, no âmbito internacional, já sob a visão da transnacionalidade, apresentando-se os métodos do direito comparado como mecanismos eficazes para construção desse direito transnacional. Para a construção dessas normas, o método proporá a realização de um corte transversal em diversas legislações nacionais, identificando seus pontos culturais de contato e de distanciamento, podendo, então, estabelecer as linhas gerais de composição de uma legislação que seja culturalmente acessível a todos os países e, consequentemente, a toda comunidade internacional, maximizando o ideal da dignidade da pessoa humana.

58.

Ao cabo, MALLOY concluirá que as normas de soft law representam o que se há de mais vanguardista em termos de regulação e que, mesmo sem uma imperatividade ou vinculatividade plenas, atualmente, trazem uma carga maior de segurança jurídica das relações envolvendo a nanotecnologia.

59. Para os fins desta tese, o embate entre teoria da transnacionalidade e teoria da fragmentação não parece tão relevante no que tange à nanotecnologia, desde que a legislação seja criada por alguém.

60.

Com base na revisão de literatura em saúde e segurança do trabalho aplicada à nanotecnologia, as questões centrais que mais têm desafiado os higienistas ocupacionais são: identificação dos riscos de saúde; critérios para adaptação dos métodos de detecção e medição; estudo de cenários reais de exposição no local de trabalho; definição e delimitação de locais de trabalho específicos para nanomateriais; recomendações para a segurança do trabalhador pelas autoridades e pela indústria; bem como cuidados médicos preventivos ocupacionais.

61.

Outro ponto comum também identificado na literatura é que, na maioria das vezes, os trabalhadores em laboratórios de pesquisa são os primeiros a serem expostos a este tipo de partícula. Por se tratar de trabalhadores que normalmente têm conhecimento e treinamento para lidar com tal exposição, a ocorrência de acidentes acaba sendo menor. Só a partir da evolução dos métodos de produção, passando da bancada do laboratório para a industrialização e comercialização dos produtos, é que os trabalhadores com menor grau de instrução e sem o conhecimento sobre a exposição passam a ser afetados, sendo que a fácil geração de aerodispersóides e a correspondente ausência de instrumentos de detecção 100\% preparados para medição da concentração dessas partículas dispersas no ar são agravantes severos do risco de exposição ocupacional. As medições continuam difíceis, porque os nanomateriais industrializados devem ser distinguidos das muitas partículas de poeira 
normais, sendo um desafio particular a detecção de poeira em forma de fibra e outras partículas, especialmente fibras longas e finas, sendo estas bastante perigosas quando inaladas.

62 .

Em relevantíssimo trabalho de coleta de dados, Carla dos Santos RICCARDI, Marcio Luiz dos SANTOS e Antônio Carlos GUASTALDI identificaram um total de 422 diplomas legais internos e internacionais, vigentes até 2014, além de diretrizes e regulamentos produzidos por entidades de metrologia e padronização.

63. Considerando a grande variedade de normas de direito estrangeiro e de organizações internacionais existentes, e dado o risco de baixa adesão dessa solução pela Magistratura, já que ela é oriunda de método normativo heterointegrativo - o que demandaria do Juiz a realização da necessária a sobreposição dos demais elementos influenciadores de suas realidades socioeconômicas e culturais num nível muito mais profundo do que se fez nesta tese, inclusive -, e para justificar o recorte metodológico apresentado, ao invés de partir da análise comparada dos ordenamentos jurídicos de diversos países, optou-se por propor a análise a partir de diplomas de soft law, já que estes também representam produtos normativos do direito comparado, inclusive com melhor observância dos princípios da proporcionalidade e da compatibilidade, facilitando a aplicação pelo Magistrado ao caso concreto.

64. Ainda sobre o recorte metodológico, acredita-se que gerará maior aceitação social a escolha de diplomas de soft law recentemente publicados e produzidos por organizações internacionais com as quais o Governo Brasileiro tenha oficialmente relações e enlaces, inclusive para justificar a atribuição, pelo Julgador, de imperatividade à norma de soft law, sem que isso represente uma violação ao princípio da soberania nacional (art. $1^{\circ}, \mathrm{I}$, $\mathrm{CF})$.

65 .

Após a submissão dos diversos diplomas existentes ao crivo metodológico definido ora proposto, estando todos eles indicados na bibliografia consultada, por serem os únicos a preencher os requisitos estabelecidos, passa-se à análise do conjunto de normas sobre exposição ocupacional produzido pela Organização Mundial de Saúde (OMS) publicada em 2017 - “Diretrizes para Proteção dos Trabalhadores de Potenciais Riscos dos Nanomateriais Manufaturados", o qual contou com participação de cientistas brasileiros na elaboração e revisão.

66.

A intenção divulgada pelo próprio documento é a de organizar e sistematizar as melhores práticas para proteção dos trabalhadores contra a exposição ocupacional aos nanomateriais manufaturados, visando auxiliar os formuladores de legislação e de políticas 
públicas a construírem as regras de saúde e segurança do trabalho, apesar de reconhecer a necessidade de maior aprofundamento. Logo, trata-se de um documento em evolução, que passará por revisões conforme a nanotecnologia for se desenvolvendo, todavia, sempre focado na proteção dos trabalhadores e na relação com os empregadores e governos.

67.

Os princípios de que partem estas diretrizes, princípio da precaução e da hierarquia das formas de controle, são compatíveis com os princípios propostos no Capítulo 2, sendo que o princípio da hierarquia nas formas de controle está incorporado ao princípio do design seguro. A visão manifestada sobre a aplicação do princípio da precaução diz que a exposição aos nanomateriais deve se dar da forma mais diminuta possível, em destaque quando houver a qualquer suspeita razoável de potencial danoso, mesmo que haja incertezas sobre os efeitos colaterais adversos. No que tange ao princípio da hierarquia nas formas de controle, este imporá que, quando houver a possibilidade de escolha entre as medidas de controle a serem aplicadas a um caso concreto, as que forem mais próximas da raiz do problema deverão sempre ser preferidas, em relação àquelas que sobrecarregam os trabalhadores, como o uso de equipamentos de proteção individual (EPI) ou pagamento de adicional de insalubridade.

68. Como medidas de boas práticas, as Diretrizes propõem (i) segregar os nanomateriais em, pelo menos, três grupos - os que já têm alguma toxicidade específica, os que possuem formato de fibras e os que possuem partículas granulares biopersistentes; (ii) educar e treinar os trabalhadores em questões específicas envolvendo saúde e segurança dos nanomateriais; e (iii) envolver os trabalhadores em todas as fases de avaliação e gerenciamento de risco.

69. O grupo de toxicidade específica, citado no item (i) das boas práticas, consistirá em (a) nanomateriais manufaturados com altas taxas de dissolução através da liberação de íons ou passíveis de biodegradação; e (b) nanomateriais manufaturados com baixas taxas de dissolução, mas com alta toxicidade específica. Os materiais do item (b) serão os nanomateriais manufaturados com toxicidade específica, que é mediada pelas propriedades químicas específicas de seus componentes.

70. No que concerne às boas práticas de educação e o treinamento dos trabalhadores, condição que também envolve as boas práticas de participação, estes devem focar os aspectos dos nanomateriais manufaturados que são tratados nas Diretrizes e que são adicionais ou diferentes de educação e treinamento no manuseio seguro de produtos químicos a granel. Os tópicos abrem as temáticas de quais perigos são específicos para nanomateriais manufaturados, diferenciando-os do material à granel; quais classes de perigo 
são atribuídas aos nanomateriais manufaturados; quais rotas de exposição são de importante monitoramento; quais exposições no local de trabalho foram medidas e quais tarefas colocam os trabalhadores em maior risco; como os limites de exposição ocupacionais propostos podem ser interpretados; quando e como deve ser feito o controle de bandas de exposição, além de outros controles específicos e EPIs para nanomateriais manufaturados podem ser usados.

71. Por sua vez, as recomendações normativas, feitas pelas Diretrizes, são reunidas em cinco grupos diferentes: (A) Avaliação dos perigos dos nanomateriais para a saúde; (B) Avaliação das formas de exposição aos nanomateriais; (C) Mecanismos de controle de exposição aos nanomateriais; (D). Vigilância Sanitária; e (E) Capacitação e participação dos trabalhadores. As recomendações foram consideradas "fortes" ou "condicionais", dependendo da qualidade das evidências científicas, dos valores e preferências e dos custos relacionados a cada recomendação.

72. São as diretrizes, em tradução livre:

a. As recomendações sobre avaliação dos perigos à saúde:

i. Para uso nas fichas de dados de segurança, recomenda-se que a classificação de perigo dos nanomateriais manufaturados seja realizada de acordo com o Sistema GHS - Globally Harmonized System of Classification and Labeling of Chemicals (em português, Sistema Globalmente Harmonizado para Classificação e Rotulagem de Produtos Químicos). As diretrizes fornecem essas informações apenas para um pequeno número de nanomateriais (forte recomendação, evidência de qualidade moderada).

ii. As fichas de dados de segurança devem ser atualizadas com informações sobre os riscos específicos dos nanomateriais manufaturados ou que os parâmetros toxicológicos que não foram adequadamente examinados sejam indicados (forte recomendação, evidência de qualidade moderada).

iii. Com relação ao grupo de fibras respiráveis e ao grupo de partículas granulares biopersistentes, a classificação existente dos nanomateriais manufaturados seja usada para classificar provisoriamente nanomateriais do mesmo grupo (recomendação condicional, evidência de baixa qualidade). 
b. No que tange às formas de avaliação de exposição ocupacional, a aplicação das Diretrizes são adaptáveis com algumas previsões da legislação trabalhista, notadamente os arts. 190 e 191, CLT, e das Normas Regulamentadoras, positivadas pela Portaria MTE n. 3.214/78, em especial a previsão da NR 15, item 15.1.5, vez que as Diretrizes também propõem a observância de Limites de Exposição Ocupacional (LEO) ou, conforme a nomenclatura brasileira, Limites de Tolerância:

i. Recomenda-se que a exposição dos trabalhadores no local de trabalho seja medida e avaliada usando métodos semelhantes aos utilizados para determinar o valor limite de exposição ocupacional (LEO) do nanomaterial específico em questão (recomendação condicional, evidência de baixa qualidade).

ii. Como não existem valores regulamentares específicos do LEO para os nanomateriais manufaturados no local de trabalho, propõem-se avaliar se a exposição no local de trabalho excede o valor de LEO proposto para o nanomaterial manufaturado em questão. Uma lista de valores LEO propostos está contida no Anexo 1 das diretrizes [Anexo 1 desta tese]. O valor de LEO escolhido deve ser, pelo menos, tão protetor quanto o limite de tolerância imposto por lei para a forma micro/macroscópica do material em questão (recomendação condicional, evidência de baixa qualidade).

iii. Se não houver valores específicos de LEO para nanomateriais manufaturados no local de trabalho, propõe-se uma abordagem gradual para avaliar a exposição por inalação: primeiro uma avaliação do potencial de exposição, depois uma avaliação básica da exposição e, finalmente, uma avaliação abrangente da exposição, como as propostas pela Organização para Cooperação e Desenvolvimento Econômico (OCDE) ou o Comitê Europeu para Padronização (CEN) (recomendação condicional, evidência de qualidade moderada). No que diz respeito à exposição cutânea, as evidências são insuficientes para recomendar um método de avaliação em detrimento de outro.

c. O terceiro grupo de recomendações das Diretrizes é direcionado ao controle da exposição aos nanomateriais manufaturados: 
i. Seguindo o princípio de precaução, recomenda-se que o controle da exposição se baseie em evitar a exposição por inalação, a fim de se reduzir tanto quanto possível (forte recomendação, evidência de qualidade moderada).

ii. Recomenda-se a redução da exposição a uma série de nanomateriais manufaturados sistematicamente medidos no local de trabalho, especialmente durante a limpeza e manutenção, a coleta de materiais de reatores e a alimentação de linhas de produção de nanomateriais manufaturados. $\mathrm{Na}$ ausência de informações toxicológicas, recomenda-se que os controles mais rigorosos sejam implementados para evitar qualquer exposição dos trabalhadores. Quando há informações sobre o assunto, recomenda-se uma abordagem mais específica (recomendação firme, evidência de qualidade moderada).

iii. Recomenda-se que as medidas de controle sejam baseadas no princípio da hierarquia dos controles; ou seja, a primeira medida de controle deve ser a eliminação da fonte de exposição, e não a aplicação de medidas de controle que dependam mais da participação dos trabalhadores; o equipamento de proteção individual deve ser usado apenas como último recurso. De acordo com este princípio, quando há um alto nível de exposição por inalação ou quando as informações toxicológicas são escassas ou inexistentes, controles de engenharia devem ser usados. Na ausência de controles de engenharia apropriados, equipamentos de proteção individual, especialmente proteção respiratória, devem ser usados dentro da estrutura de um programa de proteção respiratória que inclua verificações de ajuste de equipamento (recomendação firme, evidência de qualidade moderada).

iv. O GED se propõe a evitar a exposição dérmica com medidas de higiene ocupacional, como limpeza de superfícies e uso de luvas apropriadas (recomendação condicional, evidência de baixa qualidade).

v. Quando não há um especialista em segurança do trabalho para realizar as avaliações e medições, propõe-se que o método de gestão gradual dos riscos relacionados aos nanomateriais manufaturados seja 
utilizado para a escolha das medidas de controle da exposição no ambiente de trabalho. Devido à falta de estudos, não se pode recomendar um método de gerenciamento de risco gradual em detrimento de outros (recomendação condicional, evidência de qualidade muito baixa).

d. Em sequência, ao tratar da Vigilância Sanitária, quarto item das recomendações, as Diretrizes dizem que, por falta de evidências científicas, não há como se indicar um programa de vigilância sanitária específico para nanomateriais manufaturados em preferência aos programas que já são utilizados pelas autoridades.

e. Por fim, o último conjunto de recomendações trazidas diz respeito à capacitação de participação dos trabalhadores. As Diretrizes consideram que a capacitação dos trabalhadores e sua participação em questões relacionadas à saúde e segurança é uma prática ótima. Mas, devido à falta de estudos sobre o assunto, não há como se recomendar uma forma de treinamento ou participação dos trabalhadores, nem mesmo recomendar a participação de uns trabalhadores com detrimento de outros. Como são esperados progressos consideráveis em relação aos métodos de medição e avaliação de risco validados, a OMS pretende atualizar essas diretrizes dentro do prazo de 5 anos, isto é, em 2022.

73. Diante do todo exposto, em que pese a abordagem sobre limites de exposição ocupacional, denominado na NR 15.1.5 como limite de tolerância, ser altamente criticada, os anexos 11, 12 e 13 da NR 15, no direito do trabalho brasileiro, servem de base para definição dos métodos para avaliação da exposição e dos limites ocupacionais de exposição aos agentes de risco, os quais poderão ser incrementados com as recomendações apresentadas pela OMS, já que demonstrada sua compatibilidade, servido de orientação para empregados, empregadores e peritos, especialmente os judiciais, quando da realização de seus misteres.

74. O direito comparado terá função tripla no direito do trabalho, quais sejam, a de fornecer supletividade normativa; a de promover a renovação do direito e a de indicar critérios de escolha. Destarte, ante a lacuna legislativa sobre a nanotecnologia e na eventual necessidade de resolução do caso concreto de exposição ocupacional aos nanomateriais, seria juridicamente possível ao Juiz do Trabalho captar as disposições presentes nas Diretrizes da OMS para Proteção dos Trabalhadores de Potenciais Riscos dos Nanomateriais 
Manufaturados e determinar a aplicação desse diploma de soft law em território nacional, atribuindo-lhe imperatividade.

75. $\mathrm{O}$ trabalho é uma das mais importantes manifestações de afirmação e realização do indivíduo perante a sociedade. É neste contexto que a proteção da pessoa humana dentro do meio ambiente do trabalho torna-se absolutamente necessária. Não obstante, as predições da teoria econômica, qualquer que seja ela, fato é que a Constituição Federal de 1988 planejou um caminho diferente a ser trilhado, estabelecendo como objetivo da República Federativa do Brasil a construção de uma sociedade livre, justa e igualitária, que garanta o desenvolvimento nacional, com erradicação da pobreza e redução das desigualdades regionais e sociais, promovendo o bem de todos (art. $3^{\circ}$, caput e incisos).

76.

Atualmente, faz parte dos direitos precípuos à dignidade da pessoa humana a garantia de um meio ambiente laboral equilibrado, o qual deve ser considerado como indisponível, já que, devidamente revestido da pompa de direito social, previsto nos arts. $7^{\circ}$, XXII; art. 200, VIII; e art. 225, todos da Carta Magna. Os debates doutrinários apontam que a adição do elemento trabalho à ideia de meio ambiente proporciona um aumento radical da complexidade envolvendo a definição do termo presente no art. 200, VIII, da Carta Magna e, por tal razão, a doutrina vem alargando o conceito previsto na lei, haja vista ser considerado este incompleto no que se refere ao meio ambiente do trabalho.

77. $\mathrm{O}$ direito ao meio ambiente equilibrado não significa a imutabilidade do mesmo. O meio ambiente é sistematicamente alterado pela ação humana. Todavia, essas alterações não podem causar desequilíbrios significativos no(s) ecossistema(s) em que a ação foi praticada, sendo um desafio científico social e político a apuração dos impactos e decisão sobre a implementação das inovações, por conta dos riscos tecnológicos gerados.

78. Do ponto de vista da ordem econômica, ao invocar o art. 170, VI, CF, o STF afirmou existir uma limitação - isto é, uma submissão, um condicionamento - do desenvolvimento socioeconômico à proteção ao meio ambiente, incluído aí o do trabalho, resultando na concretização do princípio do design seguro, sendo que tal premissa se torna condição sine qua non para a realização de uma série de direitos sociais dos trabalhadores, todos da CF: art. $6^{\circ}$ (saúde, trabalho e segurança) e art. $7^{\circ}$, caput (direitos que venham a melhorar a condição social do trabalhador), inciso XXII (redução dos riscos inerentes ao trabalho, por meio de normas de saúde, higiene e segurança) e XXVIII (seguro contra acidentes de trabalho, a cargo do empregador, sem excluir a indenização a que este está obrigado, quando incorrer em dolo ou culpa. 
79.

$\mathrm{O}$ art. $3^{\circ}$, da Lei n. 8.080/90, afirma que pertencerá ao conceito de saúde do cidadão tudo aquilo que disser respeito ao seu bem-estar físico, mental e social, aqui incluído o trabalhador, funcionando como critério de avaliação de efetividade desse direito o acesso de qualidade a alimentação, a moradia, o saneamento básico, o meio ambiente, o trabalho, a renda, a educação, a atividade física, o transporte, o lazer e o acesso aos bens e serviços essenciais.

80.

Por maiores que sejam as críticas que se possam fazer à famigerada Reforma Trabalhista, promovida pela Lei n. 13.427/2017, a inserção da integridade física no rol de bens juridicamente tuteláveis dos trabalhadores, no art. 223-C da CLT representa um avanço em relação à situação anterior.

81. Como já afirmado anteriormente, a problemática da exposição ocupacional aos nanomateriais é a ausência de percepção do risco dos produtos químicos em geral, já que majoritariamente imperceptíveis aos sentidos humanos. Infelizmente, não é raro nos depararmos com catástrofes envolvendo o meio ambiente do trabalho. Apesar da queda dos números de acidente de trabalho nos últimos anos, a situação ainda é alarmante, vez que o Brasil se mantém na quarta posição do ranking mundial de acidentes de trabalho.

82.

Dadas as condições de nosso pátio tecnológico nacional e o grau de investimento no desenvolvimento da nanotecnologia até o momento, seria ingenuidade pensar que tal sorte de catástrofe não possa ocorrer com as nanopartículas, pois estas dispõem de diversas rotas de entrada para o corpo humano. Exatamente para garantir a proteção à higidez física do trabalhador, medida maior de sua dignidade humana, já que o trabalho não deveria ser fonte de doenças, mas tão somente de sustento, é que a CLT incorporou diversas normas jurídicas de saúde e segurança do trabalho

83.

A analogia é um método, na concepção desta tese, autointegrativo - já que busca a solução no direito interno, mantendo incólumes os princípios da soberania nacional e da unicidade do ordenamento jurídico - prestigiado pelo direito brasileiro. $\mathrm{O} \S 1^{\circ}$ do art. $8^{\circ}$, CLT, decreta que "o direito comum será fonte subsidiária do direito do trabalho". No caso em tela, a seara do direito que socorrerá o direito do trabalho para preenchimento desta lacuna, segundo se sugere, é o direito ambiental, único ramo apto a delinear os fundamentos do que vem se designando Direito Ambiental do Trabalho ou Direito Labor-Ambiental.

84. Os conceitos essenciais para se construir a ideia de nanopoluição laborambiental encontram-se na Lei n. 6.938/83 - Art. $3^{\circ}$. Para os fins previstos nesta Lei, entende-se por: I - meio ambiente, o conjunto de condições, leis, influências e interações de ordem física, química e biológica, que permite, abriga e rege a vida em todas as suas formas; 
II - degradação da qualidade ambiental, a alteração adversa das características do meio ambiente; III - poluição, a degradação da qualidade ambiental resultante de atividades que direta ou indiretamente: a) prejudiquem a saúde, a segurança e o bem-estar da população; b) criem condições adversas às atividades sociais e econômicas; c) afetem desfavoravelmente a biota; d) afetem as condições estéticas ou sanitárias do meio ambiente; e) lancem matérias ou energia em desacordo com os padrões ambientais estabelecidos; IV - poluidor, a pessoa física ou jurídica, de direito público ou privado, responsável, direta ou indiretamente, por atividade causadora de degradação ambiental.

85.

Os efeitos gerados pelo uso do produto se compatibilizam com todas as hipóteses previstas no art. $3^{\circ}$, III, supracitado, subsumindo-se, então, o fato ocorrido (contaminação dos trabalhadores) à definição legal de poluição. Como a poluição ocorreu no meio ambiente do trabalho, entende-se, consequentemente, por se tratar de uma poluição labor-ambiental. Ao cabo, por ser o agente poluente um nanomaterial, a terminologia que ora se apresenta para o fato narrado é a de nanopoluição labor-ambiental.

86. No final do ciclo de vida do produto, os nanomateriais podem se dispersar no meio ambiente ou se depositar nas estações de tratamento de resíduos como, por exemplo, nos filtros industriais ou estações de tratamento de água, vindo a contaminar o trabalhador que efetua a manutenção dessas áreas. Segundo a medicina ocupacional, há quatro vias usuais possíveis para contaminação do corpo humano (contato oral, contato dérmico, contato ocular ou inalação), embora pouco seja conhecido sobre como os nanomateriais se comportam na fase de descarte e se surgem potenciais riscos ambientais ou à saúde.

87. Os nanomateriais podem ser gerados de maneira voluntária ou involuntariamente. Aos que são gerados de maneira voluntária, sob a ótica dos princípios presentes no Capítulo 2, deve-se obedecer a seguinte hierarquia para a controle de geração de resíduos e futura destinação, com enfoque na responsabilidade civil objetiva e compartilhada: 1. prevenção de resíduos; 2. preparação para reutilização; 3. reciclagem 4. outra utilização (por exemplo, recuperação de energia); 5. disposição do material.

88. Para uma correta captação, tratamento e destinação dos nanorresíduos, segundo as formulações de BOLDRIN et al, há difíceis desafios a serem superados, tais como: (i) desenvolvimento de técnicas analíticas para a caracterização de resíduos de nanocompostos e sua transformação durante processos de tratamento de resíduos; (ii) construção de mecanismos para a liberação de nanomateriais manufaturados, (iii) estabelecer quantificação de quantias de resíduos escala; (iv) fixar uma definição de valores-limite 
aceitáveis para exposição aos nanomateriais manufaturados, a partir de resíduos de nanocomponentes; e (v) o relatório de dados de geração de nanopartículas.

89.

A degradação no meio ambiente de trabalho, como bem avisa FELICIANO,

"resultante de atividades que prejudiquem a saúde, a segurança e o bem-estar dos trabalhadores, sem dúvida alguma, caracteriza-se como poluição do meio ambiente do trabalho, de acordo com o tratamento constitucional dado à matéria."

90. No que concerne na responsabilidade civil, consoante os arts. 223-B e 223-C, CLT, conjugado com o art. 186, CC/2002, a todo trabalhador que, nas hipóteses de dolo, negligência, imprudência e imperícia, tiver sua integridade física lesada, será garantida a devida tutela jurídica. No caso dos acidentes de trabalho, a ação ou omissão do empregador estará relacionada com a ocorrência de qualquer uma das hipóteses previstas nos arts. 19, 20 e 21 da Lei n. 8.213/91. Em sequência, uma vez configurado o ilícito, por força dos arts. 223-A e 223-F, bem como do art. 927, CC/2002, o Juiz obrigará o devedor a reparar o dano experimentado pelo credor. Com isto, a responsabilidade civil do empregador estaria calcada num comando constitucional (art. $7^{\circ}$, XXVIII), o qual abraça a teoria da responsabilidade civil subjetiva, fazendo-se mister a demonstração de culpabilidade, juntamente com o ato ilícito, dano e nexo causal, para que surja, então, o dever de indenizar. Esta corrente é tradicionalmente aplicada pelo Judiciário trabalhista aos casos individualizados e de causalidade tópica, ou seja, sem relação com algum desequilíbrio mais profundo do meio ambiente laboral.

91. Não obstante a previsão constitucional do art. $7^{\circ}$, XXVIII, uma outra leitura possível apoia-se na previsão do art. $7^{\circ}$, XXII (redução de riscos laborais por meio da expedição de normas sobre saúde, higiene e segurança do trabalho), interpretado conjuntamente ao art. 200, VIII, e ao art. $225, \S 3^{\circ}$, todos da CF/88. Nesta leitura, as condutas e atividades que representem riscos laborais e que sejam consideradas lesivas aos diversos meios ambientes (dentre eles, o meio ambiente do trabalho) sujeitarão os infratores a sanções penais e administrativas, independentemente da obrigação de reparar os danos causados. Além dos dispositivos constitucionais, a tese da responsabilidade objetiva se apoia também na redação do art. 927, parágrafo único, CC/2002, e do art. 14, § $1^{\circ}$, da Lei 6.983/81, pois tais artigos desprezam o animus do agente, bastando o estabelecimento de nexo causal entre o dano e o ato ilícito para que surja o dever de indenizar. Segundo FELICIANO, a aplicação dessa tese se daria nas hipóteses de causalidade sistêmica, em outras palavras, nas hipóteses de ocorrência dos riscos "que representam a concreção de um quadro de desequilíbrio na disposição ou na combinação dos fatores de produção, i.e., da poluição labor-ambiental”. 
92.

Como corolário dos dispositivos legais citados, observa-se que, do ponto de vista da lógica jurídica, a norma relativa à responsabilidade civil é definida como uma relação de implicação ( $S \rightarrow P$, leia-se "Se $S$, então $P$ ”), na qual $S$ representa um antecedente e $P$ representa um consequente. Na responsabilidade civil subjetiva adota-se como núcleo do antecedente o (i) inadimplemento obrigacional, que pode se dar por ato ilícito ou descumprimento de contrato, somado à (ii) ocorrência de danos; à (iii) existência de uma condição causal entre o inadimplemento e os danos; e à (iv) culpabilidade do inadimplente e da vítima. O núcleo do consequente fica por conta da identificação dos (v) sujeitos da relação jurídica e da (vi) definição do quantum do dever de indenizar pelos danos causados. Na norma da responsabilidade civil objetiva, deverá ser excluído o item (iv) do antecedente, mantendo-se os demais incólumes, já que esta não verifica a culpabilidade do agente.

93. O embate jurídico sobre o tipo de responsabilidade civil aplicável ao empregador, normalmente, ficaria adstrita a estas duas teorias (subjetiva e objetiva). Entretanto, para esta tese, nas situações que envolvam dano decorrente de exposição ocupacional aos nanomateriais, propõem-se a aplicação de uma terceira teoria: teoria da responsabilidade civil objetiva e compartilhada na cadeia produtiva. Essa proposta surge diante da constatação de que, em casos como o relatado no texto, a persecução patrimonial para satisfação do crédito indenizatório - além da própria formação do título executivo judicial - ficaria restrita ao empregador e seus sócios. Essa limitação se torna sensível diante da condição de que, muitas vezes, o empregador não tem patrimônio suficiente para arcar com a integralidade da condenação, frustrando a execução trabalhista e prejudicando a pacificação social. E, mesmo com a inclusão da importadora mineira no polo passivo e imputação da responsabilidade objetiva e solidária para ambas, ainda assim parece bastante alta a chance de insatisfação do crédito, o que leva ao questionamento sobre o grau de responsabilidade da fabricante alemã e como se poderia estabelecer uma possível estratégia jurídica para conseguir atingir seu patrimônio.

94. Mais uma vez, repisando-se os riscos potenciais de liberação dos nanomateriais manufaturados no meio ambiente, especialmente o do trabalho, e estudadas as hipóteses de responsabilidade civil mais tradicionais, a tese a ser defendida acusa a insuficiência da aplicação da responsabilidade civil exclusivamente à figura do empregador, nos moldes da hermenêutica clássica, para propor a aplicação de uma responsabilidade civil objetiva e compartilhada na cadeia produtiva, vez que, segundo a Lei n. 12.305/2010, é obrigação de todos os participantes da cadeia produtiva a adoção de medidas para reduzir os impactos causados à saúde humana e à qualidade ambiental decorrentes do ciclo de vida dos 
produtos, bem como cabe à cadeia produtiva responder solidária e objetivamente pelos eventuais danos causados.

95. Ao optar por adotar a nanotecnologia, campo da tecnologia que ainda está em desenvolvimento e com grandes possibilidades de insucessos no percurso desse desenvolvimento, para incluí-la aos meios e ferramentas de produção, o empregador voluntariamente incrementa o risco - que passa de um risco comum a um risco tecnológico, nos exatos moldes da previsão contida no art. $2^{\circ}$, III, Decreto n. 9.283/2018 - de expor seus trabalhadores aos nanomateriais, criando potencial danoso à saúde humana. Portanto, dada a já tão repetida ausência de conhecimento sobre os efeitos, o campo também parece fértil para se estudar pela perspectiva de uma teoria de responsabilidade por dano futuro, já que, a depender das taxas de exposição e de abalo do organismo, as doenças podem demorar anos para aparecer, e muitos mais anos para desaparecer (aqui incluídas tanto as hipóteses de cura, quanto as de morte) ou se amenizar.

96. Conforme dispõe o art. $1^{\circ}, \S 1^{\circ}$, da Lei, 12.305/2010, estão sujeitas à observância desta lei as "pessoas físicas ou jurídicas, de direito público ou privado, responsáveis, direta ou indiretamente, pela geração de resíduos sólidos e as que desenvolvam ações relacionadas à gestão integrada ou ao gerenciamento de resíduos sólidos". A lei também trará as definições de resíduos sólidos, geradores de resíduos sólidos, uma classificação desses resíduos conforme sua origem e periculosidade, além do conceito de responsabilidade compartilhada pelo ciclo de vida dos produtos, concebida como o "conjunto de atribuições individualizadas e encadeadas dos fabricantes, importadores, distribuidores e comerciantes, dos consumidores e dos titulares dos serviços públicos de limpeza urbana e de manejo dos resíduos sólidos, para minimizar o volume de resíduos sólidos e rejeitos gerados, bem como para reduzir os impactos causados à saúde humana e à qualidade ambiental decorrentes do ciclo de vida dos produtos".

97. Tal responsabilidade compartilhada pelo ciclo de vida dos produtos tem os seguintes objetivos: (i) compatibilizar interesses entre os agentes econômicos e sociais e os processos de gestão empresarial e mercadológica com os de gestão ambiental, desenvolvendo estratégias sustentáveis; (ii) promover o aproveitamento de resíduos sólidos, direcionando-os para a sua cadeia produtivas ou para outras cadeias produtivas; (iii) reduzir a geração de resíduos sólidos, o desperdício de materiais, a poluição e os danos ambientais; (iv) incentivar a utilização de insumos de menor agressividade ao meio ambiente e de maior sustentabilidade; (v) estimular o desenvolvimento de mercado, a produção e o consumo de produtos derivados de materiais reciclados e recicláveis; (vi) propiciar que as atividades 
produtivas alcancem eficiência e sustentabilidade; (vii) incentivar as boas práticas de responsabilidade sócioambiental.

98. Mas, mesmo com este grau de responsabilidade, ainda assim haverá a necessidade de apuração da existência de algum nexo (causalidade ou concausalidade) entre o dano experimentado e a conduta do agente poluidor, sendo necessário se refletir sobre a dilação e o ônus probatório da nanopoluição labor-ambiental. A teoria adotada pelo legislador brasileiro foi a teoria da causalidade adequada, direta e imediata, positivada no art. 403, CC. Há que se considerar, porém, que para o fenômeno denominado nanotecnologia, agregada das suas incertezas, o estabelecimento desse nexo causal adequado, direto e imediato se torna difícil para quem não detiver a aptidão técnica para produção da prova, razão pela qual, nestes casos, caberá ao Juízo, se entender necessário, promover a inversão do ônus da prova.

99. Não obstante à teoria adotada pelo Código Civil, somada à possibilidade de inversão do ônus da prova na CLT, a verdade é que o fenômeno da exposição ocupacional aos nanomateriais está consubstanciado em fatos muito complexos para serem observados tão somente à luz da teoria do nexo causal adequado, direito e imediato, pois, mesmo sendo positivada, não há unanimidade doutrinada e jurisprudencial sobre a eficácia dessa teoria. Considerando, então, que o estabelecimento da responsabilidade incidente nos acidentes de trabalho e doenças ocupacionais oriundos do uso da nanotecnologia envolve uma grande quantidade de análises e ponderações sobre os eventos que supostamente levarão ao dano experimentado, na visão dos doutrinadores de escol, é necessária a flexibilização dos pressupostos da responsabilidade civil, focando na proteção da vítima contra danos injustos. Não será por outro motivo que se sustentará a adoção da teoria do risco integral, assim explicada por GONÇALVES: “A responsabilidade objetiva, como já dito, baseia-se na teoria do risco. Nela se subsume a ideia do exercício de atividade perigosa como fundamento da responsabilidade civil. O exercício de atividade que possa oferecer algum perigo representa, sem dúvida, um risco que o agente assume de ser obrigado a ressarcir os danos que venham resultar a terceiros. O princípio da responsabilidade por culpa é substituído pelo da responsabilidade por risco (socialização dos riscos). Neste passo, limitase o campo das exonerações possíveis, com a absorção do caso fortuito".

100. Embora a adoção da teoria do risco integral revela-se um tanto quanto radical quando comparada com as demais teorias e, em especial, quando se pensa a responsabilidade sob a ótica da infortunística laboral, para os casos envolvendo nanotecnologia, a aplicação da teoria do risco integral para configuração da responsabilidade civil objetiva e 
compartilhada garantirá a possibilidade real e efetiva de reparação integral do dano experimentado pelo trabalhador, já que toda a cadeia produtiva será responsável por ele. 
ANEXO I - DIRETRIZES DA OMS PARA PROTEÇÃO DOS TRABALHADORES DE POTENCIAIS RISCOS DOS NANOMATERIAIS MANUFATURADOS 


\section{WHO GUIDELINES ON PROTECTING WORKERS FROM POTENTIAL RISKS OF MANUFACTURED NANOMATERIALS}


WHO guidelines on protecting workers from potential risks of manufactured nanomaterials ISBN 978-92-4-155004-8

\section{(c) World Health Organization 2017}

Some rights reserved. This work is available under the Creative Commons Attribution-NonCommercial-ShareAlike 3.0 IGO licence (CC BY-NC-SA 3.0 IGO; https:/creativecommons.org/licenses/by-nc-sa/3.0/ igo).

Under the terms of this licence, you may copy, redistribute and adapt the work for non-commercial purposes, provided the work is appropriately cited, as indicated below. In any use of this work, there should be no suggestion that WHO endorses any specific organization, products or services. The use of the WHO logo is not permitted. If you adapt the work, then you must license your work under the same or equivalent Creative Commons licence. If you create a translation of this work, you should add the following disclaimer along with the suggested citation:"This translation was not created by the World Health Organization (WHO). WHO is not responsible for the content or accuracy of this translation. The original English edition shall be the binding and authentic edition".

Any mediation relating to disputes arising under the licence shall be conducted in accordance with the mediation rules of the World Intellectual Property Organization.

Suggested citation. WHO guidelines on protecting workers from potential risks of manufactured nanomaterials. Geneva: World Health Organization; 2017. Licence: CC BY-NC-SA 3.0 IGO.

Cataloguing-in-Publication (CIP) data. CIP data are available at http://apps.who.int/iris.

Sales, rights and licensing. To purchase WHO publications, see http://apps.who.int/bookorders. To submit requests for commercial use and queries on rights and licensing, see http:/www.who.int/about/licensing.

Third-party materials. If you wish to reuse material from this work that is attributed to a third party, such as tables, figures or images, it is your responsibility to determine whether permission is needed for that reuse and to obtain permission from the copyright holder. The risk of claims resulting from infringement of any third-party-owned component in the work rests solely with the user.

General disclaimers. The designations employed and the presentation of the material in this publication do not imply the expression of any opinion whatsoever on the part of WHO concerning the legal status of any country, territory, city or area or of its authorities, or concerning the delimitation of its frontiers or boundaries. Dotted and dashed lines on maps represent approximate border lines for which there may not yet be full agreement.

The mention of specific companies or of certain manufacturers' products does not imply that they are endorsed or recommended by WHO in preference to others of a similar nature that are not mentioned. Errors and omissions excepted, the names of proprietary products are distinguished by initial capital letters.

All reasonable precautions have been taken by WHO to verify the information contained in this publication. However, the published material is being distributed without warranty of any kind, either expressed or implied. The responsibility for the interpretation and use of the material lies with the reader. In no event shall WHO be liable for damages arising from its use.

The opinions expressed in this report do not necessarily represent the opinions or policies of the organizations and governments who employ the contributors to this report.

Design and layout: designisgood.info

Cover illustration by Mstroeck at the English language Wikipedia, CC BY-SA 3.0, https://commons.wikimedia. org/w/index.php?curid $=11668445$ 


\section{CONTENTS}

Glossary

Abbreviations and acronyms

Executive summary $\quad 4$

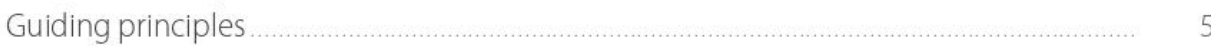

Best practice

Methods

Recommendations

A. Assess health hazards of MNMs

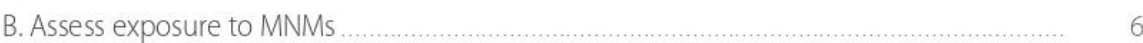

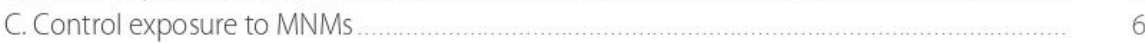

D. Health surveillance .............................................................................

E. Training and involvement of workers ....................................................................

Résumé d'orientation

Sinopsis $\quad 12$

Исполнительное резюме

要概行执 20

25

1. Introduction 28

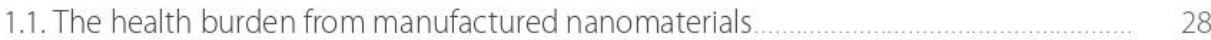

1.2. Scope of the guidelines and key questions $\ldots$

1.3. WHO guidelines relating to this topic $\ldots$

1.4. Other international programmes on MNM safety ................................................... 31

1.5. Target audience $\ldots$

2. Process for guideline development $\quad 33$

2.1. Getting started

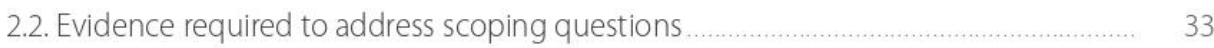

2.3. Summary of evidence review process $\ldots$

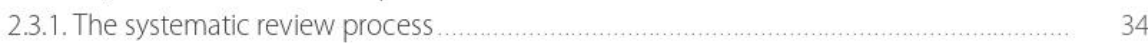

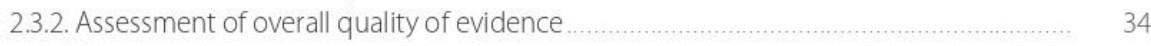

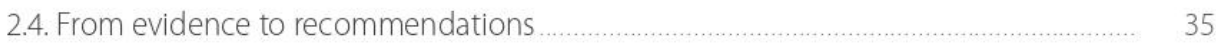

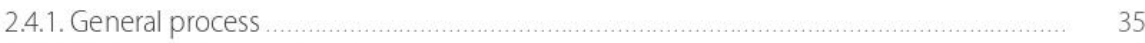

2.4.2. Workers'values and preferences $\ldots$

3. Individuals and partners involved in guideline development

3.1. WHO Guideline Steering Group

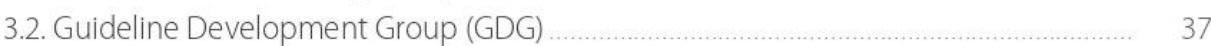

3.3. Systematic review teams $\ldots$

3.4. External Review Group.

3.5. Management of conflicts of interest 
4. Formulating the recommendations

4.1. Focus of the recommendations

4.2. Guiding principles $\quad 39$

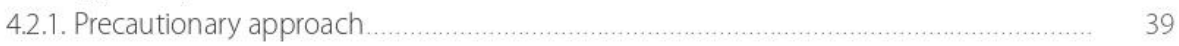

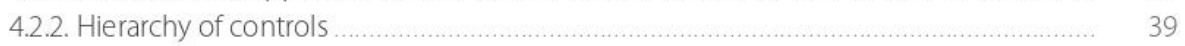

5. Best practice $\ldots 41$

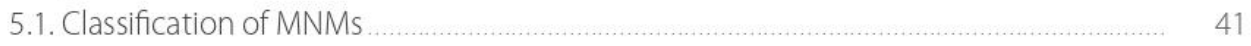

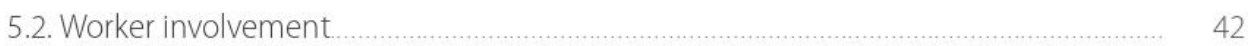

5.3. Additional training and education of workers $\ldots$

6. Specific recommendations $\quad 43$

6.1. Assess health hazards of MNMs $\ldots$

6.2. Assess exposure to MNMs

6.3. Control exposure to MNMs $\ldots$

6.3.1. Focus on prevention of inhalation of MNMs $\ldots$

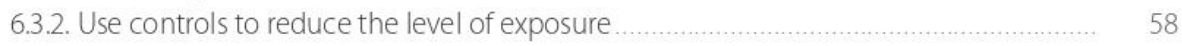

6.4. Health surveillance $\ldots$

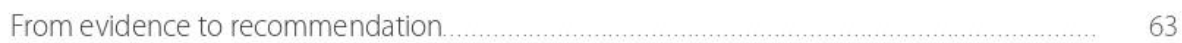

Summary of findings: health examinations of workers exposed to MNMs _...................... 63

Quality of the evidence $\ldots \ldots \ldots$

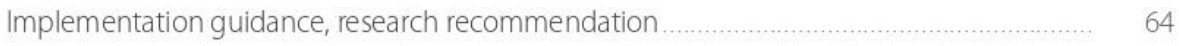

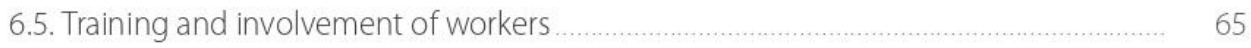

Summary of findings: training and involvement of workers $\ldots$

Evidence summary $\ldots$

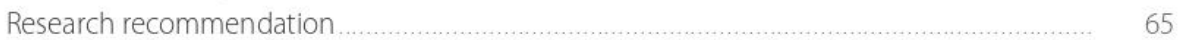

7. Implementation of the guidelines $\ldots 6$

8. Updating the guidelines

References

Annex 1: List of proposed occupational exposure limit (OEL) values for MNMs 71

Annex 2: Steering group, guideline development group, systematic review teams and external review group

Annex 3: Summary of evidence, routes of exposure to MNMs $\quad 82$ 
GLOSSARY

\section{Acute exposure}

Exposure occurring over a short time, generally less than one day.

Acute effect

A health or physiological effect that occurs suddenly over hours or days, for example lung inflammation resulting from inhalation exposure.

\section{Aerosol}

Mixture of small particles (solid, liquid or a mixed variety) and a carrier gas (usually air).

\section{Breathing zone}

The area immediately surrounding a worker's nose and mouth from where the majority of air is drawn into their lungs.

\section{Bulk material}

The larger counterpart of a nanomaterial not confined to the nanoscale in any dimension, e.g. gold as the bulk material and nano-gold as the nano-form material.

\section{Carbon nanofibres}

Cylindrical nanostructures with graphene layers arranged as stacked cones, cups or plates.

\section{Carbon nanotubes}

Hollow nano-objects with two similar external dimensions in the nanoscale and the third dimension significantly larger, composed of carbon (ISO/TS 80004-3:2010).

\section{Chronic effect}

An effect that occurs or builds up over a long period; for humans over years, for example cardiovascular disease.

\section{Chronic exposure}

Exposure over a long period, for humans over years.

\section{Confounder}

A factor in an exposure study that is both related to the exposure and to the outcome. The uneven distribution of the confounder will lead to distorted or spurious results.

\section{Control banding}

A risk management approach to identify and recommend exposure control measures for potentially hazardous substances for which toxicological information is limited.

\section{Engineering controls}

Use of mechanical or technical measures such as enclosure, ventilation and workplace design to minimize exposure.

\section{Fibre diameter}

Fibre dimension.

\section{Fibre length}

Fibre dimension.

Grading of Recommendations, Assessment, Development and Evaluations (GRADE) A systematic and explicit approach to making judgements about quality of evidence and strength of recommendations. GRADE also stands for GRADE working group, the group that formulates the guidelines for the approach.

Globally Harmonized System of Classification and Labelling of Chemicals

A classification and labelling system developed by the United Nations, addressing classification of chemicals by types of hazard and proposing harmonized hazard communication elements, including labels and safety data sheets.

\section{Granular biopersistent particles}

Particles that are characterized as respirable granular and biopersistent but not fibrous. Also known as "poorly soluble particles" or as "poorly soluble, low-toxicity particles".

\section{Hazard}

The inherent potential to cause physical or psychological harm to the health of people.

\section{Manufactured nanomaterials}

Solid, particulate substances intentionally manufactured at the nanoscale, consisting of nano-objects with at least one dimension between 1 and $100 \mathrm{~nm}$, and their aggregates and agglomerates.

\section{Multi-walled carbon nanotubes}

Tubes of multiple concentric cylindrical oneatom-thick layers of graphene as opposed to single-walled nanotubes (SWCNTS).

\section{Nano-object}

A material with one, two or three external dimensions in the nanoscale. 
Nano-objects and their aggregates and agglomerates

Nano-objects ( $<100 \mathrm{~nm}$ ) and their aggregates and agglomerates (> $100 \mathrm{~nm}$ ).

\section{Nanoparticle}

Nano-object with all three external dimensions in the nanoscale $(<100 \mathrm{~nm}$ diameter).

\section{Nanoscale}

Size range from approximately $1 \mathrm{~nm}$ to $100 \mathrm{~nm}$.

\section{Occupational exposure limit}

Maximum concentration of airborne contaminants deemed to be acceptable, as defined by the authority having jurisdiction (ISO 16972:2010),

\section{Particulate matter}

A mixture of solid particles and liquid droplets suspended in the air.

\section{Personal protective equipment}

Equipment (clothing, gloves, hard hat, respirator and so on) worn by an individual to minimize risk to the individual's health and safety.

\section{PICO}

Systematic framework to answer the scoping questions, used as an acronym: P for Population, I for Intervention, C for Comparator, O for Outcome(s).

\section{Protection factor (PF)}

The ratio of exposure level without the controls divided by the exposure level with the controls. If the PF is $>1$, controls reduce exposure. A PF of 10 indicates that controls reduce exposure by $90 \%$.

\section{Read across}

Transfer of hazard information from one material to another based on similarities between the materials.

\section{Risk of bias}

The risk that the results of a study can be distorted due to methodological limitations such as the presence of confounders.

\section{Safety data sheet}

Document that provides information on the properties of hazardous chemicals, how they affect health and safety in the workplace and how to manage hazardous chemicals in the workplace (ISO/TR13329:2012).

\section{Short-term exposure limit}

Fifteen-minute time-weighted average (TWA) exposure which should not be exceeded at any time during a workday, even if the 8-hour TWA is within the threshold limit value TWA.

\section{Single-walled carbon nanotubes}

A cylindrical one-atom-thick layer of graphite called graphene as opposed to multi-walled nanotubes.

\section{Solubility}

The ability of a material to release ions in water or in another liquid. Solubility may be expressed by the dissolution rate of the material and may also be described using words such as insoluble, very soluble or poorly soluble.

\section{Threshold limit value}

Health-based occupational exposure limit value published by the American Conference of Governmental Industrial Hygienists.

\section{Tiered approach}

A stepwise approach in which each step has an increased level of complexity; here it refers to a risk-based approach for conducting an exposure or release assessment to determine whether exposure to manufactured nanomaterials (MNMs) may occur and to determine if there is a need for further risk management steps to be taken.

\section{Time-weighted average}

An average concentration of an airborne contaminant that workers may be exposed to, over a period of time such as an 8-hour day or 40-hour week (an average work shift).

\footnotetext{
' Harmonized tiered approach to measure and assess the potential exposure to airborne emissions of engineered nanoobjects and their agglomerates and aggregates at workplaces. Series on the Safety of Manufactured Nanomaterials No. 55. Environment Directorate Joint Meeting of the Chemicals Committee and the Working Party on Chemicals, Pesticides and Biotechnology. ENV/JM/MONO(2015)19. Paris: Organisation for Economic Co-operation and Development; 2015 (http://www.oecd.org/officialdocuments/publicdisplaydocumentpdf/?cote=env/jm/mono(2015)19\&doclanguage=en, accessed 31 August 2017).
} 


\section{ABBREVIATIONS AND ACRONYMS}

CEN Comité Européen de Normalisation (European Committee for Standardization)

CNFs carbon nanofibres

CNTs carbon nanotubes

CUPE Canadian Union of Public Employees

EC elemental carbon

ETUC European Trade Union Confederation

FD fibre diameter

FL fibrelength

GBP granular biopersistent particles

GDG Guideline Development Group

GHS Globally Harmonized System (of Classification and Labelling of Chemicals)

GLP good laboratory practice

GRADE Grading of Recommendations, Assessment, Development and Evaluation

GRC Guidelines Review Committee

IARC International Agency for Research on Cancer

ILO International Labour Organization

IOMC Inter-Organization Programme for the Sound Management of Chemicals

ISO International Organization for Standardization

ITUC International Trade Union Confederation

IUF International Union of Food Agricultural, Hotel, Restaurant, Catering, Tobacco and Allied Workers' Associations

LMI low-and middle-income (countries)

MNMs manufactured nanomaterials
MWCNTs multi-walled carbon nanotubes

NIOSH National Institute for Occupational Safety and Health, United States of America (USA)

NOAAs nano-objects and their aggregates and agglomerates

NP nanoparticle

OECD Organisation for Economic Cooperation and Development

OEL occupational exposure limit

OSHA Occupational Safety and Health Administration, USA

PF protection factor

PICO Population, Intervention Comparator, Outcome(s)

PM particulate matter

PPE personal protective equipment

SDS safety data sheet

SME small and medium-sized enterprises

SWCNTs single-walled carbon nanotubes

TWA time-weighted average

USA United States of America

WHO World Health Organization

WPMN (OECD) Working Party on Manufactured Nanomaterials 


\section{EXECUTIVE SUMMARY}

The term nanomaterials refers to materials that have at least one dimension (height, width or length) that is smaller than 100 nanometres $\left(10^{-7}\right.$ metre), which is about the size of a virus particle. This particular size dimension represents a major characteristic of manufactured nanomaterials (MNMs). The unique properties of MNMs may result in highly desirable behaviour leading to such varying applications as better paints, better drugs and faster electronics. However, for the same reason, MNMs may also present health hazards that differ from those of the substance in bulk form, and may require different test methods for hazard, exposure and risk assessment from their bulk material counterparts.

The toxicity of MNMs may largely depend on numerous physicochemical properties, including size, shape (i.e. size in a particular dimension), composition, surface characteristics, charge and rate of dissolution. There is currently a paucity of precise information about human exposure pathways for MNMs, their fate in the human body and their ability to induce unwanted biological effects such as generation of oxidative stress. Data from in vitro, animal and human MNM inhalation studies are available for only a few MNMs. So far, no long-term adverse health effects in humans have been observed. This could be due to the recent introduction of MNMs, the precautionary approach to avoid exposure and ethical concerns about conducting studies on humans. This means that, except for a few materials where human studies are available, health recommendations must be based on extrapolation of the evidence from in vitro, animal or other studies from fields that involve exposure to nanoscale particles, such as air pollution, to the possible effects in humans.

The increased production of MNMs and their use in consumer and industrial products means that workers in all countries will be at the front line of exposure to these materials, placing them at increased risk for potential adverse health effects.

Therefore, the World Health Organization (WHO) has developed these guidelines with recommendations on how best to protect workers from the potential risks of MNMs. The recommendations are intended to help policy-makers and professionals in the field of occupational health and safety in making decisions about the best protection against potential risks specific to MNMs in workplaces. These guidelines are also intended to support workers and employers. However, they are not intended as a handbook or manual for safe handling of MNMs in the workplace because this requires addressing more general occupational hygiene issues beyond the scope of these guidelines. 


\section{GUIDING PRINCIPLES}

The Guideline Development Group (GDG) used a precautionary approach as one of its guiding principles. This means that exposure has to be reduced, despite uncertainty about the adverse health effects, when there are reasonable indications to do so.

In addition, the hierarchy of controls was an important guiding principle. This means that when there is a choice between control measures, those measures that are closer to the root of the problem should always be preferred over measures that put a greater burden on workers, such as the use of personal protective equipment (PPE).

\section{BEST PRACTICE}

The GDG considers the following to be best practice in preventing the adverse health effects of MNMS:

- Group nanomaterials into MNMs with specific toxicity, MNMs that are fibres and MNMs that are granular biopersistent particles.

- Educate and train workers in the specific health and safety issues of MNMs.

- Involve workers in all phases of risk assessment and control.

\section{METHODS}

For all important issues, systematic reviews of the current state of the science were commissioned to inform the recommendations according to the process set out in the WHO Handbook for guideline development. The recommendations were rated as "strong" or "conditional" depending on the quality of the scientific evidence, values and preferences, and costs related to the recommendation. All recommendations were made based on consensus within the GDG.

\section{RECOMMENDATIONS}

\section{A. Assess health hazards of MNMs}

1. The GDG recommends assigning hazard classes to all MNMs according to the Globally Harmonized System (GHS) of Classification and Labelling of Chemicals for use in safety data sheets. For a limited number of MNMs this information is made available in these guidelines (strong recommendation, moderate-quality evidence).

2. The GDG recommends updating safety data sheets with MNM-specific hazard information or indicating which toxicological end-points did not have adequate testing available (strong recommendation, moderate-quality evidence).

3. For the respirable fibres and granular biopersistent particles' groups, the GDG suggests using the available classification of MNMs for provisional classification of nanomaterials of the same group (conditional recommendation, low-quality evidence). 


\section{B. Assess exposure to MNMs}

4. The GDG suggests assessing workers' exposure in workplaces with methods similar to those used for the proposed specific occupational exposure limit (OEL) value of the MNM (conditional recommendation, low-quality evidence).

5. Because there are no specific regulatory OEL values for MNMs in workplaces, the GDG suggests assessing whether workplace exposure exceeds a proposed OEL value for the MNM. A list of proposed OEL values is provided in Annex 1 of these guidelines. The chosen OEL should be at least as protective as a legally mandated OEL for the bulk form of the material (conditional recommendation, low-quality evidence).

6. If specific OELs for MNMs are not available in workplaces, the GDG suggests a stepwise approach for inhalation exposure with, first an assessment of the potential for exposure; second, conducting basic exposure assessment and third, conducting a comprehensive exposure assessment such as those proposed by the Organisation for Economic Cooperation and Development (OECD) or Comité Européen de Normalisation (the European Committee for Standardization, CEN) (conditional recommendation, moderatequality evidence). For dermal exposure assessment, there was insufficient evidence to recommend one method of dermal exposure assessment over another.

\section{Control exposure to MNMs}

7. Based on a precautionary approach, the GDG recommends focusing control of exposure on preventing inhalation exposure with the aim of reducing it as much as possible (strong recommendation, moderate-quality evidence).

8. The GDG recommends reduction of exposures to a range of MNMs that have been consistently measured in workplaces especially during cleaning and maintenance, collecting material from reaction vessels and feeding MNMs into the production process. In the absence of toxicological information, the GDG recommends implementing the highest level of controls to prevent workers from any exposure. When more information is available, the GDG recommends taking a more tailored approach (strong recommendation, moderate-quality evidence).

9. The GDG recommends taking control measures based on the principle of hierarchy of controls, meaning that the first control measure should be to eliminate the source of exposure before implementing control measures that are more dependent on worker involvement, with PPE being used only as a last resort. According to this principle, engineering controls should be used when there is a high level of inhalation exposure or when there is no, or very little, toxicological information available. In the absence of appropriate engineering controls PPE should be used, especially respiratory protection, as part of a respiratory protection programme that includes fit-testing (strong recommendation, moderate-quality evidence).

10. The GDG suggests preventing dermal exposure by occupational hygiene measures such as surface cleaning, and the use of appropriate gloves (conditional recommendation, lowquality evidence). 
11. When assessment and measurement by a workplace safety expert is not available, the GDG suggests using control banding for nanomaterials to select exposure control measures in the workplace. Owing to a lack of studies, the GDG cannot recommend one method of control banding over another (conditional recommendation, very low-quality evidence).

\section{Health surveillance}

The GDG cannot make a recommendation for targeted MNM-specific health surveillance programmes over existing health surveillance programmes that are already in use owing to the lack of evidence.

\section{E. Training and involvement of workers}

The GDG considers training of workers and worker involvement in health and safety issues to be best practice but cannot recommend one form of training of workers over another, or one form of worker involvement over another, owing to the lack of studies available.

It is expected that there will be considerable progress in validated measurement methods and risk assessment. Therefore, the GDG proposes to update these guidelines in five years' time, in 2022. 


\section{RESUMM D'ORIENTATION}

Le terme nanomatériaux fait référence à des matériaux dont au moins une dimension (hauteur, largeur ou longueur) est inférieure à 100 nanomètres ( $10^{-7}$ mètre), ce qui correspond approximativement à la taille d'une particule virale. Cette dimension particulière constitue une caractéristique majeure des nanomatériaux manufacturés (NMM). Les propriétés uniques des NMM peuvent aboutir à un comportement très intéressant qui trouve de nombreuses applications comme de meilleures peintures, de meilleurs médicaments et des produits électroniques plus rapides. Néanmoins, pour cette même raison, les NMM peuvent aussi présenter des dangers pour la santé différents de ceux des substances de forme micro/macroscopique et peuvent nécessiter des méthodes de test différentes pour estimer le danger, l'exposition et le risque.

La toxicité des NMM est essentiellement due aux nombreuses propriétés physicochimiques, notamment la taille, la forme (taille dans une dimension particulière), la composition, les caractéristiques de surface, la charge et la vitesse de dissolution. On manque actuellement de données précises sur les voies de l'exposition humaine pour les NMM, leur devenir dans l'organisme et leur capacité à induire des effets biologiques indésirables, comme la génération d'un stress oxydatif. Des données issues d'études d'inhalation de NMM in vitro, chez l'animal et chez l'homme ne sont disponibles que pour quelques NMM. Jusqu'à présent, aucun effet indésirable sur la santé n'a été observé chez l'homme à long terme. Cela peut s'expliquer par la récente introduction des NMM, le principe de précaution appliqué pour éviter l'exposition et des considérations éthiques associées aux études conduites chez l'homme. Ainsi, à l'exception de quelques matériaux pour lesquels on dispose d'études chez l'homme, les recommandations sanitaires doivent se fonder sur l'extrapolation des données issues des études in vitro, chez l'animal et autres études menées sur le terrain qui impliquent une exposition à des particules nanométriques, comme la pollution atmosphérique, pour évaluer les effets possibles chez l'homme.

La production croissante de NMM et leur utilisation dans des produits de consommation et industriels signifient que les personnes qui travaillent avec ces produits, dans tous les pays, seront en première ligne en termes d'exposition à ces matériaux avec un risque accru d'effets indésirables potentiels sur la santé.

L'Organisation mondiale de la Santé (OMS) a donc élaboré ces lignes directrices qui contiennent des recommandations pour protéger au mieux les travailleurs contre les risques potentiels des NMM. Ces recommandations ont pour vocation d'aider les responsables de l'élaboration des politiques et les professionnels de la santé et de la sécurité au travail à prendre des décisions en matière de protection optimale contre les risques potentiels spécifiquement liés aux NMM sur le lieu de travail. Ces lignes directrices visent également à servir aux travailleurs et aux employeurs. Néanmoins, elles ne constituent pas un manuel pour la manipulation sans danger des NMM sur le lieu de travail; cette question nécessite d'aborder des problèmes plus généraux de l'hygiène au travail qui sortent du champ d'application de ces lignes directrices. 


\section{PRINCIPES DIRECTEURS}

L'un des principes directeurs du Groupe d'élaboration des lignes directrices (GDG) est le principe de précaution. Cela signifie que l'exposition doit être réduite, même si l'on n'a aucune certitude concernant les effets indésirables sur la santé, dans les situations où il est raisonnablement indiqué de le faire.

La hiérarchie des contrôles a également constitué un important principe directeur. En l'espèce, quand on a le choix entre différentes mesures de contrôle, les mesures les plus proches de la racine du problème doivent toujours être privilégiées par rapport aux mesures qui pèsent davantage sur les travailleurs, comme le port d'un équipement de protection individuelle (EPI).

\section{MEILLEURES PRATIQUES}

Le GDG considère que les meilleures pratiques pour prévenir les effets indésirables des NMM sur la santé sont les suivantes:

- regrouper les nanomatériaux en NMM à toxicité spécifique, NMM sous forme de fibres et NMM sous forme de particules granulaires biopersistantes;

- éduquer et former les travailleurs aux problèmes de santé et de sécurité spécifiques aux NMM;

- impliquer les travailleurs dans toutes les phases de lévaluation et du contrôle des risques.

\section{MÉTHODES}

Pour toutes les questions importantes, des revues systématiques de l'état actuel de la science ont été prévues pour éclairer les recommandations conformément au processus décrit dans le WHO Handbook for guideline development. Ces recommandations ont été considérées comme «fortes » ou «conditionnelles » selon la qualité des données scientifiques, les valeurs et les préférences, et les coûts associés aux recommandations. Toutes les recommandations ont fait l'objet d'un consensus au sein du GDG.

\section{RECOMMANDATIONS}

\section{A. Évaluer les risques sanitaires des NMM}

1. Le GDG recommande d'affecter à chaque NMM une classe de danger conformément au Système général harmonisé (SGH) de classification et d'étiquetage des produits chimiques à faire figurer dans les fiches de données de sécurité. Cette information est fournie dans les présentes lignes directrices pour un petit nombre de NMM (recommandation forte, données de qualité moyenne).

2. Le GDG recommande de mettre à jour les informations des fiches de données de sécurité relatives au danger spécifique aux NMM ou d'indiquer les critères toxicologiques qui n'ont pas été testés de manière adéquate (recommandation forte, données de qualité moyenne).

3. Pour le groupe des fibres respirables et celui des particules granulaires biopersistantes, le GDG suggère d'utiliser la classification existante des NMM aux fins du classement provisoire des nanomatériaux du même groupe (recommandation conditionnelle, données de faible qualité). 


\section{B. Évaluer l'exposition aux NMM}

4. Le GDG suggère d'évaluer l'exposition des travailleurs sur le lieu de travail en employant des méthodes similaires à celles utilisées pour déterminer la valeur limite d'exposition professionnelle (VLEP) spécifique proposée pour un NMM donné (recommandation conditionnelle, données de faible qualité).

5. Du fait qu'il n'existe pas de VLEP réglementaires pour les NMM sur le lieu de travail, le GDG suggère d'évaluer si l'exposition sur le lieu de travail excède la VLEP proposée pour un NMM donné. Une liste de VLEP proposées est fournie en annexe 1 de ces lignes directrices. La VLEP choisie doit être au moins aussi protectrice que celle imposée par la loi pour la forme micro/macroscopique du matériau considéré (recommandation conditionnelle, données de faible qualité).

6. Si les VLEP spécifiques pour des NMM donnés ne sont pas disponibles sur le lieu de travail, le GDG suggère d'adopter une approche par étape pour évaluer l'exposition par inhalation: d'abord une évaluation du potentiel d'exposition, puis une évaluation basique de l'exposition, et enfin une évaluation complète de l'exposition, comme celles que propose l'Organisation de coopération et de développement économiques (OCDE) ou le Comité européen de normalisation (CEN) (recommandation conditionnelle, données de qualité moyenne). Pour l'évaluation de l'exposition dermique, on ne dispose pas de preuves suffisantes pour recommander une méthode plutôt qu'une autre.

\section{Contrôler l'exposition aux NMM}

7. Selon le principe de précaution, le GDG recommande d'axer le contrôle de l'exposition sur la prévention de l'exposition par inhalation afin de réduire celle-ci autant que possible (recommandation forte, données de qualité moyenne).

8. Le GDG recommande de réduire les expositions aux NMM systématiquement mesurées sur le lieu de travail, en particulier lors des tâches de nettoyage et de maintenance, de recueil de matériaux issus de réacteurs et d'alimentation des lignes de production en NMM. En l'absence d'informations toxicologiques, le GDG recommande de mettre en œuvre des contrôles rigoureux afin de prévenir l'exposition des travailleurs. Quand ces informations sont disponibles, le GDG recommande d'adopter une approche plus spécifique au contexte (recommandation forte, données de qualité moyenne).

9. Le GDG recommande de prendre des mesures de contrôle en respectant le principe de hiérarchie des contrôles: la première mesure de contrôle doit être d'éliminer la source d'exposition avant d'appliquer des mesures de contrôle davantage liées à l'implication des travailleurs, l'EPI ne devant être utilisé qu'en dernier recours. Selon ce principe, les contrôles d'ingénierie doivent être effectués en cas de forte exposition par inhalation ou quand il existe peu ou pas d'informations toxicologiques. En l'absence de contrôles d'ingénierie adéquats, il faut utiliser un EPI, en particulier une protection pour les voies respiratoires, dans le cadre d'un programme de protection qui inclut un test d'aptitude (recommandation forte, données de qualitémoyenne).

10. Le GDG suggère de prévenir l'exposition dermique en appliquant des mesures d'hygiène au travail, comme le nettoyage des surfaces et le port de gants appropriés (recommandation conditionnelle, données de faible qualité). 
11. En l'absence d'expert de la sécurité au travail pour effectuer les évaluations et les mesures, le GDG suggère d'employer la méthode dite de gestion graduée des risques liés aux nanomatériaux pour choisir les mesures de contrôle de l'exposition sur le lieu de travail. Le manque d'études sur le sujet ne permet pas au GDG de recommander une méthode plutôt qu'une autre (recommandation conditionnelle, données de très faible qualite).

\section{Veille sanitaire}

En raison du manque de données disponibles, le GDG ne peut pas formuler de recommandations pour des programmes de veille sanitaire ciblée propres aux NMM par rapport aux programmes de veille sanitaire existants.

\section{E. Formation et implication des travailleurs}

Le GDG considère la formation des travailleurs et leur implication dans les questions de santé et de sécurité comme les meilleures pratiques, mais il ne peut pas recommander une modalité de formation/implication des travailleurs plutôt qu'une autre, du fait de l'absence d'études disponibles sur le sujet.

Des progrès considérables sont attendus dans le domaine des méthodes validées de mesure et d'évaluation des risques. Le GDG propose donc de mettre à jour ces lignes directrices dans cinq ans, soit en 2022. 


\section{SINOPSIS}

El término nanomateriales hace referencia a aquellos materiales que tienen al menos una dimensión (altura, anchura o longitud) inferior a 100 nanómetros ( $10^{-7}$ metros), que corresponde aproximadamente al tamaño de una partícula vírica. Este tamaño peculiar es una de las principales características de los nanomateriales fabricados (NMF). Las propiedades singulares de los NMF pueden dar lugar a comportamientos muy deseables que los hacen aptos para aplicaciones tan variables como mejores pinturas, mejores fármacos o componentes electrónicos más rápidos. Sin embargo, por este mismo motivo, los NMF también suponer peligros para la salud diferentes de los que conllevan los materiales micro/macroscópicos, y pueden necesitar métodos de evaluación del peligro, la exposición y el riesgo diferentes de los utilizados con estos últimos.

La toxicidad de los NMF puede depender en gran medida de numerosas propiedades fisicoquímicas, como el tamaño, la forma (es decir, su tamaño en una de las tres dimensiones), la composición, las características de su superficie, la carga o la velocidad de disolución. Hay escasa información precisa sobre las vías de exposición humana a los NMF, su destino en el organismo y su capacidad para producir efectos biológicos no deseados, como la generación de estrés oxidativo. Sólo hay datos de estudios in vitro, en animales y en humanos, sobre la inhalación de muy pocos NMF. Hasta la fecha no se han observado efectos adversos a largo plazo en la salud humana. Esto podría deberse a la introducción reciente de los NMF, al principio de precaución aplicado para evitar la exposición y a los problemas éticos relacionados con la realización de estudios en el ser humano. Esto significa que, excepto en relación con los escasos materiales acerca de los cuales hay estudios en humanos, las recomendaciones sanitarias tienen que basarse en la extrapolación a los posibles efectos en humanos de los datos procedentes de estudios in vitro, estudios en animales o estudios de otros ámbitos que implican una exposición a nanopartículas, como los estudios sobre la contaminación atmosférica.

El aumento de la producción de NMF y su uso en productos de consumo e industriales significa que los trabajadores de todos los países estarán en la primera línea de exposición a estos materiales, lo que les supone un mayor riesgo de posibles efectos adversos en la salud.

Por consiguiente, la Organización Mundial de la Salud (OMS) ha elaborado las presentes directrices que contienen recomendaciones sobre la mejor forma de proteger a los trabajadores de los posibles riesgos de los NMF. Dichas recomendaciones se destinan a ayudar a los planificadores de políticas y a los profesionales de la salud y la seguridad laborales a tomar decisiones sobre la mejor protección frente a posibles riesgos específicos de los NMF en los lugares de trabajo. Asimismo, tienen por objetivo servir a los trabajadores y a los empleadores. Sin embargo, no están concebidas como un manual sobre la manipulación segura de los NMF en el lugar de trabajo, dado que ello requeriría abordar cuestiones más generales de higiene laboral que están fuera del alcance de las presentes directrices. 


\section{PRINCIPIOS RECTORES}

Uno de los principios rectores empleados por el Grupo de Elaboración de Directrices (GED) fue el principio de precaución. Ello significa que, pese a las incertidumbres sobre los efectos adversos en la salud, hay que reducir la exposición siempre que haya indicaciones razonables para ello.

Otro principio rector importante fue la jerarquización de los controles. Esto significa que cuando haya que elegir entre diferentes medidas de control se dará preferencia a las que estén más cerca de la raíz del problema sobre aquellas que supongan una mayor carga para los trabajadores, como el uso de equipos de protección personal.

\section{PRÁCTICAS ÓPTIMAS}

El GED considera que las prácticas óptimas para prevenir los efectos adversos de los NMF en la salud consisten en:

- Agrupar los nanomateriales en NMF con toxicidad específica, NMF que son fibras y NMF que son partículas granulares biopersistentes.

- Educar y capacitar a los trabajadores con respecto a los problemas de salud y seguridad específicos de los NMF.

- Implicar a los trabajadores en todas las fases de la evaluación y del control de los riesgos.

\section{MÉTODOS}

Para que sirvieran de base a la formulación de recomendaciones de conformidad con el proceso descrito en el Manual de la OMS para la Elaboración de Directrices, se encargaron revisiones sistemáticas del estado actual de la ciencia sobre todas las cuestiones importantes. Las recomendaciones se consideraron "firmes" o "condicionales", dependiendo de la calidad de las evidencias científicas, los valores y preferencias, y los costos relacionados con cada recomendación. Todas las recomendaciones se adoptaron por consenso del GED.

\section{RECOMENDACIONES}

\section{A. Evaluación de los peligros de los NMF para la salud}

1. El GED recomienda que a cada NMF se le asigne una clase de peligrosidad de acuerdo con el Sistema Mundialmente Armonizado de Clasificación y Etiquetado de Productos Químicos para uso en las fichas de datos de seguridad. En las presentes directrices se proporciona esta información con respecto a un reducido número de NMF (recomendación firme, evidencias de calidad moderada).

2. El GED recomienda que se actualicen las fichas de datos de seguridad con información acerca de los peligros específicos de los NMF o que se indiquen los criterios de valoración toxicológica que no se han examinado adecuadamente (recomendación firme, evidencias de calidad moderada).

3. Con respecto al grupo de las fibras respirables y al grupo de las partículas granulares biopersistentes, el GED propone que se utilice la clasificación existente de los NMF para clasificar provisionalmente los nanomateriales del mismo grupo (recomendación condicional, evidencias de baja calidad). 


\section{B. Evaluación de la exposición a los NMF}

4. El GDG propone que la exposición de los trabajadores en el lugar de trabajo se evalúe con métodos similares a los utilizados para determinar el valor límite de exposición ocupacional (LEO) específico del NMF en cuestión (recomendación condicional, evidencias de bajacalidad).

5. Como no hay valores reglamentarios específicos del LEO para los NMF en el lugar de trabajo, el GED propone evaluar si la exposición en el lugar de trabajo supera el valor LEO propuesto para el NMF en cuestión. En el anexo 1 de las presentes directrices figura una lista de valores LEO propuestos. El valor LEO elegido debe ser al menos tan protector como el impuesto por la ley para la forma micro/macroscópica del material en cuestión (recomendación condicional, evidencias de baja calidad).

6. Si no hay valores LEO específicos para los NMF en el lugar de trabajo, el GED propone un enfoque escalonado para evaluar la exposición por inhalación: primero una evaluación del potencial de exposición, a continuación una evaluación básica de la exposición y, por último, una evaluación integral de la exposición, como las que proponen la Organización de Cooperación y Desarrollo Económicos (OCDE) o el Comité Europeo de Normalización (CEN) (recomendación condicional, evidencias de calidad moderada). En lo que se refiere a la exposición dérmica, las evidencias son insuficientes para recomendar un método de evaluación con preferencia a otro.

\section{Control de la exposición a los NMF}

7. Siguiendo el principio de precaución, el GED recomienda que el control de la exposición se base en la prevención de la exposición por inhalación con el fin de reducirla lo máximo posible (recomendación firme, evidencias de calidad moderada).

8. El GED recomienda reducir las exposiciones a una serie de NMF medidos sistemáticamente en el lugar de trabajo, especialmente durante la limpieza y mantenimiento, la recogida de materiales de los reactores y la alimentación de las líneas de producción de NMF. En ausencia de información toxicológica, el GED recomienda que se pongan en práctica los controles más rigurosos para evitar toda exposición de los trabajadores. Cuando haya información al respecto, el GED recomienda un enfoque más específico (recomendación firme, evidencias de calidad moderada).

9. El GED recomienda que las medidas de control se basen en el principio de jerarquización de los controles; es decir, la primera medida de control debe ser la eliminación de la fuente de exposición, antes que la aplicación de medidas de control que dependen más de la participación de los trabajadores; los equipos de protección personal deben emplearse solo como último recurso. De acuerdo con este principio, cuando haya un alto nivel de exposición por inhalación o la información toxicológica sea escasa o nula deben utilizarse los controles de ingeniería. En ausencia de controles de ingeniería apropiados deberán utilizarse equipos de protección personal, especialmente de protección respiratoria, en el marco de un programa de protección respiratoria que incluya comprobaciones del ajuste del equipo (recomendación firme, evidencias de calidad moderada).

10. El GED propone que se evite la exposición dérmica con medidas de higiene ocupacional, como la limpieza de las superficies y el uso de guantes apropiados (recomendación condicional, evidencias de baja calidad). 
11. Cuando no haya un experto en seguridad laboral para realizar las evaluaciones y mediciones, el GED propone que se utilice el método de gestión gradual de los riesgos relacionados con los nanomateriales para elegir las medidas de control de la exposición en el lugar de trabajo. Debido a la inexistencia de estudios, el GED no puede recomendar un método de gestión gradual de los riesgos con preferencia a otros (recomendación condicional, evidencias de muy baja calidad).

\section{Vigilancia sanitaria}

Debido a la falta de evidencias, el GED no puede recomendar programas de vigilancia sanitaria específicos para los NMF con preferencia a los programas de vigilancia sanitaria ya existentes.

\section{E. Capacitación y participación de los trabajadores}

El GED considera que la capacitación de los trabajadores y su participación en las cuestiones relacionadas con la salud y la seguridad es una práctica óptima, pero, debido a la falta de estudios sobre el tema, no puede recomendar una forma de capacitación ni de participación de los trabajadores con preferencia a otras.

Como son de prever avances considerables con respecto a los métodos de medición validados y a la evaluación de los riesgos, el GED se propone actualizar las presentes directrices dentro de 5 años, es decir, en 2022. 


\section{ИСПОЛНИТЕЛЬНОЕ РЕЗЮМЕ}

Термин «наноматериалы» означает материалы, у которых хотя бы один размер (высота, ширина или длина) не превышает 100 нанометров (10-7 метров), что примерно соответствует размеру вирусной частицы. Именно этот размерный параметр является главной отличительной особенностью производимых наноматериалов (ПНМ). В силу своих уникальных свойств, ПНМ могут обладать весьма привлекательными характеристиками, благодаря которым их можно широко применять в самых различных областях, в частности, для создания более совершенных красок, более эффективных лекарств и более быстродействующих электронных устройств. Однако по этой же причине ПНМ могут также создавать угрозы для здоровья, не характерные для веществ в объемной форме, и для оценки их опасности, воздействия и связанного с этим риска могут потребоваться иные по сравнению с макроматериалами методы испытаний.

Токсичность ПНМ может быть в значительной степени обусловлена большим числом физикохимических характеристик, таких как размер, форма (т.е. размер в определенной плоскости), состав, характеристики поверхности, заряд и скорость растворения. В настоящее время имеется крайне скудная информация о путях воздействия ПНМ на человека, их «судьбе» в человеческом организме и их способности вызывать нежелательные биологические последствия, в частности, провоцировать окислительный стресс. Ингаляционные исследования in vitro либо с участием животных и людей проводились только по небольшому числу ПНМ. Наблюдениями до сих пор не было зарегистрировано долгосрочных негативных последствий для здоровья человека. Это может объясняться недавним появлением ПНМ, использованием мер предосторожности во избежание их воздействия, а также существованием этических возражений против проведения исследований на людях. Соответственно, если речь не идет о нескольких материалах, по которым имеются результаты исследований на людях, то рекомендации по охране здоровья должны вырабатываться на основе фактических данных исследований, проведенных in vitro и на животных, а также в других областях, связанных с воздействием наночастиц, включая загрязнение воздуха, путем их экстраполяции на возможные последствия для человека.

В результате роста производства ПНМ и их применения в составе потребительской и промышленной продукции производственный персонал во всех странах будет первым контактировать с этими материалами, подвергаясь повышенному риску возможных негативных последствий для здоровья.

В связи с этим Всемирная организация здравоохранения (ВО3) разработала настоящие руководящие принципы, включив в них рекомендации о наилучших способах защиты персонала от потенциальных рисков ПНМ. Рекомендации призваны помочь директивным органам и специалистам в сфере охраны и гигиены труда принимать решения о выборе наиболее эффективных средств защиты от возможныхспецифических рисков, исходящих от ПНМ на рабочих местах. Также предполагается, что этими руководящими принципами смогут воспользоваться персонал и работодатели. Они, однако, не предназначены служить руководством или пособием по безопасному обращению с ПНМ на рабочем месте, поскольку для этого потребовалось бы осветить более широкие вопросы гигиены труда, выходящие за рамки настоящих руководящих принципов. 


\section{РУКОВОДЯЩИЕ ПРИНЦИПЫ}

Предосторожность была одним из ведущих принципов, на которые ориентировалась Группа по разработке руководящих принципов (ГРП). Он предполагает, что воздействие необходимо ограничивать даже при отсутствии определенности относительно его неблагоприятных последствий для здоровья, если для этого имеются разумные основания.

Другим важным руководящим принципом была иерархия средств контроля. Этот принцип означает, что при возможности выбора мер контроля приоритет должен отдаваться мерам, более тесно связанным с коренной причиной проблемы, а не мерам, которые создают повышенную нагрузку на персонал, таким как использование средств индивидуальной защиты (СИЗ).

\section{ПЕРЕДОВАЯ ПРАКТИКА}

ГРП рассматривает перечисленные ниже методы в качестве передовой практики в области профилактики воздействия ПНМ на здоровье:

- распределение наноматериалов по группам: ПНМ со специфической токсичностью, ПНМ, являющиеся волокнами, и ПНМ - гранулярные биоустойчивые частицы;

- информирование и подготовка персонала по специфическим вопросам охраны здоровья и обеспечения безопасности при работе с ПНМ;

обеспечение участия персонала на всех этапах процесса оценки и контроля рисков.

\section{МЕТОДЫ}

По каждому из важных аспектов проблемы было организовано проведение систематического обзора современного состояния научных знаний в целях разработки на их основе рекомендаций, как того требует порядок, изложенный в «Пособии ВОЗ по разработке руководящих принципов». Рекомендациям присваивался статус «настоятельных» либо «условных» в зависимости от качества научных данных, ценностей и предпочтений, а также расходов, связанных с их выполнением. Все рекомендации выносились на основе консенсуса между членами ГРП.

\section{РЕКОМЕНДАЦИИ}

\section{А. Оценка опасных для здоровья факторов ПНМ}

1. ГРП рекомендует распределить все ПНМ по классам опасности в соответствии с Согласованной на глобальном уровне системой (СГС) классификации и маркировки химических веществ для ихуказания в паспортах безопасности. По ограниченному числу ПНМ такая информация приведена в данных руководящих принципах (настоятельная рекомендация, научные данные среднего качества).

2. ГРП рекомендует обновить паспорта безопасности, дополнив их информацией о факторах опасности, связанных непосредственно с ПНМ, либо указав, в отношении каких конечных точек токсикологического воздействия не имеется данных надлежащего тестирования (настоятельная рекомендачия, научные данные среднего качества).

3. В отношении групп респирабельных волокон и гранулярных биоустойчивых частиц ГРП предлагает использовать существующую классификацию ПНМ для предварительного классифицирования наноматериалов той же группы (условная рекомендация, научные данные низкого качества). 


\section{В. Оценка воздействия ПНМ}

4. ГРП предлагает оценивать воздействие на персонал на рабочих местах методами, которые аналогичны использованным для определения предлагаемого значения предельной производственной экспозиции (ППЭ) конкретно для ПНМ (условная рекомендачия, научные данные низкого качества).

5. Поскольку конкретных нормативных значений ППЭ для ППН на рабочих местах не установлено, ГРП предлагает при оценке исходить из того, превышает ли воздействие на рабочем месте предлагаемое значение ППЭдля ПНМ. Перечень предлагаемых значений ППЭ приводится в Приложении 1 к данным руководящим принципам. Выбранная ППЭ должна обеспечивать как минимум такую же защиту, что и предусмотренная законом ППЭ для объемной формы этого материала (условная рекомендация, научные данные низкого качества).

6. В тех случаях когда конкретная ППЭ для ПНМ на рабочих местах отсутствует, ГРП предлагает поэтапный порядок оценки ингаляционного воздействия, предполагающий, во-первых, оценку вероятности воздействия; во-вторых, проведение базовой оценки воздействия; и, в-третьих, проведение комплексной оценки воздействия, аналогичной той, которая предлагается Организацией экономического сотрудничества и развития (ОЭСР) или Европейским комитетом по стандартизации (ЕКС) (условная рекомендация, научные данные среднего качества). В отношении оценки кожного воздействия имеющихся фактических данных было недостаточно, чтобы рекомендовать более предпочтительный по сравнению с другими метод оценки воздействия на кожные покровы.

\section{С. Контроль воздействия ПнМ}

7. В соответствии с принципом предосторожности, ГРП рекомендует уделять основное внимание в рамках контроля за воздействием предотвращению ингаляционного воздействия в целях его максимально возможного ограничения (настоятельная рекомендачия, научные данные среднего качества).

8. ГРП рекомендует уменьшить воздействие целого ряда ПНМ, содержание которых последовательно измерялось на рабочих местах, особенно во время уборки и технического обслуживания, забора материала из реакционных емкостей и подачи ПНМ в производственный процесс. При отсутствии токсикологической информации ГРП рекомендует применять наивысший уровень контроля во избежание какого-либо воздействия на персонал. При наличии большего объема информации ГРП рекомендует применять более индивидуальный подход (настоятельная рекомендация, научные данные среднего качества).

9. ГРП рекомендует принимать меры контроля, руководствуясь принципом иерархии средств контроля, согласно которому первая мера контроля должна заключаться в ликвидации причины воздействия и лишь после нее внедряются меры контроля, которые в большей степени зависят от участия персонала, а СИЗ используются лишь в качестве крайней меры. В соответствии с этим принципом, в ситуациях высокого уровня ингаляционного воздействия и отсутствия или крайней скудости токсикологической информации следует применять инженерно-технические средства контроля. При отсутствии надлежащих инженерно-технических средств должны использоваться СИЗ, особенно для защиты органов дыхания, в рамкахпрограммы по защите органов дыхания, предусматривающей индивидуальную подгонку защитных средств (настоятельная рекомендачия, научные данные среднего качества). 
10. ГРП предлагает предотвращать кожное воздействие при помощи таких мер производственной гигиены, как очистка поверхностей и использование подходящих перчаток (условная рекомендация, научные данные низкого качества).

11. При невозможности проведения оценки и измерений инженером по охране труда ГРП рекомендует применять по отношению к наноматериалам метод ранжирования мер контроля (control banding), позволяющий подбирать меры по контролю воздействия на рабочем месте. В связи с недостаточностью исследований на этот счет ГРП не может рекомендовать какой-либо предпочтительный по сравнению с остальными метод ранжирования (условная рекомендачия, научные данные крайне низкого качества).

\section{D. Наблюдение за состоянием здоровья}

Ввиду нехватки фактических данных, ГРП не может сформулировать рекомендацию, которая предусматривала бы разработку адресных, относящихся конкретно к ПНМ программ наблюдения за состоянием здоровья, в отличие от уже существующих и реализуемых программ наблюдения за здоровьем.

\section{Е. Подготовка и обеспечение участия персонала}

ГРП рассматривает подготовку персонала и его участие в решении вопросов охраны здоровья и обеспечения безопасности в качестве передовой практики, однако по причине недостаточности имеющихся исследований не может рекомендовать какую-либо одну форму подготовки персонала либо какую-либо одну форму обеспечения их участия по сравнению со всеми другими.

В области валидации методов измерений и оценки риска ожидается значительное продвижение вперед. В связи с этим ГРП предлагает обновить настоящие руководящие принципы через пять лет, в 2022 году. 


\section{执行概要}

纳米材料这一术语指三维空间（高度、宽度或长度）中至少有一 维小于 100 纳米 $\left(10^{-7}\right.$ 米) 的材料, 即大约一个病毒颗粒的尺寸。这一 特定尺寸的维度是人工纳米材料的主要特征。人工纳米材料的独特性 质可能实现非常理想的性能, 从而导致各种不同的应用, 如更好的涂 料, 更好的药物和更快的电子产品等。然而, 出于同样的原因, 人工 纳米材料也可能会造成不同于块体物质的健康危害, 并且可能需要不 同于其较大块体对应物的检测方法来进行危害、接触量和风险评估。

人工纳米材料的毒性在很大程度上可能取决于许多物理化学性 质, 包括尺寸、形状（即某一特定维度中的尺寸）、组成、表面特 性、电荷和溶解速率等。目前, 缺乏精确信息说明人类接触人工纳米 材料的途径及其在人体中的结局以及其诱发意外生物效应（例如产生 氧化应激）的能力。目前仅具备关于少数人工纳米材料的体外, 动物 和人类吸入研究数据。迄今为止, 尚未观察到对人类的长期不良健康 影响。这可能是因为人工纳米材料的应用刚开始不久, 而且采取了避 免接触的防范措施, 另外对人类进行研究存在一系列伦理问题。这意 味着, 除了少数材料具有可用的人类研究之外, 健康建议必须依赖推 断, 即从涉及与纳米尺度颗粒（例如空气污染）接触的体外研究、动 物研究或其它领域研究产生的证据来推断可能对人类的影响。

人工纳米材料的产量增加及其在消费产品和工业产品中的使用意 味着所有国家的工人将处于接触这些材料的第一线, 使其面临潜在不 良健康影响的更大风险。

因此，世界卫生组织（世卫组织）制定了该指南，并就如何最 有效地保护工人免受人工纳米材料的潜在风险提出了建议。这些建议 旨在帮助职业健康与安全领域的决策者和专业人员决定在工作场所防 止人工纳米材料所特有的潜在风险的最佳保护措施。该指南还旨在支 持工人和雇主。但不准备作为在工作场所安全处理人工纳米材料的手 册, 因为这需要处理超出本指南范围的更一般性职业卫生问题。 


\section{指导原则}

指南制定小组将防范方针作为其指导原则之一。这意味着, 只要 有合理的迹象表明应减少接触, 即使对不良健康影响并不确定, 也必 须减少接触。

另外, 控制措施的等级结构是一项重要指导原则。这意味着如果 可在控制措施之间进行选择, 那些更接近问题根源的措施应该始终优 先于可能对工人造成更大负担的措施，例如使用个人防护装备等。

\section{最佳做法}

指南制定小组认为以下是防止人工纳米材料不良健康影响的最佳 做法：

- 将纳米材料归为具有特定毒性的人工纳米材料, 纤维状人工纳米 材料和生物持久性颗粒状人工纳米材料三个组别。

- 就人工纳米材料的具体健康和安全问题对工人进行教育和培训。

- 让工人参与风险评估和控制的各个阶段。

\section{方法}

关于所有重要问题, 已委托对科学现状进行了系统审查, 以便 根据《世卫组织指南制定手册》中载明的程序指导提出建议。根据科 学证据的质量、价值观和偏好以及与建议有关的费用, 将所提建议评 定为 “强烈” 或 “有条件”。所有建议都由指南制定小组协商一致提 出。

\section{建议}

\section{A. 评估人工纳米材料的健康危害}

1. 指南制定小组建议根据《全球化学品统一分类和标签制度》 (GHS) 为所有人工纳米材料确定危险等级以便用于安全数据 表。本指南对数量有限的人工纳米材料提供了这方面信息（强 烈建议, 证据质量中等)。 
2. 指南制定小组建议更新载有特定人工纳米材料危害信息的安全 数据表, 或指明哪些毒理学终点没有可用的充分测试 (强烈建 议, 证据质量中等）。

3. 对于可吸入的纤维状和生物持久性颗粒状材料, 指南制定小组 建议使用已有的人工纳米材料危险等级对同组别的纳米材料进 行临时分级（有条件的建议, 证据质量低）。

\section{B. 评估人工纳米材料的接触情况}

4. 指南制定小组建议使用类似于拟定人工纳米材料的具体职业接 触限值 (OEL) 时所用的方法来评估工人在工作场所的接触情 况（有条件的建议, 证据质量低）。

5. 由于工作场所没有具体监管人工纳米材料的职业接触限值, 因 此, 指南制定小组建议评估工作场所的接触量是否超过拟议的 人工纳米材料职业接触限值。本指南附件 1 中提供了拟议的职 业接触限值表。选定的职业接触限值应至少与法律授权用于块 体材料的职业接触限值具有同样的保护作用 (有条件的建议, 证据质量低）。

6. 如果工作场所不具备针对人工纳米材料的具体职业接触限值, 指南制定小组建议对吸入接触采用阶梯式方法, 第一步评估接 触的可能性; 第二步评估基本接触情况，第三步按照经济合作 与发展组织 (经合组织) 或欧洲标准化委员会的建议, 进行全 面接触评估（有条件的建议, 证据质量中等）。关于皮肤接触 评估, 证据不足以建议一种最好的皮肤接触评估方法。

\section{C. 控制人工纳米材料的接触量}

7. 根据防范方针, 指南制定小组建议在控制接触时着重关注防止 吸入接触, 目的是尽可能减少接触量 (强烈建议, 证据质量中 等)。

8. 指南制定小组建议减少与在工作场所持续测量的一系列人工纳 米材料的接触, 特别是在清洁和维护, 从反应容器中收集材料 以及将人工纳米材料输入生产流程的过程中。在没有毒理学信 息的情况下, 指南制定小组建议实施最高级别的控制措施, 以防止工人发生任何接触。如果能获得更多信息, 指南制定小 
组建议采取更加切合具体情况的方法 (强烈建议, 证据质量中 等)。

9. 指南制定小组建议根据控制措施的等级结构原则采取相应措 施, 这意味着第一级控制措施应该是在实施更有赖工人参与 的控制措施之前消除接触源, 而个人防护装备仅被用作最后手 段。根据这一原则, 在有高量吸入接触或者在毒理学信息没有 或很少的情况下, 应采取工程控制措施。如果没有适当的工程 控制措施, 应使用个人防护装备, 特别是呼吸防护装置, 作为 呼吸防护规划的一部分, 包括进行密合度检测（强烈建议, 证 据质量中等）。

10. 指南制定小组建议通过职业卫生措施, 如清洁表面和使用适当 的手套来预防皮肤接触（有条件的建议, 证据质量低）。

11. 如果工作场所没有安全专家进行评估和测量, 指南制定小组建 议使用纳米材料分级管理方法来选择工作场所的接触控制措 施。由于缺乏研究, 指南制定小组无法推荐一种最佳的分级管 理方法（有条件的建议, 证据质量极低）。

D. 健康监测

由于缺乏证据, 指南制定小组无法建议一项胜过目前使用中的健 康监测规划的明确针对人工纳米材料的健康监测规划。

\section{E. 工人的培训和参与}

指南制定小组认为, 培训工人并让其参与健康和安全问题是最佳 做法, 但由于缺乏可用的研究, 无法建议一种最佳的工人培训方式或 最佳的工人参与形式。

预计将在验证测量方法和风险评估方面取得重大进展。因此, 指 南制定小组建议五年后, 即 2022 年更新本指南。 


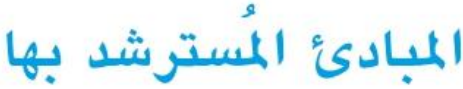

اتبع الفريق المعني بوضع المبادئ التوجيهية نهجاً تحوطياً بوصفه واحداً من المبادئ المُسترشد بها، ما

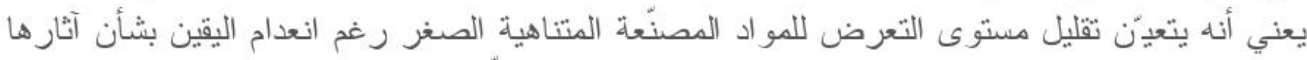

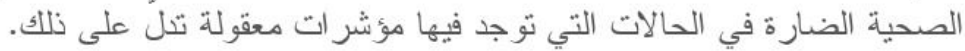

و إضافة إلى ذللك، فإن التسلسل الهرمي لضو ابط مكافحة التعرض لهذه المواد هو من المبادئ الهامة

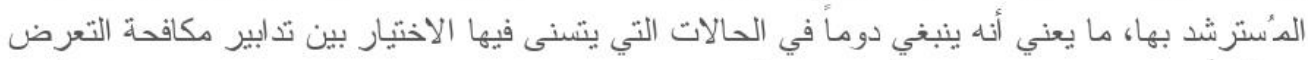

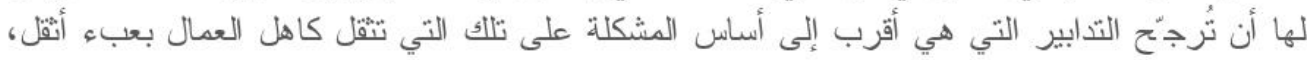
مثل استخدام معدات الوقاية الثخصية.

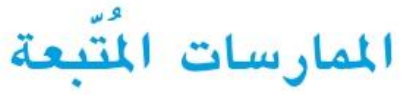

أفضل

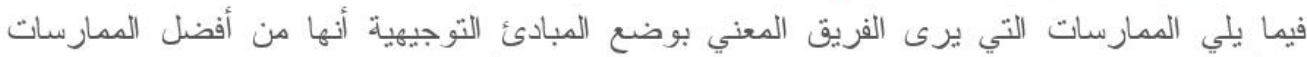

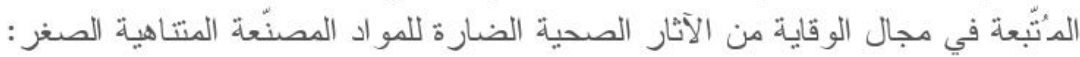

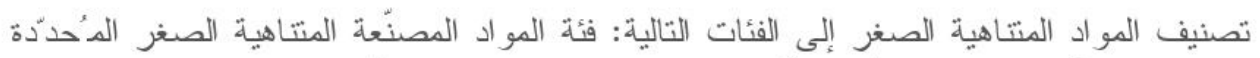

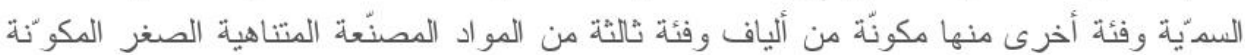
من جسيمات حبيبية ثابتة بيولو جياً. تثقيف العاملين وتدرييهم على التعامل مع المشاكل التي تطرحها المواد المصنّعة المتناهية الصغر في مجالي الصحة و السلامة. إشر الك العمال في جميع مر احل تقييم مخاطر تلك المو اد ومكافحتها.

\section{الأساليب المُنتهجة}

صدر تكليف، في إطار تناول المسائل الهامة، بإجراء استعر اضات منهجية لحالة العلوم في الوقت

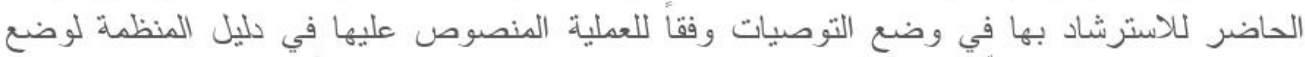

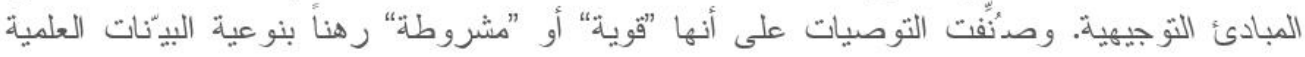

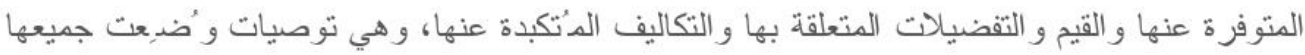
بناءً على تو افق الآر اء داخل الفريق المعني بوضع المبادئ التوجيهية.

\section{التوصيات الموضوعة}

ألف: تقدير المخاطر الصحية المترتبة على المواد المصنّعة المتناهية الصفر ا. ـيوصي الفريق المعني بوضع المبادئ التوجيهية بتحديد فئات المخاطر المترتبة على جميع المواد

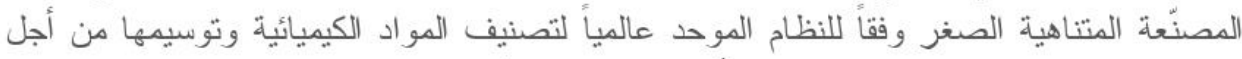

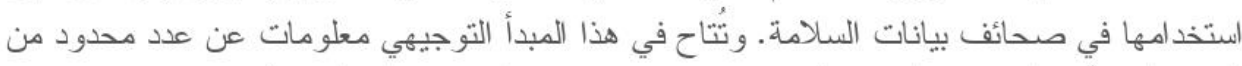
المو اد المصنُعة المتناهية الصغر (توصية قوية مشفوعة بييّنات معتدلة الجودة). 


\section{ماخص تنفيذي}

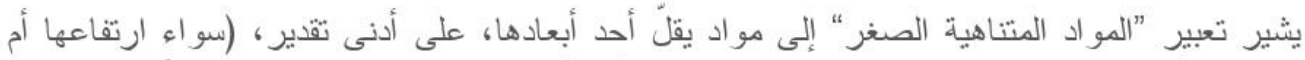

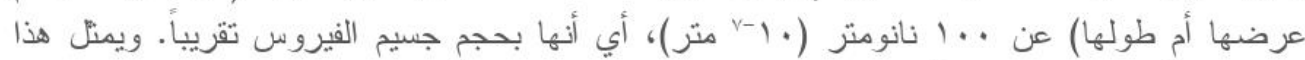

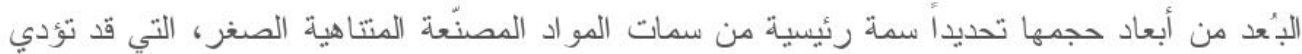

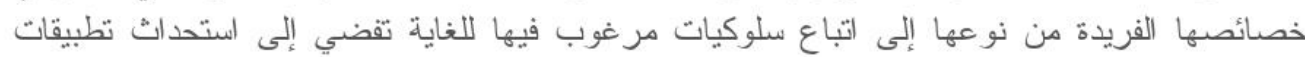

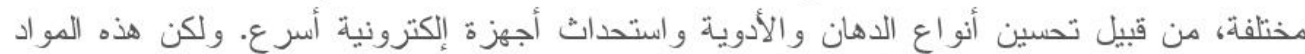

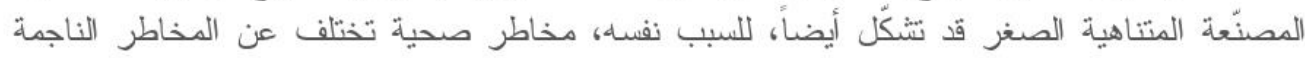

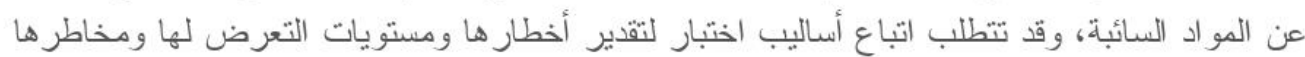
تختلف عن نظير اتها من المو اد السائبة.

وقد تتوقف إلى حد كبير سميّة هذه المو اد المصنّعة المتتاهية الصغر على العديد من خصائصها الفيزيائية

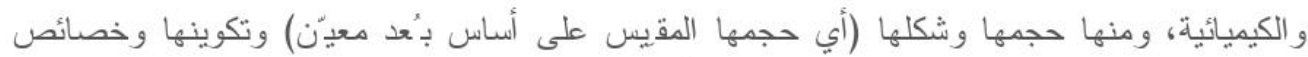

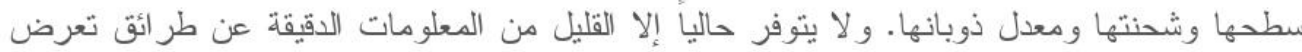

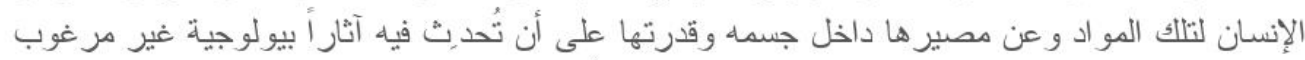

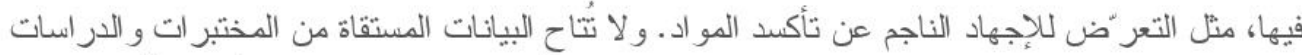

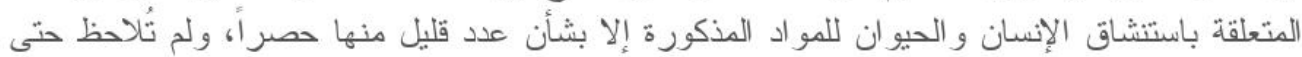

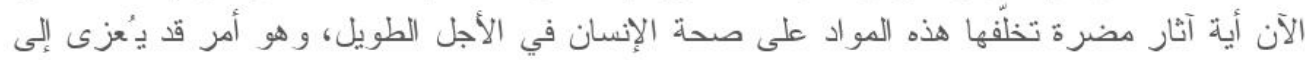

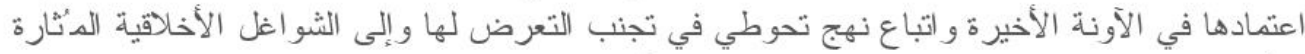

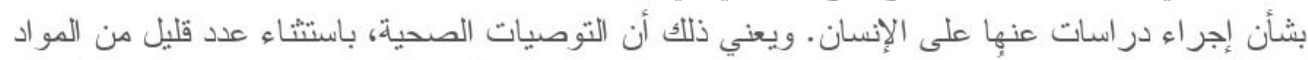

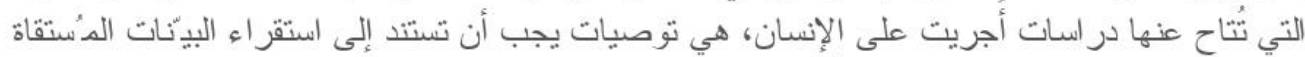

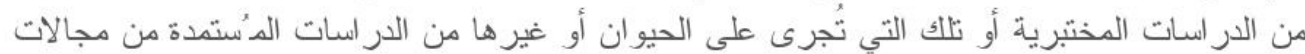

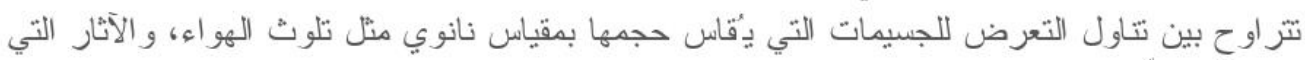
يمكن أن تخلفها على صحة الإنسان.

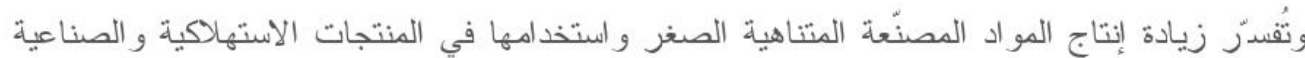

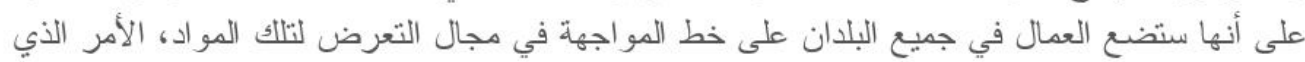

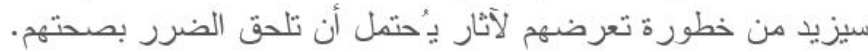

لذلك وضعت هنظمة الصحة العالمية (المنظمة) هذه المبادئ التوجيهية المقترنة بتوصيات بشأن أفضل

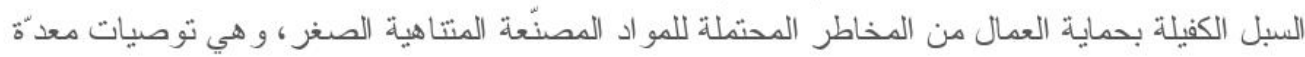
لغرض مساعدة راسمي السياسات و المهنيين العاملين في مجال الصحة و السلامة المهنيتين على اتخاذ

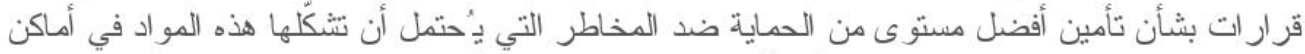

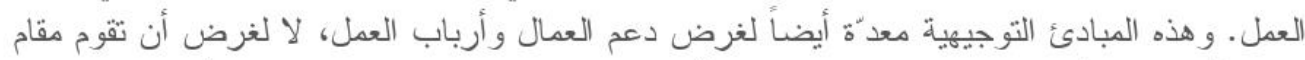

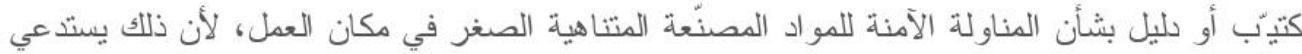

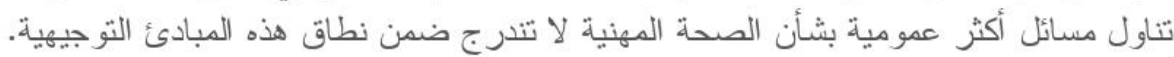




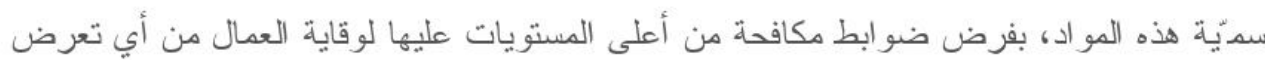

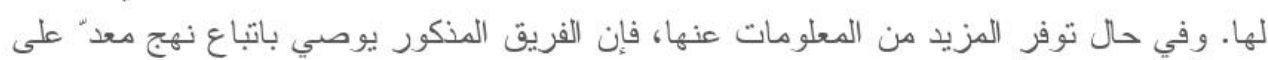

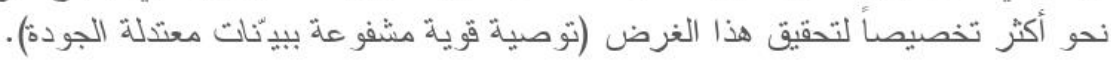

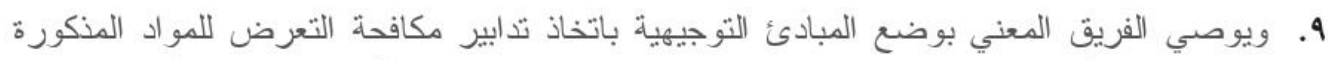

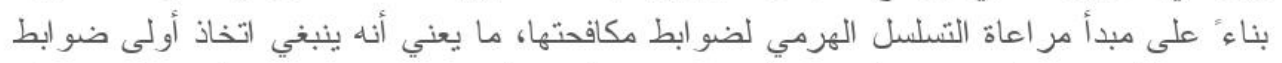

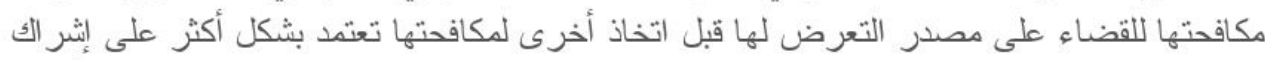

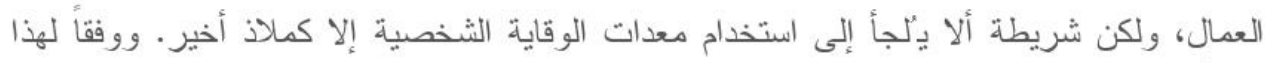

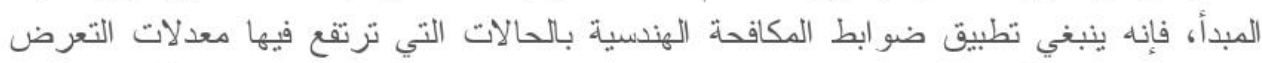

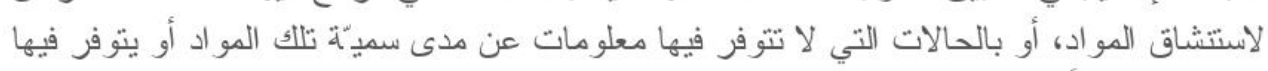

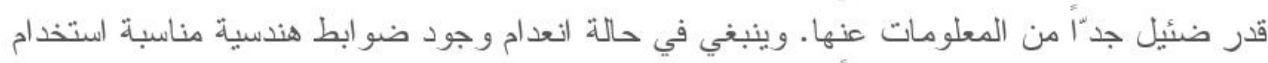

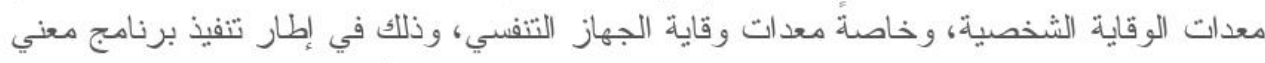

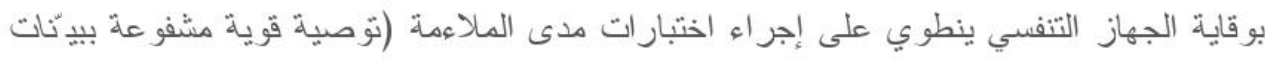
معتدلة الجودة).

• 1 ـ اويقترح الفريق المعني بوضع المبادئ التو جيهية وقاية الجلد من التعرض لهذه المو اد بو اسطة اتخاذ

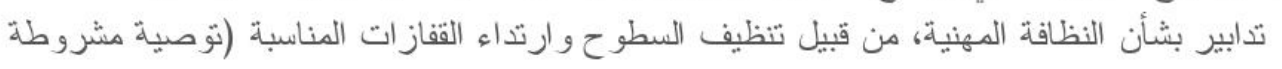

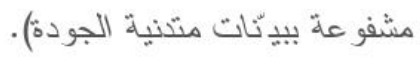

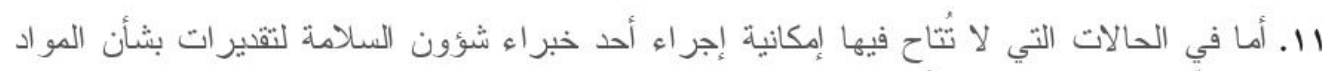

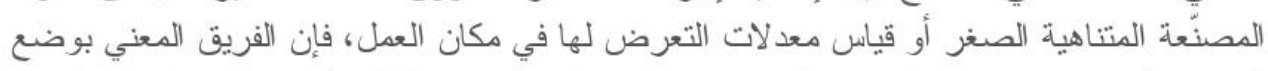

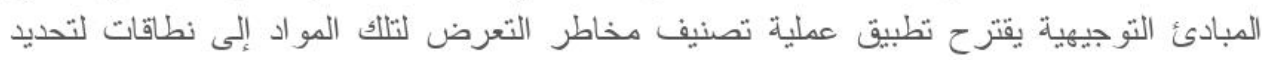

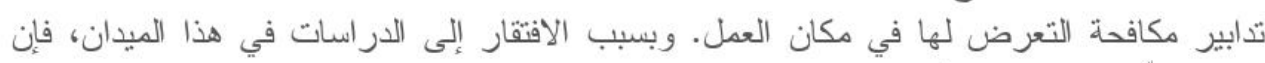

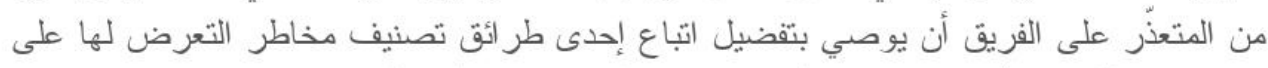
سو اها من الطر ائق (توصية مشروطة مشفو علة بييّنات منتنية الجودة).

دال: ترضّد الآثار الصحية

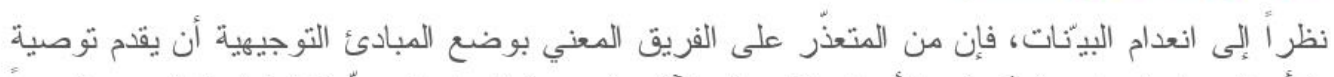

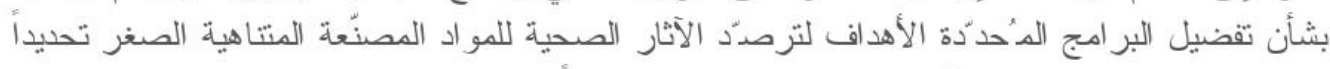

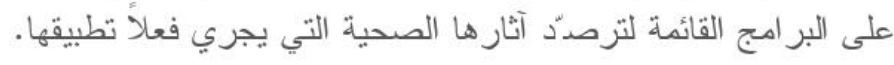

$$
\text { هاء: تدريب العمال وإشراكهم }
$$

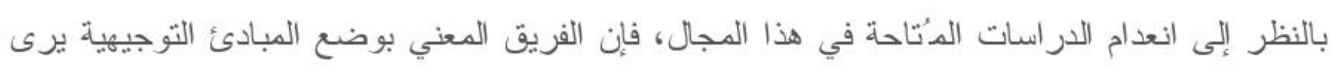

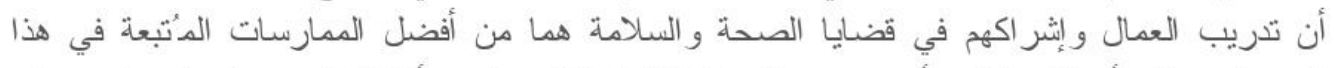

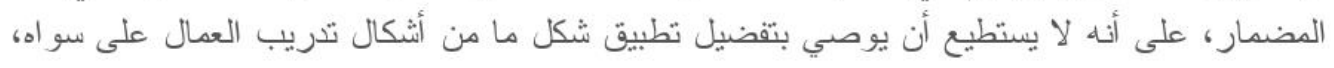
و لا بتقضيل شكل معيّن لإشر اكهم على غيره.

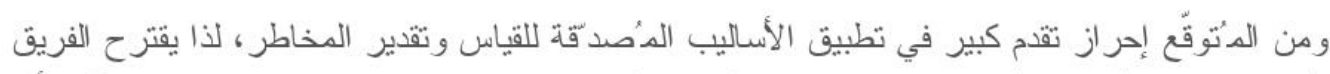

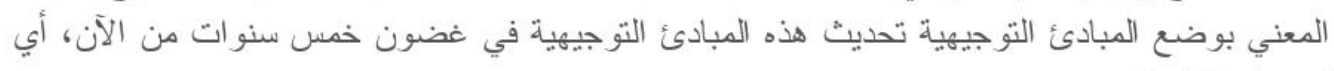

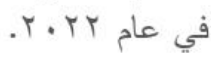


r. ويوصي الفريق المعني بوضع المبادئ التوجيهية بتحديث صحائف بيانات السلامة عن طريق

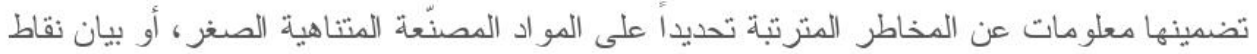

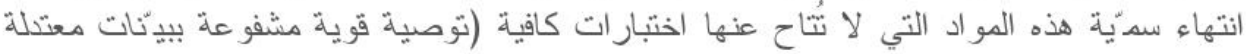
الجودة). r. و ويقترح الفريق المعني بوضع المبادئ التوجيهية فيما يخص فئة المواد المصنُّة المتناهية الصغر

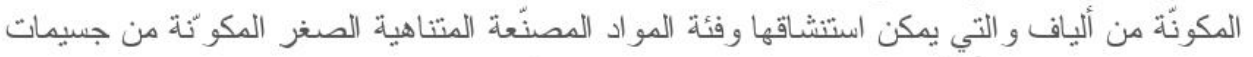

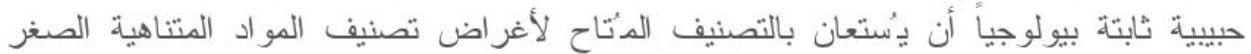

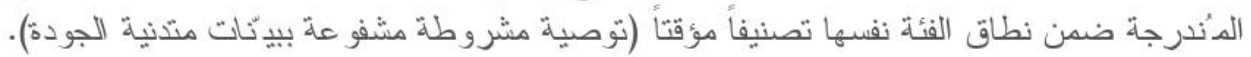

\section{باء: تقدير مدى التعرض للمواد المصنّعة المتناهية الصفر}

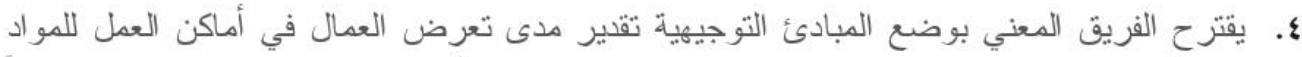

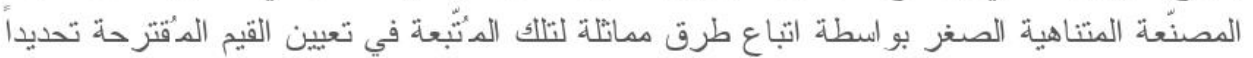

لحدود التعرض المهني لتلكي المو اد (توصية مشروطة مشفو عة بييّنات منتية الجودة).

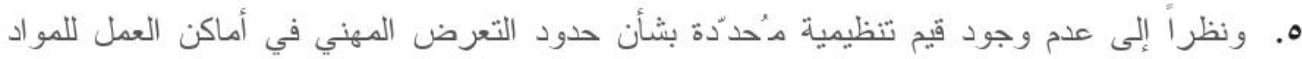

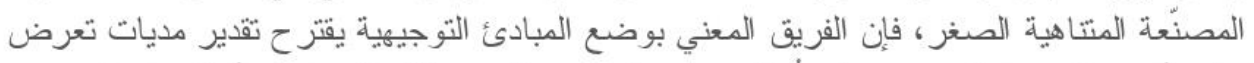

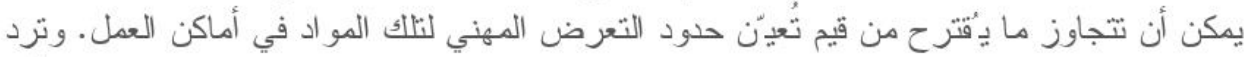

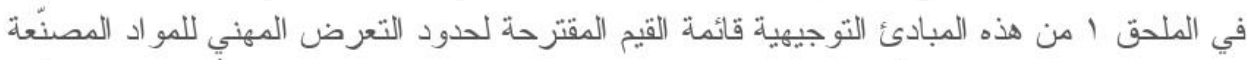

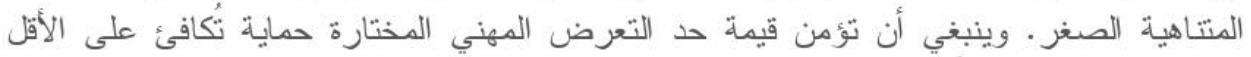

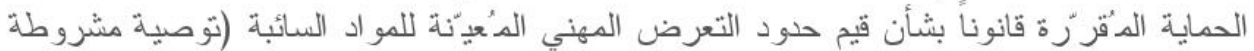

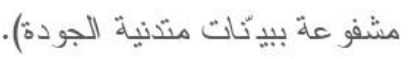

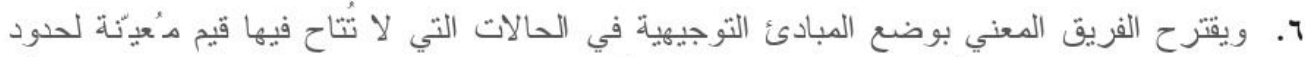

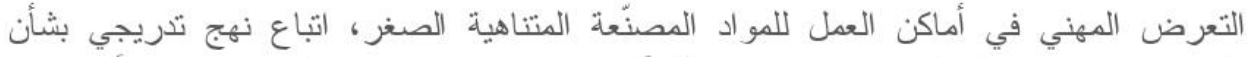

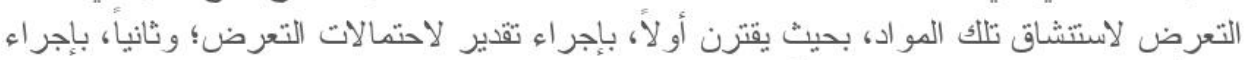

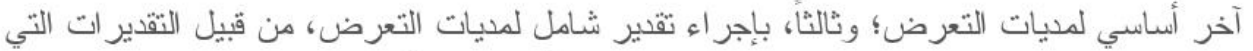

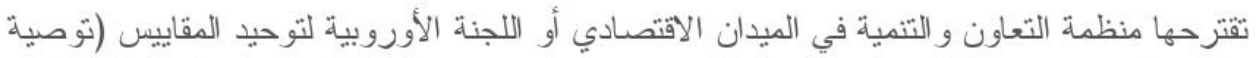

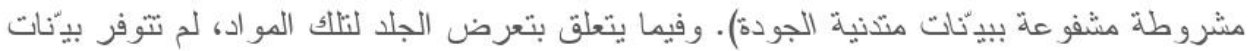

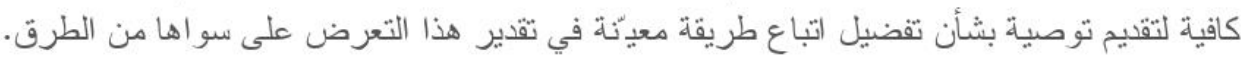

\section{جيم: ضوابط مكافحة التعرض للمواد المصنّعة المتناهية الصفر}

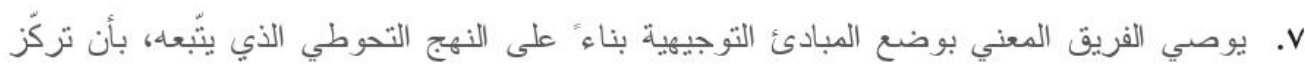

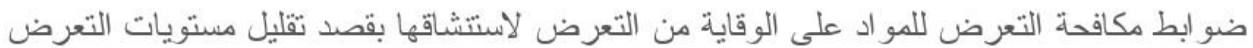

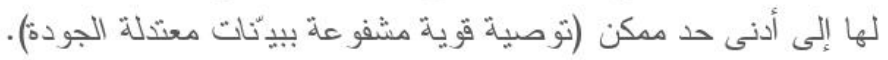

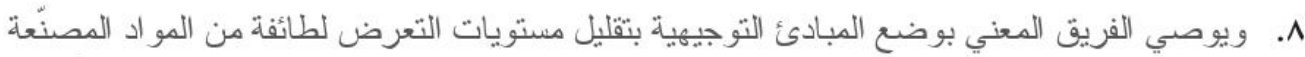

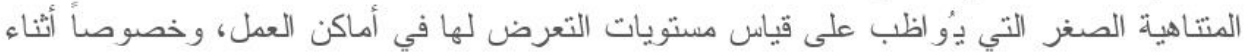

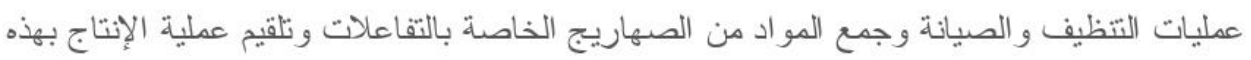

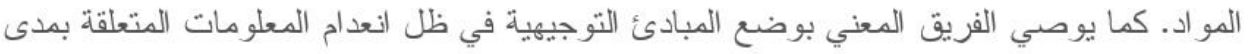




\section{INTRODUCTION}

The increased production of manufactured nanomaterials (MNMs) and their use in consumer and industrial products means that workers in all countries will be at the front line of any exposure, placing them at risk of potential adverse health effects.

The term "nanomaterials" refers to materials that have at least one dimension (height, width or length) that is smaller than 100 nanometres $\left(10^{-7}\right.$ metre), which is about the size of a virus particle. This particular size dimension, which falls between single atoms and their bulk material counterparts, represents a major characteristic of MNMs.

The unique properties of MNMs may result in highly desirable behaviour, including but not limited to increased reactivity, or higher conductivity. As such, the past decade has witnessed the exploitation of these unique properties for industrial and consumer applications, and various types of MNMs have found their way into a plethora of sectors, including aerospace, cosmetics, foods, electronics, construction and medicine, among others.

Significant academic and industrial resources have been dedicated to the field of nanotechnology, increasing the scope and number of MNMs that will be available for future use. However, MNMs may also present health hazards that differ from those of the substance in bulk form, and require different test methods for hazard, exposure and risk assessment from their bulk material counterparts.

The World Health Assembly identified the assessment of health impacts of new technologies, work processes and products as one of the activities under the Global Plan of Action on Workers' Health adopted in 2007, and the WHO Global Network of Collaborating Centres in Occupational Health has selected MNMs as a key focus of its activity.

WHO developed these guidelines with the aim of protecting workers from the potential risks of MNMs. The recommendations are intended to help policy-makers and professionals in the field of occupational health and safety in making decisions about protection against the potential risks of MNMs. These guidelines are also intended to support workers and employers. However, the guidelines are not intended as a handbook or manual for safe handling of MNMs in the workplace, because this requires addressing more general occupational hygiene issues beyond the scope of these guidelines.

\subsection{THE HEALTH BURDEN FROM MANUFACTURED NANOMATERIALS}

At the nanoscale, MNMs may exhibit unique characteristics that distinguish their behaviour from bulk materials and may facilitate interaction with their environment. Of particular importance is their small size, which may allow for increased penetration of environmental and biological barriers. In addition, MNMs have far larger surface areas than similar masses of larger-scale materials. A larger surface area provides a larger interface for molecular and chemical interactions within the external environment, potentially promoting their reactivity.

The multiplicity of novel material designs for the same chemical composition with different physicochemical properties presents significant challenges for risk characterization, because toxicological properties may adapt to changes in their physicochemical properties such as size and shape. Nanomaterials are being used in a rapidly growing number of products and industries. 
The number of workers exposed to MNMs is not known but is increasing with the industrial production and use of MNMs.

In the workplace, health hazards can result from inhalation, ingestion or skin absorption of MNMs. The human lungs represent an excellent entry portal for MNMs due to their high surface area, thin epithelial barriers and extensive vasculature; and while dermal and oral exposure may occur, inhalation is more likely to result in a larger systemic dose of MNMs. Currently, inhalation of biopersistent particles and fibres with an asbestos-like morphology is the greatest known health hazard possibly resulting in local inflammation and cancer.

Translocation of inhaled MNMs to the circulation and to secondary organs is estimated to be limited to not more than $1 \%$ of the mass-based dose. However, this figure is based on extrapolations from animal studies, resulting in a lack of precise information on biokinetics of inhaled MNMs and their long-term fate in humans. Nevertheless, while acute effects from MNMs' translocation to secondary organs are likely to be minimal, it is possible that chronically exposed populations may face greater risks from cumulative, low-dose translocation processes.

While humans have long been exposed to unintentionally produced nanoparticles, such as those from combustion processes, the recent increase in MNM production demands greater investigation into the potential toxicity and adverse health effects of these materials following exposure. Since newly developed MNMs are not tested sufficiently for possible health hazards, it is generally recommended to take a precautionary approach until testing results are available. This means that MNMs should be considered as hazardous unless there is clear proof that they are not.

The toxicity of MNMs may largely depend on numerous physicochemical properties, including size, shape (i.e. size in a particular dimension), composition, surface characteristics, charge and extent of their dissolution. There is currently a paucity of precise information about human exposure pathways for MNMs, their fate in the human body and their ability to induce unwanted biological effects such as generation of oxidative stress. Data from in vitro and animal in vivo MNM inhalation studies are available for only a few MNMs. So far, only a small number of controlled human exposure studies have assessed the fate and health effects of MNM exposure; this is due mainly to ethical concerns.

Even though there are estimates available of the tonnes ( $\mathrm{t}$ ) of nanomaterials produced annually and used worldwide, the GDG did not find convincing evidence of how these estimates can be correlated with worker exposure. The current estimates of the number of workers potentially exposed to nanomaterials in specific countries indicate that they are still a relatively small proportion of all workers (1).

According to one source the volume of MNMs on the market can be ranked as follows (2):

1. carbon black ( 9.6 million $\mathrm{t}$ )

2. synthetic amorphous silica ( 1.5 million $\mathrm{t})$

3. aluminium oxide $(200000 \mathrm{t})$

4. barium titanate $(15000 \mathrm{t})$

5. titanium dioxide $(10000 \mathrm{t})$

6. cerium dioxide (10 000 t)

7. zinc oxide (8000 t)

8. carbon nanotubes (CNTs) and carbon nanofibres (CNFs), (100-3000 t)

9. silver nanoparticles $(20 \mathrm{t})$. 
The focus of these guidelines is on low-and middle-income (LMI) countries where nanotechnology is an important means of economic progress. For example, middle-income countries such as Brazil and South Africa produce MNMs and have research laboratories that produce CNTs. LMI countries produce nanosilver that is incorporated in milk packs, fabrics and clothes and MNMs are also produced for use by the pharmaceutical industry.

However, the implementation of health and safety at work regulations is usually less effective in LMI countries, which means that workers in these countries are at greater risk of the potential negative health effects than their counterparts in high-income countries. This is partly because the use of MNMs is often not known about or well understood. Despite the publication of a large number of scientific articles about nanotechnology by authors from LMI countries, only a few are about the potential toxicity of MNMs and very few report on safety or risk assessment (3).

\subsection{SCOPE OF THE GUIDELINES AND KEY QUESTIONS}

The GDG has identified the following key issues and questions where evidence should be reviewed leading to recommendations that can improve workers' health and safety.

\section{Risks of MNMs}

Which specific MNMs and groups of MNMs are most relevant with respect to reducing risks to workers and which should these guidelines now focus on, taking into account toxicological considerations and quantities produced and used.

2. Specific hazard classes

Which hazard class should be assigned to specific MNMs or groups of MNMs and how?

3. Forms and routes of exposure

For the specific MNMs and groups of MNMs identified, what are the forms and routes of exposure that are of concern for worker protection?

4. Typical exposure situations

What are the typical exposure situations and industrial processes of concern for relevant specific MNMs or groups of MNMs?

5. Exposure measurement and assessment

How will exposure be assessed and are there alternatives to current exposure assessment techniques for MNMs that should be recommended in LMI countries?

6. Occupational exposure limit (OEL) values

Which OEL or reference value should be used for specific MNMs or groups of MNMs?

7. Control banding

Can control banding be useful to ensure adequate controls for safe handling of MNMs?

8. Specific risk mitigation techniques

What risk mitigation techniques should be used for specific MNMs, or groups of MNMs in specific exposure situations, and what are the criteria for evaluating the effectiveness of controls?

9. Training for workers to prevent risks from exposure

What training should be provided to workers who are at risk from exposure to the specific MNMs or groups of MNMs? 
10. Health surveillance to detect and prevent risks from exposure

What health surveillance approaches, if any, should be implemented for workers at risk from exposure to specific MNMs or groups of MNMs?

11. Involvement of workers and their representatives

How will workers and their representatives participate in the workplace risk assessment and management of handling MNMs?

Initially, the GDG had decided that there would be a question about worker involvement in controlling risks of MNM exposure (see question 11). However, preliminary searches found no studies on this topic and the GDG decided it was better formulated as a best practice statement rather than pursuing a systematic review.

For all other questions, the GDG commissioned systematic reviews from teams of authors found through the WHO Global Network of Collaborating Centres.

The systematic reviews to answer question 1 on risks of MNMs and question 9 on worker training were used to inform section 5 on best practices. In occupational health and safety these describe methods or techniques accepted as being the best in protecting workers and are based on consensus among experts. They should be used when implementing the current recommendations.

The review of the literature on hazards of MNMs revealed that there is a general consensus about grouping them, but this did not lend itself very well to making an evidence-based recommendation. The review on worker training did not find specific studies that showed this would lead to a decrease in exposure or to better availability of controls. Nevertheless, the GDG was of the opinion that there are sufficient arguments that worker training is important. Given the complicated nature of the potential health effects of MNMs, worker training was considered to be necessary and regarded as best practice.

\subsection{WHO GUIDELINES RELATING TO THIS TOPIC}

Despite the increase in MNM production, particles at the nanoscale are not a new phenomenon to nature and biology. In the field of air pollution the presence of nanoscale particles has long been recognized, and there are air quality guidelines that also address nanoparticles even though no specific exposure limits are given for ultrafine particles $(4,5)$. Air quality is influenced by small particles that are usually divided into particulate matter smaller than 10 micrometres $\left(\mathrm{PM}_{10}\right)$, smaller than 2.5 micrometres $\left(\mathrm{PM}_{25}\right)$ and ultrafine nanoparticles that are smaller than 100 nanometres. The ultrafine particles are naturally occurring in air and a result of combustion processes. However, these guidelines only address MNMs that are intentionally produced.

\subsection{OTHER INTERNATIONAL PROGRAMMES ON MNM SAFETY}

A number of international organizations are active in the area of nanomaterial safety. The most active and influential are the Organisation for Economic Co-operation and Development (OECD) and the International Organization for Standardization (ISO).

The OECD Working Party on Manufactured Nanomaterials (WPMN) has four steering groups. The first steering group on testing and assessment is in the process of publishing dossiers with data on toxicity testing and physicochemical characterization for 11 nanomaterials. It is also responsible for 
updating safety testing guidelines to make them suitable for nanomaterials. The second steering group on risk assessment and regulatory programmes reviews approaches for risk assessment of nanomaterials. The third steering group on exposure measurement and mitigation focuses on developing guidance for exposure assessment and mitigation of exposure to nanomaterials in the workplace, during consumer use of nano-enabled products and for the environment. Finally, the fourth steering group is looking at environmentally sustainable use of nanomaterials. As of 31 May 2016 the OECD working party had published 58 reports in total. ${ }^{2}$

The ISO Technical Committee 229 (TC229) Nanotechnologies has five working groups. Of these, Working Group 3 (WG3) is tasked with developing standards related to the safety of nanomaterials and nanotechnology. As of 22 March 2017 this technical committee had published a total of 55 standards of which 18 were prepared by WG3; they deal directly with the health and safety issues of nanomaterials including specific standards on safe handling of nanomaterials in the workplace aimed at industrial hygienists. ${ }^{3}$

The involvement of experts from the WHO GDG in both the OECD and the ISO programme ensures that information is effectively exchanged between the various international organizations. There are also more formal mechanisms for coordination of work among these three organizations. OECD WPMN is a formal participant in ISO TC229, which allows it to review and comment on all ISO TC229 documents under development, while experts from ISO TC229 can reciprocally participate in the development of OECD WPMN documents. A similar status for the WHO GDG with ISO TC229 would further facilitate expert participation in both groups.

WHO and OECD are also members of the Inter-Organization Programme for the Sound Management of Chemicals (IOMC), which coordinates activities among international public organizations with national body memberships on chemicals in general and on nanomaterials specifically.

These links ensure that the knowledge base and expertise developed by these organizations are effectively shared, resulting in the highest quality guidelines, although goals, approaches and stakeholders may differ. For example, ISO aims to develop standards to facilitate commerce, while OECD addresses the needs of government organizations among its 35 member countries; and WHO addresses the needs of government organizations among its 194 member countries including many that are LMI. Despite these differences, recommendations produced by ISO, OECD and WHO are in general very consistent and aim to proactively minimize workers' exposure even though full information about nanomaterial risks is not yet available.

\subsection{TARGET AUDIENCE}

These guidelines are targeted at:

- occupational health professionals and policy-makers at the local, national or international level, who are responsible for the health and safety of workers exposed to MNMs;

- workers and their employers with premises with a potential risk of exposure to MNMs.

\footnotetext{
${ }^{2}$ http://www.oecd.org/science/nanosafety/publications-series-safety-manufactured-nanomaterials.htm.

${ }^{3} \mathrm{http}: /$ www.iso.org/iso/home/store/catalogue_tc/catalogue_tc_browse.htm?commid=381 983\&published=on\&includesc=true, accessed 15 May 2017.
} 


\section{PROCESS FOR GUIDELINE} DEVELOPMENT

\subsection{GETTING STARTED}

According to established WHO procedures, the Interventions for Healthy Environments Unit in the Department of Public Health, Environmental and Social Determinants of Health, obtained planning approval in 2010 to develop guidelines and established a WHO Guideline Steering Group and a Guideline Development Group (GDG). The GDG was composed of leading experts and end-users responsible for the process of developing the evidence-based recommendations.

Members of the WHO Guideline Steering Group and the GDG are listed in Tables A.2.1 and A.2.2 of Annex 2. Funding for meetings and the costs of the methodologist were provided by the WHO Department of Public Health, Environmental and Social Determinants of Health. Experts participated in the GDG on an in-kind basis and systematic reviews were conducted by volunteer teams.

The project started with the development of a background paper on the development of guidelines for protecting workers from potential risks of exposure to MNMs by the WHO Guideline Steering Group. In 2010-2011 there were several public calls for experts to join the GDG and External Review Group and to identify volunteers to carry out systematic reviews. Once the GDG was formed it worked to identify key questions through several rounds of the Delphi process (6).

A first face-to-face meeting of the GDG was held in Johannesburg, South Africa, on 30 September and 1 October 2013 where GDG experts finalized the key questions to be addressed, found authors for systematic reviews of the evidence and agreed on a plan and timeline for completing the work.

Based on decisions made by the GDG, the systematic reviews were commissioned and drafts discussed at evidence review meetings held in:

- Paris, France, on 9 and 10 February 2015

- Brussels, Belgium on 4 and 5 September 2015

- Dortmund, Germany on 18 and 19 April 2016.

\subsection{EVIDENCE REQUIRED TO ADDRESS SCOPING QUESTIONS}

To incorporate significant research undertaken in the area of MNM health and safety, teams of researchers were identified who could carry out systematic reviews of the pertinent literature according to the process outlined in the WHO Handbook for guideline development (7). The systematic review teams are listed in Table A.2.3 of Annex $\mathbf{2}$.

The first step in the evidence search and retrieval procedure was to identify and define the type of evidence required to address the scoping questions. First, the systematic review teams 
reformulated the key questions posed in section 1.2 so that they could be answered by a systematic review. Then they defined the best available evidence to provide the answers. Owing to the complex nature of the issues being addressed, and the scarcity of experimental studies directly assessing the impact of interventions on occupational health and safety, several distinct areas of evidence were required for each scoping question.

\subsection{SUMMARY OF EVIDENCE REVIEW PROCESS}

Very few existing systematic reviews were found. This is probably because methods for this type of assessment are not very well established in the field of toxicology, occupational health or exposure assessment. Therefore, systematic reviews were commissioned for all questions with the aim of locating studies that could answer the pertinent questions.

\subsubsection{The systematic review process}

The systematic review process used for each question varied slightly but followed the principles set out in the WHO Handbook for guideline development. First, for a study to be included it must comprise the four PICO elements: population, intervention, comparator and outcome(s), which are used to assess the exposure or the intervention (7). The PICO approach guarantees that the systematic review process collects the evidence that is needed to answer the question at hand. The searches conducted for the systematic reviews included any observational or experimental study of persons or workplaces exposed to MNMs. For each study, the risk of bias was systematically assessed.

Systematic review conclusions were based on the findings of the included studies. The findings were summarized and provided as support for the recommendations in these guidelines. The summary of findings paragraphs included in the specific recommendations (section 6) contain similar information to the summary of findings tables advocated by the GRADE (Grading of Recommendations, Assessment, Development and Evaluations) approach, even though we could not provide the summary in the same numerical format.

\subsubsection{Assessment of overall quality of evidence}

The systematic review teams determined the quality of evidence for each conclusion ( 7 ). The handbook recommends using the GRADE approach for making these assessments (8). GRADE allows the reviewer to systematically and transparently grade the quality of the body of evidence for the effectiveness of medical interventions. At the start of the rating it is assumed that the evidence is of high quality and based on randomized clinical trials. The quality of the body of evidence is then downgraded based on five specific qualifiers including risk of bias and inconsistency of results. This results in one of four quality ratings: high, moderate, low or very low quality of evidence.

However, some of the questions that were used to formulate recommendations in these guidelines were very far from clinical intervention questions, so the GRADE approach for interventions could not be applied. Therefore, a modified GRADE approach was used to assess the overall quality of evidence for the systematic reviews that were conducted to answer the nonintervention questions. The adaptation was based on the existing GRADE guidance for qualitative and prognostic studies $(9,10)$. The guidance on prognostic studies is most applicable also to exposure studies. 
The rating process ranked a study design as high quality if it was considered the best for the question at hand. The quality was downgraded if, in one or more domains, criteria for high quality were not met (Table 1). Numerical summaries of findings were not provided in all reviews and in those cases the systematic reviewers used GRADE guidance for qualitative studies as summarized in Table 1. The reviewers did not use any qualifiers for upgrading the evidence, as is possible in the GRADE approach for non-randomized intervention studies.

TABLE 1. GRADE ADAPTATION: DOMAINS AND CRITERIA TO ASSESS THE QUALITY OF THE EVIDENCE

\begin{tabular}{|c|c|c|c|c|c|}
\hline Domain & $\begin{array}{l}\text { Risk of bias/ } \\
\text { limitations }\end{array}$ & $\begin{array}{l}\text { Consistency/ } \\
\text { coherence }\end{array}$ & $\begin{array}{l}\text { Directness/ } \\
\text { relevance }\end{array}$ & $\begin{array}{l}\text { Precision/ } \\
\text { adequacy of } \\
\text { data }\end{array}$ & Publication bias \\
\hline $\begin{array}{l}\text { Criteria for } \\
\text { high quality }\end{array}$ & $\begin{array}{l}\text { Majority/most } \\
\text { important } \\
\text { contributing } \\
\text { studies do } \\
\text { not have } \\
\text { methodological } \\
\text { limitations. }\end{array}$ & $\begin{array}{l}\text { Majority of the } \\
\text { studies have } \\
\text { similar findings } \\
\text { in size and } \\
\text { direction. No } \\
\text { contradictory } \\
\text { findings that } \\
\text { cannot be } \\
\text { explained. }\end{array}$ & $\begin{array}{l}\text { Studies address } \\
\text { PICO precisely; } \\
\text { are performed } \\
\text { in the field and } \\
\text { representative } \\
\text { of the } \\
\text { population/ } \\
\text { material } \\
\text { concerned. }\end{array}$ & $\begin{array}{l}\text { Numerical } \\
\text { data provide } \\
\text { estimates of } \\
\text { precision. If no } \\
\text { numerical data, } \\
\text { at least two, } \\
\text { adequately } \\
\text { sized studies } \\
\text { available to } \\
\text { support a } \\
\text { conclusion. }\end{array}$ & $\begin{array}{l}\text { Arguments } \\
\text { for or against } \\
\text { publication } \\
\text { bias provided. }\end{array}$ \\
\hline
\end{tabular}

GRADE: Grading of Recommendations, Assessment, Development and Evaluations; PICO: population, intervention, comparator, outcome(s).

a Based on the GRADE approach for qualitative and prognostic studies; domains and criteria.

Based on these criteria, each systematic review's conclusion was rated for the quality of the evidence. We interpreted the quality levels as proposed by the GRADE working group as follows:

- High quality - further research is very unlikely to change our confidence in the estimate of effect.

- Moderate quality - further research is likely to have an important impact on our confidence in the estimate of effect and may change the estimate.

- Low quality - further research is very likely to have an important impact on our confidence in the estimate of effect and is likely to change the estimate.

- Very low quality - any estimate of effect is uncertain.

\subsection{FROM EVIDENCE TO RECOMMENDATIONS}

\subsubsection{General process}

After the systematic reviews had been conducted, the GDG developed recommendations based on the conclusions. To formulate recommendations and to determine the strength of the recommendations, the GDG used the balance between harms and benefits, values and preferences, monetary costs and the quality of evidence. For most of the recommendations, no 
numerical values for benefits and harms were available. Therefore, the GDG balanced benefits and harms in a global, qualitative way. Similarly, the costs of an intervention, or the implementation costs of a recommendation, were considered and based on the expert opinion of the GDG members. No formal cost-benefit or cost-effectiveness analyses have been performed.

With each recommendation in these guidelines there is an explanation of how the GDG reached the recommendation based on the evidence. All recommendations were proposed, discussed and based on consensus within the GDG, which was reached through face-to-face meetings. Disagreements were reconciled through adjustments in the recommendations and all GDG members agreed with the final versions.

The strength of the recommendation ranked as either:

- Strong: the GDG agrees that the quality of the evidence combined with certainty about the values, preferences, benefits and feasibility of this recommendation means it should be carried out in most circumstances; or

- Conditional: there was less certainty about the combined quality of the evidence and values, preferences, benefits and feasibility of this recommendation meaning there may be circumstances or settings in which it will not apply.

\subsubsection{Workers' values and preferences}

Even though the economic benefits of nanotechnology are fully appreciated by all stakeholders, concerns about health and safety risks are especially articulated by workers and their organizations across the globe. The GDG considered the values and preferences of this sector based on the opinion of the groups' members and also conducted a general search for the opinions of key organizations with the following findings.

A few years ago the IUF (International Union of Food, Agricultural, Hotel, Restaurant, Catering, Tobacco and Allied Workers' Associations) called on companies to: adopt a detailed public policy explaining their use of nanomaterials, if any; publish a safety analysis for any nanomaterials being used; issue supplier standards; label all products that contain nanoparticles smaller than $500 \mathrm{~nm}$; and adopt a hierarchy of hazard controls approach to prevent employees' exposure to nanomaterials (11). Similar concerns were also expressed by the ITUC (International Trade Union Confederation), an organization that unites hundreds of trade unions worldwide.

In Europe, the European Trade Union Confederation (ETUC) has expressed its concern about health and safety issues surrounding MNMs. The ETUC emphasizes that to achieve sustainable growth, the innovation resulting from nanotechnologies should include social equity, environmental protection and economic efficiency, while ensuring full health and safety protection and protection of the environment. The ETUC has criticized the failure to fund research on health and safety, ethical, social and environmental issues at the same levels as research and development work on nanotechnologies (12).

In Canada, the Canadian Union of Public Employees recommends following a precautionary approach that prevents workers' exposure until sufficient data can show there are no harmful effects on human health or the environment (13). The Australian Council of Trade Unions has expressed similar concerns (14). 


\section{INDIVIDUALS AND PARTNERS INVOLVED IN GUIDELINE DEVELOPMENT}

\subsection{WHO GUIDELINE STEERING GROUP}

Members of the WHO Guideline Steering Group are listed in Table A.2.1, Annex 2. They include WHO staff members who are involved in work relevant to the topic of MNM and associated health outcomes. The Guideline Steering Group was involved at all stages of planning, selecting members of the GDG and external review group, review of the evidence and developing potential recommendations at the main expert meetings as well as ongoing consultation on revisions following peer review.

\subsection{GUIDELINE DEVELOPMENT GROUP [GDG]}

The GDG consists of content experts gathered to investigate all aspects of evidence contributing to the recommendations. This group defined the key questions and priorities of the research, chose outcomes and provided advice on any modifications of the scope as established by the WHO Steering Group. The GDG interpreted the evidence, with explicit consideration of the overall balance of benefits and harms, and ultimately formulated the final recommendations, taking into account diverse values and preferences. The group also determined the strength of the recommendations and responded to external reviews. The complete list of GDG members, their affiliations and geographical locations, can be found in Table A.2.2 of Annex 2.

\subsection{SYSTEMATIC REVIEW TEAMS}

Systematic reviews were commissioned by WHO staff using external contractors. WHO issued public calls for volunteers to carry out reviews including via the WHO Global Network of Collaborating Centres for occupational health. In addition, the GDG recommended several authors to conduct the systematic reviews based on their knowledge of the field. Table A.2.3 in Annex 2 lists the systematic review team authors.

\subsection{EXTERNAL REVIEW GROUP}

The external review group is composed of technical experts, end-users and stakeholders with a geographical and gender balance. Technical content experts and end-users were selected for their expertise in the subject at hand. The group also includes representatives from professional groups and industry that will be implementing the guidelines. Members were asked to review the material at the end of the development process and they provided extensive comments that 
were used to further improve the recommendations and the wording of the text. The list of group members and their affiliations is provided in Table A.2.4, Annex 2.

\subsection{MANAGEMENT OF CONFLICTS OF INTEREST}

All members of the GDG and systematic review authors completed WHO declaration of interest forms that were accompanied by Annex B (code of conduct for WHO experts) and Annex C (confidentiality undertaking). These were reviewed by the WHO Focal Point and the Ethics, Risk and Compliance office for potential conflicts of interest. Based on their statements there were two requests for further information until finally all of the GDG members and the authors of the systematic review teams were accepted by WHO in their respective roles.

In addition, at the start of each meeting, all members received a briefing about the nature of all types of conflict of interest (i.e. financial, academic/intellectual and non-academic) and were asked to declare to the meeting any conflicts they may have. No member of the GDG or the systematic review team was excluded from his or her respective role.

For transparency purposes only, also the External Review Group members provided declaration of interest forms, as well as confidentiality statements. 


\section{FORMULATING}

\section{THE RECOMMENDATIONS}

\subsection{FOCUS OF THE RECOMMENDATIONS}

The specific recommendations 1 to 3 aim to define specific nanomaterials and their health hazards and recommendations 4, 5 and 6 focus on assessing exposures that impact on workers' health and safety. In addition, recommendations 7 to 11 focus on interventions that are generally used to protect workers' health. Finally, the GDG reached conclusions regarding health surveillance for workers and worker training and involvement. These recommendations are listed in sections 6.4 and 6.5 .

\subsection{GUIDING PRINCIPLES}

\subsubsection{Precautionary approach}

The GDG decided early on that in cases where a health concern is identified but scientific data do not permit an evaluation of the magnitude of the risk based on data from studies in humans, recourse to precaution should be used to reduce or prevent exposure as far as possible. This was seen as an important underlying approach in the interest of protecting workers' health, especially given previous experience with asbestos. Several definitions of a precautionary approach exist. All include a component that urges acting despite uncertainty when there are reasonable indications to do so (15).

For MNMs, potentially adverse effects have been identified for a number of materials. New MNMs are constantly being developed but the ability to predict their hazardous properties is still limited (16). Therefore, as a precautionary approach, the GDG considered that in the absence of toxicological information, workers should not be exposed. This means that in these cases the strictest control measures to prevent workers' exposure should be in place. Only when toxicological information is available can there be a more tailored control strategy. Along similar lines, the control-banding strategy elaborated in these guidelines is based on the same principles.

\subsubsection{Hierarchy of controls}

The hierarchy of controls is a concept of risk management that is generally accepted in occupational health and safety. It stipulates that the implementation of controls to reduce workers' exposure should be considered the goal of a successful industrial hygiene programme. The hierarchy of controls is an approach to risk reduction or elimination of hazard or exposure (17). The first step should be to try and eliminate the hazard. If that is not possible, the hazardous material should be substituted by a less harmful agent. Then, engineering controls should be applied such as isolation, local exhaust ventilation or dust suppression techniques. If all these are not feasible, then administrative controls should be considered such as worker education, and 
training or scheduling. As a last resort, personal protective equipment (PPE) can be used, but reducing the exposure at source provides better protection for workers and better cost-benefit for employers.

Often, there will be a combination of control measures to minimize the risk. For instance, it might be possible to eliminate or reduce the hazardous properties of nanomaterials without altering their beneficial properties. However, in the case of MNMs, substitution is a control measure that will be difficult to realize, because it is all about the very use of the MNMs. Some have argued that substitution is too limited and should be replaced by process change to reduce worker exposure (18). Changing the process in such a way that no MNMs will be released into the air should therefore always be one of the first control measures to consider. 


\section{BEST PRACTICE}

The GDG considers it best practice to class MNMs into the following three groups: those with specific toxicity, those that are respirable fibres and those that are granular biopersistent particles.

\subsection{CLASSIFICATION OF MNMS}

The specific toxicity group consists of (i) MNMs with high dissolution rates through the release of ions or amenable to biodegradation and, (ii) MNMs with low dissolution rates but with high specific toxicity. The latter are MNMs with specific toxicity, which is mediated by the specific chemical properties of their components (19).

The respirable fibres group consists of MNMs that are rigid, biopersistent or biodurable and respirable, which have dimensions agreed upon by a WHO working group for man-made mineral fibres in the past. These dimensions are a fibre length $(F L)>5 \mu \mathrm{m}$, fibre diameter $(F D)<3 \mu \mathrm{m}$ and an aspect ratio (FL/FD) $>3$ (20). Although this group of fibres is characterized as being rigid, it should be kept in mind that there is no consensus on specific criteria for rigidity even though some have proposed crystallinity as a measure of rigidity for MNMs (21).

The granular biopersistent particles (GBP) group consists of respirable granular biodurable particles that are characterized by both low dissolution rates and lack of high specific toxicity. GBP are respirable granular and biopersistent but not fibrous (as defined above) and these particles are also known as poorly soluble particles or poorly soluble, low-toxicity particles (19).

Forming groups of MNMs with similar properties is important in the absence of information on the hazards of many new materials. This enables the transfer of hazard information, also called bridging or read across, from one material to another. Because there is no general accepted approach on how to do this, the GDG commissioned a systematic review of possibilities to group MNMs based on toxicological considerations. The systematic review was undertaken by Zienolddiny \& Skaug (2017) (22). The systematic review team located 22 reviews of grouping MNMs, or approaches to transfer hazard information from one MNM to another. To be included in the overview the authors of the reviews had to have considered which mechanisms of action could lead to toxicity of nanomaterials. The systematic review team authors concluded that there is evidence that there are three main mechanisms of toxicity of nanomaterials: specific toxicity of the material, inhalation and biopersistence in the lungs, and one mediated specifically by the fibre structure. For other potentially hazardous properties, such as genotoxicity, there was no consistency in the included reviews that this is inherent to the nanoscale size of the MNMs.

Given that the grouping of MNMs is based on expert opinion, the GDG considered that changes are likely when more research becomes available. 


\subsection{WORKER INVOLVEMENT}

The GDG considers it best practice that workers should be involved in health and safety issues and that this will lead to more optimal control of health and safety risks.

In most countries, worker involvement in health and safety issues is mandatory. Article 19 of the International Labour Organization (ILO)'s C155 Occupational Safety and Health Convention, 1981, stipulates that representatives of workers in the undertaking cooperate with the employer in the field of occupational safety and health. In many other ILO conventions and European Union (EU) directives, the term "worker participation" is frequently used.

\subsection{ADDITIONAL TRAINING AND EDUCATION OF WORKERS}

\section{The GDG considers it best practice that workers potentially exposed to MNMs should be educated on the risks of MNMs and trained in how they can best protect themselves.}

MNMs have risk aspects that are specific to being a nanomaterial and that are not self-evident. For proper control measures to be well implemented, workers need information about these risks. Safety data sheets (SDS) do not always provide reliable information on MNMs and users should be aware of this. In addition, MNMs require specific control measures that can be different from those for the bulk material. This is also recognized by the EU, which has provided specific guidance for workers (23).

There are good training materials available, for instance from the National Institute of Environmental Health Sciences in the United States of America (USA) and from the Health and Safety Executive in the United Kingdom of Great Britain and Northern Ireland, which can easily be adapted to local circumstances $(24,25)$.

Education and training should focus on those aspects of MNMs that are dealt with in these guidelines and that are additional to, or different from, education and training in the safe handling of bulk material chemicals. Topics should include which hazards are specific to MNMs and different from the bulk material; which hazard classes are assigned to MNMs; which routes of exposure are important; which workplace exposures have been measured and which tasks put workers most at risk; how proposed OELs can be interpreted; when and how control banding, specific controls and PPE for MNMs can be used.

ILO Convention 155 concerning Occupational Safety and Health and the Working Environment also states that there should be a national policy to provide information and education and implement training for workers, including necessary further training, qualification and motivation of persons involved, in one capacity or another, in the achievement of adequate levels of safety and health. This also holds for workers exposed to MNMs. 
6. SPECIFIC RECOMMENDATIONS

\subsection{ASSESS HEALTH HAZARDS OF MNMS}

Recommendation 1: The GDG recommends assigning hazard classes to all MNMs according to the Globally Harmonized System (GHS) of Classification and Labelling of Chemicals for use in safety data sheets. For a limited number of MNMs this information is made available in these guidelines (Table 2) (STRONG, moderate quality evidence).

Recommendation 2: The GDG recommends updating safety data sheets with MNM-specific hazard information, or indicating which toxicological end-points did not have adequate testing available (STRONG, moderatequality evidence).

Recommendation 3: For the respirable fibres and granular biopersistent particles' groups, the GDG suggests using the available classification of MNMs given in Table 2 for provisional classification of nanomaterials of the same group (CONDITIONAL, low-quality evidence).

A list of selected nanomaterials and their up-to-date hazard classes, according to the GHS and as assigned by the systematic review team, is available in Table 2. The most common hazard classes assigned to MNMs are:

a specific target organ toxicity after repeated exposure

arcinogenicity

- germ cell mutagenicity

- serious eye damage

a respiratory or skin sensitization.

\section{From evidence to recommendation}

\section{Evidence}

The animal and genotoxicity studies, as collected and reviewed by the OECD and reported in the specific nanomaterial dossiers, formed the evidence for the assignment of hazard classes to the various MNMs. In addition to the OECD data, the evidence for carcinogenic properties was based on assessment of a limited number of MNMs by the International Agency for Research on Cancer (IARC). Based on an assessment of study limitations, the quality of the evidence was rated as moderate to high for the various MNMs. 
Recommendation 3 to bridge the hazard classes from specific materials within a group to other materials within that same group, is based on low-quality evidence that the respirable fibres or GBP materials have similar toxicological properties (see Best practice, Classification of MNMs, section 5.1).

\section{Benefits and harms}

The benefits of having MNMs properly classified and labelled according to their hazards, in terms of focus on risk and control measures, clearly outweigh the possible harm that the classification might be overly cautious given the lack of information about the hazards of MNMs in general. In some cases, the classification system could also result in underestimation of the hazard.

\section{Values and preferences}

The hazard classification forms the basis for labelling products according to their hazards. In many countries, this is legally binding. This information is also included in the SDS informing workers and employers about the safety and hazards of the products they use. Even though the GHS might not be optimal for MNMs, and is being continually developed, it is a systematic approach that is generally recognized globally.

Grouping MNMs with similar properties is important, especially in the absence of information on the hazards of many new materials.

\section{Net benefits worth the costs}

Assigning hazard classes to MNMs is not a very costly procedure if data from studies are available.

\section{Strength of the recommendation}

Based on the above considerations, the GDG makes a strong recommendation for the assignment of hazard classes to MNMs. For bridging from specific materials within the same group, the recommendation is conditional.

\section{Summary of findings: MNMs and hazard class assignment}

Systematic review question: Which hazard classes can be assigned to specific MNMs according to the UN GHS and making use of MNM-specific dossiers as developed by the OECD? The MNM dossiers compiled by the OECD give an overview of the available toxicological data for a number of specific MNMs.

\section{Evidence summary}

The systematic review was undertaken by Lee et al. (2017) (26) and was published by WHO.

\section{Number of studies and participants}

There were $11 \mathrm{OECD}$ dossiers containing toxicity testing information. These were used by the systematic review team to assign one or more hazard classes, according to the GHS, to the following nanomaterials: fullerene, single-walled carbon nanotubes (SWCNT) and multi-walled carbon nanotubes (MWCNT), silver, gold, silicon dioxide, titanium dioxide, cerium dioxide, dendrimer, nanoclay and zinc oxide in nanoparticle form. For the assessment of carcinogenicity, the review team also used the evidence summaries compiled by IARC on SWCNTS, MWCNTS and titanium dioxide. 


\section{Data in the dossiers}

Dossiers mostly contained results of in vivo animal studies and in vitro genotoxicity studies supplied by member countries and nongovernmental organizations such as the Business and Industry Advisory Committee to the OECD.

\section{Risk of bias in the included dossiers}

The main limitations to the studies included in the dossiers were that they did not fulfil the OECD criteria for good methodological quality, such as being published in a peer-reviewed journal and complying with good laboratory practice (GLP). For some studies, the GLP test data were not fully disclosed because of the company's intellectual property rights. Studies were classified at low risk of bias if they were in the OECD category 1 or 2, complied with GLP, were based on test guidelines and resulted in a peer-reviewed publication; at medium risk of bias if the above applied but there was no compliance with GLP; and at high risk of bias if none of the above applied.

\section{Classification of MNMs}

The MNMs were classified as having a specific hazard according to the GHS, having no hazard according to the available studies, or as having no data when these were not available for classification. "No hazard" does not necessarily imply that there is no hazard but only that this was not found in the studies used in the OECD dossiers.

For fullerene, there was evidence that there is no hazard for acute toxicity, skin-, eye- or respiratory damage, germ cell mutagenicity or specific target organ toxicity after repeated exposure but, for the other hazard classes, data were missing.

For SWCNT, there was evidence of a hazard for germ cell mutagenicity (Cat 2) and specific organ toxicity after repeated exposure (Cat 1 ). For reproductive toxicity no clear hazard could be established based on the available data. There was also evidence of no hazard in acute toxicity, skin damage, respiratory/skin sensitization, or reproductive toxicity. For specific target toxicity after single exposure, there were no data. For carcinogenicity there were no data but there is an IARC classification 3, meaning not classifiable.

For MWCNT, there was evidence of a hazard for eye damage (Cat 2), germ cell mutagenicity (Cat 2), carcinogenicity (Cat 2, IARC 2B/3) and specific organ toxicity after repeated exposure (Cat 1). There was also evidence of no hazard in acute toxicity, skin damage, respiratory/skin sensitization, or reproductive toxicity. For specific target toxicity after single exposure, there were no data.

For silver nanoparticles, there was evidence of a hazard for respiratory/skin sensitization (Cat 1B) and specific target organ toxicity after repeated exposure (Cat 1区2). For acute toxicity, skin corrosion, eye damage, germ cell mutagenicity and reproductive toxicity there was evidence of no hazard. For carcinogenicity and specific target organ toxicity after single exposure, there were no data.

For gold nanoparticles, there was evidence for specific target organ toxicity after repeated exposure (Cat 1). There were no data for the other classes.

For silicon dioxide, there was evidence for specific target organ toxicity after repeated exposure (Cat 2), but no hazard for acute toxicity, skin or eye damage, respiratory or skin sensitization, germ cell mutagenicity and reproductive toxicity. For carcinogenicity and specific organ toxicity after single exposure, there were no data. 
For titanium dioxide, there was evidence for possible carcinogenicity ((IARC Cat 2B), reproductive toxicity (Cat 1), and specific organ toxicity after repeated exposure (Cat 1), but also evidence of no hazard for acute toxicity, skin or eye damage, respiratory or skin sensitization or germ cell mutagenicity. There were no data for specific organ toxicity after single exposure.

For cerium dioxide, there was evidence of specific target organ toxicity after repeated exposure (Cat 1), but also evidence of no hazard for acute toxicity. There were no data for the other hazard classes.

For dendrimer and nanoclay, there were no animal toxicity or genotoxicity data to use for classification.

For zinc oxide, there was evidence for specific organ toxicity after repeated exposure (Cat 1) but also evidence of no hazard for acute toxicity, skin or eye damage, germ cell mutagenicity and reproductive toxicity. There were no data for respiratory/skin sensitization, carcinogenicity and specific organ toxicity after single exposure.

For physical hazards, there was evidence that silicon dioxide and titanium dioxide were not flammable or explosive. There was no evidence for the other MNMs.

\section{Quality of the evidence}

The evidence was rated as high quality if there was at least one study at low risk of bias; as moderate quality if there was at least one moderate-quality study; and as low quality if there were only studies at high risk of bias. The quality of the evidence for all but one of the classifications of hazards was in the moderate or high category (Table 2).

\section{Implementation guidance, research recommendation \\ Implications for research}

There is high to moderate-quality evidence for 11 specific MNMs to be classified according to the GHS. This exercise should also be undertaken for other MNMs not mentioned here. Where data are available, they should be used for the development of SDS. 


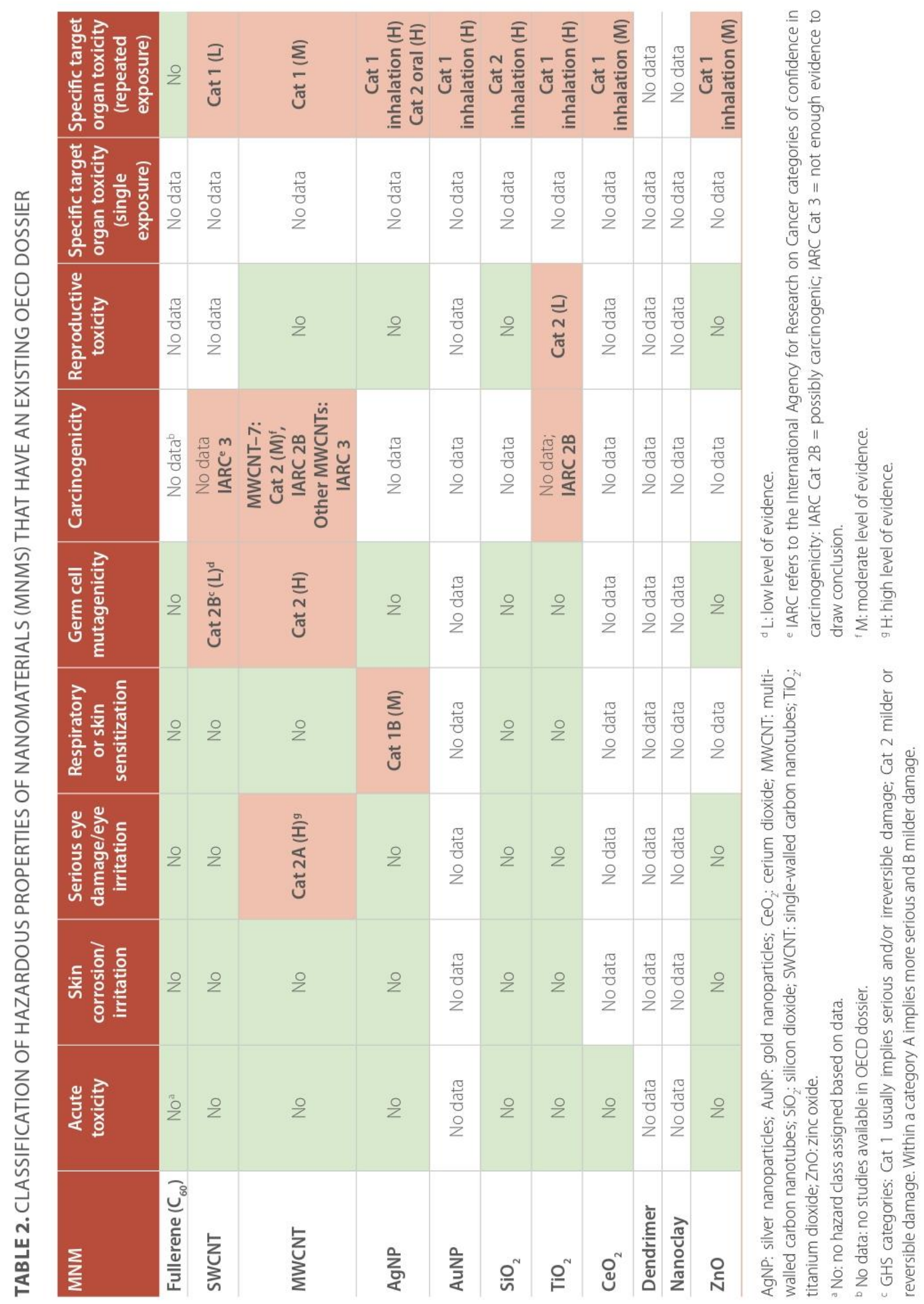




\subsection{ASSESS EXPOSURE TO MNMS}

Recommendation 4: The GDG suggests assessing workers' exposure in workplaces with methods similar to those used for the proposed specific OEL value of the MNM (CONDITIONAL, low-quality evidence).

Recommendation 5: Because there are no specific regulatory OEL values for MNMs in workplaces, the GDG suggests assessing if workplace exposure exceeds a proposed OEL value for the MNM. A list of proposed OEL values is provided in Annex 1 of these guidelines. The chosen OEL should be at least as protective as a legally mandated OEL for the bulk form of the material (CONDITIONAL, low-quality evidence).

Recommendation 6: If specific OELs for MNMs are not available in workplaces, the GDG suggests a stepwise approach for inhalation exposure with, first an assessment of the potential for exposure; second, conducting a basic exposure assessment and third, conducting a comprehensive exposure assessment such as proposed by OECD or CEN (CONDITIONAL, moderate-quality evidence). For dermal exposure assessment, there was insufficient evidence to recommend one method of dermal exposure assessment over another.

Knowledge about exposure and subsequent risk assessment forms the basis for measures to control exposure. However, without an exposure level that can serve as a benchmark or guideline level that indicates a risk for adverse health effects, it will be difficult to make decisions about control measures.

There are several alternative ways to measure MNM exposure such as the number concentration or the mass concentration of an MNM, where it is unclear which method is best for assessing health risks. Therefore, the GDG recommends using the same method as has been used for proposed OEL values. This determines the measurement method and at the same time enables a comparison with a benchmark level that probably indicates a safe exposure level.

Only when no proposed OEL is available for an MNM does the GDG recommend using a more generic exposure assessment that consists of a tiered approach. In the first tier, a qualitative assessment is made of possible absence or presence of exposure. In the second tier, called a basic measurement, a quantitative assessment is made of the exposure concentration. In the third tier, called a comprehensive measurement, the size distribution, morphology and chemical composition of particles is characterized.

The recommendations are based on the evidence compiled in two systematic reviews on the quality of exposure assessments in studies and on OELs proposed for various MNMs.

A comprehensive and up-to-date list of proposed OEL values for MNMs is available in Annex 1, Table A.1.1. The values proposed come from a wide range of institutions and countries. Some authors propose one value for all MNMs (general approach), others propose one value for a 
group of MNMs (categorical approach), but most propose a value for one specific MNM (specific approach).

The user should be aware that these OELs do not imply a safe level below which adverse health effects do not occur, because they are all based on extrapolation from animal research, or other fields such as air pollution, since there are only very limited data available on long-term humanhealth effects. Users should make their own choice of the best applicable OEL value. This is similar to the selection of OELs for bulk materials, where a range of values may be available and the user has to make a choice.

Deveau et al. provide a practical framework for how to find the best applicable OEL for a particular problem from a list of varying OELs for one chemical. This approach can also be used for the list of OELs for MNMs (27).

The exposure assessment and measurement strategy as proposed by OECD and the Comité Européen de Normalisation (European Committee for Standardization: CEN) distinguishes the following three levels of assessment that can be used as stand-alone modules or embedded in a harmonized tiered approach (28).

- The initial assessment provides information on the likelihood of MNMs being released during an activity or process, and usually does not comprise any measurements.

- The basic assessment, using hand-held or personal devices or samplers, measures exposure as particle number concentration(s) or as respirable mass, or both, in the breathing zone or the workstation air and in the background air. These measurements are supported by laboratory analysis of the samples to characterize the MNM(s) either by chemical composition or morphology.

- In addition to the basic assessment, the comprehensive assessment provides a characterization of the aerosols in the breathing zone that enables, for example, estimation of the dose of MNMs that is deposited in the gas-exchange region of the lung.

\section{From evidence to recommendation}

\section{Evidence}

The evidence for these recommendations is based first on a systematic review of all available proposed OELS (29). Since there is no consensus on a valid way of deriving OELs for MNMs, the GDG could not take the quality of the evidence into account and therefore has only formulated conditional recommendations.

Second, the recommendation is informed by a systematic review of exposure measurement methods that shows there is moderate-quality evidence that basic and comprehensive inhalation exposure assessment methods are feasible in practice (30). There was only very low-quality evidence about feasibility of measurements for dermal exposure assessment.

\section{Benefits and harms}

The benefits of OELs are that they can constitute a benchmark against which local measurements can be compared. The drawback is that many associate the OEL with a safe level below which no adverse health effects will occur. Since both measurements and adverse health effects are uncertain, the OELs can give a false sense of security. However, balancing the two, the GDG decided that the benefits outweigh the harms. 
Comprehensive assessment can be time consuming and requires expert knowledge and instrumentation. Many countries would struggle to carry out comprehensive exposure assessments and few companies would be able to pay for such assessments, especially small and medium-sized enterprises (SMEs). Therefore, the GDG recommended the tiered approach.

\section{Values and preferences}

The OEL is a familiar concept to stakeholders and widely used for assessing bulk materials. The same holds for the exposure assessment approach, which is used in general for chemicals.

\section{Net benefits and costs}

The costs of derivation of an OEL depend on the method, but it is not necessarily expensive. The GDG considers the measurement of MNMs and comparison with OELs to be an important strategy and its costs to be a useful investment in prevention.

The costs for the measurement instruments are considerable - at least several thousand dollars for hand-held particle measurement devices. However, in many countries it is possible to rent the equipment for short periods. The benefit of measuring is that it enables comparison with an OEL and evaluation by means of a before-after comparison to determine whether measures to control exposure are successful.

\section{Strength of the recommendation}

Given the difficulty of establishing the quality of the OELs, the recommendation for using them is conditional. Given the complexities and the costs of measurements, the GDG makes a conditional recommendation for the assessment of exposure.

\section{Summary of findings: systematic review of proposed OELs}

Systematic review question: Which specific OEL values that should protect workers are proposed for workers or workplaces with potential exposure to an MNM or a group of MNMs based on studies that proposed a value underpinned with empirical research or arguments.

\section{Evidence summary}

The systematic review by Mihalache et al. (2017) was published as a journal article (29).

\section{Number of studies and participants}

Twenty studies from a wide range of countries and institutes that proposed 56 OEL values were included in the systematic review. Of these, two proposed one value for all MNMs, 14 proposed one value for a group of MNMs and 40 proposed a value for a specific MNM.

\section{OELs in studies}

All studies that considered inhalation exposure proposed OELs for chronic exposure. One study proposed OELs for dermal and oral exposure for CNTs and fullerenes and two studies derived OELs for acute/peak exposure.

In 15 of the studies the exposure values were derived by extrapolation from animal studies. Two studies derived the OEL from the background level or from an environmental exposure limit. Six studies used a bridging approach to derive an OEL for a group of MNMs, arguing that the risks 
will similarly apply to members of the whole group (fibres, GBPs, MNMs with specific toxic bulk material with an OEL, soluble MNMs and non-biopersistent MNMs).

Two studies proposed limits for all MNMs. Six studies proposed OELs for a group of MNMs. The rest proposed OELs for specific MNMs: seven for titanium dioxide (TiO2) nanoparticles, six for CNTs, three for fullerenes, three for silver nanoparticles and one study each for silicon dioxide nanoparticles, low-toxicity dust consisting of GBP, nanocellulose fibres and nanoclays.

\section{Risk of bias in the included studies}

One of the study limitations was that the authors did not always give sufficient information about the specific MNM or group of MNMs and the way the OELs were derived. Also, it was unclear if the proposed OELs, especially the number-based OELs for primary nanoscale particles, can be matched with measurements at the workplace where mostly micro-sized agglomerates of MNMs are assessed.

\section{Proposed OELs that are publicly available}

Four studies proposed the asbestos OEL of 0.01 fibres $/ \mathrm{cm}^{3}$ for nanofibres.

Four studies proposed values for GBP, of which two studies each had two proposals. One study proposed $500 \mu \mathrm{g} / \mathrm{m} 3$ and $1250 \mu \mathrm{g} / \mathrm{m}^{3}$ for the respirable fractions dependent on whether particles exhibited specific toxicity or not. In the other study, the proposals for metal and metal oxide nanoparticles are 20000 particles $/ \mathrm{cm}^{3}$ and 40000 particles $/ \mathrm{cm}^{3}$ dependent on particle density.

One study proposed the same OEL for non-biopersistent material as for their bulk material.

For carbonaceous material, proposed OELs ranged from $0.67 \mu \mathrm{g} / \mathrm{m}^{3}$ for MWCNT to $390 \mu \mathrm{g} / \mathrm{m}^{3}$ for fullerenes.

For nanosilver there are six proposals varying from $0.098 \mu \mathrm{g} / \mathrm{m}^{3}$ up to $50 \mu \mathrm{g} / \mathrm{m}^{3}$.

There are 10 proposals for $\mathrm{TiO}_{2}$ nanoparticles from the lowest, $17 \mu \mathrm{g} / \mathrm{m}^{3}$, to the highest, $2000 \mu \mathrm{g} / \mathrm{m}^{3}$. Some variations in reported OELs for nanomaterials that are chemically the same are due to different models used to derive OELs and some are due to different physicochemical properties including specific toxicity of nanomaterials.

\section{Quality of the evidence}

The GDG did not consider the limitations in the studies because there is no generally accepted way of deriving OELs. There were multiple studies with consistent proposals for fibres only. For all other MNMs there was considerable variation. Therefore, the GDG considered the quality of the evidence as low.

\section{Implementation guidance, research recommendation}

\section{Implications for practice}

Workplace exposure studies indicate that in most situations, exposure exceeds the majority of the proposed OELs. This should be a strong incentive for exposure control measures.

\section{Implications for research}

More studies are needed to derive OELS for specific MNMs. Harmonization of OELs requires agreement about interspecies and intraspecies' adjustment factors and exposure values. 


\section{Summary of findings: systematic review on exposure assessment and measurement}

Systematic review question: In workers potentially exposed to MNMs or workplaces with exposure to MNMs, which exposure measurement techniques to assess MNMs are feasible based on studies that assessed and measured exposure?

\section{Evidence summary}

The systematic review was published by Boccuni et al. (2017) as a journal article (30).

\section{Number of studies and participants}

The systematic review included papers on exposure through inhalation and dermal absorption. There were no papers identified on exposure through ingestion. The systematic review identified 59 articles that described 53 measurement techniques. Among these, four papers analysed both inhalation and dermal exposure. Three studies of dermal exposure were conducted in the workplace and one in the laboratory setting. These papers reported very poor data on specific techniques for dermal exposure measurements. Therefore, systematic review conclusions were focused on measurements of exposures through inhalation.

\section{Measurements in studies}

There were 53 descriptions of a basic measurement technique and of these there were 13 additional descriptions of a comprehensive technique to assess the presence or absence of MNMs in workplace air. All 53 techniques measured exposure by inhalation; of these, four studies also considered exposure by dermal absorption.

\section{Outcomes in studies}

The studies used either a basic assessment technique or a comprehensive technique.

\section{Risk of bias in the included studies}

The basic exposure assessment was rated as moderate quality in 40 studies and as high quality in two studies.

The comprehensive exposure measurement was rated as moderate quality in 11 studies and as high quality in two studies.

\section{Exposure measurements carried out}

A basic exposure measurement that assesses the presence or absence of MNMs in the workplace air was demonstrated in 53 studies.

A comprehensive exposure measurement was demonstrated in 13 studies.

Comprehensive measurement techniques are more expensive than basic measurement techniques.

\section{Quality of the evidence}

The quality of the evidence is moderate for both basic and comprehensive assessments because the majority of the studies demonstrate at least a moderate-quality exposure assessment. There was very low quality and inconsistent evidence on specific techniques of dermal exposure measurement. 
Implementation guidance, research recommendation

Implications for practice

The GDG concludes that there is moderate-quality evidence that both basic and comprehensive measurement techniques are feasible in the workplace.

\section{Implications for research}

Studies to validate basic and comprehensive measurement techniques including techniques to assess dermal exposure are needed.

\subsection{CONTROL EXPOSURE TO MNMS}

\subsubsection{Focus on prevention of inhalation of MNMs}

Recommendation 7: Based on a precautionary approach, the GDG recommends focusing control of exposure on preventing inhalation exposure with the aim of reducing it as much as possible (STRONG, moderate-quality evidence).

Recommendation 8: The GDG recommends reduction of exposures to a range of MNMs that have been consistently measured in workplaces especially during cleaning and maintenance, collecting material from reaction vessels and feeding MNMs into the production process. In the absence of toxicological information, the GDG recommends implementing the highest level of controls to prevent any exposure of workers. When more information is available, the GDG recommends taking a more tailored approach (STRONG, moderate-quality evidence).

Sometimes, specific types of MNMs are processed in a specific way, such as in an open or closed system during synthesis, and thus this determines the likelihood of exposure. The GDG recommends that under these circumstances, the distinctive processes related to the type of MNM are taken into account in the evaluation of workers'likelihood of exposure and the routes of exposure.

The GDG further notes that there is a need to perform high-quality evaluations of worker exposures to nanomaterials in LMI countries.

\section{From evidence to recommendation}

\section{Evidence}

The evidence for these recommendations is based on two systematic reviews of studies that measured exposure to specific MNMs in the work environment. One review assessed what the most likely routes of exposure were and during which tasks these exposures occurred. This review was published by Basinas et al. (2017) (31). The other review assessed the levels of exposure to MNMs, how well the exposures were measured and during which tasks the exposures occurred. This review by Debia et al. (2016) was published as a journal article (32). The studies on inhalation 
were considered of high quality, but those on dermal and ingestion exposure contained assumptions that reduced the quality of the evidence. The studies on workplace exposure measurements mostly used well elaborated exposure assessment strategies and were rated as high-quality studies.

\section{Benefits and harms}

To be able to implement an effective control strategy, it is important to know if there is exposure to MNMs and what the most important route of uptake is. The recommendation aims at preventing potential harmful effects of MNMs through a focused control strategy.

\section{Values and preferences}

The routes of uptake form an important part of the occupational hygiene strategy to reduce exposure to chemicals. There are no specific values or preferences connected to this issue.

\section{Net benefits and costs}

It is important to know the routes of exposure. For inhalation exposure, the methods of measurement are well-defined, but for dermal and ingestion exposure this is more complicated and not yet standardized. Certainty about the dermal route of exposure would imply more specific exposure assessment and involve considerably more work and cost.

\section{Strength of the recommendation}

For inhalation exposure, based on the above considerations, the recommendation is strong. For dermal exposure, the quality of evidence is low and thus the recommendation is conditional.

\section{Summary of findings: routes of exposure to MNMs}

Systematic review question: In workers with potential exposure to MNMs, what are the most likely routes of exposure for specific MNMs and during specific tasks based on workplace measurements of MNMs?

\section{Evidence summary}

The systematic review was published by Basinas et al. (2017) (31).

\section{Number of studies and participants}

There were 107 studies reporting a total of 424 exposure assessment situations, i.e. combinations of activity and type of MNM with workers' potential exposure to MNMs and sufficient data to allow assessment of the likelihood of exposure by route.

\section{Exposures in studies}

The exposure assessment situations related to potential workers' exposure to CNTs and CNFs $(N=63)$, Si-based $(N=42), \mathrm{TiO}_{2}(N=43)$, other metal oxides $(N=77)$, metals $(N=38)$, and other nanomaterials $(N=61)$.

\section{Outcomes in studies}

For every exposure assessment situation, the likelihood of a route of exposure was assessed by applying specific criteria. For inhalation exposure, an adapted set of criteria was used based on the CEN Standard (PREN 17058) Workplace exposure-Assessment of inhalation exposure to nano-objects 
and their agglomerates and aggregates (33). Dermal exposure was based on an established sourceto-reception model. For each combination of activity and type of MNM, the likelihood of exposure by a particular route was derived by aggregating across the relevant individual assessments.

\section{Risk of bias in the included studies}

The main limitations of the studies are listed below:

- The data that were available from studies included in the review comprised measurement in small and research scale-productions and therefore may not adequately represent the exposure conditions in industrial workplaces.

- For the inhalation route, there was a lack of harmonized methods to measure personal exposure at the workers' breathing zone. Most of the evaluated exposure assessments were based on stationary sampling, not necessarily representative of workers' exposure via inhalation.

- For the dermal route only, there were limited indirect measurement data available that resulted from the analysis of collected surface samples.

- No measurement data are available on ingestion exposure.

- Protection provided by PPE was not considered in the review because it is not relevant to determine the route and form of exposure.

\section{Results}

There is high-quality evidence that, in general, the form and route of exposure depends mainly on the activity (i.e. process and operational conditions), rather than just on the type of MNM handled (Annex 3).

There is also high-quality evidence that the likelihood of exposure is affected by the presence of risk management measures and the scale of production. In principle, both inhalation and dermal exposure are less likely when the process is enclosed. For example, CNTs, Si-based and various metal oxides are processed within enclosed reaction vessels, which makes exposure unlikely during production. Other materials such as $\mathrm{TiO}_{2}$ and metals can be synthesized with flame pyrolysis and mechanical reduction in a not fully enclosed process, which makes exposure more likely to occur.

When a worker can possibly inhale MNMs, potential for dermal exposure also exists. However, for some forms (e.g. when an MNM is in suspension/liquid form), dermal exposure or ingestion exposure can be possible even when inhalation exposure is unlikely.

For the following situations and MNMs, exposure was unlikely:

For CNTs and CNFs, there is high-quality evidence that inhalation exposure usually does not occur in the reaction phase of synthesis and handling and transfer of liquids. There is high-quality evidence that dermal exposure does not occur in the reaction phase of synthesis.

For Si-based nanomaterials, there is high-quality evidence that inhalation and dermal exposure do not occur in the reaction phase of synthesis.

For other metal oxides and mixtures, there is high-quality evidence that inhalation and dermal exposure do not occur in the reaction phase of synthesis.

For other MNMs, there is high-quality evidence that inhalation and dermal exposure do not occur in the reaction phase of synthesis. 


\section{Quality of the evidence}

Quality of the studies was dependent on the methods used to quantify release and the applicability or not of the adapted set of criteria described in the CEN Standard (PREN 17058) Workplace exposure - Assessment of inhalation exposure to nano-objects and their agglomerates and aggregates (33).

Conclusions reached using the adapted CEN criteria and both off-line and online data, were considered to be based on high-quality data. For some MNMs there is an established exposure assessment method based on chemical analysis, e.g. for CNT and TiO2. When this chemical analysis was used to quantify the release, the quality was considered high even if no online measurements were available or if the available online measurements for the activity involving MNMs were not considerably higher than background.

For dermal exposure, evidence was considered as high quality if surface contamination was clearly established and/or if release was confirmed through both online and off-line measurements and a transparent description of the process and operational conditions was provided.

\section{Implementation guidance, research recommendation}

\section{Implications for practice}

The GDG concludes that there is high-quality evidence for workers' inhalation exposure and lowquality evidence for dermal exposure to MNMs in general.

There is also high-quality evidence that in some situations inhalation exposure is unlikely, such as for CNTs and CNFs during handling and transfer of liquid intermediaries and ready-to-use products, and high-quality evidence that dermal exposure does not occur during the reaction phase of synthesis for most MNMs.

There were no studies of ingestion exposure. However, established conceptual models imply that where dermal exposure occurs, ingestion exposure is likely.

\section{Implications for research}

There is a need to conduct more representative studies to better estimate workers' inhalation exposure by assessing MNMs at the personal breathing zone, rather than in the near-field. Studies that directly measure dermal and ingestion exposure of workers to MNMs are needed. For all routes of exposure more measurements are needed under real industrial production conditions. More research should be conducted to characterize exposures to nanomaterials in a broad range of industries where nanomaterials are used.

\section{Summary of findings: workplace exposures to MNMs}

Systematic review question: In workplaces where MNMs are in use according to the OECD list, does comprehensive measurement of exposure lead to confirmation of exposure to MNMs and if so during which tasks? Any study type in which exposure to MNMs was comprehensively measured was included.

\section{Evidence summary}

The systematic review was published by Debia et al. (2016) as a journal article (32). 


\section{Number of studies and participants}

Over the reviewed period (January 2000-January 2015), 50 studies in 72 workplaces with 306 exposure situations were eligible and included in the review. Studies were mainly located in the Republic of Korea and the United States, but none in LMI countries. Most studies (62.5\%) were in research laboratories or pilot plants.

\section{Exposures in the studies}

Exposures to carbonaceous and metallic nanomaterials and nanoclays were evaluated in the studies.

\section{Outcomes in studies}

Authors reported weight-based concentrations (mass concentration), count-based concentrations (number concentration) and off-line qualitative analysis.

\section{Risk of bias in the included studies}

The main limitations in the studies were that the exposure measurements were not real breathing zone sampling and not as comprehensive as would be advisable.

\section{Confirmed exposure}

Of the 306 exposure situations, there was confirmed exposure in $233(76 \%)$ ranging from $100 \%$ for nanoclays, $83 \%$ for carbonaceous MNMs and 73\% for metallic MNMs.

In 233 of the exposure situations, confirmed workers' exposure was mainly confined to microsized agglomerated MNMs with only a few studies reporting the sampling of nanoscale airborne MNMs.

Exposures to carbonaceous MNMs ranged from not detected to $910 \mu \mathrm{g} / \mathrm{m}^{3}$ of elemental carbon (EC) with local engineering controls and from not detected to $1000 \mu \mathrm{g} / \mathrm{m}^{3} \mathrm{EC}$ without controls.

Carbon nanofibre exposure ranged from not detected to $1.6 \mathrm{CNF}$ structures $/ \mathrm{cm}^{3}$ with local engineering controls and from $0.09 \mathrm{CNF}$ structures $/ \mathrm{cm}^{3}$ to $193 \mathrm{CNF}$ structures $/ \mathrm{cm}^{3}$ without controls.

Titanium dioxide nanoparticle exposure ranged from 0.24 to $0.43 \mu \mathrm{g} / \mathrm{m}^{3}$ with local engineering controls and from 0.09 to $33 \mu \mathrm{g} / \mathrm{m}^{3}$ without controls.

Aluminium oxide nanoparticle exposure was not detected with local engineering controls and ranged from not detected to $0.157 \mu \mathrm{g} / \mathrm{m}^{3}$ without controls.

Silver nanoparticle exposure ranged from 0.09 to $4.99 \mu \mathrm{g} / \mathrm{m}^{3}$ during dry synthesis with no controls (only general ventilation) and from 0.38 to $0.43 \mu \mathrm{g} / \mathrm{m}^{3}$ during wet synthesis (with fume hood). Reactor cleaning activities yielded the highest exposure, up to $33 \mu \mathrm{g} / \mathrm{m}^{3}$ (with local exhaust ventilation).

Iron nanoparticle exposure ranged from $32 \mu \mathrm{g} / \mathrm{m}^{3}$ with local engineering controls to $335 \mu \mathrm{g} / \mathrm{m}^{3}$ without controls.

In 231 of the exposure situations, workers were exposed to micro-sized agglomerated MNMs and in two of the exposure situations to nanoscale MNMs. 


\section{Quality of the evidence}

GRADE had to be considerably adapted to fit the type of studies reviewed. Consistent results in several studies with comprehensive measurements were considered high-quality evidence. The GDG judged that given the comprehensiveness of the measurements and the consistency of the results, there was overall high-quality evidence that workers are exposed to micro-sized agglomerated MNMs in workplaces during production and use of products. For the same reasons, the evidence for handling tasks was rated as high quality.

\section{Implementation guidance, research recommendation \\ Implications for practice}

The GDG concludes that there is high-quality evidence that workers are exposed to micro-sized agglomerated nanoparticles and that exposure occurs mostly during handling tasks, cleaning operations and machining of products. There was low-quality evidence of exposure to nanoscale primary airborne nanoparticles in workplaces. There were no studies, and therefore there was no evidence of exposures in LMI countries.

\section{Implications for research}

Longitudinal studies evaluating workers' exposure over time are needed. Studies of workers' exposure in LMl countries are also needed.

\subsubsection{Use controls to reduce the level of exposure}

Recommendation 9: The GDG recommends taking control measures based on the principle of hierarchy of controls, meaning that the first control measure should be to eliminate the source of exposure before implementing control measures that are more dependent on worker involvement, with PPE being used only as a last resort. According to this principle, engineering controls should be used when there is a high level of inhalation exposure or when there is no, or very little, toxicological information available. In the absence of appropriate engineering controls PPE should be used, especially respiratory protection, as part of a respiratory protection programme that includes fit-testing (STRONG, moderate-quality evidence).

Recommendation 10: The GDG suggests preventing dermal exposure by occupational hygiene measures such as surface cleaning and the use of appropriate gloves (CONDITIONAL, low-quality evidence).

Recommendation 11: When assessment and measurement by a workplace safety expert is not available, the GDG suggests using control banding for nanomaterials to select exposure control measures in the workplace. Owing to a lack of studies, the GDG cannot recommend one method of control banding over another (CONDITIONAL, very lowquality evidence). 
The GDG considered that in the absence of toxicological information on MNMs, the most stringent control measures should be applied to prevent workers from being exposed. This is also called a no-exposure policy.

Control banding is an approach to risk management for SMEs that can be applied to prevent worker exposures in cases of incomplete information about a nanomaterial. Control-banding strategies are often found in toolkits with categories, or bands, of health hazards, that are combined with exposure scenarios to determine the desired controls. This approach allows users to make meaningful inferences about likely exposures and to make decisions about necessary controls, reducing the exposures within four or five hazard bands (34).

When there is only limited toxicological information available for MNMs, or when analogies can be made with hazard properties of similar materials in broad groups, this should lead to control banding. When full toxicological information is available, this should lead to full risk assessment. The GDG therefore notes that control banding does not replace risk assessment, but it can still be beneficial for communication and better risk management.

\section{From evidence to recommendation}

\section{Evidence}

The evidence for these recommendations is based on two systematic reviews, both of which were published as journal articles. The first, by Myojo, Nagata \& Verbeek (2017), reviewed the effects of control measures (35). The other, by Eastlake, Zumwalde \& Geraci (2016), assessed the effects of the control-banding approach (36). For the control measures varying levels of evidence were found and therefore parts of the recommendation are conditional. Overall the risk of bias across studies was low but precision was unclear. For PPE the quality of the evidence was further downgraded because of indirectness, meaning that there were only laboratory studies and no field studies. For control banding there were only two studies, with a high risk of bias.

Control-banding tools such as those listed in the systematic review (36) can be used proactively as a low-cost intervention to reduce exposures to nanomaterials in the workplace.

\section{Benefits and harms}

There are clear benefits of preventing and decreasing exposure by engineering controls.

\section{Values and preferences}

The hierarchy of controls is a generally accepted concept in occupational hygiene, in which increased value is given to what are known as "more preventive" solutions (see Hierarchy of controls). Control banding is an approach that is well understood by employers and employees and seems feasible with bulk materials (37).

\section{Net benefits and costs}

The costs for full enclosure or process change can be considerable but decrease with the hierarchy of controls. The GDG attaches much weight to more preventive solutions. Control banding requires training but no considerable investments (38). 


\section{Strength of the recommendation}

Based on the above considerations, the GDG makes a strong recommendation for control measures for inhalation exposure but a conditional recommendation for full body protection to prevent dermal exposure and a conditional recommendation for control banding.

\section{Evidence summary of controls to reduce exposure to MNMs}

Systematic review question: In workers or workplaces with exposure to MNMs, what is the effect of workplace ventilation, PPE or organization of work aimed at reducing exposure, on the level of exposure to MNMs compared to no controls or protective equipment based on studies that compared a situation with the intervention to a situation without the intervention?

The effect of the controls was expressed as the protection factor (PF), which is defined as the ratio of exposure level (either mass-based or particle-based) without the controls divided by the exposure level with the controls. If the PF is $>1$ controls reduce exposure. A PF of 10 indicates that controls reduce exposure by $90 \%$.

\section{Evidence summary}

The systematic review by Myojo and Nagata (2017) was published as a journal article (35).

\section{Number of studies and participants}

There were 50 studies with 55 workplaces/participants. Of these studies, 27 were before-after comparisons.

\section{Controls evaluated in studies}

There were 14 studies with 27 workplaces that evaluated ventilation, 19 studies with 23 participants evaluated PPE, 16 studies evaluated other control strategies: five on suppression with fluids, two on automation of a process with five workplaces, eight on other organizational strategies, and one on the use of SDS. All studies were about MNM exposure and 15 of these were on exposure to carbon nanotubes.

\section{Outcomes in studies}

All outcomes were expressed as a PF.

\section{Risk of bias in the included studies}

The main limitations were no control group for the studies on engineering controls and no fieldwork for the respiratory protection studies. Risk of bias in the studies was 2 to 3 on a scale that ranged from -3 to 3 , in which -3 meant a very high risk of bias and +3 a very low risk of bias.

\section{Effects of exposure}

For engineering controls, enclosure achieved the highest PFs of $>100$ (seven cases).

For ventilation, PFs varied from 0.12 to 55 (20 cases) with 15 cases providing PFs $>3$. For ventilation of fume cupboards, the PF was influenced by the face velocity of the air and the movements of workers. Face velocity is the inward airflow velocity measured in several specific locations across the plane of the fume cupboard sash opening. 
For process automation, the PFs varied between 2.5 and 8.2 (five cases) but, owing to interruption of the process by handling material, one case yielded a PF of 0.073 . The studies on dustiness and fluid-dust suppression did not provide before-after measurements and did not allow for a PF calculation.

For respiratory protection, masks rated at the protection level of N95 respirators provided a PF of more than 10 in 11 cases. Higher rated P100 respirators provided higher PFs of around 100. One study evaluated a cloth mask which yielded a PF of 1.1 to 1.35 . One study reported on a loosefitting powered air-purifying respirator with PFs over 1.1 million. Most studies were performed in the laboratory under ideal conditions with exposure to sodium chloride as a proxy for MNM because of its size. However, it is unclear whether these results can be extrapolated to mask performance in real workplaces.

\section{Quality of the evidence}

Risk of bias in the studies was low. Except for the respiratory protection studies the evidence was direct. The results were consistent across studies. Precision of the effects was unclear because the authors did not provide estimates of statistical precision. Publication bias can be expected, but could not be assessed owing to a lack of data.

The rating of the evidence was defined as low quality at the outset because all studies were nonrandomized and non-controlled. The evidence was not upgraded or downgraded.

\section{Implementation guidance, research recommendation}

\section{Implications for practice}

The GDG concludes that there is only low-quality evidence that exposure to MNMs can be decreased with engineering controls such as enclosure and ventilation, when the specific exposure situations are taken into consideration. There is also only low-quality evidence that respiratory protection can considerably decrease exposure, if the proper type is used and fittesting is performed for each wearer.

\section{Implications for research}

Field studies that evaluate dust control techniques, such as modification and suppression are needed. In addition, studies on the effectiveness of respiratory protection under real workplace conditions are needed.

\section{Evidence summary: control banding for safe handling of manufactured nanomaterials}

Systematic review question: In workers or workplaces with potential exposure to MNM, what is the effect of the use of a control-banding tool on controls in place or level of exposure compared to no risk assessment tool or an alternative risk assessment tool based on any type of controlled study?

\section{Evidence summary}

The full review was published by Eastlake, Zumwalde \& Geraci (2016) as a journal article (36). 


\section{Number of studies and participants}

There were two studies that evaluated 32 different exposure situations. One study was conducted in two MNM research laboratories with exposure to metal and ceramic nanoparticles and CNTs in the United States. The other study reported an additional 27 cases of potential exposure to a variety of MNMs, but did not provide details of the geographical location or the worksite.

\section{Interventions in studies}

Both studies were about evaluating potential exposure to a variety of MNMs using the controlbanding nanotool developed by Paik, Zalk \& Swuste (38).

The use of the control-banding nanotool was compared to assessments performed by an experienced occupational hygienist.

\section{Outcomes in studies}

The outcome in both studies was the recommendation of an engineering control.

\section{Risk of bias in the included studies}

The main limitations were that there was only a qualitative analysis and no exposure measurements. One of the studies did not provide details of the work situations.

\section{Effects of exposure}

In the two studies, the recommendations provided using the control-banding nanotool concurred with those of the occupational hygienist in 59\% (19/32) of cases. The control-banding nanotool recommended a lower level of control than the occupational hygienist in 28\% (9/32) of cases. The control-banding nanotool recommended a higher level of control than the occupational hygienist in 13\% (4/32) of cases.

No exposure assessment data were provided to verify that engineering controls recommended by the occupational hygienist reduced exposure potential.

\section{Quality of the evidence}

According to GRADE, observational studies start as low-quality evidence, unless they can be upgraded. Based on the limitations of the studies (qualitative analysis, no exposure assessment data, no details about workplaces), the evidence found in this systematic review was downgraded to very low quality.

\section{Implementation guidance, research recommendation Implications for practice}

The GDG concludes that there is only very low-quality evidence that use of the control-banding nanotool leads to similar control measures to those an experienced occupational hygienist would recommend. Professionals, employers and workers would all need training to be able to use the tool.

\section{Implications for research}

The low quality of evidence on the effectiveness of control-banding approaches to reduce worker exposure to nanomaterials to safe levels, suggests that more research needs to be conducted 
in this area. Specifically, effectiveness of control banding to reduce exposures to MNMs should be evaluated by carrying out measurements selected through the use of control-banding tools (against more comprehensive risk assessment and risk management approaches). Controlbanding tools should be further evaluated for use with MNMs. Control-banding tools should be calibrated against exposure measurements and guidance for selection of the appropriate tool for specific situations should be developed.

\subsection{HEALTH SURVEILLANCE}

The GDG cannot make a recommendation for targeted MNM-specific health surveillance programmes over existing health surveillance programmes that are already in use, due to the lack of evidence.

The GDG further notes that existing occupational health surveillance systems could be implemented to monitor health outcomes possibly associated with MNM exposure where there are health concerns. Given that knowledge of MNMs and their adverse health effects is increasing rapidly, this recommendation should be updated in five years to take into account new findings.

\section{From evidence to recommendation}

\section{Evidence}

The evidence for this recommendation is based on a small number of non-randomized studies at high risk of bias that did not show the benefits of health examinations.

\section{Benefits and harms}

The benefits of health examinations could not be assessed. Setting up a health surveillance system for workers exposed to MNMs would be costly. In addition, it would be difficult, with the current lack of knowledge, to ascribe adverse health effects to MNM exposure.

\section{Values and preferences}

It is well known that general health examinations are highly valued by consumers and this is probably also the case for workers (39).

\section{Net benefits and costs}

Since the GDG could not assess any benefits of health examinations that are specific for MNMs, only considerable costs remain.

\section{Strength of the recommendation}

Based on the above considerations, there is no recommendation for specific health examinations.

\section{Summary of findings: health examinations of workers exposed to MNMs}

Systematic review question: In workers exposed to MNMs, what is the effect of health surveillance on any adverse health outcome compared to no health surveillance or an alternative form of health surveillance based on any study that described or evaluated health surveillance?

The systematic review was published by Gulumian et al. (2016) as a journal article (40). 


\section{Number of studies and participants}

There were seven studies of which six compared health indicators between exposed and unexposed workers, with 1278 participants. One study described a programme, but did not report any health outcomes. Studies showed that workers were exposed to a mixture of MNMs (3), CNTs (2), nanosilver (1) and $\mathrm{TiO}_{2}(1)$.

\section{Health examinations in studies}

Studies reported on biomarkers from exhaled breath condensate, blood and urine such as markers of oxidative stress and antioxidant enzymes; early health effects such as pulmonary and neurobehavioural test results; and self-reported health outcomes.

\section{Risk of bias in the included studies}

The main limitations were that there were no controlled studies with a longitudinal design; all of them were cross-sectional.

\section{Effects of exposure}

Two studies found biomarker levels (exhaled breath condensate concentrations of malondialdehyde, 4-hydroxy hexenal (4-HHE) and n-hexanal/aldehyde) elevated in exposed groups compared to unexposed groups.

Early health indicators (lung function parameters) did not deviate from physiologically normal parameters or did not differ between groups.

The prevalence of allergic dermatitis and sneezing was higher among workers exposed to MNMs in one study.

\section{Quality of the evidence}

According to GRADE, observational studies start as low-quality evidence unless they can be upgraded. The evidence found in this systematic review was further downgraded because of limitations in study design. There were no reasons to upgrade the evidence.

\section{Implementation guidance, research recommendation \\ Implications for practice}

The GDG concludes that there is only very low-quality evidence on whether targeted nanomaterial health surveillance might reveal early signs of adverse health effects. There was no evidence on specific items that should be included in a surveillance programme.

\section{Implications for research}

More research needs to be conducted to (i) identify biomarkers specific to nanomaterial exposures; (ii) identify potential early signs predicting potential long-term adverse health effects, and (iii) validate current medical tests for use in asymptomatic nanomaterial-exposed workers. It is important to emphasize to workers participating in health surveillance that these programmes at this point are research efforts with unproven benefit and health significance to participants.

Exposure registry studies, based on which workers can be followed over time to validate candidate biomarkers, are needed. 


\title{
6.5. TRAINING AND INVOLVEMENT OF WORKERS
}

\author{
The GDG considers training of workers and worker involvement in health and \\ safety issues to be best practice, but cannot recommend one form of training \\ of workers over another, or one form of worker involvement over another, \\ owing to the lack of studies available.
}

The GDG commissioned a systematic review to answer the question "what training should be provided to workers?". The question was reformulated to look at the effects of additional training and education on workers potentially exposed to MNMs. The systematic review by von Mering \& Schumacher (2017) was published by WHO (41). The GDG also conducted preliminary searches to answer the question about worker participation in the workplace risk assessment and management of MNMs. However, no studies were found on this topic.

\section{Summary of findings: training and involvement of workers}

Systematic review question: In workers exposed to MNMs, does specific training or education on safe handling of MNMs have an effect on the level of exposure to MNMs or on the level of controls (including PPE) implemented compared to no training, or an alternative form of training?

\section{Evidence summary}

The systematic review did not locate any studies on the effects of worker training. There were no studies that established specific workers' training needs related to MNMs.

\section{Research recommendation \\ Implications for research}

The GDG recommends evaluating the effect of worker and employer training on the level of MNM exposure and the installation of controls compared to alternative forms of training, preferably with a controlled before-after design. Similarly, the GDG recommends evaluating the effect of different forms of worker involvement on level of exposure and implementation of controls. 


\section{IMPLEMENTATION OF THE GUIDELINES}

Given the current high exposures to MNMs documented in the exposure review, considerable efforts are needed by all stakeholders to ensure country implementation of these guidelines with a particular focus on LMI countries.

WHO will officially launch these guidelines with its partners from the Collaborating Centres for Occupational Health and nongovernmental organizations in official relations with WHO, in addition to presenting the guidelines for further distribution at diverse forums.

With regard to a corporate launch, discussions will be held internally with the Director Public Health, Environmental and Social Determinants of Health, Department of Communication and the WHO regions to devise a communications plan. This can be achieved through stakeholder networks including those of GDG members and the WHO Global Network of Collaborating Centres.

In addition to this document, simplified summaries will be prepared for employers and workers to ease implementation and monitoring. 


\section{UPDATING THE GUIDELINES}

The field of MNM safety is evolving rapidly. A research agenda set by Stone et al. in collaboration with stakeholders in 2014, foresaw considerable progress in validated measurement methods and the assessment of routes of exposure and monitoring strategies in the short term (42). Therefore the GDG proposes to update these guidelines in 2022. 


\section{REFERENCES}

1. Honnert B, Grzebyk M. Manufactured nano-objects: an occupational survey in five industries in France. Ann Occup Hyg. 2014;58:121-35. doi: 10.1093/annhyg/met058.

2. Types and uses of nanomaterials, including safety aspects. Commission Staff Working Paper. Brussels: European Commission; 2012

3. Arduin R. Brazilian scenario - sustainable nanotechnology. Venice: Sustainable Nanotechnology Organization; 2015

4. Air quality guidelines for Europe, 2nd edition. Bonn:World Health Organization; 2000.

5. Air quality guidelines: global update 2005. Copenhagen:WHO Regional Office for Europe; 2006.

6. Brown BB. Delphi process: a methodology used for the elicitation of opinions of experts. Santa Monica (CA): Rand Corp; 1968.

7. WHO handbook for guideline development, 2nd edition. Geneva: World Health Organization; 2014.

8. Guyatt GH, Oxman AD, Vist GE, Kunz R, Falck-Ytter Y, Alonso-Coello P et al. GRADE: an emerging consensus on rating quality of evidence and strength of recommendations. BMJ. 2008;336:924-6. doi: 10.1136/bmj.39489.470347.AD.

9. Iorio A, Spencer FA, Falavigna M, Alba C, Lang E, Burnand B et al. Use of GRADE for assessment of evidence about prognosis: rating confidence in estimates of event rates in broad categories of patients. BMJ. 2015;350:h870. doi: 10.1136/bmj.h870.

10. Lewin S, Glenton C, Munthe-Kaas H, Carlsen B, Colvin CJ, Gülmezoglu M et al. Using qualitative evidence in decision making for health and social interventions: an approach to assess confidence in findings from qualitative evidence syntheses (GRADE-CERQual). PLoS Med. 2015;12:e1001895. doi: 0.1371/journal.pmed.1001895.

11. IUF (International Union of Food, Agricultural, Hotel, Restaurant, Catering, Tobacco and Allied Workers' Associations). Small particles, big risks: IUF, international NGOs release recommendation on the use of nanotech in foods. 12 March 2015 (http://www.iuf.org/w/?q=node/4073, accessed 15 May 2017).

12. European Trade Union Confederation (ETUC). 2nd resolution on nanotechnologies and nanomaterials; 2010 (https://www.etuc.org/documents/etuc-2nd-resolution-nanotechnologies-and-nanomaterials\#. WZrnez4jG70, accessed 30 May 2016).

13. Canadian Union of Public Employees. Fact sheet: Nanomaterials; 2016 (https://cupe.ca/fact-sheetnanomaterials, accessed 15 May 2017).

14. Australian Council of Trade Unions. Fact sheet; 2009 (http://www.actu.org.au/media/149927/actu_ factsheet_ohs_-nanotech_090409.pdf, accessed 15 May 2017).

15. Hau M, Cole D, Vanderlinden L, MacFarlane R, Mee C, Archbold J et al. Development of a guide to applying precaution in local public health. Int J Occup Environ Health. 2014;20:174-84. doi: 10.1179/2049396713Y.0000000051.

16. Nel AE, Nasser E, Godwin $H$, Avery D, Bahadori T, Bergeson L et al. A multi-stakeholder perspective on the use of alternative test strategies for nanomaterial safety assessment. ACS Nano 2013;7:6422-33. doi: $10.1021 / \mathrm{nn} 4037927$.

17. The National Institute for Occupational Safety and Health (NIOSH). Hierarchy of controls (http//www. cdc.gov/niosh/topics/hierarchy/default.html, accessed 15 May 2017). 
18. Ellenbecker MJ. Engineering controls as an intervention to reduce worker exposure. Am J Ind Med. 1996:29:303-7. doi: 10.1002/(SICI) 1097-0274(199604)29:4<303::AID-AJIM5>3.0.CO;2-P.

19. Gebel T, Foth H, Damm G, Freyberger A, Kramer PJ, Lilienblum W et al. Manufactured nanomaterials: categorization and approaches to hazard assessment. Arch Toxicol. 2014;88:2191-211. doi: 10.1007/ s00204-014-1383-7.

20. The WHO/EURO man-made mineral fiber reference scheme. By the WHO/EURO Technical Committee for Monitoring and Evaluating MMMF. Scand J Work Environ Health. 1985;11:123-9.

21. Nagai H, Okazaki Y, Chew SH, Misawa N, Yamashita Y, Akatsuka S et al. Diameter and rigidity of multiwalled carbon nanotubes are critical factors in mesothelial injury and carcinogenesis. Proc Natl Acad Sci U S A. 2011;108:E1330-8. doi: 10.1073/pnas.1110013108.

22. Landvik N, Mohr B, Verbeek J, Skaug V, Zienolddiny S. Criteria for grouping of manufactured nanomaterials to facilitate hazard and risk assessment, a systematic review of expert opinions. Regulatory Toxicology and Pharmacology; 2017. Submitted.

23. Working safely with manufactured nanomaterials, guidance for workers. Luxembourg: European Commission; 2014.

24. Kulinowski K, Lippy B. Training workers on risks of nanotechnology. Washington (DC): US Department of Health and Human Services/National Institutes of Health, National Institute of Environmental Health Sciences; 2011.

25. Health and safety training: a brief guide (INDG345). London: Health and Safety Executive (HSE); 2012 (http://www.hse.gov.uk/pubns/indg345.htm, accessed 12 September 2017).

26. Lee N, Lim CH, Kim T, Son EK, Chung GS, Rho CJ et al. Which hazard category should specific nanomaterials or groups of nanomaterials be assigned to and how? Geneva: World Health Organization; 2017. Licence: CC BY-NC-SA 3.0 IGO.

27. Deveau M, Chen CP, Johanson G, Krewski D, Maier A, Niven KJ et al. The global landscape of occupational exposure limits - implementation of harmonization principles to guide limit selection. J Occup Environ Hyg. 2015;12 Suppl 1:S127-44. doi: 10.1080/15459624.2015.1060327.

28. Environment Directorate Joint Meeting of the Chemicals Committee and the Working Party on Chemicals, Pesticides and Biotechnology. Harmonized tiered approach to measure and assess the potential exposure to airborne emissions of engineered nano-objects and their agglomerates and aggregates at workplaces. Series on the Safety of Manufactured Nanomaterials, No. 55 (http://www.oecd. org/officialdocuments/publicdisplaydocumentpdf/?cote=env/jm/mono(2015)19\&doclanguage=en, accessed 15 May 2017).

29. Mihalache R, Verbeek J, Graczyk H, Murashov V, van Broekhuizen P. Occupational exposure limits for manufactured nanomaterials, a systematic review. Nanotoxicology. 2017;11:7-19. doi: 10.1080/17435390.2016.1262920.

30. Boccuni F, Gagliardi D, Ferrante R, Rondinone BM, lavicoli S. Measurement techniques of exposure to nanomaterials in the workplace for low- and medium-income countries: A systematic review. Int J Hyg Environ Health. 2017;220:1089-97. doi: 10.1016/j.jjheh.2017.06.003.

31. Basinas I, Sánchez Jiménez A, Galea K, van Tongeren M, Hurley F. A systematic review of the routes and forms of exposure to engineered nanomaterials. Ann Work Exposure Health; 2017. Submitted.

32. Debia M, Bakhiyi B, Ostiguy C, Verbeek JH, Brouwer DH, Murashov V. A systematic review of reported exposure to engineered nanomaterials. Ann Occup Hyg. 2016;60:916-35. doi: 10.1093/annhyg/ mew041.

33. Workplace exposure - assessment of inhalation exposure to nano-objects and their agglomerates and aggregates (BS EN 17058). London: British Standards Institution; 2016. 
34. Zalk DM, Heussen GH. Banding the world together; the global growth of control banding and qualitative occupational risk management. Saf Health Work. 201 1;2:375-9. doi: 10.5491/SHAW.2011.2.4.375.

35. Myojo T, Nagata T, Verbeek J. The effectiveness of specific risk mitigation techniques used in the production and handling of manufactured nanomaterials: a systematic review. J UOEH. 2017;39:18799. (https:/www.jstage.jst.go.jp/article/juoeh/39/3/39_187/_pdf, accessed 16 September 2017).

36. Eastlake A, Zumwalde R, Geraci C. Can control banding be useful for the safe handling of nanomaterials? A systematic review. J Nanoparticle Res. 2016;1 8:169. doi: 10.1007/s11051-016-3476-0.

37. Bracker AL, Morse TF, Simcox NJ. Training health and safety committees to use control banding: lessons learned and opportunities for the United States. J Occup Environ Hyg. 2009;6:307-14. doi: 10.1080/15459620902810083.

38. Paik SY, Zalk DM, Swuste P. Application of a pilot control banding tool for risk level assessment and control of nanoparticle exposures. Ann Occup Hyg. 2008;52:419-28. doi: 10.1093/annhyg/men041.

39. Oboler SK, Prochazka AV, Gonzales R, Xu S, Anderson RJ. Public expectations and attitudes for annual physical examinations and testing. Ann Intern Med. 2002;136:652-9.

40. Gulumian M, Verbeek J, Andraos C, Sanabria N, de Jager P. Systematic review of screening and surveillance programs to protect workers from nanomaterials. PLoS One. 2016;11:e0166071. doi: 10.1371/journal.pone.0166071.

41. von Mering $Y$, Schumacher $C$. What training should be provided to workers who are at risk from exposure to the specific nanomaterials or groups of nanomaterials? Geneva: World Health Organization; 2017. Licence: CC BY-NC-SA 3.0 IGO.

42. Stone V, Pozzi-Mucelli S, Tran L, Aschberger K, Sabella S, Vogel U et al. ITS-NANO - prioritising nanosafety research to develop a stakeholder driven intelligent testing strategy. Part Fibre Toxicol. 2014;11:9. doi: 10.1186/1743-8977-11-9. 


\section{ANNEX 1:}

\section{LIST OF PROPOSED OCCUPATIONAL}

EXPOSURE LIMIT COEL]

VALUES FOR MNMS

TABLE A.1.1 OCCUPATIONAL EXPOSURE LIMIT VALUES AS PROPOSED FOR MNMS

\begin{tabular}{|c|c|c|c|c|c|c|c|}
\hline Category & $\begin{array}{l}\text { Study } \\
\text { reference }\end{array}$ & $\begin{array}{l}\text { Nanomaterials } \\
\text { and } \\
\text { specifications }\end{array}$ & OEL name & $\begin{array}{c}\text { Mass } \\
\text { concentration } \\
\mu \mathrm{g} / \mathrm{m}^{3}\end{array}$ & $\begin{array}{c}\text { Particle } \\
\text { concentration } \\
\text { (particle/ml, } \\
\text { fibres } / \mathrm{cm}^{3} \text { ) }\end{array}$ & $\begin{array}{c}\text { Surface } \\
\text { concentration } \\
\left(\mathrm{nm}^{2} / \mathrm{cm}^{3}\right)\end{array}$ & $\begin{array}{l}\text { Derivation } \\
\text { approach }\end{array}$ \\
\hline \multicolumn{8}{|c|}{ Inhalation exposure: general MNM approach } \\
\hline MNM & $\begin{array}{l}\text { Guidotti } \\
2010\end{array}$ & $\begin{array}{l}\text { Fine particulate } \\
\text { matter } \leq 2500 \mathrm{~nm}\end{array}$ & BOEL & 30 & ND & ND & Environmental \\
\hline MNM & $\begin{array}{c}\text { McGarry } \\
2013\end{array}$ & $\begin{array}{c}\text { Airborne } \\
\text { particles from } \\
\text { nanotechnology } \\
\text { processes }\end{array}$ & $\mathrm{PCV}$ & ND & $\begin{array}{l}3 \text { times LBPC } \\
\text { for more than } \\
30 \text { minutes }\end{array}$ & ND & Environmental \\
\hline \multicolumn{8}{|c|}{ Inhalation exposure: categorical MNM approach } \\
\hline CMAR & BSI 2007 & $\begin{array}{c}\text { CMAR } \\
\text { nanomaterials, } \\
\text { NM }\end{array}$ & BEL & $0.1 \times$ bulk WEL & ND & ND & Bridging \\
\hline Fibres & AGS 2013 & $\begin{array}{l}\text { Non-entangled } \\
\text { fibrous NM }\end{array}$ & $\begin{array}{c}\text { Acceptance } \\
\text { level } \\
\text { (default), } \\
\text { respirable } \\
\text { fraction }\end{array}$ & ND & 0.01 & ND & $\begin{array}{l}\text { Bridging/ } \\
\text { grouping }\end{array}$ \\
\hline Fibres & BSI 2007 & Fibrous NM & BEL & ND & 0.01 & ND & $\begin{array}{l}\text { Bridging/ } \\
\text { grouping }\end{array}$ \\
\hline Fibres & $\begin{array}{l}\text { Stockmann- } \\
\text { Juvala } 2014\end{array}$ & $\begin{array}{c}\text { Carbon } \\
\text { nanofibres, CNFs }\end{array}$ & OEL & ND & 0.01 & ND & $\begin{array}{l}\text { Bridging/ } \\
\text { grouping }\end{array}$ \\
\hline Fibres & $\begin{array}{c}\text { van } \\
\text { Broekhuizen } \\
2012\end{array}$ & $\begin{array}{c}\text { Carbon } \\
\text { nanotubes, CNTs, } \\
\text { insoluble NM } \\
\text { with high aspect } \\
\text { ratio }>3: 1\end{array}$ & NRV & ND & 0.01 & ND & $\begin{array}{l}\text { Bridging/ } \\
\text { grouping }\end{array}$ \\
\hline
\end{tabular}




\begin{tabular}{|c|c|c|c|c|c|c|c|}
\hline Category & $\begin{array}{l}\text { Study } \\
\text { reference }\end{array}$ & $\begin{array}{l}\text { Nanomaterials } \\
\text { and } \\
\text { specifications }\end{array}$ & OEL name & $\begin{array}{c}\text { Mass } \\
\text { concentration } \\
\mu \mathrm{g} / \mathrm{m}^{3}\end{array}$ & $\begin{array}{c}\text { Particle } \\
\text { concentration } \\
\text { (particle/ml, } \\
\text { fibres } / \mathrm{cm}^{3} \text { ) }\end{array}$ & $\begin{array}{c}\text { Surface } \\
\text { concentration } \\
\left(\mathrm{nm}^{2} / \mathrm{cm}^{3}\right)\end{array}$ & $\begin{array}{l}\text { Derivation } \\
\text { approach }\end{array}$ \\
\hline \multicolumn{8}{|c|}{ Inhalation exposure: categorical MNM approach } \\
\hline GBP & AGS 2013 & $\begin{array}{l}\text { In operations } \\
\text { with NM: } \\
\text { nanosized GBP } \\
\text { with no specific } \\
\text { toxicity }\end{array}$ & $\begin{array}{l}\text { OEL } \\
\text { respirable } \\
\text { fraction, } \\
\text { default }\end{array}$ & 500 & ND & ND & Grouping \\
\hline GBP & AGS 2013 & $\begin{array}{l}\text { No specific } \\
\text { operations with } \\
\text { NM: G }\end{array}$ & $\begin{array}{l}\text { OEL } \\
\text { respirable } \\
\text { fraction }\end{array}$ & 1250 & ND & ND & Grouping \\
\hline GBP & BSI 2007 & $\begin{array}{c}\text { Insoluble } \\
\text { nanomaterials }\end{array}$ & BEL & $\begin{array}{c}0.066 \times \text { bulk } \\
\text { WEL }\end{array}$ & 20000 & ND & Bridging \\
\hline GBP & $\begin{array}{l}\text { Pauluhn } \\
2011\end{array}$ & $\begin{array}{l}\text { Inhaled poorly } \\
\text { soluble particles }\end{array}$ & DNEL & $\begin{array}{c}0.5 \mu \mathrm{IPM} \\
\text { respirable } / \mathrm{m}^{3} \\
\times \text { agglomerate } \\
\text { density }\end{array}$ & ND & ND & $\begin{array}{l}\text { Categorical } \\
\text { QRA/grouping }\end{array}$ \\
\hline GBP & $\begin{array}{c}\text { van } \\
\text { Broekhuizen } \\
2012\end{array}$ & $\begin{array}{l}\text { Metals and } \\
\text { metal oxides, } \\
\text { biopersistent } \\
\text { granular NM } \\
>6000 \mathrm{~kg} / \mathrm{m}^{3}\end{array}$ & NRV & ND & 20000 & ND & Grouping \\
\hline GBP & $\begin{array}{l}\text { van } \\
\text { Broekhuizen } \\
2012\end{array}$ & $\begin{array}{l}\text { Metals and } \\
\text { metal oxides, } \\
\text { biopersistent } \\
\text { granular NM } \\
<6000 \mathrm{~kg} / \mathrm{m}^{3}\end{array}$ & NRV & ND & 40000 & ND & Grouping \\
\hline $\begin{array}{l}\text { Low-toxicity } \\
\text { dust }\end{array}$ & $\begin{array}{l}\text { Stockmann- } \\
\text { Juvala } 2014\end{array}$ & & OEL & $\begin{array}{l}300 \text { (respirable } \\
\text { fraction), } \\
4000 \text { (inhalable } \\
\text { fraction) }\end{array}$ & ND & ND & $\begin{array}{l}\text { Bridging/ } \\
\text { grouping }\end{array}$ \\
\hline $\begin{array}{l}\text { Non- } \\
\text { biopersistent }\end{array}$ & $\begin{array}{l}\text { van } \\
\text { Broekhuizen } \\
2012\end{array}$ & $\begin{array}{c}\text { Non- } \\
\text { biopersistent } \\
\text { granular NM } \\
1-100 \mathrm{~nm}\end{array}$ & NRV & $\begin{array}{c}\text { Applicable OEL, } \\
\text { WEL }\end{array}$ & ND & ND & Bridging \\
\hline Soluble & BSI 2007 & $\begin{array}{c}\text { Soluble } \\
\text { nanomaterials }\end{array}$ & BEL & $0.5 \times$ bulk WEL & ND & ND & Bridging \\
\hline \multicolumn{8}{|c|}{ Inhalation exposure: specific MNM approach } \\
\hline Carbon & $\begin{array}{c}\text { Aschberger } \\
2011\end{array}$ & $\begin{array}{l}\text { Multi-walled } \\
\text { carbon } \\
\text { nanotubes, } \\
\text { MWCNT } 10 \mathrm{~nm}\end{array}$ & INEL & 1 & ND & ND & QRA \\
\hline Carbon & $\begin{array}{c}\text { Aschberger } \\
2011\end{array}$ & MWCNT $140 \mathrm{~nm}$ & INEL & 2 & ND & ND & QRA \\
\hline Carbon & Luizi 2009 & $\begin{array}{c}\text { Carbon } \\
\text { nanotubes, CNTs }\end{array}$ & $\begin{array}{l}\text { No effect } \\
\text { concentra- } \\
\text { tion in air }\end{array}$ & 2.5 & ND & ND & QRA \\
\hline
\end{tabular}

72 WHO GUIDELINES ON PROTECTING WORKERS FROM POTENTIAL RISKS OF MANUFACTURED NANOMATERIALS 


\begin{tabular}{|c|c|c|c|c|c|c|c|}
\hline Category & $\begin{array}{l}\text { Study } \\
\text { reference }\end{array}$ & $\begin{array}{l}\text { Nanomaterials } \\
\text { and } \\
\text { specifications }\end{array}$ & OEL name & $\begin{array}{c}\text { Mass } \\
\text { concentration } \\
\mu \mathrm{g} / \mathrm{m}^{3}\end{array}$ & $\begin{array}{c}\text { Particle } \\
\text { concentration } \\
\text { (particle/ml, } \\
\text { fibres } / \mathrm{cm}^{3} \text { ) }\end{array}$ & $\begin{array}{c}\text { Surface } \\
\text { concentration } \\
\left(\mathrm{nm}^{2} / \mathrm{cm}^{3}\right)\end{array}$ & $\begin{array}{l}\text { Derivation } \\
\text { approach }\end{array}$ \\
\hline \multicolumn{8}{|c|}{ Inhalation exposure: specific MNM approach } \\
\hline Carbon & $\begin{array}{c}\text { Nakanishi } \\
2015\end{array}$ & $\begin{array}{l}\text { Carbon nanotube } \\
\text { group, SWCNT, } \\
\text { DWCNT, MWCNT }\end{array}$ & OEL 15 years & 30 & ND & ND & QRA \\
\hline Carbon & NIOSH 2013 & $\begin{array}{c}\text { All CNTs and } \\
\text { nanofibres }\end{array}$ & $\begin{array}{l}\text { REL } \\
\text { respirable } \\
\text { elemental } \\
\text { carbon }\end{array}$ & $<1$ & ND & ND & QRA \\
\hline Carbon & $\begin{array}{l}\text { Pauluhn } \\
2010\end{array}$ & $\begin{array}{l}\text { MWCNT } \\
\text { Baytubes }^{\circ}\end{array}$ & $\begin{array}{c}\text { OEL, } \\
\text { inhalable } \\
\text { fraction }\end{array}$ & 50 & ND & ND & QRA \\
\hline Carbon & Stone 2009 & MWCNT & $\begin{array}{l}\text { DNEL chronic } \\
\text { inhalation, } \\
\text { systemic } \\
\text { immune } \\
\text { effect }\end{array}$ & 0.67 & ND & ND & QRA \\
\hline Carbon & $\begin{array}{l}\text { Kuempel } \\
2006\end{array}$ & $\begin{array}{l}\text { Carbon black, } \\
\text { CB ultrafine }\end{array}$ & $\begin{array}{l}\text { BMDL } \\
45 \text { years } \\
\text { (lung } \\
\text { dosimetry, } \\
\text { model 1) }\end{array}$ & 120 & ND & ND & QRA \\
\hline Carbon & $\begin{array}{l}\text { Kuempel } \\
2006\end{array}$ & $\begin{array}{l}\text { Carbon black, } \\
\text { CB ultrafine }\end{array}$ & $\begin{array}{l}\text { BMDL } \\
45 \text { years } \\
\text { (lung } \\
\text { dosimetry, } \\
\text { model 2) }\end{array}$ & 240 & ND & ND & QRA \\
\hline Carbon & $\begin{array}{c}\text { Aschberger } \\
2011\end{array}$ & Fullerenes, C60 & INEL & 7.4 & ND & ND & QRA \\
\hline Carbon & $\begin{array}{c}\text { Shinohara } \\
2011\end{array}$ & Fullerenes, C60 & $\begin{array}{l}\text { OEL }(P L) \\
15 \text { years }\end{array}$ & 390 & ND & ND & QRA \\
\hline Nanocellulose & $\begin{array}{l}\text { Stockmann- } \\
\text { Juvala } 2014\end{array}$ & Nanocellulose & OEL & ND & 0.01 & ND & Bridging \\
\hline Nanoclays & $\begin{array}{l}\text { Stockmann- } \\
\text { Juvala } 2014\end{array}$ & Nanoclays & OEL & $\begin{array}{c}300 \\
\text { (respirable } \\
\text { fraction), } \\
4000 \\
\text { (inhalable } \\
\text { fraction) }\end{array}$ & ND & ND & $\begin{array}{l}\text { Bridging/ } \\
\text { grouping }\end{array}$ \\
\hline Nanosilver & $\begin{array}{c}\text { Aschberger } \\
2011\end{array}$ & Nano Ag & $\begin{array}{l}\text { INEL lung } \\
\text { function }\end{array}$ & 0.33 & ND & ND & QRA \\
\hline Nanosilver & $\begin{array}{c}\text { Aschberger } \\
2011\end{array}$ & Nano Ag & $\begin{array}{l}\text { INEL lung } \\
\text { other effects }\end{array}$ & 0.67 & ND & ND & QRA \\
\hline
\end{tabular}




\begin{tabular}{|c|c|c|c|c|c|c|c|}
\hline Category & $\begin{array}{l}\text { Study } \\
\text { reference }\end{array}$ & $\begin{array}{l}\text { Nanomaterials } \\
\text { and } \\
\text { specifications }\end{array}$ & OEL name & $\begin{array}{c}\text { Mass } \\
\text { concentration } \\
\mu \mathrm{g} / \mathrm{m}^{3}\end{array}$ & $\begin{array}{c}\text { Particle } \\
\text { concentration } \\
\text { (particle/ml, } \\
\text { fibres } / \mathrm{cm}^{3} \text { ) }\end{array}$ & $\begin{array}{c}\text { Surface } \\
\text { concentration } \\
\left(\mathrm{nm}^{2} / \mathrm{cm}^{3}\right)\end{array}$ & $\begin{array}{l}\text { Derivation } \\
\text { approach }\end{array}$ \\
\hline \multicolumn{8}{|c|}{ Inhalation exposure: specific MNM approach } \\
\hline Nanosilver & Stone 2009 & Nano Ag & $\begin{array}{l}\text { DNEL lung } \\
\text { exposure, } \\
\text { extrapolating } \\
\text { factor } 10\end{array}$ & 0.098 & 1200 & $2.2 \times 106$ & QRA \\
\hline Nanosilver & Stone 2009 & Nano Ag & $\begin{array}{l}\text { DNEL lung } \\
\text { exposure, } \\
\text { extrapolating } \\
\text { factor } 3\end{array}$ & 0.33 & 4000 & $7.2 \times 106$ & QRA \\
\hline Nanosilver & Stone 2009 & Nano Ag & $\begin{array}{l}\text { DNEL liver } \\
\text { effect }\end{array}$ & 0.67 & 7000 & $1.2 \times 107$ & QRA \\
\hline Nanosilver & $\begin{array}{l}\text { Swidwinska } \\
2015\end{array}$ & Nano Ag & $\begin{array}{l}\text { MAC-TWA } \\
\text { inhalable } \\
\text { fraction }\end{array}$ & 10 & ND & ND & QRA \\
\hline $\begin{array}{l}\text { Silicon } \\
\text { dioxide }\end{array}$ & $\begin{array}{l}\text { Stockmann- } \\
\text { Juvala } 2014\end{array}$ & $\begin{array}{l}\text { Amorphous silica, } \\
\qquad \mathrm{SiO}_{2}\end{array}$ & $\begin{array}{l}\text { OEL } \\
\text { respirable } \\
\text { fraction }\end{array}$ & 300 & ND & ND & QRA \\
\hline $\begin{array}{l}\text { Titanium } \\
\text { dioxide }\end{array}$ & $\begin{array}{c}\text { Aschberger } \\
2011\end{array}$ & $\mathrm{TiO}_{2}$ & INEL & 17 & ND & ND & QRA \\
\hline $\begin{array}{l}\text { Titanium } \\
\text { dioxide }\end{array}$ & $\begin{array}{l}\text { Kuempel } \\
2006\end{array}$ & $\begin{array}{c}\mathrm{TiO}_{2} \\
\text { ultrafine }\end{array}$ & $\begin{array}{l}\text { BMDL } \\
45 \text { years } \\
\text { (lung } \\
\text { dosimetry, } \\
\text { model 1) }\end{array}$ & 73 & ND & ND & QRA \\
\hline $\begin{array}{l}\text { Titanium } \\
\text { dioxide }\end{array}$ & $\begin{array}{l}\text { Kuempel } \\
2006\end{array}$ & $\begin{array}{l}\mathrm{TiO}_{2} \\
\text { ultrafine }\end{array}$ & $\begin{array}{l}\text { BMDL } \\
45 \text { years } \\
\text { (lung } \\
\text { dosimetry, } \\
\text { model 2) }\end{array}$ & 140 & ND & ND & QRA \\
\hline $\begin{array}{l}\text { Titanium } \\
\text { dioxide }\end{array}$ & NIOSH 2011 & $\begin{array}{c}\mathrm{TiO}_{2} \\
\text { ultrafine }\end{array}$ & $\begin{array}{l}\text { REL (up to } \\
10 \mathrm{~h} / \text { day, } \\
40 \mathrm{~h} / \text { week) }\end{array}$ & 300 & ND & ND & QRA \\
\hline $\begin{array}{l}\text { Titanium } \\
\text { dioxide }\end{array}$ & Ogura 2011 & $\mathrm{TiO}_{2}$ & $\begin{array}{l}\text { OEL }(P L) \\
15 \text { years }\end{array}$ & 610 & ND & ND & QRA \\
\hline $\begin{array}{l}\text { Titanium } \\
\text { dioxide }\end{array}$ & $\begin{array}{l}\text { Stockmann- } \\
\text { Juvala } 2014\end{array}$ & $\mathrm{TiO}_{2}$ & $\begin{array}{l}\text { OEL } \\
\text { respirable } \\
\text { fraction }\end{array}$ & 100 & ND & ND & QRA \\
\hline $\begin{array}{l}\text { Titanium } \\
\text { dioxide }\end{array}$ & $\begin{array}{l}\text { Swidwinska } \\
2014\end{array}$ & $\mathrm{TiO}_{2}$ & MAC & 300 & ND & ND & QRA \\
\hline $\begin{array}{l}\text { Titanium } \\
\text { dioxide }\end{array}$ & Warheit 2013 & $\begin{array}{l}\text { High surface } \\
\text { reactivity } \\
\text { anatase-rutile } \\
\text { nanoscale } \mathrm{TiO}_{2}\end{array}$ & OEL & 1000 & ND & ND & QRA \\
\hline
\end{tabular}

74 WHO GUIDELINES ON PROTECTING WORKERS FROM POTENTIAL RISKS OF MANUFACTURED NANOMATERIALS 


\begin{tabular}{|c|c|c|c|c|c|c|c|}
\hline Category & $\begin{array}{l}\text { Study } \\
\text { reference }\end{array}$ & $\begin{array}{l}\text { Nanomaterials } \\
\text { and } \\
\text { specifications }\end{array}$ & OEL name & $\begin{array}{c}\text { Mass } \\
\text { concentration } \\
\mu \mathrm{g} / \mathrm{m}^{3}\end{array}$ & $\begin{array}{c}\text { Particle } \\
\text { concentration } \\
\text { (particle/ml, } \\
\text { fibres } / \mathrm{cm}^{3} \text { ) }\end{array}$ & $\begin{array}{c}\text { Surface } \\
\text { concentration } \\
\left(\mathrm{nm}^{2} / \mathrm{cm}^{3}\right)\end{array}$ & $\begin{array}{l}\text { Derivation } \\
\text { approach }\end{array}$ \\
\hline \multicolumn{8}{|c|}{ Inhalation exposure: specific MNM approach } \\
\hline $\begin{array}{l}\text { Titanium } \\
\text { dioxide }\end{array}$ & Warheit 2013 & $\begin{array}{c}\text { Low surface } \\
\text { reactivity } \\
\text { nanoscale } \mathrm{TiO}_{2}\end{array}$ & OEL & 2000 & ND & ND & QRA \\
\hline $\begin{array}{l}\text { Titanium } \\
\text { dioxide }\end{array}$ & Warheit 2013 & $\begin{array}{l}\text { Pigment-grade } \\
\mathrm{TiO}_{2^{\prime}} \text { particle } \\
\text { types }\end{array}$ & OEL & 5000 & ND & ND & QRA \\
\hline \multicolumn{8}{|c|}{ Dermal exposure } \\
\hline Carbon & Stone 2009 & MWCNT & $\begin{array}{l}\text { DNEL dermal } \\
\text { chronic } \\
\text { exposure, } \\
\text { assessment } \\
\text { factor } 3\end{array}$ & $\begin{array}{c}5.9 \mu \mathrm{g} / \mathrm{kg} \\
\text { body weight }\end{array}$ & ND & ND & QRA \\
\hline Carbon & Stone 2009 & MWCNT & $\begin{array}{c}\text { DNEL dermal } \\
\text { chronic } \\
\text { exposure }\end{array}$ & $\begin{array}{c}17.7 \mu \mathrm{g} / \mathrm{kg} \\
\text { body weight }\end{array}$ & ND & ND & QRA \\
\hline \multicolumn{8}{|c|}{ Oral exposure } \\
\hline Carbon & Stone 2009 & $\begin{array}{l}\text { Fullerite, mixture } \\
\qquad \text { of } C_{60}+C_{70}\end{array}$ & $\begin{array}{l}\text { DNEL oral } \\
\text { acute } \\
\text { exposure }\end{array}$ & $\begin{array}{c}40 \mathrm{mg} / \mathrm{kg} \\
\text { body weight }\end{array}$ & ND & ND & QRA \\
\hline Carbon & Stone 2009 & $\begin{array}{c}\text { Water-soluble } \mathrm{C}_{60^{\prime}} \\
\text { polyalkyl- } \\
\text { sulfonated }\end{array}$ & $\begin{array}{l}\text { DNEL oral } \\
\text { chronic } \\
\text { exposure }\end{array}$ & $\begin{array}{c}0.17 \mathrm{mg} / \mathrm{kg} \\
\text { body weight }\end{array}$ & ND & ND & QRA \\
\hline \multicolumn{8}{|c|}{ Acute short-term exposure } \\
\hline MNM & $\begin{array}{c}\text { McGarry } \\
2013\end{array}$ & $\begin{array}{c}\text { Airborne } \\
\text { particles from } \\
\text { nanotechnology } \\
\text { processes }\end{array}$ & $\begin{array}{l}\text { PCVs, single } \\
\text { short-term } \\
\text { measure- } \\
\text { ment }\end{array}$ & & $\begin{array}{l}5 \text { times the } \\
\text { local particle } \\
\text { reference value }\end{array}$ & ND & Environmental \\
\hline Carbon & Stone 2009 & MWCNT & $\begin{array}{l}\text { DNEL acute } \\
\text { inhalation, } \\
\text { systemic } \\
\text { immune } \\
\text { effect }\end{array}$ & 4.02 & ND & ND & QRA \\
\hline Carbon & $\begin{array}{c}\text { Aschberger } \\
2010\end{array}$ & $\begin{array}{l}\text { Fullerenes, } \\
\text { C }_{60}\end{array}$ & $\begin{array}{l}\text { INEL short- } \\
\text { term, } \\
\text { inhalable } \\
\text { fraction }\end{array}$ & 44.4 & ND & ND & QRA \\
\hline Carbon & Stone 2009 & MWCNT & $\begin{array}{l}\text { DNEL acute } \\
\text { inhalation, } \\
\text { pulmonary } \\
\text { effect }\end{array}$ & 201 & ND & ND & QRA \\
\hline
\end{tabular}




\begin{tabular}{|c|c|c|c|c|c|c|c|}
\hline Category & $\begin{array}{l}\text { Study } \\
\text { reference }\end{array}$ & $\begin{array}{l}\text { Nanomaterials } \\
\text { and } \\
\text { specifications }\end{array}$ & OEL name & $\begin{array}{c}\text { Mass } \\
\text { concentration } \\
\mu \mathrm{g} / \mathrm{m}^{3}\end{array}$ & $\begin{array}{c}\text { Particle } \\
\text { concentration } \\
\text { (particle/ml, } \\
\text { fibres } / \mathrm{cm}^{3} \text { ) }\end{array}$ & $\begin{array}{c}\text { Surface } \\
\text { concentration } \\
\left(\mathrm{nm}^{2} / \mathrm{cm}^{3}\right)\end{array}$ & $\begin{array}{l}\text { Derivation } \\
\text { approach }\end{array}$ \\
\hline \multicolumn{8}{|c|}{ Acute short-term exposure } \\
\hline Carbon & Stone 2009 & MWCNT & $\begin{array}{c}\text { DNEL dermal } \\
\text { acute } \\
\text { exposure }\end{array}$ & $\begin{array}{c}106 \mu \mathrm{g} / \mathrm{kg} \\
\text { body weight }\end{array}$ & ND & ND & QRA \\
\hline Carbon & Stone 2009 & MWCNT & $\begin{array}{c}\text { DNEL dermal } \\
\text { acute } \\
\text { exposure, } \\
\text { assessment } \\
\text { factor } 3\end{array}$ & $\begin{array}{l}35.5 \mu \mathrm{g} / \mathrm{kg} \\
\text { body weight }\end{array}$ & ND & ND & QRA \\
\hline
\end{tabular}

AGS: German Hazardous Substances Committee; BEL: benchmark exposure level; BMDL: benchmark dose lower (95\% confidence limit of the benchmark dose; BOEL: benchmark occupational exposure level; BSI: British Standards Institute CMAR: carcinogenic, mutagenic, asthmagenic or a reproductive toxin; CNF: carbon nanofibre; CNT: carbon nanotube; DNEL: derived no-effect level; DWCNT: double-walled carbon nanotube; GBP: granular biopersistent particles; INEL: indicative no-effect level; LBPC: local background particle concentration; MAC: maximum admissible concentration; MAC-TWA: maximum admissible concentration time-weighted average; MNM: manufactured nanomaterial; MWCNT: multi-walled carbon nanotube; ND: no data; NIOSH: National Institute for Occupational Safety and Health (United States); NM: nanomaterial: NRV: nano reference value; OEL (PL): occupational exposure limit period-limited; OEL: occupational exposure limit; PCVs: particle control values; QRA: traditional quantitative risk assessment; REL: recommended exposure limit; SWCNT: single-walled carbon nanotube; WEL: workplace exposure limit. 


\section{ANNEX 2:}

\section{STEERING GROUP,}

\section{GUIDELINE DEVELOPMENT GROUP,}

SYSTEMATIC REVIIEW TEAMS

\section{AND EXTERNAL REVIEW GROUP}

TABLE A.2.1 WHO GUIDELINE STEERING GROUP

\begin{tabular}{|c|c|c|}
\hline Name & Role & Organization \\
\hline Vladimir MURASHOV & Technical Adviser (Chair) & $\begin{array}{l}\text { National Institute for } \\
\text { Occupational Safety and Health, } \\
\text { Washington, DC, UNITED STATES } \\
\text { OF AMERICA (USA) }\end{array}$ \\
\hline Evelyn KORTUM & $\begin{array}{l}\text { Steering Group Member and } \\
\text { WHO Focal Point }\end{array}$ & $\begin{array}{l}\text { WHO, Department of Public } \\
\text { Health, Environmental and } \\
\text { Social Determinants of Health, } \\
\text { Geneva, SWITZERLAND }\end{array}$ \\
\hline Aida PONCE DEL CASTILLO & Technical Adviser (Vice-Chair) & $\begin{array}{l}\text { European Trade Union Institute, } \\
\text { Brussels, BELGIUM }\end{array}$ \\
\hline Richard BROWN & Steering Group Member & $\begin{array}{l}\text { WHO, Department of Public } \\
\text { Health, Environmental and } \\
\text { Social Determinants of Health, } \\
\text { Geneva, SWITZERLAND }\end{array}$ \\
\hline Angelika TRITSCHER & Steering Group Member & $\begin{array}{l}\text { WHO, Department of Food } \\
\text { Safety and Zoonoses, Geneva, } \\
\text { SWITZERLAND }\end{array}$ \\
\hline Marco MARTUZZI & Steering Group Member & $\begin{array}{l}\text { Environment and Health } \\
\text { Intelligence and Forecasting, } \\
\text { WHO Bonn Office, GERMANY }\end{array}$ \\
\hline JOS VERBEEK & $\begin{array}{l}\text { Technical Advisor } \\
\text { (Methodologist) }\end{array}$ & $\begin{array}{l}\text { Finnish Institute of Occupational } \\
\text { Health, Kuopio, FINLAND }\end{array}$ \\
\hline
\end{tabular}


TABLE A.2.2 GUIDELINE DEVELOPMENT GROUP

\begin{tabular}{|c|c|}
\hline Name & Affiliation \\
\hline Delphine BARD & $\begin{array}{l}\text { Health and Safety Executive, UNITED KINGDOM OF GREAT BRITAIN } \\
\text { AND NORTHERN IRELAND }\end{array}$ \\
\hline Derk BROUWER & University of Witwatersrand, SOUTH AFRICA \\
\hline Mahmoud GHAZI-KHANSARI & $\begin{array}{l}\text { Tehran University of Medical Sciences (TUMS), ISLAMIC REPUBLIC } \\
\text { OF IRAN }\end{array}$ \\
\hline Mary GULUMIAN & $\begin{array}{l}\text { Toxicology and Biochemistry Department, National Institute for } \\
\text { Occupational Health (NIOH), Johannesburg, SOUTH AFRICA }\end{array}$ \\
\hline Evelyn KORTUM & $\begin{array}{l}\text { WHO, Department of Public Health, Environmental and Social } \\
\text { Determinants of Health, Geneva, SWITZERLAND }\end{array}$ \\
\hline Naroo LEE & $\begin{array}{l}\text { Korea Occupational Safety and Health Agency (KOSHA), Ulsan, } \\
\text { REPUBLIC OF KOREA }\end{array}$ \\
\hline Yair Ray LIFSHITZ & $\begin{array}{l}\text { Research Center for Ergonomics, Industrial Engineering and } \\
\text { Management, Technion - Israel Institute of Technology, Haifa, } \\
\text { ISRAEL }\end{array}$ \\
\hline Jaroslav MRAZ & $\begin{array}{l}\text { National Institute of Public Health, Center of Occupational Health, } \\
\text { Prague, CZECH REPUBLIC }\end{array}$ \\
\hline Vladimir MURASHOV & $\begin{array}{l}\text { National Institute for Occupational Safety and Health, Washington, } \\
\text { DC, USA }\end{array}$ \\
\hline Toshihiko MYOJO & $\begin{array}{l}\text { Institute of Industrial Ecological Sciences, University of } \\
\text { Occupational \& Environmental Health (UOEH), Iseigaoka, JAPAN }\end{array}$ \\
\hline Rolf PACKROFF & $\begin{array}{l}\text { Federal Institute for Occupational Safety and Health (BAuA), } \\
\text { Dortmund, GERMANY }\end{array}$ \\
\hline Aida PONCE DEL CASTILLO & European Trade Union Institute, Brussels, BELGIUM \\
\hline Darius D SIVIN & $\begin{array}{l}\text { International Union, UAW, Health \& Safety Department, } \\
\text { Washington, DC, USA }\end{array}$ \\
\hline Pieter VAN BROEKHUIZEN & $\begin{array}{l}\text { IVAM, University of Amsterdam (UvA), Amsterdam, the } \\
\text { NETHERLANDS }\end{array}$ \\
\hline Maria de Fatima Torres F VIEGAS & $\begin{array}{l}\text { FUNDACENTRO, Ministry of Labour and Social Security, São Paulo, } \\
\text { BRAZIL }\end{array}$ \\
\hline William WAISSMANN & $\begin{array}{l}\text { Sergio Arouca National School of Public Health, Fundação } \\
\text { Oswaldo Cruz, Rio de Janeiro, BRAZIL }\end{array}$ \\
\hline Yuxin ZHENG & $\begin{array}{l}\text { National Institute of Occupational Health, China Center for } \\
\text { Disease Control and Prevention, Beijing, CHINA }\end{array}$ \\
\hline Arline Sydnéia Abel ARCURI ${ }^{a}$ & FUNDACENTRO/Ministry of Labour, São Paulo, BRAZIL \\
\hline Bill KOJOLAa & $\begin{array}{l}\text { American Federation of Labor and Congress of Industrial } \\
\text { Organizations (AFL-CIO), Washington, DC, USA }\end{array}$ \\
\hline Claude OSTIGUYa & $\begin{array}{l}\text { Institute de Recherche Robert-Sauvé en Santé et en Sécurité de } \\
\text { Travail, Québec, CANADA }\end{array}$ \\
\hline Judy SNG & National University of Singapore, SINGAPORE \\
\hline Nathalie THIERIET ${ }^{a}$ & $\begin{array}{l}\text { French Agency for Food, Environmental and Occupational Health } \\
\text { and Safety (ANSES), Paris, FRANCE }\end{array}$ \\
\hline Jeong-Sun YANGa & $\begin{array}{l}\text { Korea Occupational Safety and Health Agency (KOSHA), Ulsan, } \\
\text { REPUBLIC OF KOREA }\end{array}$ \\
\hline
\end{tabular}

${ }^{a}$ GDG members who resigned before the completion of these guidelines. 
TABLE A.2.3 SYSTEMATIC REVIEW TEAMS

\begin{tabular}{|c|c|c|}
\hline Question & Experts Involved ${ }^{\mathrm{a}}$ & Affiliation \\
\hline Risks of MNMs & Skaug V, Zienolddiny S, Mohr B. & $\begin{array}{l}\text { Norwegian Institute of } \\
\text { Occupational Health, Oslo, } \\
\text { NORWAY }\end{array}$ \\
\hline Specific hazard classes & $\begin{array}{l}\text { Lee N, Lim CH, Kim T, Sohn EK, } \\
\text { Chung GS, Rho CJ, Lee SR, Yu IJ. }\end{array}$ & $\begin{array}{l}\text { Korean Occupational Health and } \\
\text { Safety Agency, Ulsan, REPUBLIC } \\
\text { OF KOREA }\end{array}$ \\
\hline Forms and routes of exposure & $\begin{array}{l}\text { Sánchez Jiménez A, Basinas I, } \\
\text { Galea K, van Tongeren M, } \\
\text { Hurley F. }\end{array}$ & $\begin{array}{l}\text { Institute of Occupational } \\
\text { Medicine, Edinburgh, } \\
\text { SCOTLAND }\end{array}$ \\
\hline Typical exposure situations & $\begin{array}{l}\text { Debia M, Bakhiyi B, Ostiguy C, } \\
\text { Verbeek J, Brouwer D, } \\
\text { Murashov V. }\end{array}$ & $\begin{array}{l}\text { Université de Montréal, } \\
\text { Département de Santé } \\
\text { Environnementale et Santé au } \\
\text { Travail, Montréal, CANADA }\end{array}$ \\
\hline $\begin{array}{l}\text { Exposure measurement and } \\
\text { assessment }\end{array}$ & $\begin{array}{l}\text { Boccuni F, Ferrante R, } \\
\text { Gagliardi D, lavicoli S, } \\
\text { Rondinone BM. }\end{array}$ & $\begin{array}{l}\text { INAIL, Italian National Institute } \\
\text { for Insurance against Accidents } \\
\text { at Work, Rome, ITALY }\end{array}$ \\
\hline $\begin{array}{l}\text { Occupational exposure limit } \\
\text { values }\end{array}$ & $\begin{array}{l}\text { Mihalache R, Verbeek J, } \\
\text { Graczyk H, MurashovV, } \\
\text { van Broekhuizen P. }\end{array}$ & $\begin{array}{l}\text { Finnish Institute of Occupational } \\
\text { Health, Kuopio, FINLAND }\end{array}$ \\
\hline Control banding & $\begin{array}{l}\text { Eastlake A, Zumwalde R, } \\
\text { Geraci C. }\end{array}$ & $\begin{array}{l}\text { National Institute for } \\
\text { Occupational Safety and Health, } \\
\text { Cincinatti, OH, USA }\end{array}$ \\
\hline $\begin{array}{l}\text { Specific risk mitigation } \\
\text { techniques }\end{array}$ & Myojo T, Nagata T. & $\begin{array}{l}\text { University of Occupational } \\
\text { and Environmental Health, } \\
\text { Kitakyushu, JAPAN }\end{array}$ \\
\hline $\begin{array}{l}\text { Health surveillance to detect } \\
\text { and prevent risks from exposure }\end{array}$ & $\begin{array}{l}\text { Gulumian M, Verbeek J, } \\
\text { Andraos C, Sanabria N, } \\
\text { de Jager P. }\end{array}$ & $\begin{array}{l}\text { National Institute of } \\
\text { Occupational Health, } \\
\text { Johannesburg, SOUTH AFRICA }\end{array}$ \\
\hline $\begin{array}{l}\text { Training of workers to prevent } \\
\text { risks from exposure }\end{array}$ & von Mering Y, Schumacher $C$. & $\begin{array}{l}\text { Institut für Arbeitsschutz, } \\
\text { Deutsche Gesetzlichen } \\
\text { Unfallversicherung, Sankt- } \\
\text { Augustin, GERMANY }\end{array}$ \\
\hline $\begin{array}{l}\text { Involvement of workers and } \\
\text { their representatives }\end{array}$ & Andrade, LRB. & $\begin{array}{l}\text { FUNDACENTRO, Impactos da } \\
\text { nanotecnologia na saúde dos } \\
\text { trabalhadores e meio ambiente, } \\
\text { Ministerio do Trabalho, São } \\
\text { Paulo, BRAZIL }\end{array}$ \\
\hline
\end{tabular}

aThe first person mentioned was the leader of the systematic review team. 
TABLE A.2.4 EXTERNAL REVIEW GROUP

\begin{tabular}{|c|c|}
\hline Name & Affiliation \\
\hline Rob AITKEN & $\begin{array}{l}\text { Institute of Occupational Medicine Singapore, SafeNano, } \\
\text { SINGAPORE }\end{array}$ \\
\hline Jeremy ALLAN & $\begin{array}{l}\text { Australian Nanotechnology Network, Centre for Applied } \\
\text { Philosophy and Public Ethics, Australian National University, } \\
\text { Canberra, AUSTRALIA }\end{array}$ \\
\hline Alba AVILA & $\begin{array}{l}\text { Department of Electrical and Electronics Engineering, } \\
\text { Universidad de los Andes, Bogota, COLOMBIA }\end{array}$ \\
\hline Shahnaz BAKAND & $\begin{array}{l}\text { School of Health \& Society, University of Wollongong, } \\
\text { New South Wales, AUSTRALIA }\end{array}$ \\
\hline Chunying CHEN & $\begin{array}{l}\text { Key Laboratory for Biomedical Effects of Nanomaterials and } \\
\text { Nano-safety, National Center for Nanoscience and Technology } \\
\text { of China, Beijing, CHINA }\end{array}$ \\
\hline Kar CHOWDHURY & $\begin{array}{l}\text { CSIR-Indian Institute of Toxicology Research, Uttar Pradesh, } \\
\text { INDIA }\end{array}$ \\
\hline Nalin DE SILVA & $\begin{array}{l}\text { Sri Lanka Institute of Nanotechnology (SLINTEC), University of } \\
\text { Colombo, Colombo, SRI LANKA }\end{array}$ \\
\hline Johan L DU PLESSIS & $\begin{array}{l}\text { Occupational Hygiene and Health Research Initiative (OHHRI), } \\
\text { Northwest University, Potchefstroom Campus, Potchefstroom, } \\
\text { SOUTH AFRICA }\end{array}$ \\
\hline Stefan ENGEL & $\begin{array}{l}\text { Industrial Hygiene and Hazardous Chemicals Management, } \\
\text { BASF, Ludwigshafen, GERMANY }\end{array}$ \\
\hline Michael FISCHMAN & $\begin{array}{l}\text { a) Occupational \& Environmental Medical Group, } \\
\text { Intel Corporation } \\
\text { b) Division of Occupational \& Environmental Medicine, } \\
\text { University of California San Francisco, Walnut Creek (CA), USA }\end{array}$ \\
\hline Asun GALERA RODRIGO & $\begin{array}{l}\text { Department of Business Organization, Universitat Politécnica de } \\
\text { Catalunya, Barcelona, SPAIN }\end{array}$ \\
\hline Henri HEUSSEN & $\begin{array}{l}\text { CTO Cosanta, Solutions for Chemical Risks, Amstelveen, the } \\
\text { NETHERLANDS }\end{array}$ \\
\hline Jafariah JAAFAR & $\begin{array}{l}\text { Department of Chemistry, Faculty of Science, Universiti } \\
\text { Teknologi Malaysia, Johor, MALAYSIA }\end{array}$ \\
\hline Eileen KUEMPEL & $\begin{array}{l}\text { Nanotechnology Research Center, National Institute for } \\
\text { Occupational Safety and Health, Cincinnati }(\mathrm{OH}) \text {, USA }\end{array}$ \\
\hline Tanasugarn LERSON & $\begin{array}{l}\text { Department of Biochemistry, Faculty of Science, Chulalongkorn } \\
\text { University, Bangkok, THAILAND }\end{array}$ \\
\hline Bruce LIPPY & $\begin{array}{l}\text { The Center for Construction Research and Training, Silver Spring } \\
\text { (MD), USA }\end{array}$ \\
\hline Filipe MUNOZ GERALDO & $\begin{array}{l}\text { Process Safety, Department of Chemical Engineering, } \\
\text { Universidad de los Andes, Bogota, COLOMBIA }\end{array}$ \\
\hline Ndeke MUSEE & $\begin{array}{l}\text { Department of Chemical Engineering, University of Pretoria, } \\
\text { Pretoria, SOUTH AFRICA }\end{array}$ \\
\hline Emmanuel ODJAM-AKUMATEY & Ecological Restorations, Accra, GHANA \\
\hline
\end{tabular}




\begin{tabular}{l|l}
\hline Name & Affiliation \\
\hline Michele OSTRAAT & $\begin{array}{l}\text { Aramco Services Company, Caltech Cambridge (MA), USA } \\
\text { Institute of Occupational Medicine Singapore, SafeNano, } \\
\text { Michael RIEDEKER }\end{array}$ \\
\hline Chen Sau SOON & $\begin{array}{l}\text { Energy and Environment Flagship, SIRIM Industrial Research, } \\
\text { Selangor, MALAYSIA }\end{array}$ \\
\hline Helene STOCKMANN & $\begin{array}{l}\text { Finnish Institute of Occupational Health, Helsinki, FINLAND } \\
\text { Innovative OHS Risk Solutions, Adelaide, AUSTRALIA }\end{array}$ \\
\hline Stephen THOMAS & $\begin{array}{l}\text { Department of Environmental and Radiological Health Science, } \\
\text { Colorado State University, Fort Collins, USA }\end{array}$ \\
\hline Candice Stephen TSAI & CEO PLIN Nanotechnology, Thermi, GREECE \\
\hline Alexander TSOUKNIDAS & $\begin{array}{l}\text { 3M Personal Safety, 3M, North Carolina State University, Saint } \\
\text { Paul (MI), USA }\end{array}$ \\
\hline Andrew VINER &
\end{tabular}




\section{ANNEX 3:}

\section{SUMMARY OF EVIDENCE,}

ROUTES OF EXPOSURE TO MNMS

TABLE A.3.1 ASSESSING INHALATION AND DERMAL EXPOSURE BY ACTIVITY SCENARIO ANDTYPE OF MNM

\begin{tabular}{|c|c|c|c|c|c|c|c|c|}
\hline \multirow{3}{*}{\multicolumn{2}{|c|}{ Activity scenario }} & \multirow{3}{*}{$\begin{array}{l}\text { Quality } \\
\text { assigned }\end{array}$} & \multicolumn{6}{|r|}{ Number of } \\
\hline & & & \multicolumn{2}{|c|}{ CNTs and CNFs } & \multicolumn{2}{|c|}{ Si-based } & \multicolumn{2}{|c|}{$\mathrm{TiO}_{2}$} \\
\hline & & & $\begin{array}{l}\text { Inhalation } \\
\text { exposure }\end{array}$ & $\begin{array}{c}\text { Dermal } \\
\text { exposure }^{a}\end{array}$ & $\begin{array}{l}\text { Inhalation } \\
\text { exposure }\end{array}$ & $\begin{array}{l}\text { Dermal } \\
\text { exposure }^{\mathrm{a}}\end{array}$ & $\begin{array}{l}\text { Inhalation } \\
\text { exposure }\end{array}$ & $\begin{array}{c}\text { Dermal } \\
\text { exposure }^{a}\end{array}$ \\
\hline \multirow{3}{*}{\multicolumn{2}{|c|}{$\begin{array}{l}\text { Machining } \\
\text { and abrasion }\end{array}$}} & High & $32(12)$ & 14 & $3(2)$ & 1 & $3(3)$ & 0 \\
\hline & & Medium & 821 & 8 & $3(2)$ & 1 & $4(3)$ & 0 \\
\hline & & Low & 4 & 3 & 0 & 0 & 0 & 1 \\
\hline \multirow{3}{*}{\multicolumn{2}{|c|}{$\begin{array}{l}\text { Cleaning and } \\
\text { maintenance }\end{array}$}} & High & 7 & 8 & 4 & 1 & 0 & 0 \\
\hline & & Medium & 4 & 1 & 2 & 3 & 0 & 1 \\
\hline & & Low & 0 & 2 & 0 & 2 & 1 & 0 \\
\hline \multirow{6}{*}{$\frac{\frac{n}{n}}{\frac{c}{n}}$} & \multirow{3}{*}{$\begin{array}{l}\text { Reaction } \\
\text { phase }\end{array}$} & High & 18 & 17 & 1 & 1 & 7 & 4 \\
\hline & & Medium & 6 & 6 & 3 & 2 & 2 & 2 \\
\hline & & Low & 3 & 4 & 0 & 1 & 2 & 5 \\
\hline & \multirow{3}{*}{$\begin{array}{l}\text { Collection, } \\
\text { sorting and } \\
\text { processing }\end{array}$} & High & 11 & 6 & 1 & 0 & 3 & 2 \\
\hline & & Medium & 1 & 3 & 0 & 1 & 0 & 2 \\
\hline & & Low & 0 & 3 & 0 & 0 & 1 & 0 \\
\hline \multirow{3}{*}{\multicolumn{2}{|c|}{$\begin{array}{l}\text { Handling and } \\
\text { transfer of liquids }\end{array}$}} & High & 4 & 2 & 2 & 0 & 0 & 1 \\
\hline & & Medium & 1 & 3 & 0 & 1 & 0 & 1 \\
\hline & & Low & 3 & 3 & 1 & 2 & 2 & 0 \\
\hline \multirow{3}{*}{\multicolumn{2}{|c|}{$\begin{array}{l}\text { Weighing and } \\
\text { mixing }\end{array}$}} & High & 14 & 13 & 4 & 2 & 1 & 1 \\
\hline & & Medium & 2 & 3 & 1 & 2 & 1 & 3 \\
\hline & & Low & 3 & 3 & 0 & 1 & 2 & 0 \\
\hline \multirow{3}{*}{\multicolumn{2}{|c|}{$\begin{array}{l}\text { Handling and } \\
\text { transfer of } \\
\text { powders }\end{array}$}} & High & $9(2)$ & 9 & 1 & 1 & 4 & 4 \\
\hline & & Medium & 4 & 4 & 0 & 0 & 0 & 0 \\
\hline & & Low & 2 & 0 & 0 & 0 & 1 & 1 \\
\hline \multirow{3}{*}{\multicolumn{2}{|c|}{ Recycling }} & High & 2 & 0 & 0 & 0 & 0 & 0 \\
\hline & & Medium & 0 & 0 & 0 & 0 & 0 & 0 \\
\hline & & Low & 3 & 5 & 0 & 0 & 0 & 0 \\
\hline
\end{tabular}


exposure assessment situations

\begin{tabular}{|c|c|c|c|c|c|c|c|}
\hline \multicolumn{2}{|c|}{$\begin{array}{l}\text { Other metal oxides } \\
\text { and mixtures }\end{array}$} & \multicolumn{2}{|c|}{ Metals } & \multicolumn{2}{|c|}{ Other MNMs } & \multicolumn{2}{|c|}{ Total } \\
\hline $\begin{array}{l}\text { Inhalation } \\
\text { exposure }\end{array}$ & $\begin{array}{l}\text { Dermal } \\
\text { exposure }^{\mathrm{a}}\end{array}$ & $\begin{array}{l}\text { Inhalation } \\
\text { exposure }\end{array}$ & $\begin{array}{l}\text { Dermal } \\
\text { exposure }\end{array}$ & $\begin{array}{l}\text { Inhalation } \\
\text { exposure }\end{array}$ & $\begin{array}{l}\text { Dermal } \\
\text { exposure }^{a}\end{array}$ & $\begin{array}{l}\text { Inhalation } \\
\text { exposure }\end{array}$ & $\begin{array}{l}\text { Dermal } \\
\text { exposure }^{a}\end{array}$ \\
\hline $3(3)$ & 0 & 0 & 0 & $3(3)$ & 0 & $44(33)$ & 15 \\
\hline $1(1)$ & 0 & 0 & 0 & $3(3)$ & 0 & $12(9)$ & 9 \\
\hline 0 & 0 & 0 & 0 & 0 & 0 & 4 & 4 \\
\hline 27 & 18 & 13 & 4 & 2 & 0 & 53 & 31 \\
\hline 0 & 8 & 3 & 9 & 0 & 4 & 9 & 26 \\
\hline 0 & 1 & 0 & 3 & 2 & 0 & 3 & 8 \\
\hline 2 & 0 & 4 & 4 & 3 & 2 & 35 & 28 \\
\hline 2 & 2 & 1 & 3 & 0 & 0 & 14 & 15 \\
\hline 1 & 3 & 2 & 0 & 1 & 2 & 9 & 15 \\
\hline 0 & 0 & 1 & 0 & 1 & 0 & 17 & 8 \\
\hline 6 & 0 & 1 & 2 & 5 & 3 & 13 & 11 \\
\hline 0 & 6 & 1 & 1 & 2 & 5 & 4 & 15 \\
\hline 3 & 0 & 0 & 0 & 0 & 0 & 9 & 3 \\
\hline 0 & 1 & 0 & 0 & 0 & 0 & 1 & 6 \\
\hline 0 & 2 & 0 & 0 & 0 & 0 & 6 & 7 \\
\hline 3 & 0 & 0 & 0 & 5 & 2 & 27 & 18 \\
\hline 3 & 4 & 0 & 0 & 0 & 3 & 7 & 15 \\
\hline 0 & 2 & 1 & 1 & 2 & 2 & 8 & 9 \\
\hline $3(1)$ & 1 & $2(1)$ & 1 & 4 & 1 & $23(4)$ & 17 \\
\hline 0 & 1 & 0 & 0 & 0 & 3 & 4 & 8 \\
\hline 0 & 0 & 0 & 0 & 0 & 0 & 3 & 1 \\
\hline 0 & 1 & 0 & 0 & $1(1)$ & 0 & $3(1)$ & 1 \\
\hline 0 & 0 & 0 & 0 & 0 & 0 & 0 & 0 \\
\hline 1 & 0 & 0 & 0 & 0 & 0 & 4 & 5 \\
\hline
\end{tabular}




\begin{tabular}{|c|c|c|c|c|c|c|c|}
\hline \multirow[t]{3}{*}{ Activity scenario } & \multirow{3}{*}{$\begin{array}{l}\text { Quality } \\
\text { assigned }\end{array}$} & \multicolumn{6}{|r|}{ Number of } \\
\hline & & \multicolumn{2}{|c|}{ CNTs and CNFs } & \multicolumn{2}{|c|}{ Si-based } & \multicolumn{2}{|c|}{$\mathrm{TiO}_{2}$} \\
\hline & & $\begin{array}{l}\text { Inhalation } \\
\text { exposure }\end{array}$ & $\begin{array}{l}\text { Dermal } \\
\text { exposure }^{a}\end{array}$ & $\begin{array}{l}\text { Inhalation } \\
\text { exposure }\end{array}$ & $\begin{array}{l}\text { Dermal } \\
\text { exposure }^{\mathrm{a}}\end{array}$ & $\begin{array}{c}\text { Inhalation } \\
\text { exposure }\end{array}$ & $\begin{array}{l}\text { Dermal } \\
\text { exposure }^{a}\end{array}$ \\
\hline \multirow{3}{*}{$\begin{array}{l}\text { Spraying and } \\
\text { finishing related } \\
\text { processes }\end{array}$} & High & $10(1)$ & 4 & 4 & 1 & 0 & 1 \\
\hline & Medium & 0 & 4 & 1 & 2 & 2 & 0 \\
\hline & Low & 0 & 1 & 0 & 2 & 1 & 2 \\
\hline \multirow{3}{*}{$\begin{array}{l}\text { Feeding into a } \\
\text { process }\end{array}$} & High & 6 & 2 & 6 & 0 & 0 & 0 \\
\hline & Medium & 0 & 1 & 0 & 4 & 0 & 0 \\
\hline & Low & 0 & 3 & 0 & 2 & 0 & 0 \\
\hline \multirow{3}{*}{$\begin{array}{l}\text { Testing and } \\
\text { characterization }\end{array}$} & High & $3(1)$ & 3 & 1 & 0 & 0 & 0 \\
\hline & Medium & 2 & 2 & 0 & 0 & 0 & 0 \\
\hline & Low & 2 & 1 & 0 & 1 & 0 & 0 \\
\hline \multirow{3}{*}{$\begin{array}{l}\text { Extrusion/injection } \\
\text { moulding }\end{array}$} & High & 2 & 1 & 0 & 0 & 0 & 0 \\
\hline & Medium & 1 & 2 & 0 & 0 & 1 & 0 \\
\hline & Low & 0 & 0 & 0 & 0 & 1 & 2 \\
\hline \multirow[t]{3}{*}{ Packing } & High & 1 & 1 & 4 & 3 & 3 & 3 \\
\hline & Medium & 2 & 1 & 0 & 0 & 1 & 0 \\
\hline & Low & 0 & 1 & 0 & 1 & 0 & 1 \\
\hline Total & & $163(16)$ & 147 & $42(4)$ & 38 & $43(6)$ & 37 \\
\hline
\end{tabular}

CNF: carbon nanofibres; CNT: carbon nanotubes; MNM: manufactured nanomaterials; Si-based: silicon-based; $\mathrm{TO}_{2}$ : titanium dioxide.

${ }^{a}$ Indicates that the likelihood for dermal and/or ingestion exposure is considered to be equal. The number of simulation studies is given in parentheses. 


\begin{tabular}{c|c|c|c|c|c|c|c|}
\hline \multicolumn{2}{|c|}{ exposure assessment situations } & \multicolumn{2}{c|}{ Other MNMs } & \multicolumn{2}{c|}{ Total } \\
\hline $\begin{array}{c}\text { Other metal oxides } \\
\text { and mixtures }\end{array}$ & \multicolumn{2}{|c|}{ Metals } \\
\hline $\begin{array}{c}\text { Inhalation } \\
\text { exposure }\end{array}$ & $\begin{array}{c}\text { Dermal } \\
\text { exposure }\end{array}$ & $\begin{array}{c}\text { Inhalation } \\
\text { exposure }\end{array}$ & $\begin{array}{c}\text { Dermal } \\
\text { exposure }\end{array}$ & $\begin{array}{c}\text { Inhalation } \\
\text { exposure }\end{array}$ & $\begin{array}{c}\text { Dermal } \\
\text { exposure }\end{array}$ & $\begin{array}{c}\text { Inhalation } \\
\text { exposure }\end{array}$ & $\begin{array}{c}\text { Dermal } \\
\text { exposure }\end{array}$ \\
\hline 2 & 1 & 3 & 2 & $5(2)$ & 1 & $24(3)$ & 10 \\
\hline 2 & 0 & 1 & 2 & 2 & 3 & 8 & 11 \\
\hline 2 & 5 & 1 & 1 & 2 & 3 & 6 & 14 \\
\hline $8(3)$ & 1 & 0 & 0 & $3(3)$ & 0 & $23(6)$ & 3 \\
\hline 2 & 5 & 0 & 0 & 0 & 0 & 2 & 10 \\
\hline 0 & 1 & 0 & 0 & 0 & 0 & 0 & 6 \\
\hline 0 & 0 & 1 & 1 & 2 & 1 & $7(1)$ & 5 \\
\hline 0 & 0 & 1 & 0 & 0 & 1 & 3 & 3 \\
\hline 0 & 0 & 0 & 1 & 0 & 0 & 2 & 3 \\
\hline $4(3)$ & 0 & 0 & 0 & $5(3)$ & 0 & $11(6)$ & 1 \\
\hline 0 & 1 & 0 & 0 & 0 & 2 & 2 & 5 \\
\hline 0 & 0 & 0 & 0 & 1 & 1 & 2 & 3 \\
\hline 2 & 1 & 1 & 1 & 5 & 0 & 16 & 9 \\
\hline 0 & 1 & 1 & 1 & 2 & 3 & 6 & 6 \\
\hline 0 & 0 & 0 & 0 & 0 & 4 & 0 & 7 \\
\hline $77(11)$ & 66 & $38(1)$ & 37 & $61(15)$ & 46 & $424(53)$ & 371 \\
\hline
\end{tabular}




\section{BIBLIOGRAFIA CONSULTADA}

ABBOTT, Kenneth W.; MARCHANT, Gary E.; CORLEY, Elizabeth A.. Soft Law Oversight Mechanisms for Nanotechnology. In: Jurimetrics, v. 52, 2012, p. 279-312.

ABBUD, André de Albuquerque Cavalcanti. Soft law e produção de provas na arbitragem internacional. São Paulo: Atlas, 2014.

ACCIOLY, Hildebrando; SILVA, G. E. do Nascimento e; CASELLA, Paulo Borba. Manual de direito internacional público. 22.ed., São Paulo: Saraiva, 2015.

AGÊNCIA BRASILEIRA DE DESENVOLVIMENTO INDUSTRIAL Panorama de Patentes de Nanotecnologia. Brasília, DF, 2011.

Nanotecnologias: subsídios para a problemática dos riscos e regulação. Brasília, DF, 2011.

ALEXY, Robert. Teoria dos direitos fundamentais. São Paulo: Malheiros, 2008.

ALMEIDA, Ildeberto Muniz de; VILELA, Rodolfo Andrade de Gouveia; SILVA, Alessandro José Nunes da et al. Modelo de Análise e Prevenção de Acidentes - MAPA: ferramenta para a vigilância em Saúde do trabalhador. In: Ciência \& saúde coletiva, vol.19, n.12, 2014, p. 4679-4688.

ALMEIDA, Úrsula Ribeiro de. Tutela de Urgência no Direito Ambiental: Instrumento de Efetivação do Princípio da Precaução. São Paulo: Atlas, 2015.

ALVARENGA, Rúbia Zanotelli de. $O$ direito do trabalho como dimensão dos direitos humanos. São Paulo: LTr, 2009.

ANDRADE, Luís Renato Balbão. Sistemática de ações de segurança e saúde no trabalho para laboratórios de pesquisa com atividades de nanotecnologia. Tese de Doutorado (Engenharia). Universidade Federal do Rio Grande do Sul, Porto Alegre, 2013.

ANTUNES, Paulo de Bessa. Direito Ambiental. 17.ed., São Paulo: Atlas, 2015.

AQUINO, Afonso Rodrigues de; PALETTA, Francisco Carlos; ALMEIDA, Josimar Ribeiro de (Orgs.). Vulnerabilidade ambiental. São Paulo: Blucher, 2017.

Risco Social. São Paulo: Blucher, 2017.

Risco Ambiental. São Paulo: Blucher, 2017.

ARBIX, Glauco. Inovar ou inovar: A indústria brasileira entre o passado e o futuro. São Paulo: Editora Papagaio, 2007. 
ARCURE, Arline Sydineia Abel. Introdução à nanotecnologia e ao conceito de convergência tecnológica: aplicações gerais e nos vários setores econômicos. Importância do tamanho. Palestra proferida durante do curso "Impactos à saúde dos trabalhadores das nanotecnologias e outras novas tecnologias", realizado de 10 à 12 de julho de 2018, na sede da FUNDACENTRO em São Paulo/SP.

; PONTES, Jorge Marques. Nanotecnologia e seus impactos na saúde, meio ambiente e no mundo do trabalho. In: HESS, Sonia (org.). Ensaios sobre a poluição e doenças no Brasil. São Paulo: Outras expressões, 2018, p.315-336.

AREOSA, João; AZERES, Pedro; VELOSO NETO, Hernâni. Manual sobre riscos psicossociais no trabalho. Porto: Civeri Publishing, 2014.

ARMOND, Geraldo Henrique de Souza. A responsabilidade objetiva do empregador no acidente de trabalho. Dissertação de Mestrado (Direito). Universidade de São Paulo, São Paulo, 2011.

ARNAUT, Danilo. Da biosfera à sociedade global: Contribuições das teorias do risco para a sociologia da globalização. In: Cadernos Ceru, v. 24, n. 1, p. 137-168.

ASMATULU, Ramazan. Nanotechnology safety. San Diego: Elsevier, 2008.

ASSOCIAÇÃO BRASILEIRA DE NORMAS TÉCNICAS. ABNT/CEE - 089 - Comissão de Estudo Especial de Nanotecnologia. Disponível em <http://www.abnt.org.br/cee-89>. Visitado em 08.mai.2019.

ASSOCIAÇÃO NACIONAL DE MEDICINA DO TRABALHO. Brasil é quarto lugar no ranking mundial de acidentes de trabalho. Disponível em $<$ https://www.anamt.org.br/portal/2018/04/19/brasil-e-quarto-lugar-no-ranking-mundialde-acidentes-de-trabalho/>. Visitado em 08.mai.2019.

ATCHABAHIAN, Ana Cláudia Ruy Cardia. A transterritorialidade como mecanismo de responsabilização de empresas por violações aos direitos humanos. Tese de Doutorado (Direito). Pontifícia Universidade Católica de São Paulo, São Paulo, 2019.

ATHIAS, Jorge Alex Nunes. Responsabilidade civil e meio-ambiente: Breve panorama do direito brasileiro. In: BENJAMIN, Antônio Herman V. (Coord.). Dano Ambiental: prevenção, reparação e repressão. São Paulo: RT, 1993, p. 237-249.

AUSTRIAN ACADEMY OF SCIENCES. NanoTrust-Dossier No. 017en, February 2011 (What are synthetic nanoparticles?). Disponível em <epub.oeaw.ac.at/ita/nanotrustdossiers/dossier002en.pdf>. Visitado em 08.mai.2019. 
NanoTrust-Dossier No. 029en, April 2012 (Nanomaterials and occupational

safety $\quad-\quad$ An overview). Disponível em

<http://epub.oeaw.ac.at/0xc1aa5576\%200x002af794.pdf>. Visitado em 08.mai.2019.

. NanoTrust-Dossier No. 039en, May 2013 (Definition of the term “nanomaterial”). Disponível em <epub.oeaw.ac.at/ita/nanotrustdossiers/dossier039en.pdf>. Visitado em 08.mai.2019.

. NanoTrust-Dossier No. 040en, Aug 2014 ("Nanowaste”: Naomaterialcontaining products at the end of their life cycle). Disponível em <epub.oeaw.ac.at/ita/nanotrust-dossiers/dossier040en.pdf>. Visitado em 08.mai.2019.

ÁVILA, Humberto. Teoria dos princípios: Da definição à aplicação dos princípios jurídicos. 2.ed., São Paulo: Malheiros, 2003.

BAKER, John; BARRIE, Martin D.; GERALCI, Charles L; HOOVER, Mark D. Soft Law and Nanotechnology. Disponível em <http://synergist.aiha.org/201604-soft-law-andnanotechnology>. Visitado em 08.mai.2019.

BARROS, Rosa Maria da Silva. Nanoalimentos e nanotecnologias aplicadas a alimentos riscos potenciais, necessidades regulatórias e propostas de instrumento para verificar opiniões sobre riscos potenciais à saúde e ao ambiente. Dissertação de Mestrado (Saúde Pública). Escola Nacional de Saúde Pública Sergio Arouca (FIOCRUZ), Rio de Janeiro, 2011.

BARROS, Wellington Pacheco; BARROS, Wellington Gabriel Zuchetto. A proporcionalidade como princípio de direito. Porto Alegre: Livraria do Advogado, 2006.

BARTIS, James T.; LANDREE, Eric. Nanomaterials in the workplace: Policy and planning workshop on occupational safety and health. Arlington: RAND, 2006.

BATISTA, Ariane de Jesus Sousa; PEPE, Vera Lúcia Edais. Os desafios da nanotecnologia para a vigilância sanitária de medicamentos. In: Ciência \& Saúde Coletiva, Vol. 19, n. 7, 2014, p. 2105-2114.

BAUM, Rudy. C\&EN: Cover story $\quad-\quad$ nanotechnology. <http://pubs.acs.org/cen/coverstory/8148/8148counterpoint.html>. Visitado em 08.mai.2019.

BECK, Ulrich. Sociedade de risco: Rumo a uma outra modernidade. São Paulo: Editora 34, 2010 . 
; GIDDENS, Anthony; LASH, Scott. Modernização reflexiva: Política, tradição e estética na ordem social moderna. 2.ed., São Paulo: Ed. UNESP, 2012.

BELTRÃO, Antonio Figueiredo Guerra. Curso de direito ambiental. 2.ed. (ebook), São Paulo: Método, 2014.

BENACCHIO, Marcelo (coord.); VALLATI, Diogo Basilio (org.); DOMINIQUI, Eliete Dorette (org.). A sustentabilidade da relação entre empresas transnacionais e direitos humanos. Curitiba: Editora CRV, 2016.

BENETT, Belinda. Expanding horizons: Scientific frontiers, legal regulation and globalization. In: Indiana Journal of Global Legal Studies, v. 19, 2012, p. 507-531.

BENJAMIN, Antônio Herman V.. Responsabilidade civil por dano ambiental. In: Revista de Direito Ambiental, v. 9, ano 3, jan-mar/1998, p. 05-52.

BERNSTEIN, Peter L. Desafio aos deuses: A fascinante história do risco. 9.ed., Rio de Janeiro: Campus, 1997.

BHUSHAN, Bharat. Governance, policy, and legislation of nanotechnology: a perspective. In: Microsystem Technologies, v. 21, n. 5, mai/2015, p. 1137-1155.

BIANCHI, Patrícia. Eficácia das normas ambientais. São Paulo: Saraiva, 2010.

BJORNSTAD, David J. et al. What Can Nanotechnology Learn from Biotechnology? San Diego: Elsevier, 2008.

BOBBIO, Norberto. Da estrutura à função: Novos estudos de teoria do direito. Barueri: Manole, 2007.

Teoria do ordenamento jurídico. 10.ed., Brasília: Editora Universidade de Brasília, 1999

BOHOLM, Åsa. The cultural nature of risk: Can there be an anthropology of uncertainty? In: Ethnos Journal of Anthropology, v. 68, n. 2, jun/2003, p.159-178.

BOLDRIN, Alessio et al. Environmental exposure assessment framework for nanoparticles in solid waste. In: Journal of Nanoparticle Research, n. 16, Jun/2014, p. 2394 e ss.

BONAVIDES, Paulo. Curso de direito constitucional. 29.ed. São Paulo: Malheiros Editores, 2014.

BORGES, Roxana. Função ambiental da propriedade rural. São Paulo: LTr, 1999.

BORJES, Isabel Cristina Porto; GOMES, Taís Ferraz; ENGELMANN, Wilson. Responsabilidade civil e nanotecnologias. São Paulo: Atlas, 2014. 
BRAGA, Marco Aurélio Cezarino. Subdesenvolvimento, tecnologia e direito econômico: $O$ programa nacional de nanotecnologia e o desafio furtadiano. Dissertação de Mestrado (Direito). Universidade de São Paulo, São Paulo, 2013.

BRITISH STANDARDS INSTITUTION. Nanotechnologies - Part 2: Guide to safe handling and disposal of manufactured nanomaterials. Londres, 2007.

. Safe approach to nanotechnology - BSI British Standards publishes new guidance for UK industry. Disponível em <https://www.bsigroup.com/en-GB/aboutbsi/media-centre/press-releases/2008/1/Safe-approach-to-nanotechnology--BSI-BritishStandards-publishes-new-guidance-for-UK-industry/> . Visitado em 08.mai.2019.

CABRAL, Angelo Antonio. Direito Ambiental do Trabalho na Sociedade de Risco. Curitiba: Juruá, 2016.

CANOTILHO, José Joaquim Gomes. Direito constitucional ambiental brasileiro. 6.ed., São Paulo: Saraiva, 2015.

. Direito constitucional e teoria da constituição. 5.ed. Coimbra: Almedina, (s.d.).

CARRARO, Fernando Luiz; MEDITSCH; Jorge de Oliveira. Dicionário de química. Porto Alegre: Ed. Globo, (sd).

CARRAZZA, Roque Antonio. Curso de direito constitucional tributário. 21. ed., São Paulo: Malheiros, 2015.

CARSON, Rachel. Primavera silenciosa. 2.ed., São Paulo: Melhoramentos, 1969.

CASTRO, Janaína Vieira de; PASQUALETO, Olívia de Quintana Figueiredo. Nanotecnologia, saúde e segurança do trabalho: Espaço para regulação. In: Revista dos Estudantes de Direito da Universidade de Brasília, n. 12, 2016. Disponível em <http://periodicos.unb.br/index.php/redunb/article/download/21738/15494>. Visitado em 08.mai.2019.

CAVALCANTE, Jouberto de Quadros Pessoa. A proteção jurídica do emprego frente às inovações tecnológicas: uma proposta sistêmica. Tese de Doutorado (Direito). Universidade de São Paulo, São Paulo, 2017.

COMISSÃO MUNDIAL SOBRE MEIO AMBIENTE E DESENVOLVIMENTO. Nosso futuro comum. Rio de Janeiro: Fundação Getúlio Vargas, 1988. 
CONPEDI, Anais do XVIII Encontro Nacional do CONPEDI. Florianópolis: Fundação Boiteux, 2009

CORLEY, Elizabeth A.; KIM, Youngjae; SCHEUFELE, Dietram A.. Public Challenges of Nanotechnology Regulation. In: Jurimetrics, v. 52, 2012, p. 371-381.

COUTINHO, Diogo R.; FOSS, Maria Carolina; MOUALLEM; Pedro Salomon B. (orgs.). Inovação no Brasil: avanços e desafios jurídicos e institucionais. E-book. São Paulo: Blucher, 2017.

CRUZ, Gisela Sampaio da. O problema do nexo causal na responsabilidade civil. Rio de Janeiro: Renovar, 2005.

DAVID, Marília Luz. Sobre os conceitos de risco em Luhmman e Giddens. In: Em Tese Revista de Pós-Graduandos em Sociologia Política da UFSC, v. 8, n. 1, jan-jul/2011, p. 3045 .

DEKKERS, Susan et al. Towards a nanospecific approach for risk assessment. In: Regulatory Toxicology and Pharmacology, v. 80, out/2016, p. 46-59.

DELGADO, Gabriela Neves. Direitos humanos dos trabalhadores: Perspectiva de análise a partir dos princípios internacionais do direito do trabalho e do direito previdenciário. In: Revista do TST, vol. 77, n. 3, jul-set/2011, p. 59-76.

DELGADO, Mauricio Godinho; DELGADO, Gabriela Neves. Constituição da república e diretos fundamentais. 2.ed. São Paulo: LTr, 2013.

DELMAS-MARTY, Mireille. Três Desafios para um Direito Mundial. Tradução de Fauzi Hassan Choukr. Rio de Janeiro: Editora Lumen Juris, 2003.

DIAS, Bruno Smolarek. Direito transnacional e a premissa de uma comunidade internacional universalista. In: Revista Brasileira de Direito. v.11, n. 1 (2015), jan.-jun. 2015, p. 68 e ss.

DREXLER, Eric. Engines of creation: The coming era of nanotechnology. Nova York: Anchor Books, 1986. . Molecular machinery and manufacturing with applications to computation.

Tese de Doutorado (Nanotecnologia Molecular). Massachusetts Institute of Technology. Cambridge, 1991.

; PETERSON, Chris; PERGAMIT, Gayle. Unbounding the Future: The Nanotechnology Revolution. Nova York: William Morrow and Company, Inc, 1991. 
DURÁN, Nelson et al. Nanotoxicologia de nanopartículas de prata: Toxicidade em animais e humanos. In: Revista Química Nova, vol. 2, n. 2, 2019, p. 206-213.

; MATTOSO, Luiz Henrique Capparelli; MORAIS, Paulo Cesar. Nanotecnologia: introdução, preparação e caracterização de nanomateriais e exemplos de aplicação. São Paulo: Artliber, 2006.

ENGELMANN, Wilson. Nanotechnology, law and innovation. E-book. Strasburg: LAP LAMBERT Academic Publishing, 2011.

; HOHENDORFF, Raquel Von; SCHAFFER, Miriam Helena. Nanotechnology as a privileged example of technological innovation: building foundations for the design of the "quadruple helix”. In: Revista Novos Estudos Jurídicos, Vol. 19, n. 3, set-dez/2014, p. 887-903.

; HUPFFER, Haide Maria (orgs.). Impactos sociais e jurídicos das nanotecnologias. São Leopoldo: Casa Leiria, 2017

; MARTINS, Patrícia Santos. As Normas ISO e as nanotecnologias: entre a autorregulação e o pluralismo jurídico. E-book. São Leopoldo: Karywa, 2017.

; SILVA, Daniele Weber da. A destinação final dos nanomateriais: o princípio da precaução como fundamento para a normatização das nanotecnologias e seus resíduos finais, p. 433-434. Disponível em: <https://www.conpedi.org.br/publicacoes/y0ii48h0/q923c0e2/eW2u7WV6kSygr378.pdf>. Visitado em 08.mai.2019.

ENGISCH, Karl. Introdução ao pensamento jurídico. 10.ed., Lisboa: Fundação CalousteGulbenkian, 2008.

ENVIRONMENTAL PROTECTION AGENCY. Nanotechnology White Paper. Washington, DC, 2007.

EUROPEAN AGENCY FOR SAFETY AND HEALTH AT WORK. New and Emerging Risks in: Occupational Safety and Health - Outlook 1, 2009. Disponível em $<$ http://osha.europa.eu/en/publicationsoutlook/te8108475enc_osh_outlook/>.Visitado em 08.mai.2019.

Workplace exposure to nanoparticles. Bilbao, 2009.

EUROPEAN COMMISSION. Towards an European strategy for nanotechnology. Bruxelas, 2004. 
EUROPEAN ENVIRONMENT AGENCY. Late lessons from early warnings: The precautionary principle 1896-2000. Copenhagen, 2001.

EUROPEAN PARLIAMENT. Resolution of 24 April 2009 on regulatory aspects of nanomaterials $(2008 / 2208(I N I))$.

Disponível em $<$ http://www.europarl.europa.eu/sides/getDoc.do?pubRef=-//EP//NONSGML+TA+P6-TA2009-0328+0+DOC+PDF+V0//EN>. Visitado em 08.mai.2019.

FEITSHANS, Ilise Levy. Global health impacts of nanotechnology law: A tool for stakeholder engagement. Singapura: Pan Stanford Publishing, 2018.

FELICIANO, Guilherme Guimarães. Curso crítico de direito do trabalho: Teoria geral do direito do trabalho. São Paulo: Saraiva, 2013.

; URIA, João (coord.). Direito ambiental do trabalho: Apontamentos para uma teoria geral. Vol. 1. São Paulo: LTr., 2013.

; URIA, João; MARANHÃO, Ney; SEVERO, Valdete Souto (coord.). Direito ambiental do trabalho: apontamentos para uma teoria geral. Vol. 2. São Paulo: LTr., 2015. FERRARI, Arianna et al. Convergência tecnológica num mundo desigual: Meio ambiente, saúde, trabalho e sociedade. Rio de Janeiro: Heinrich Böll Stiftung, 2009.

FERRAZ, Sérgio. Direito ecológico, perspectivas e sugestões. In: Revista da ConsultoriaGeral do Estado do Rio Grande do Sul, v. 2, n. 4, 1972, p. 43-52.

FERREIRA, Aldo Pacheco; SANT'ANNA, Leonardo da Silva. A nanotecnologia e a questão da sua regulamentação: Impactos à saúde e ao ambiente. In: Revista Uniandrade, v. 16, n. 3, (?), p. 119-128.

FERREIRA, Fernanda Busanello. O risco nas teorias sociológicas contemporâneas: Beck, Giddens e Luhmman. In: Revista Raízes Jurídicas, v. 7, n. 2, jul-dez/2011, p. 135-144.

FERRI, Javier Gómez. La comprension publica de la nanotecnologia en Espana. In: Revista Iberoamericana de Ciencia, Tecnología y Sociedad, vol. 20, n. 7, abr/2012, p. 177 e ss. FERRON, Mariana Maleronka. Saúde, trabalho e meio ambiente: exposição a metais em catadores de materiais recicláveis. Tese de Doutorado (Medicina). Universidade de São Paulo, São Paulo, 2015.

FERRONATO, Rafael Luiz. Nanotecnologia, ambiente e direito: Desafios para a sociedade na direção a um marco regulatório. Dissertação de Mestrado (Direito). Universidade de Caxias do Sul. Caxias do Sul, 2010. 
FIORILlO, Celso Antonio Pacheco; MORITA, Dione Mari; FERREIRA, Paulo. Licenciamento ambiental. 2.ed., São Paulo: Saraiva, 2015.

FIORINO, Daniel J.. Matching Solutions to Problems: Strategies for Nanotechnology Oversight. In: Jurimetrics, v. 52, 2012, p. 337-345.

FOLADORI, Guillermo. Riesgos a la salud y al medio ambiente en las políticas de nanotecnología en América Latina. In: Sociológica, v. 27, n. 77, set-dez/2012, pp. 143-180. FORESIGHT INSTITUTE. 1989 Nanotechnology Conference. <https://foresight.org/Conferences/MNT01/Nano1.html>. Visitado em 08.mai.2019.

A short history of nanotechnology. Disponível em <https://foresight.org/nano/history.html>. Visitado em 08.mai.2019.

Feynman Grand Prize. Disponível em <https://foresight.org/GrandPrize.1.html\#anchor183110>. Visitado em 08.mai.2019. . Foresight guideline for responsible nanotechnology development. Disponível em <https://foresight.org/guidelines/current.html>. Visitado em 08.mai.2019.

- Productive nanosystems: A technology roadmap. Disponível em $<$ https://www.foresight.org/roadmaps/Nanotech_Roadmap_2007_main.pdf>.Visitado em 08.mai.2019.

FORNASIER, Mateus de Oliveira. Diálogo ultracíclico transordinal: Possível metodologia para a regulação do risco nanotecnológico para o ser humano e o meio ambiente. Tese de Doutorado (Direito). Universidade do Vale do Rio dos Sinos, São Leopoldo, 2013.

FÓRUM ECONÔMICO MUNDIAL. These are the top 10 emerging technologies of 2016. Genebra: World Economic Forum, 2016.

FRANCO, Dmitri Montanar. Responsabilidade legal pelo dano ambiental: a aplicação das excludentes de responsabilidade. 2.ed., São Paulo: Blucher, 2017.

FRIEDRICHS, Steffi; PARK, Barry; JOHNSTONE, James. Current Developments in Standards and Regulation for Nanotechnologies. Londres: Nanotechnology Industries Association (NIA), 2013.

FULLER, Greice Patricia. O saneamento ambiental como condição primacial à sadia qualidade de vida e fator estruturante do estado democrático de direito brasileiro. Tese de Doutorado (Direito). Pontifícia Universidade Católica de São Paulo, São Paulo, 2011. 
FUNDACENTRO. Fulerenos - Nanotecnologia. Disponível em <http://www.fundacentro.gov.br/nanotecnologia/fulerenos >. Visitado em 08.mai.2019. - Nanotubos de carbono - Nanotecnologia. Disponível em $<$ http://www.fundacentro.gov.br/nanotecnologia/nanotubos-de-carbono>. Visitado em 08.mai.2019.

. Nota Técnica n. 01/2018/FUNDACENTRO: Os desafios da saúde e segurança no trabalho (SST) para uma produção segura com o uso de nanotecnologia. Brasília, DF, 2018. Disponível em <http://www.fundacentro.gov.br/arquivos/projetos/Nota\%20Tecnica\%2001_2018.pdf>. Visitado em 08.mai.2019.

GARCIA, Balmes Vega. Direito e tecnologia: Regime jurídico da ciência, tecnologia e inovação. São Paulo: LTr, 2008.

GARCIA, Gustavo Filipe Barbosa. Curso de direito do trabalho. 11.ed., Rio de Janeiro: Forense, 2017.

. Meio ambiente do trabalho: Direito, segurança e medicina do trabalho. 4.ed., São Paulo: Método, 2014.

GERBER, Alexander et al. Gold nanoparticles: recent aspects for human toxicology. In: Journal of Occupational Medicine and Toxicology, v. 8, dez/2013.

GLADY JR., Edward R.; GARCIA, Gregorio M.; MOSES, Blair H.. Nanotechnology Liability: Do We Steer or Just Go Along for the Ride?, In: Jurimetrics, v. 52, 2012, p. 313335 .

GOÉS, Maurício de Carvalho; ENGELMANN, Wilson. Direito das nanotecnologias e o meio ambiente do trabalho. Porto Alegre: Livraria do Advogado, 2015.

GOLDMAN, Lynn; COUSSENS, Christine. Implications of Nanotechnology for Environmental Health Research. Washington, DC: National Academies Press, 2005. GONÇALVES, Carlos Roberto. Responsabilidade Civil. 17.ed., São Paulo: Saraiva, 2016. GORZ, André. Ecológica. São Paulo: Annablume, 2010.

GOTTARDO, Stefania et al. NANoREG harmonised terminology for environmental health and safety assessment of nanomaterials. Ispra: Joint Research Centre, 2016.

GRAEFF, Carlos (org.). Nanotecnologia: Ciência e engenharia. São Paulo: Cultura Acadêmica, 2012. 
GREENPEACE. Bhopal, Índia: O pior desastre químico da história (1984-2002). Disponível em <http://greenpeace.org.br/bhopal/docs/Bhopal_desastre_continua.pdf>. Visitado em 08.mai.2019.

GROSO, Amela et al. Management of nanomaterials safety in research environment. Disponível em <https://particleandfibretoxicology.biomedcentral.com/articles/10.1186/ 1743-8977-7-40>. Visitado em 08.mai.2019.

GRUPO ETC. Tecnologia atômica: a nova frente das multinacionais. Trad. de Elisa Schreiner. São Paulo: Expressão Popular, 2004.

GUERRA Sidney. Curso de direito internacional público. 11.ed., São Paulo: Saraiva, 2017. GUSMÃO, Paulo Dourado de. Introdução ao estudo do direito. 49.ed., Rio de Janeiro: Forense, 2018.

GUTERRES, Sílvia S.; POHLMANN, Adriana R.. Relatório de Acompanhamento Setorial - Nanotecnologia na área da saúde: mercado, segurança e regulação. Brasília, DF: Associação Brasileira de Desenvolvimento Industrial, 2013.

HALLIDAY, David; RESNICK, Robert; WALKER, Jearl. Fundamentos de física: Óptica e física moderna. Vol. 4. 6.ed., Rio de Janeiro: LTC, 2003.

HAVE, Henk A. M. J. ten et al. Nanotechnologies, ethics and politics. Paris: UNESCO Publishing, 2007.

HEALTH \& SAFETY EXECUTIVE. Nanoparticles: An occupational hygiene review. Norwich, UK, 2004.

HERMES, Elisangela Giroto Carelli; BASTOS, Paulo Roberto Haidamus de Oliveira. Nanotecnologia: progresso científico, material, global e ético. In: Revsita Persona Y Bioética, v. 18, n.2, jul-dez/2014, p. 107-118.

HOUAISS, Antônio; VILLAR, Mauro de Salles; FRANCO, Francisco Manoel de Mello. Dicionário Houaiss da língua portuguesa. Rio de Janeiro: Objetiva, 2004.

HRISTOVSKI, Kiril D.. Scientific Challenges of Nanomaterial Risk Assessment. In: Jurimetrics, v. 52, 2012, p. 359-370.

HULL, Matthew; BOWMAN, Diana. Nanotechnology Environmental Health and Safety: Risks, Regulation and Management. San Diego: Elsevier, 2009. 
INSTITUT DE RECHERCHE ROBERT-SAUVÉ EN SANITÉ ET EN SECURITÉ DU TRAVAIL. Report R-899: Best practices guidance for nanomaterial risk management in the workplace. 2.ed., Montreal, CA, 2015.

Report R-952: Évaluation de méthodes de prélèvement et de caractérisation de nanomatériaux manufactures dans l'air et sur des surfaces des milieux de travail. Montreal, CA, 2017.

INSTITUTO DE QUÍMICA / UNESP - Aula 09: Nanociências, Nanotecnologia e Regulação - Curso sobre biomateriais. Disponível em <https://www.youtube.com/watch?v=VNrZ22yHb1s>. Visitado em 08.mai.2019.

INSTITUTO NACIONAL DE CÂNCER. Exposição no trabalho e no ambiente: Amianto. Disponível em <https://www.inca.gov.br/exposicao-no-trabalho-e-no-ambiente/amianto>. Visitado em 08.mai.2019.

INSTITUTO NACIONAL DE PROPRIEDADE INDUSTRIAL. Radar tecnológico Nanocosméticos - n. 14. Rio de Janeiro: INPI, 2017.

INSTITUTO NACIONAL DO SEGURO SOCIAL. Anuário Estatístico da Previdência Social APES - 2013. Disponível em <http://www.previdencia.gov.br/dados-abertos/aeps2013-anuario-estatistico-da-previdencia-social-2013/aeps-2013-secao-iv-acidentes-dotrabalho/aeps-2013-secao-iv-acidentes-do-trabalho-tabelas/> . Visitado em 08.mai.2019. . Anuário Estatístico da Previdência Social APES - 2017. Disponível em <http://sa.previdencia.gov.br/site/2019/04/AEPS-2017-abril.pdf>. Visitado em 08.mai.2019.

INTERNATIONAL CENTER FOR TECHNOLOGY ASSESSMENT. Princípios para a supervisão de nanotecnologias e nanomateriais. Washington, DC, 2007.

INTERNATIONAL LAW COMMISSION. Fragmentation of international law: Difficulties arising from the diversification and expansion of international law (A/CN.4/L.682). Genebra, 2006.

INTERNATIONAL ORGANIZATION FOR STANDARDIZATION. ISO/TS 800041:2015(EN) - Nanotechnologies - Vocabulary - Part 1: Core terms. Disponível em <https://www.iso.org/standard/68058.html>. Visitado em 08.mai.2019.

ISO/TS 80004-1:2015(EN) - Nanotechnologies - Vocabulary - Part 4:

Nanostructured materials. Disponível em <https://www.iso.org/standard/68058.html>. Visitado em 08.mai.2019. 
ISO/TS 80004-2:2015(EN) - Nanotechnologies - Vocabulary - Part 2: Nano-

objects. Disponível em <https://www.iso.org/standard/68058.html>. Visitado em 08.mai.2019.

. ISO/TS 80004-3:2015(EN) - Nanotechnologies - Vocabulary - Part 3: Carbon nano-objects. Disponível em <https://www.iso.org/standard/68058.html>. Visitado em 08.mai.2019.

INVERNIZZI, Noela; FOLADORI, Guillermo. Nanotechnology and the developing world: Will nanotechnology overcome poverty or widen disparities. In: Nanotechnology Law \& Business, vol. 2, n. 3, set-oct/2005, p. 294-303.

IRRC INSTITUTE. Nanotechnology and the S\&P 500: Small Sizes, Big Questions. Disponível em <https://irrcinstitute.org/wp-content/uploads/2015/09/final-nanotech-sp500october-20141.pdf>. Visitado em 08.mai.2019.

ISAACS, Alan. Breve dicionário de física. Lisboa: Editorial Presença, 1996.

JACOBS, Molly M.; ELLENBECKER, Michael; HOPPIN, Polly et al. Precarious Promise: A Case Study of Engineered Carbon Nanotubes. Disponível em <http://www.sustainableproduction.org/downloads/ECN_casestudy_0325.pdf>. Visitado em 08.mai.2019.

JARDIM, Fernando Rogério. O macrocosmo social da nanociência: Estudo sobre as pesquisas em nanotecnologia da Embrapa e da Unicamp. Tese de Doutorado (Sociologia). Universidade de São Paulo, São Paulo, 2009.

JASTRZĘBSKA, Agnieszka Maria; KURTYCZ, Patrycja; OLSZYNA, Andrzej Roman. Recent advances in graphene family materials toxicity investigations. In: Journal of Nanoparticle Research, v. 14, n. 1.320, dez/2012.

JORGE NETO, Francisco Ferreira; CAVALCANTE, Jouberto de Quadros Pessoa. Direito processual do trabalho. 7.ed., São Paulo: Atlas, 2015.

KASTIEL, Kobi. Nanotechnology and the S\&P 500. Disponível em $<$ https://corpgov.law.harvard.edu/2014/11/03/nanotechnology-and-the-sp-500/>. Visitado em 08.mai.2019.

KIMBRELL, George A.. Governance of nanotechnology and nanomaterials: Principles, regulation, and renegotiating the social contract. In: Journal of law, medicine \& ethics, 2009, p. 706-723. 
KOEPSELL, David. Law and ethics: rules, regulations, and rights in nanowares. In: KOEPSELL, David (org.). Innovation and Nanotechnology: Converging Technologies and the End of Intellectual Property. London: Bloomsbury Academic, 2011. 89-109.

KURATH, Monika et al. Cultures and strategies in the regulation of nanotechnology in Germany, Austria, Switzerland and the European Union. In: NanoEthics, v. 8, n. 2, ago/2014, p. 121-140.

LARENZ, Karl. Metodologia da ciência do direito. 3.ed., Lisboa: Fundação CalousteGulbenkian, 1997.

LEE, Naroo; LIM, Chloe Hong; KIM, Taegum et al. Which hazard category should specific nanomaterials or groups of nanomaterials be assigned to and how? Genebra: World Health Organization, 2017.

LEITE, Carlos Henrique Bezerra. Curso de direito do trabalho. 9.ed., São Paulo: Saraiva, 2018.

Curso de direito processual do trabalho. 16.ed., São Paulo: Saraiva, 2018.

LEITE, José Rubens Morato (coord.). Dano ambiental na sociedade do risco. São Paulo: RT, 2012.

; FAGÚNDEZ, Paulo Roney Ávila (org.). Biossegurança e novas tecnologias na sociedade de risco: aspectos jurídicos, técnicos e sociais. Florianópolis: Conceito Editorial, 2007.

LEMOS, Patrícia Faga Iglecias. Resíduos sólidos e responsabilidade civil pós-consumo. 2.ed., São Paulo: Revista dos Tribunais, 2012.

LENZ E SILVA, Guilherme Frederico Bernardo. Nanotecnologia: avaliação e análise dos possíveis impactos à saúde ocupacional e segurança do trabalhador no manuseio, síntese e incorporação de nanomateriais em compósitos refratários de matriz cerâmica. Trabalho de Conclusão de Curso de Especialização (Engenharia). Universidade Federal de Minas Gerais, Belo Horizonte, 2008.

LEONETTI, Paola. O risco do desenvolvimento, o princípio da precaução e sua relação com as nanotecnologias no cenário atual. Trabalho de Conclusão de Curso de Especialização (Direito). Universidade Federal do Rio Grande do Sul, Porto Alegre, 2015. LIMA, Edilson Gomes de. Tratados científicos: a nanotecnologia avançada. São Paulo: Agbook, 2009. 
LIN, Albert C.. Size matters: Regulating nanotechnology. In: Harvard Environmental Law Review, v. 31, 2007, p. 349-408.

LOPEZ, Teresa Ancona. Nexo causal e produtos potencialmente nocivos: A experiência brasileira do tabaco. São Paulo: Quartier Latin, 2008.

LUDEÑA, Mercy Escalante. Avaliação de redes de inovação em nanotecnologia: a proposta de modelo. Tese de Doutorado (Administração). Universidade de São Paulo, São Paulo, 2008.

LYRA, Marcos Mendes. Dano ambiental. In: Revista de Direito Ambiental, v. 8, ano 2, outdez/1997, p. 49-83.

MACHADO, Paulo Affonso Leme. Direito ambiental brasileiro. 26.ed., São Paulo: Malheiros, 2018.

MALLOY, Timothy F.. Soft Law and Nanotechnology: A Functional Perspective. In: Jurimetrics, v. 52, 2012, p. 347-358.

MANCUSO, Rodolfo de Camargo. Ação civil pública. São Paulo: RT, 1989.

MARCHANT, Gary E. et al. Big Issues for Small Stuff: Nanotechnology Regulation and Risk Management. In: Jurimetrics, v. 52, 2012, p. 243-277.

MARKOFF, John. A Clinton Initiative in a Science of Smallnes. Disponível em $<$ https://archive.nytimes.com/www.nytimes.com/library/tech/00/01/biztech/articles/21chip. html>. Visitado em 08.mai.2019.

MARQUES, Luiz. Capitalismo e colapso ambiental. 2.ed., Campinas: Ed. Unicamp, 2016. MARTINS, Paulo Roberto (org.). Nanotecnologia, sociedade e meio ambiente: Primeiro seminário internacional. São Paulo: Associação Editorial Humanitas, 2005.

Nanotecnologia, sociedade e meio ambiente: Trabalhos apresentados no segundo seminário internacional. São Paulo: Xamã, 2006.

Nanotecnologia, sociedade e meio ambiente em São Paulo, Minas Gerais e Distrito Federal. São Paulo: Xamã, 2007.

MARTINS, Paulo Roberto; DULLEY, Richard (org.). Nanotecnologia, sociedade e meio ambiente: Trabalhos apresentados no terceiro seminário internacional. São Paulo: Xamã, 2008.

MASCARO, Alysson Leandro. Introdução ao estudo do direito. 6.ed., São Paulo: Atlas, 2019. 
MAXIMILIANO, Carlos. Hermenêutica e aplicação do direito. 21.ed., São Paulo: Saraiva, 2017.

MAZZUCATO, Mariana. O estado empreendedor: desmascarando o mito do setor público vs. setor. São Paulo: Portfolio/Penguin, 2014.

MCCARTHY, Elise; KELTY, Christopher. Responsibility and nanotechnology. In: Social Studies of Science, v. 40, 2010, p. 405-432.

MCCONACHIE AND J.D., Charles R.. The Need for Practical Regulation of Developing Commercial Nanotechnology. In: VASILESKA, Dragica. Cutting Edge Nanotechnology. Disponível em <https://mts.intechopen.com/books/cutting-edge-nanotechnology/the-needfor-practical-regulation-of-developing-commercial-nanotechnology $>. \quad$ Visitado em 08.mai.2019.

MEDEIROS NETO, Xisto Tiago de. Dano moral coletivo. 2.ed., São Paulo: LTr, 2007.

MELLO, Celso Antônio Bandeira de. Eficácia das normas constitucionais e direitos sociais. São Paulo: Malheiros Editores, 2009.

MELO, Raimundo Simão de. Meio Ambiente de Trabalho: prevenção e reparação - juízo competente. In: Revista de Jurisprudência Trabalhista, Porto Alegre/RS, vol. 204, 2000, pp.12-18.

MENDES, José Manuel. Sociologia do risco: Uma breve introdução e algumas lições. Coimbra: Imprensa da Universidade de Coimbra, 2015.

MENEZES, Wagner. Ordem global e transnormatividade. Ijuí: Unijuí, 2005.

MILARÉ, Edis. Direito do ambiente. São Paulo: RT, 2000, p. 338.

MILLER, Mark R.; RAFTIS, Jennifer B.; LANGRISH, Jeremy P. et al. Inhaled Nanoparticles Accumulate at Sites of Vascular Disease. Disponível em <https://pubs.acs.org/doi/10.1021/acsnano.6b08551>. Visitado em 08.mai.2019.

MINISTÉRIO DA CIÊNCIA, TECNOLOGIA, INOVAÇÕES E COMUNICAÇÕES. Estratégia nacional de ciência, tecnologia e inovação 2016/2022. Brasília, DF, 2016.

$$
\text { Nanotecnologia. Disponível em }
$$

<http://www.mctic.gov.br/mctic/opencms/tecnologia/tecnologias_convergentes/paginas/na notecnologia/NANOTECNOLOGIA.html>. Visitado em 08.mai.2019.

. Nanotecnologia aplicada ao agronegócio. Brasília, DF, 2018. 
Plano de Ação de CT\&I para Tecnologias Convergentes e Habilitadoras.

Volume 1 - Nanotecnologia. Disponível em <https://www.mctic.gov.br/mctic/export/sites /institucional/tecnologia/tecnologias_convergentes/arquivos/cartilha_plano_de_acao_nanot ecnologia.pdf >. Visitado em 08.mai.2019.

Tecnologias Convergentes e Habilitadoras. Disponível em $<$ https://www.mctic.gov.br/mctic/opencms/tecnologia/tecnologias_convergentes/paginas/te cnologias_convergentes_e_habilitadoras/TECNOLOGIAS_CONVERGENTES_E_HABIL ITADORAS.html>. Visitado em 08.mai.2019. Estratégia nacional de ciência, tecnologia e inovação 2016-2022. Brasília, DF. 2018.

MINISTÉRIO PÚBLICO DO TRABALHO. Cadeias econômicas e exploração do trabalho infantil. Brasília, DF, 2014.

MONIZ, Maria da Graça de Almeida D’Eça do Canto. Direito internacional do ambiente: O caso da fundição de Trail. In: Revista Diversitates, v. 4, n. 2, 2012, p. 1-33.

MORAES, Gabriela Bueno de Almeida. O princípio da precaução no direito internacional ao meio ambiente. Dissertação de Mestrado (Direito). Universidade de São Paulo, São Paulo, 2011.

MOSES, Blair H.. The biggest issues for the smallest stuff: Nanotechnology regulation and risk management. In: Jurimetrics, v. 52, 2012, p. 239-242.

MOTTA, Renata. Resenha de Sociologia do risco: Globalizando a modernidade reflexiva. In: Sociologias, Porto Alegre, ano 11, n. 22, jul-dez/2009, p. 384-396.

MOURA, Romero Marinho de. Rachel Carson e os agrotóxicos 45 anos após primavera silenciosa. In: Anais da Academia Pernambucana de Ciência Agronômica, Recife, vols. 5 e 6, 2008-2009, p.44-52.

MUKHTAR, Maseeh; PILLAI, Unni. Nanomanufacturing: application of nanotechnology in manufacturing industries. In: Nanotechnology Law \& Business, vol. 1, n. 12, Spring/2015, p. 5-18.

MURASHOV, Vladimir; SCHULTE, Paul; HOWARD, John. Progression of occupational risk management with advances in nanomaterials. In: Journal of Occupational and Environmental Hygiene, v. 9, n. 1, 2012, p. 12-22.

NADER, Paulo. Introdução ao estudo do direito. 40.ed., Rio de Janeiro: Forense, 2018. 
NANOPHASE. About us. Disponível em <http://nanophase.com/about-us/>. Visitado em 08.mai.2019.

NANOWERK. Nanotechnology Products Database. Disponível em <https://www.nanowerk.com/products/products.php>. Visitado em 08.mai.2019

NATIONAL INSTITUTE FOR OCCUPATIONAL SAFETY AND HEALTH. Approaches to safe nanotechnology: Managing the health and safety concerns associated with engineered nanomaterials. Cincinnati, OH: U.S. Department of Health and Human Services, 2009.

Building a safety program to protect the nanotechnology workforce: a guide for small to medium-sized enterprises. Cincinnati, OH: U.S. Department of Health and Human Services, 2016.

. Current Intelligence Bulletin 63: Occupational exposure to titanium dioxide.

Cincinnati, OH: U.S. Department of Health and Human Services, 2011.

. Current Intelligence Bulletin 65: Occupational exposure to carbon nanotubes and nanofibers. Cincinnati, OH: U.S. Department of Health and Human Services, 2013. Current strategies for engineering controls in nanomaterial production and downstream handling processes. Cincinnati, OH: U.S. Department of Health and Human Services, 2013.

. Filling the knowledge gaps for safe nanotechnology in the workplace.

Cincinnati, OH: U.S. Department of Health and Human Services, 2012. General Safe Practices for Working with Engineered Nanomaterials in Research Laboratories. Cincinnati, OH: U.S. Department of Health and Human Services, 2012.

Progress toward safe nanotechnology in the workplace. Cincinnati, OH: U.S. Department of Health and Human Services, 2007. . Progress toward safe nanotechnology in the workplace: Project updates for 2007 and 2008. Cincinnati, OH: U.S. Department of Health and Human Services, 2009. . Protecting the Nanotechnology Workforce: NIOSH Nanotechnology Research and Guidance Strategic Plan 2013-2016. Cincinnati, OH: U.S. Department of Health and Human Services, 2013. 
. Strategic Plan for NIOSH Nanotechnology Research and Guidance.

Cincinnati, OH: U.S. Department of Health and Human Services, 2008.

Workplace design solutions: Protecting workers during intermediate and downstream processing of nanomaterials. Cincinnati, OH: U.S. Department of Health and Human Services, 2018.

Workplace design solutions: Protecting workers during the handling of nanomaterials. Cincinnati, OH: U.S. Department of Health and Human Services, 2018.

Workplace design solutions: Protecting workers during nanomaterial reactor operations. Cincinnati, OH: U.S. Department of Health and Human Services, 2018.

NATIONAL INSTITUTE FOR PUBLIC HEALTH AND THE ENVIRONMENT. Grouping nanomaterials: A strategy towards grouping and read-across. Ultrech, 2015.

NATIONAL NANOTECHNOLOGY INITIATIVE. Benefits and applications. Disponível em <http://www.nano.gov/you/nanotechnology-benefits>. Visitado em 08.mai.2019.

. Environmental, health and safety research needs for engineered nanoscale materials. Washington, DC, 2006.

Nanotechnology $101 \quad-\quad$ Definition. Disponível em <http://www.nano.gov/nanotech-101/what/definition>. Visitado em 08.mai.2019.

. Nanotechnology Timeline. Disponível em <https://www.nano.gov/timeline>. Visitado em 08.mai.2019.

- Nanotecnology \& You: Benefits and applications. Disponível em <http://www.nano.gov/you/nanotechnology-benefits>. Visitado em 08.mai.2019.

. Supplement for President's 2018 Budget. Washington, DC, 2017.

NATIONAL RESEARCH COUNCIL. New York's Nanotechnology Model: Building the Innovation Economy. Washington, DC: National Academies Press, 2013.

. Review offederal strategy for nanotechnology - related Environmental, Health and Safety Research. Washington, DC: National Academies Press, 2013.

. Small Wonders, Endless Frontiers: A Review of the National Nanotechnology

Initiative. Washington, DC: National Academies Press, 2002.

NEC. The pioneer who discovered carbon nanotubes. Disponível em <https://www.nec.com/en/global/innovators/s_iijima/01.html>. Visitado em 08.mai.2019.

NEHMI, Victor. Química. 6.ed., São Paulo: Ática, 1998. 
NELSON, Max; SHIPBAUGH, Calvin. The potential of nanotechnology for molecular manufacturing. California: RAND, 1995.

NEOFIODOW, Leo A.. Kondratieff Cycles. Disponível em <https://www.kondratieff.net/kondratieffcycles>. Visitado em 08.mai.2019.

NOVAES, Araceli Martins Beliato de. Desenvolvimento tecnológico e desenvolvimento econômico: A nanotecnologia como instrumento para superar a pobreza no Brasil? Dissertação de Mestrado (Direito). Universidade Presbiteriana Mackenzie, São Paulo, 2016. NUNES, Luiz Antônio Rizzatto. Manual da monografia jurídica. 5.ed. São Paulo: Saraiva, 2007.

OHNISHI, Makoto et al. Novel method using hybrid markers: development of an approach for pulmonary measurement of multi-walled carbon nanotubes. In: Journal of Occupational Medicine and Toxicology, v. 8, out/2013.

OK, Zeynep D.; BENNEYAN, James C.; ISAACS, Jacqueline A.. Risk Analysis Modeling of Production Costs and Occupational Health Exposure of Single-Wall Carbon Nanotube Manufacturing. In: Journal of Industrial Ecology, v. 12, n. 3, p. 411-434.

OLIVEIRA, Liziane Paixão Silva; MARINHO, Maria Edelvacy; FUMAGALI, Ellen de Oliveira. Nanowastes riscos para saúde humana e meio ambiente: diálogos entre o princípio da precaução e a sociedade de risco. In: Revista Iberoamericana de Filosofía, Política y Humanidades, v. 17, n. 33, jan-jun/2015, pp. 183-209.

OLIVEIRA, Sebastião Geraldo de. Indenizações por acidente do trabalho ou doença ocupacional. 9.ed., São Paulo: LTr, 2016.

ORGANIZAÇÃO DAS NAÇÕES UNIDAS PARA EDUCAÇÃO, CIÊNCIA E CULTURA. Nanotechnology and ethics: Policies and actions. Paris, 2007.

ORGANIZAÇÃO INTERNACIONAL DO TRABALHO. Promover a segurança e a saúde numa economia verde. Genebra, 2012.

. Riscos emergentes e novas formas de prevenção num mundo de trabalho em mudança. Genebra, 2010.

ORGANIZAÇÃO MUNDIAL DE SAÚDE. Declaration on workers health. Genebra, 2006. FAO/WHO Paper: State of the art on the initiatives and activities relevant to risk assessment and risk management of nanotechnologies in the food and agriculture sectors. Genebra, 2013. 
. Nanotechnology and human health: Scientific evidence and risk governance.

Copenhagen, 2013.

WHO guidelines on protecting workers from potential risks of manufactured nanomaterials. Genebra, 2017.

ORGANIZAÇÃO PARA COOPERAÇÃO E DESENVOLVIMENTO ECONÔMICO, Nanomaterials in waste streams: current knowledge on risks and impacts. Paris, 2016.

- Alternative testing strategies in risk assessment of manufactured nanomaterials: Current state of knowledge and research needs to advance their use. Paris: OECD, 2017.

. Categorisation of manufactured nanomaterials: Workshop report. Paris:

OECD, 2016

. Developments in delegations on the safety of manufactured nanomaterialsTour de table. Paris: OECD, 2017.

. Nanotechnology: An overview based on indicators and statistics. Paris, 2009. . Nanotechnology and tyres: Greening industry and transport. Paris, 2014.

. Nanotechnology for green innovation. Paris, 2013.

. Regulatory frameworks for nanotechnology in foods and medical products.

Paris, 2013.

. Report on statistics and indicator of biotechnology and nanotechnology. Paris, 2018.

. Revised proposal for the revision of the statistical definitions of biotechnology and nanotechnology. Paris, 2018.

- Science Based Support for Regulation of Manufactured Nanomaterials

Disponível em <http://www.oecd.org/chemicalsafety/nanosafety/prosafe-project.htm>. Visitado em 08.mai.2019.

. Small sizes that matter: Opportunities and risks of nanotechnologies. Paris, 2005.

- Strategies, techniques and sampling protocols for determining the concentrations of manufactured nanomaterials in air at the workplace. Paris, 2017.

. Impacts of Nanotechnology on Companies: Policy Insights from Case Studies.

Paris, 2010. 
. The Next Production Revolution: Implication for governments and business.

Paris, 2017.

ORTEGA Y GASSET, José. Meditación de la técnica. Madrid: Espasa-Calpe, 1965.

PADILHA, Norma Sueli. Do meio ambiente do trabalho equilibrado. São Paulo: LTr, 2002. ; DI PIETRO, Josilene Hernandes Ortolan. A contribuição da OIT na construção da tutela internacional do direito ao meio ambiente de trabalho equilibrado. In: Revista da Faculdade de Direito UFMG, n. 70, jan-jun/2017, pp. 529-559.

PAIK, Samuel Y.; ZALK, David M.; SWUSTE, Paul. Application of a pilot control banding tool for risk level assessment and control of nanoparticles exposures. Disponível em <https://academic.oup.com/annweh/article-abstract/52/6/419/184897>. Visitado em 08.mai.2019.

PALMBERG, Christopher; DERNIS, Hélène; MIGUET, Claire. Nanotechnology: An Overview Based on Indicators and Statistics. Paris: OECD Publishing, 2009.

PEDREIRA, Ana Maria. Responsabilidade do estado por omissão: Prevenção, precaução e controle como meios de evitar a ocorrência de danos. Dissertação de Mestrado (Direito). Universidade de São Paulo, São Paulo, 2013.

PEÑA, Carlos E.; CARTER, Dean E.; AYALA-FIERRO, Felix. Toxicologia Ambiental: Evaluación de Riesgos y Restauración Ambiental. Disponível em <toxamb.pharmacy.arizona.edu/toxamb.pdf>. Visitado em 08.mai.2019.

PEREIRA, Reginaldo; MEDEIROS, Michael. O descompasso entre a defesa de direitos difusos e o avanço da tecnologia: Uma década de (não) história da regulação da nanotecnologia no brasil. In: Revista Jurídica Direito \& Paz, v. 17, n. 33, jul-dez/2015, p. 156-176.

; WINCKLER, Silvana; TEIXEIRA, Marcelo Markus. A governança dos riscos socioambientais da nanotecnologia e o marco legal de ciência, tecnologia e inovação do Brasil. E-book. São Leopoldo: Karywa, 2017.

PFEIFFER, Maria da Conceição Maranhão. Direito à informação e ao consumo sustentável. Tese de Doutorado (Direito). Universidade de São Paulo, São Paulo, 2011.

PIETROPAOLO, João Carlos. Limites de critérios econômicos na aplicação do direito: Hermenêutica e análise econômica do direito. Tese de Doutorado (Direito). Universidade de São Paulo, São Paulo, 2010. 
PONTES, Jorge. A nanotecnologia e seus impactos éticos e sociais no mundo do trabalho. Disponível em <https://www.researchgate.net/publication/318725941>. Visitado em 08.mai.2019.

PONZILACQUA, Marcio Henrique Pereira. Sociologia ambiental do direito: Análise sociojurídica, complexidade ambiental e intersubjetividade. Petrópolis: Vozes, 2015.

PORTELA, Paulo Henrique Gonçalves. Direito internacional público e privado: Incluindo noções de direitos humanos e de direito comunitário. Salvador: JusPodium, 2016.

PRICEWATERHOUSECOOPERS AUDITORES INDEPENDENTES. O futuro do trabalho: Impactos e desafios para as organizações no Brasil. São Paulo: 2014. Disponível em <https://www.pwc.com.br/pt/publicacoes/servicos/assets/consultoria-negocios/futurotrabalho-14e.pdf>. Visitado em 08.mai.2019.

PYRRHO, Monique; SCHRAMM, Fermin Roland. A moralidade da nanotecnologia. In: Caderno de Saúde Pública, v. 28, n. 11, nov/2012, p. 2023-2033.

RAMMAZZINI, Bernardini. As doenças dos trabalhadores. 4.ed., São Paulo: FUNDACENTRO, 2016.

RAMSDEN, Jeremy. Nanotechnology: An Introduction. San Diego: Elsevier, 2010.

RAUEN, Cristiane Vianna. O novo marco legal da inovação no Brasil: o que muda na relação ICT-empresa? In: Revista Radar, n. 43, fev/2016.

RAZZOLINI, Maria Tereza Pepe; NARDOCCI, Adelaide Cássia. Avaliação de risco microbiológico: Etapas e sua aplicação na análise da qualidade da água. In: InterfacEHS, v. 1, n. 2 , dez/2006.

REALE, Miguel. Lições preliminares de direito. 24.ed., São Paulo: Saraiva, 1999.

REESE, Michelle. Nanotechnology: Using co-regulation to bring regulation of modern technologies into the $21^{\text {st }}$ century. In: Journal of Law-Medicine. Vol. 23, Sept. 2013. Disponível em <http://vlex.com/vid/nanotechnology-using-co-regulation-635859197>. Visitado em 08.mai.2019.

REVISTA GALILEU. Organismos marinhos absorvem bilhões de microplásticos em poucas horas. Disponível em <https://revistagalileu.globo.com/Ciencia/MeioAmbiente/noticia/2018/12/organismos-marinhos-absorvem-bilhoes-de-microplasticos-empoucas-horas.html>. Visitado em 08.mai.2019. 
RIBEIRO, Ricardo Lodi. Globalização, Sociedade de risco e Segurança. In: Revista de Direito Administrativo. (s.e.). São Paulo: Atlas, (s.d.), p. 267-287.

RIBEIRO, Silvia. Impactos da nanotecnologia na saúde e no meio ambiente. Palestra proferida na fundação Heinrich Böll Brasil. Disponível em <https://www.youtube.com/watch?v=jnwIK5o5AD8>. Visitado em 08.mai.2019.

RICCARDI, Carla dos Santos; SANTOS, Marcio Luiz dos; GUASTALDI, Antonio Carlos. Engineered nanomaterials: Nanotoxicology issues, nanosafety and regulatory affairs. São Paulo: Cultura Acadêmica, 2015.

ROCHA, Marcos. Teoria Atômico Molecular. Disponível em <http://allchemy.iq.usp.br/metabolizando/beta/01/atomista.htm>. Visitado em 08.mai.2019. ROCHA, Maria Isabel de Matos. Reparação de danos ambientais. In: Revista de Direito Ambiental, v. 19, ano 5, jul-set/2000, p. 129-156.

RODRIGUES, Ivandick Cruzelles. Desoneração da folha de pagamento na sociedade de risco: Uma crítica ao discurso de exclusividade da maximização da eficiência econômica. Dissertação de Mestrado (Direito). Pontifícia Universidade Católica de São Paulo, São Paulo, 2013.

RODRIGUES, Marcelo Abelha. Direito ambiental esquematizado. 5. ed., São Paulo: Saraiva, 2018.

RODRIGUEZ, Américo Plá. Princípios de direito do trabalho. São Paulo: LTr, 1997.

SALEEM, Jabran; WANG, Liming; CHEN, Chunying. Immunological effects of graphene family nanomaterials. In: NanoImpact, v. 5, jan/2017, p. 109-118.

SALIBA, Tuffi Messias. Curso básico de segurança e higiene ocupacional. 6.ed., São Paulo: LTr, 2015.

SALOMÃO, Karina Novah. A responsabilidade do empregador nas atividades de risco: Incidência do parágrafo único do art. 927 do Código Civil nas relações de trabalho. Tese de Doutorado (Direito). Universidade de São Paulo, São Paulo, 2011.

SALVADOR NETTO, Alamiro Velludo. Tipicidade penal e sociedade de risco. São Paulo: Quartier Latin, 2006.

SANTOS, Adelson Silva dos. Fundamentos do direito ambiental do trabalho. São Paulo: LTr, 2010. 
SANTOS, Juliana Vieira dos. A gestão dos resíduos sólidos urbanos: Um desafio. Tese de Doutorado (Direito). Universidade de São Paulo, São Paulo, 2009.

SARAIVA, Renato. Curso de direito processual do trabalho. 5.ed. São Paulo: Método, 2008 .

SCENIHR - Scientific Committee on Emerging and Newly Identified Health Risks. Risk assessment of products of nanotechnologies. Bruxelas, 2009.

. The scientific aspects of the existing and proposed definitions relating to products of nanoscience and nanotechnologies. Bruxelas, 2007.

SEN, Amartya; KLIKSBERG, Bernardo. As pessoas em primeiro lugar: A ética do desenvolvimento e os problemas do mundo globalizado. São Paulo: Companhia das Letras, 2010.

SERRANO, José Luis. A diferença risco/perigo. In: Revista Novos Estudos Jurídicos, v. 14, n. 2, mai-ago/2009, p. 233-250.

SILVA, Brisa Arnoud da. Uma análise sobre a modernidade reflexiva e a complexidade no estado socioambiental de direito o compromisso do desenvolvimento sustentável. In: Cadernos de pós-graduação em direito PPGDir/UFRGS, v. X, n. 2, 2015, p. 101-131.

SILVA, Homero Batista Mateus da. CLT Comentada. São Paulo: Revista dos Tribunais, 2016.

. Curso de direito do trabalho aplicado: Volume 3 - Saúde e segurança do trabalho. 2.ed., São Paulo: Revista dos Tribunais, 2015.

. Curso do direito do trabalho aplicado: Volume 1 - Parte geral. 3.ed., São Paulo: RT, 2017.

Curso do direito do trabalho aplicado: Volume 7 - Direito coletivo do trabalho. 3.ed., São Paulo: RT, 2017.

SILVA, José Afonso da. Aplicabilidade das normas constitucionais. 3.ed. São Paulo: Malheiros Editores, 1998.

. Direito ambiental constitucional. 6.ed., São Paulo: Malheiros, 2007.

SILVA, Josué Pereira da. Trabalho, cidadania e reconhecimento. São Paulo: Annablume, 2008 .

SILVA, Martiela Adams Tavares da. A dignidade da pessoa humana como elemento estruturador para embasar as pesquisas e a criação de marcos regulatórios aos 
nanocosméticos. Dissertação de Mestrado (Direito). Universidade do Vale do Rio dos Sinos, São Leopoldo, 2013.

SILVA, Paulo Emílio Vilhena da. A responsabilidade civil do empregador diante do princípio da prevenção à saúde do trabalhador: responsabilidade sem dano. Dissertação de Mestrado (Direito). Universidade de São Paulo, São Paulo, 2010.

SILVA, Tania Elias Magno da; WAISSMANN, William (orgs.). Nanotecnologias, alimentação e biocombustíveis: um olhar transdisciplinar. Aracaju: Criação, 2014.

SIMIONI, Rafael Lazzarotto. Decisão, organização e risco: a forma da decisão jurídica para além da segurança e da legitimidade. In: Revista do Programa de Pós-Graduação em Direito da UFC, vol. 37, jan-jul/2017, p. 259-279.

SOARES FILHO, José. Sociedade pós-industrial e os impactos da globalização na sociedade, trabalho, economia e Estado. Curitiba: Juruá, 2007.

SOARES, Ricardo Maurício Freire. Elementos de teoria geral do direito. 4.ed., São Paulo: Saraiva, 2017.

Hermenêutica e interpretação jurídica. 3.ed., São Paulo: Saraiva, 2017.

SRIVATSA, Naveen; KALIARNTA, Sofia; KOMELINK, Joost Groot (Eds.). Responsible innovation: From MOOC to book. Delft: Delft University of Technology, 2017.

SUPREMO TRIBUNAL FEDERAL, Acórdão das ADIs 3470 e 3406. Rel. Min. Rosa Weber, j. em 29.nov.2017, p. em 01.fev.2019.)

SURI, Sarabjeet Singh; FENNIRI, Hicham; SINGH, Baljit. Nanotechnology-based drug delivery systems. In: Journal of Occupational Medicine and Toxicology, v. 2, dez/2007.

TANASUGARN, Lerson; TANPIPAT, Noppawan. NanoSafety in Thailand. Disponível em <http://www.lerson.net/nano/>. Visitado em 08.mai.2019.

THE ROYAL SOCIETY \& THE ROYAL ACADEMY OF ENGINEERING. Nanoscience and nanotechnologies: opportunities and uncertainties. Plymouth: Latimer Trend Ltd., 2004.

TOMA, Henrique E.; SILVA, Delmárcio Gomes da; CONDOMITTI, Ulisses. Nanotecnologia experimental. São Paulo: Bluncher, 2016.

TRINDADE, Antônio Augusto Cançado. International Law for humankind: towards a new jus gentium. Vols. 1 and 2. Boston: Martinus Nijhoff Publishers, 2006. 
TÜV SÜD INDUSTRIE SERVICE GMBH. CENARIOS® Certification Standard. Disponível em $<$ http://innovationsgesellschaft.ch/wpcontent/uploads/2013/07/CENARIOS_Certification_Standard_e.pdf >. Visitado em 08.mai.2019.

U.S. OFFICE OF SCIENTIFIC AND TECHNICAL INFORMATION. Application of an informatics-based decision-making framework and process to the assessment of radiation safety in nanotechnology. Disponível em <https://www.osti.gov/servlets/purl/1239283>. Visitado em 08.mai.2019.

UIBEL, Stefanei et al. Nanoparticles and cars - analysis of potential sources. In: Journal of Occupational Medicine and Toxicology, v. 7, jun/2012.

UNITED STATES COURT OF APPEALS FOR THE NINTH CIRCUIT. Natural Resources Defense Council vs. U.S. Environmental Protection Agency. Relator Hon. Judge Melloy. Julgado em 30/05/2017.

UNITED STATES GOVERNMENT ACCOUNTABILITY OFFICE. Nanomanufacturing: Emergence and implications for U.S. competitiveness, the environment and human health. Washington, DC, 2014.

UNITED STATES OF AMERICA. 21st Century Nanotechnology Research and Development Act. Disponível em <https://www.congress.gov/108/plaws/publ153/PLAW108publ153.pdf>. Visitado em 08.mai.2019.

UNITED STATES PATENT AND TRADEMARK OFFICE. Class 977 - Nanotechnology. Disponível em <https://www.uspto.gov/web/patents/classification/uspc977/defs977.htm>. Visitado em 08.mai.2019.

VAN DEN HOVEN, Jeroen; LOKHORST, Gert-Jan; VAN DE POEL, Ibo. Engineering and the problem of moral overload. In: Science and Engineering Ethics, v. 18, n. 1, p. 143-155. VÉLEZ, Beatriz Eugenia Campillo; SALAS, Guillermo León Zuleta. Bioética y nanotecnología. In: Revista Lasallista de Investigación, v. 11, n. 1, 2014, p. 63-69.

VELMURUGAN, Chandran. Visualizing global nanotechnology research on publication deeds, 1989-2014. In: Library Philosophy and Practice, Feb. 2016. Disponível em $<$ https://digitalcommons.unl.edu/cgi/viewcontent.cgi?article=3768\&context=libphilprac $>$. Visitado em 08.mai.2019.

VENOSA, Silvio de Salvo. Introdução ao estudo do direito. 6.ed., São Paulo: Atlas, 2019. 
VIANNA José Ricardo Alvarez. Responsabilidade civil por danos ao meio ambiente à luz do novo código civil. Curitiba: Juruá, 2004.

VIEGAS, Maria de Fátima Torres Faria. Avaliação da qualidade de revisões sistemáticas sobre toxicidade de nanopartículas de prata. Dissertação de Mestrado (Saúde Pública). Escola Nacional de Saúde Pública Sergio Arouca (FIOCRUZ), Rio de Janeiro, 2018.

VON HOHENDORFF, Raquel; COIMBRA, Rodrigo; ENGELMANN, Wilson. As nanotecnologias, os riscos e as interfaces com o direito à saúde do trabalhador. In: Revista de Informação Legislativa, v. 53, n. 209, jan-mar/2009, p. 151-172.

VON MERING, Yvonne; SCHMACHER, Christian. What training should be provided to workers who are at risk from exposure to the specific nanomaterials or groups of nanomaterials? Genebra: World Health Organization, 2017.

WILSON, Robin Fretwell. Nanotechnology: The challenge of regulating known unknowns. In: Journal of law, medicine \& ethics, 2006, p. 704-713.

WINTER, Gerd. European environmental law: A comparative perspective. Aldershot: Dartmouth Publishing Co., 1996.

YANG, Chi-Yea. Anti Silver Nanoparticle Bacteria, Cutting Edge Nanotechnology. Disponível em <http://www.intechopen.com/books/cutting-edgenanotechnology/antisilver-nanoparticle-bacteria>. Visitado em 08.mai.2019.

YOKEL, Robert A.; MACPHAIL, Robert C. Engineered nanomaterials: exposures, hazards, and risk prevention. In: Journal of Occupational Medicine and Toxicology, v. 6, n.7, $\operatorname{mar} / 2011$.

YURA, Erika Tatiane Ferreira. Processo de implantação dos sistemas de logística reversa dos equipamentos eletroeletrônicos previstos na Política Nacional de Resíduos Sólidos: Uma visão dos gestores. Tese de Doutorado (Saúde Ambiental). Universidade de São Paulo, São Paulo, 2014.

ZALK, David M.; KAMERZELL, Ryan; PAIK, Samuel Y.; KAPP, Jennifer; HARRINGTON, Diana; SWUSTE, Paul. Risk level based management system: A control banding model for occupational health and safety risk management in a highly regulated environment. In: Industrial Health Journal, n. 48, 2010, p. 18-28.

ZIERO, Gabriel Webber. O conceito de conduta empresarial responsável à luz dos ordenamentos jurídicos brasileiro, internacional e transnacional. In: Revista de Direito Internacional - Brazilian Journal of International Law. v.13, n.3, 2016, p.81-94. 
ZIMMERMANN, Cirlene Luiza. A ação regressiva acidentária como instrumento de tutela do meio ambiente de trabalho. 2.ed., São Paulo: LTr, 2015.

ZIPPELIU, Reinhold. Filosofia do direito (Série IDP - Linha direito comparado). São Paulo: Saraiva, 2012.

Teoria Geral do Estado (Série IDP - Linha de direito comparado). São Paulo: Saraiva, 2016. 